\title{
Thermal and Radical Enhanced Atomic Layer Deposition of Films Containing Boron, Nitrogen and Carbon
}

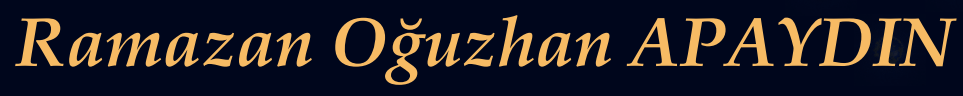




\section{THERMAL AND RADICAL ENHANCED ATOMIC LAYER DEPOSITION OF FILMS CONTAINING BORON, NITROGEN AND CARBON}

Ramazan Ŏ̆uzhan Apaydın 



\title{
THERMAL AND RADICAL ENHANCED ATOMIC LAYER DEPOSITION OF FILMS CONTAINING BORON, NITROGEN AND CARBON
}

\author{
DISSERTATION
}

\author{
to obtain \\ the degree of doctor at the University of Twente, \\ on the authority of the rector magnificus, \\ Prof.dr. T.T.M. Palstra, \\ on account of the decision of the graduation committee, \\ to be publicly defended \\ on Thursday the $2^{\text {nd }}$ of April 2020 at 14.45 hours
}

by

\section{Ramazan Oğuzhan Apaydın}

born on the 29th of April 1988 in Samsun, Turkey 
This dissertation has been approved by:

Supervisors:

Dr. Alexey Y. Kovalgin

Dr. ir. Michel P. de Jong

This work was financially supported by The Netherlands Organization for Scientific Research (NWO), Domain Applied and Engineering Sciences, Project "Ultra-thin layers and their stacks for next-generation electronics and energy storage devices", nr. 13929 and carried out at MESA+ Institute for Nanotechnology, University of Twente. Toyota Europe and ASM International are acknowledged for their partial financial support of this project.

Cover: designed by Burcu Gümüşçü Sefünç

Front and back cover image: Fast Fourier Transform (FFT) image of a sample showing the interlayer distance of $h$-BN films (chapter 4 ).

ISBN: 978-90-365-4980-6

DOI: $10.3990 / 1.9789036549806$

URL: https:// doi.org/10.3990/1.9789036549806\%20

Printed by: Ipskamp Printing (Enschede, The Netherlands)

(C) 2020 by Ramazan Oğuzhan APAYDIN, The Netherlands. All rights reserved. No parts of this thesis may be reproduced, stored in a retrieval system or transmitted in any form or by any means without permission of the author. Alle rechten voorbehouden. Niets uit deze uitgave mag worden vermenigvuldigd, in enige vorm of op enige wijze, zonder voorafgaande schriftelijke toestemming van de auteur. 


\section{Graduation committee:}

Chairman / Secretary: Prof. dr. J.N. Kok

Supervisor:

Co- Supervisor:

Dr. A.Y. Kovalgin

Dr. ir. M.P. de Jong

Committee members: Prof. dr. D.J. Gravesteijn

Prof. dr. J.G.E. Gardeniers

Prof. dr. G.C.A.M. Janssen

Prof. dr. ir. J.R. van Ommen

Prof. dr. A. Devi

Dr. S. Kinge
University of Twente

University of Twente

University of Twente

University of Twente

University of Twente

Delft University of Technology

Delft University of Technology

Ruhr-University Bochum

Toyota Motor Europe 

to my parents,

brother, sister and beautiful niece,

"Hiçbir şeye ihtiyacımız yok, yalnız bir şeye ihtiyacımız vardır; çalışkan olmak." Mustafa Kemal Atatürk 



\section{TABLE OF CONTENTS}

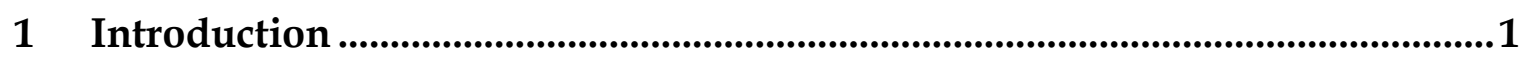

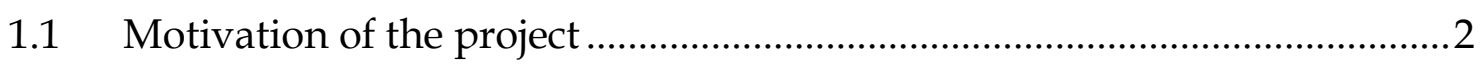

1.2 Introduction to atomic layer deposition ..............................................

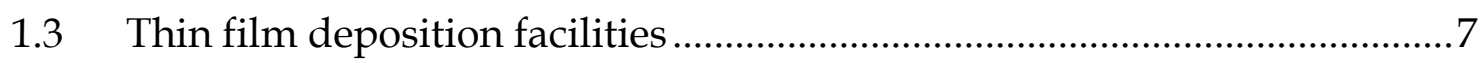

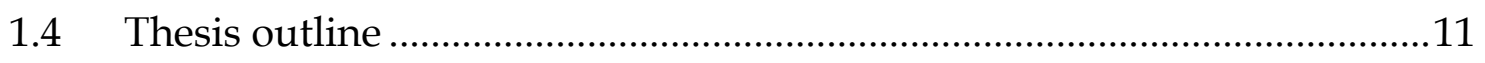

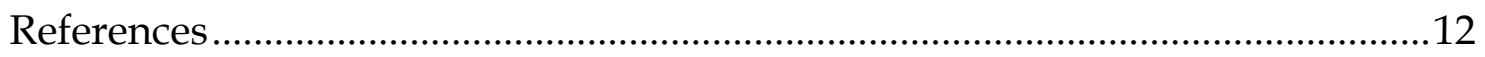

2 Studying film growth: spectroscopic ellipsometry and adduct-assisted

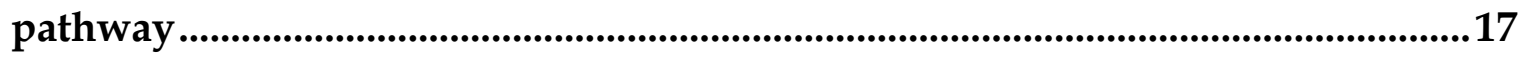

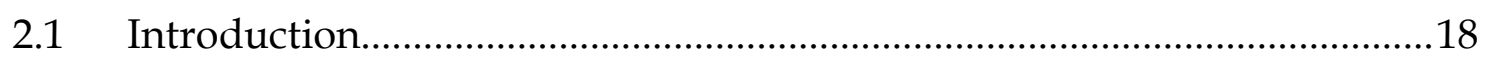

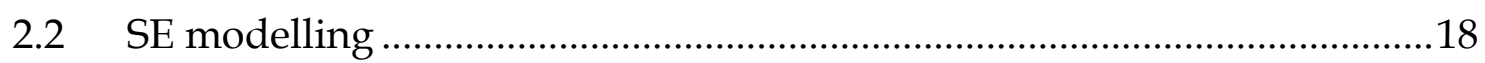

2.2.1 Comparison of the thicknesses measured by SE, TEM and XRR.......22

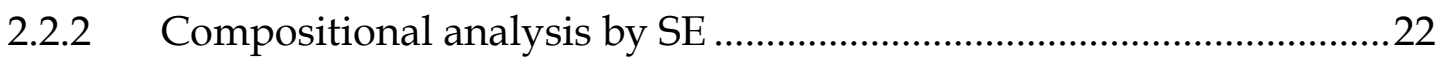

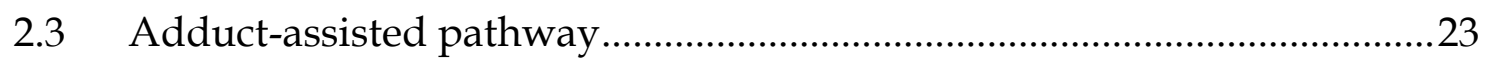

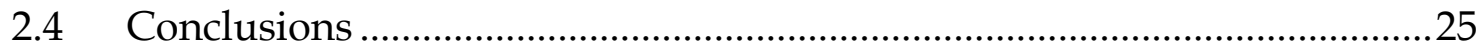

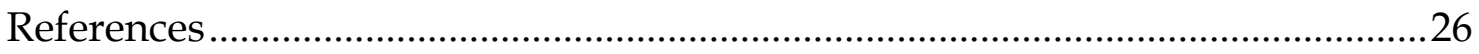

3 Studying B/BN composite material by XPS and SE...................................29

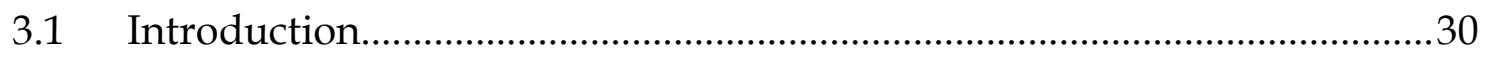

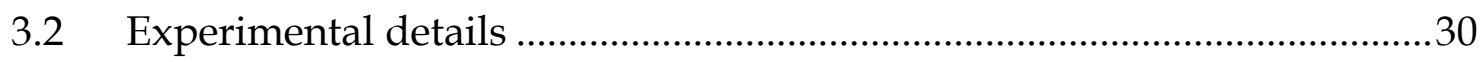

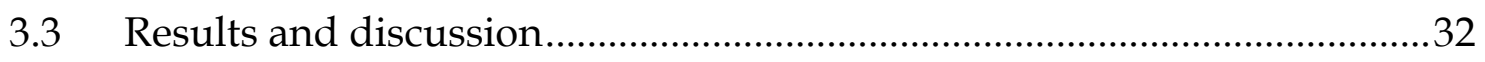

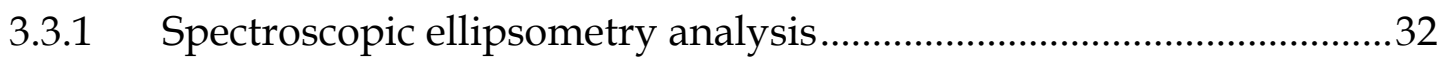

3.3.1.1 Tunable refractive index $(\mathrm{n})$ of $\mathrm{B} / \mathrm{BN}$ composites ........................32

3.3.1.2 Development of SE model for a B/BN composite ........................34

3.3.1.2.1 Parameterization approaches................................................... 34

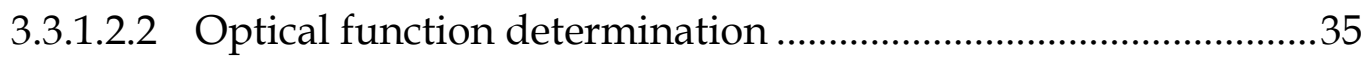


3.3.2 Confirmation of the composite nature by XPS

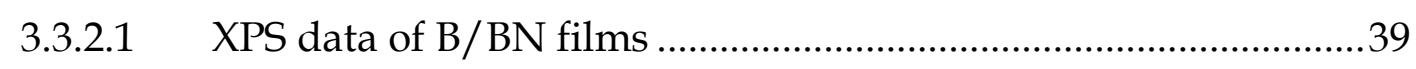

3.3.3 EFTEM analysis .............................................................................. 41

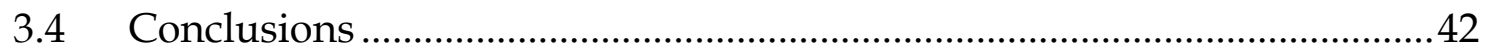

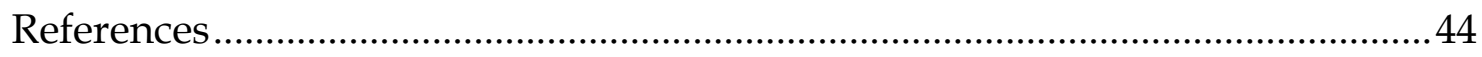

4 Comparative study of $\mathrm{B} / \mathrm{BN}$ deposition in purely thermal and radicalenhanced modes ...........................................................................................................................4

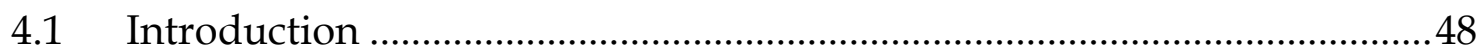

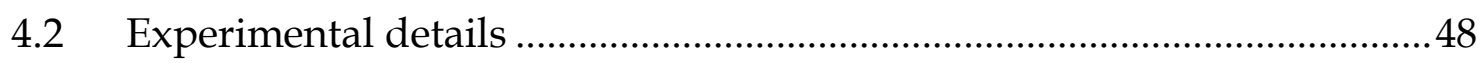

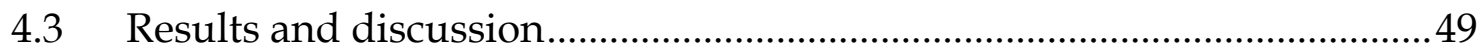

4.3.1 Purely thermal deposition .......................................................................4 49

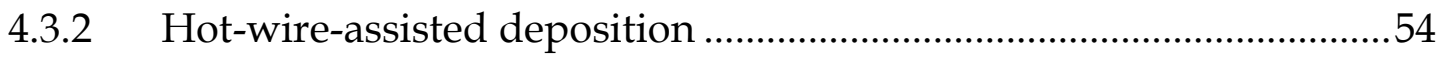

4.3.3 Plasma-assisted deposition.....................................................................5

4.3.4 Comparative analysis of the film properties...........................................56

4.3.4.1 XPS analysis...................................................................................

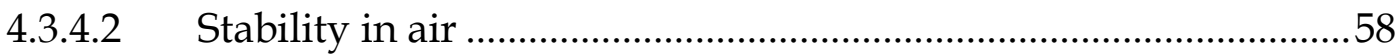

4.3.4.3 Crystallinity from HRTEM..............................................................59

4.3.4.4 Other analyses ................................................................................

4.4 Suggested deposition mechanisms .................................................................62

4.4.1 Surface-adduct pathway for purely thermal deposition.......................62

4.4.2 A comparison of pure-thermal and radical-enhanced modes.............64

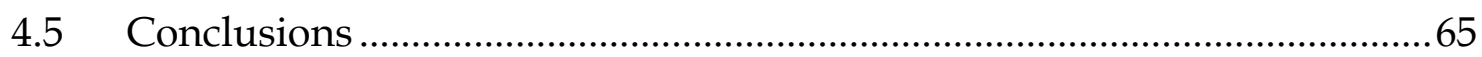

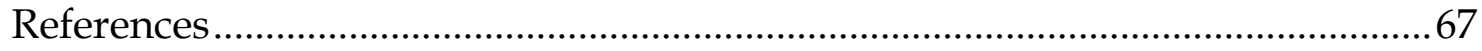

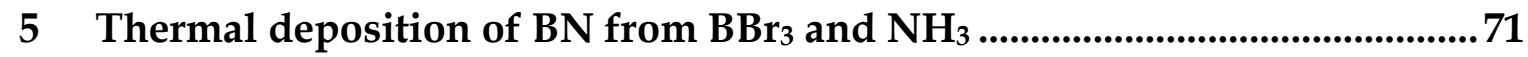

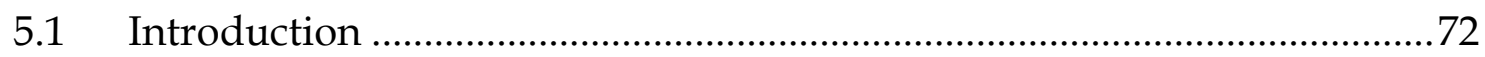




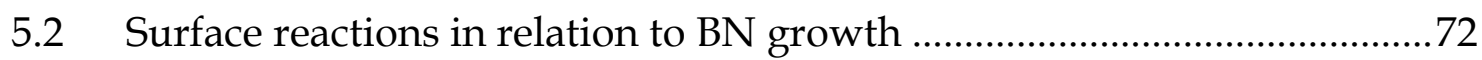

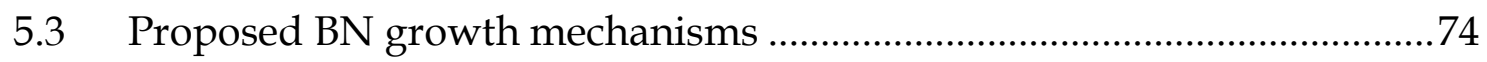

5.3.1 Thermal-BN deposition via surface adduct pathway.........................74

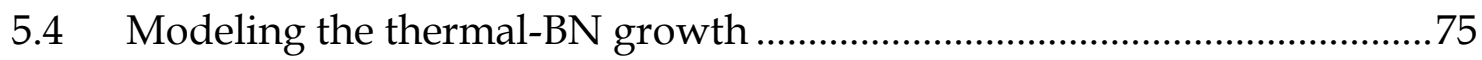

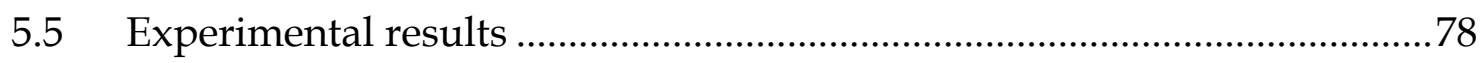

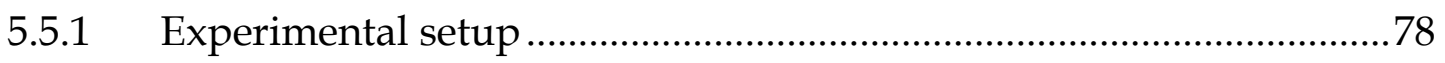

5.5.2 Kinetics of thermal-BN deposition ................................................. 78

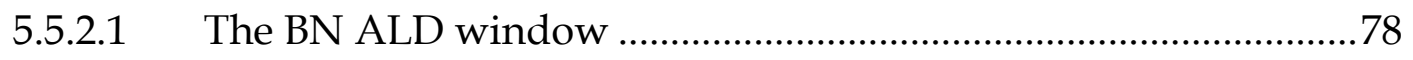

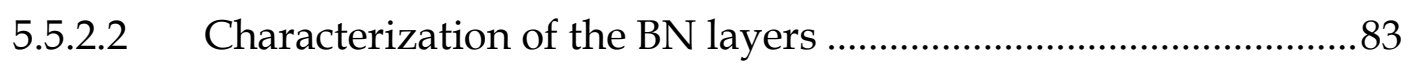

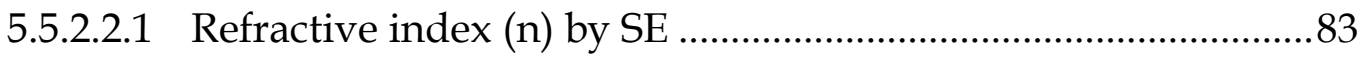

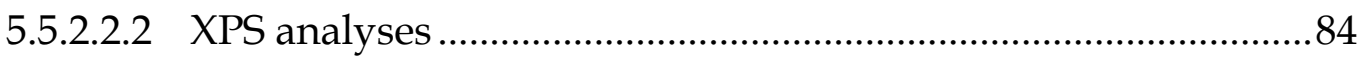

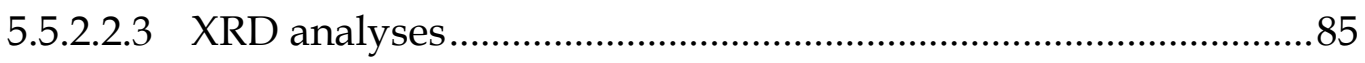

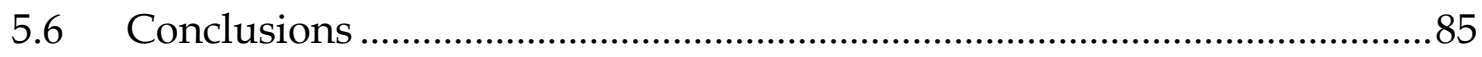

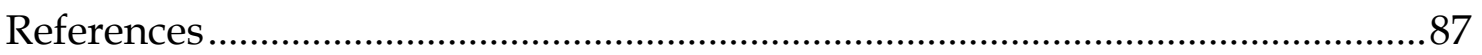

6 The effects of using alternative approaches to growing $\mathrm{BN}$ from $\mathrm{BBr}_{3}$ and

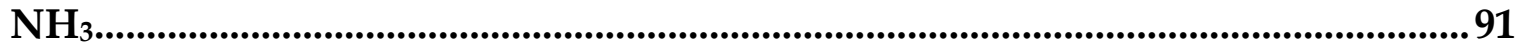

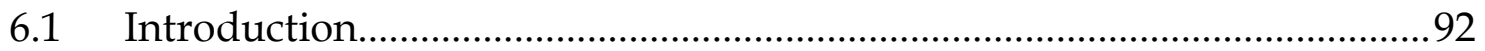

6.2 Proposed BN growth mechanism in a radical-enhanced mode ................92

6.3 Plasma-enhanced ALD of BN in a hot-wall reactor ..................................93

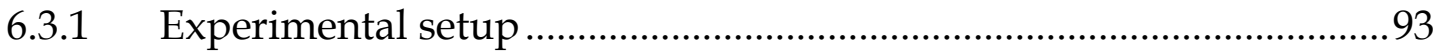

6.3.2 BN ALD window and the effect of non-optimized conditions ..........94

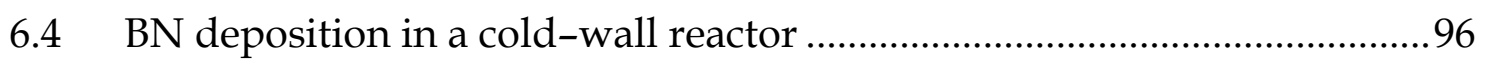

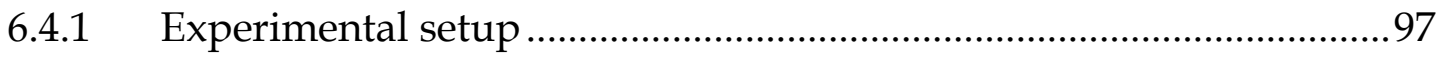

6.4.2 Purely thermal mode ....................................................................... 97

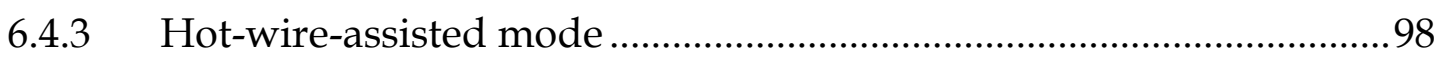




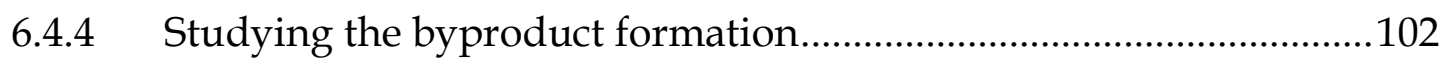

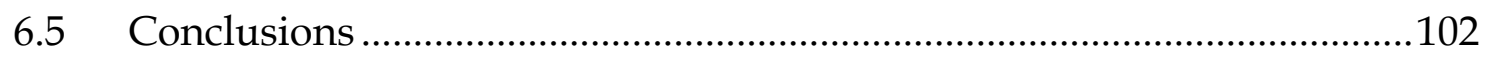

Appendix 6.1: Ammonia-decay analysis ....................................................... 104

Appendix 6.2. Ammonium bromide identification .........................................106

Appendix 6.3. In-situ study of ammonium bromide formation for optimizing

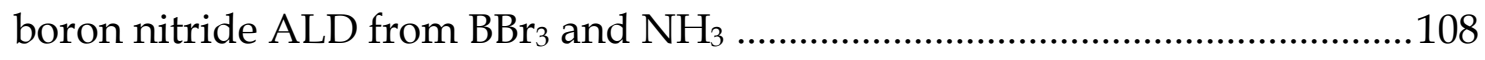

Appendix 6.4. Ammonium bromide migration and removal issues ................112

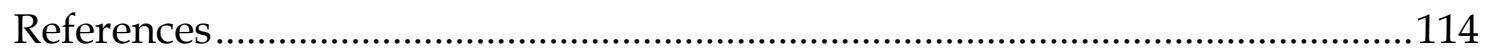

7 Growing BCN and AlBCN films from TEB and TMA precursors...............117

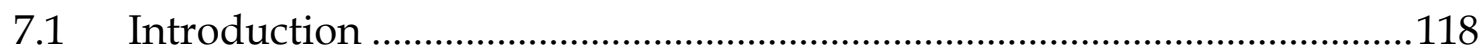

7.2 Reactions in relation to BCN growth ...................................................119

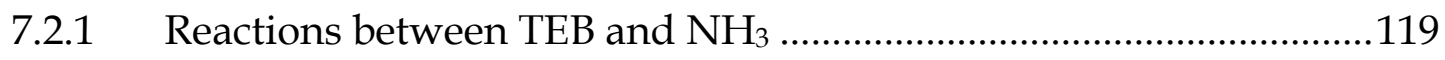

7.2.2 Reactions between TEB: $\mathrm{NH}_{3}$ and TMA: $\mathrm{NH}_{3}$ adducts .....................121

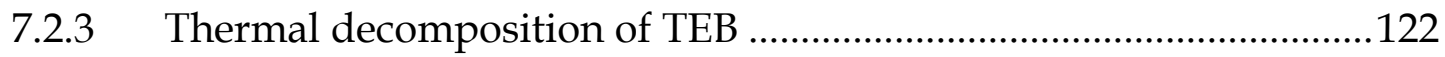

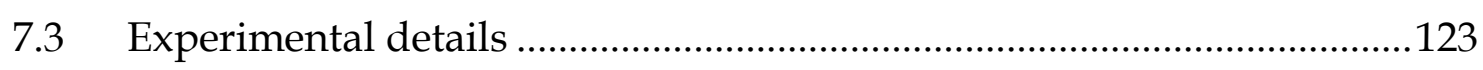

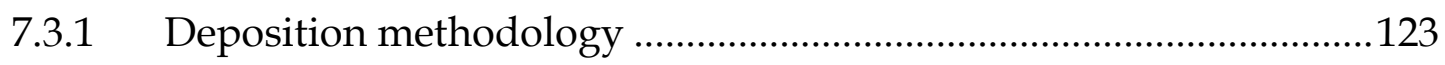

7.3.2 Tuning the deposition conditions....................................................123

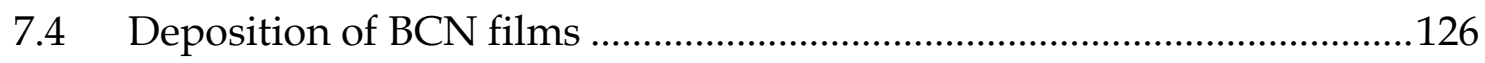

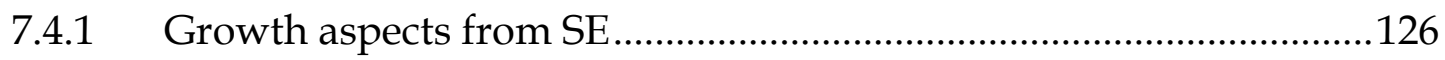

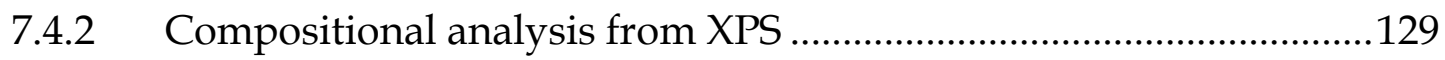

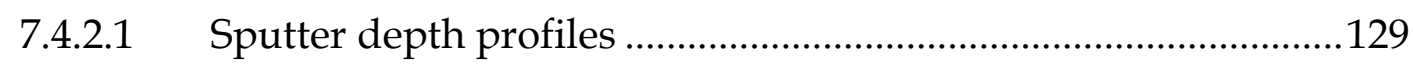

7.4.2.2 Chemical bonding environments ...........................................130

7.5 AlBCN films obtained by super-cycles ................................................133

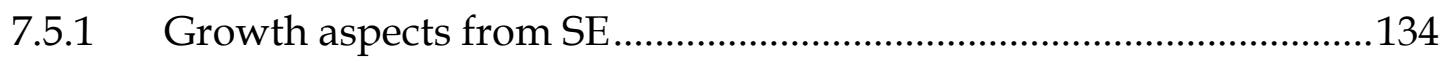

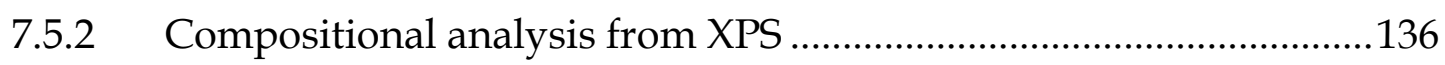


7.5.2.1 Sputter depth profiles .............................................................136

7.5.2.2 Chemical bonding environments ..........................................137

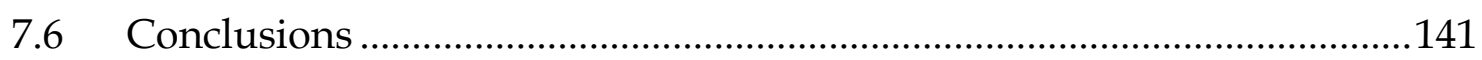

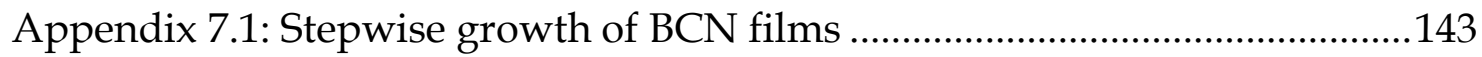

Appendix 7.2: Thickness variation of BCN films mapped by ex-situ SE ..........144

Appendix 7.3: Thickness variation of AlBCN films mapped by ex-situ SE......145

Appendix 7.4: Sputter depth profile line intensities ....................................... 146

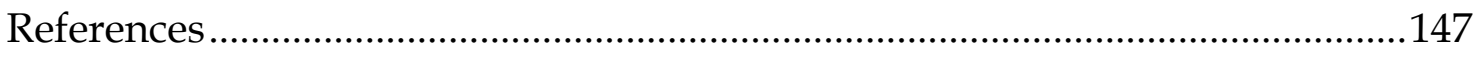

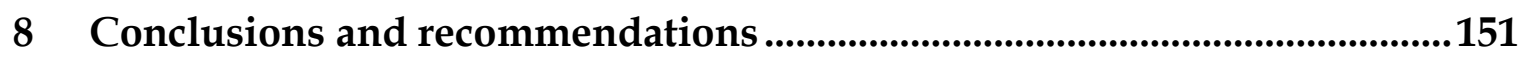

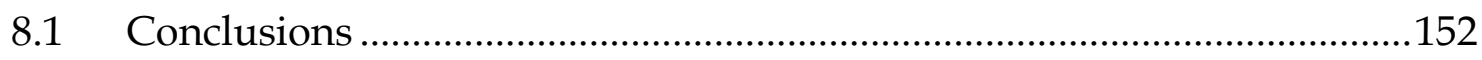

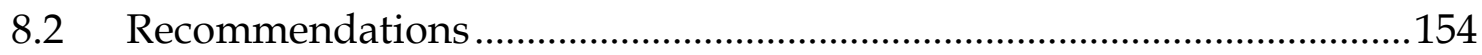

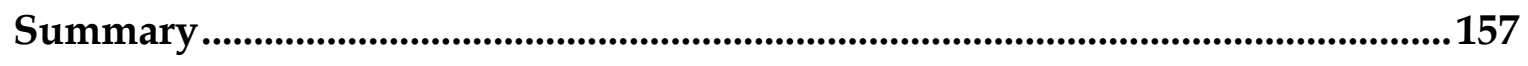

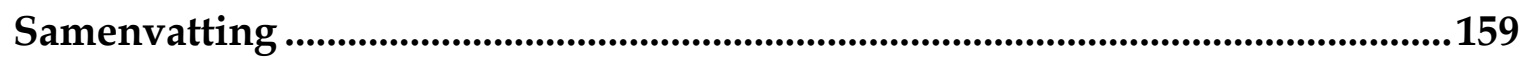

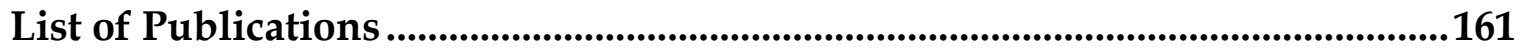

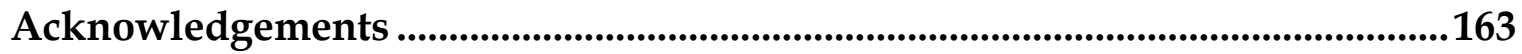

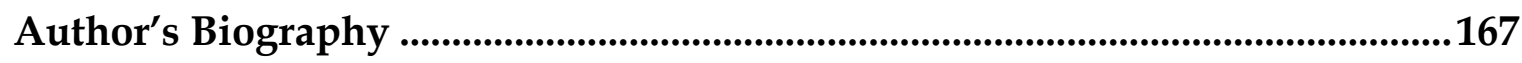


1 Introduction 


\subsection{Motivation of the project}

The family of boron, nitrogen and carbon containing materials exhibits a variety of attractive optical, electronic and chemical properties and shows an example of excellent possibility to combine several functionalities in one compound ${ }^{1-6}$. Graphene, hexagonal boron nitride (h-BN) and $s p^{2}-$ hybridized Boron-Carbon-Nitrogen (BCN) composites exhibit a near-perfect match of their crystal lattices ${ }^{7-9}$. Ultra-thin layers of these materials and their vertical stacks, with compositions varying from pure graphene to pure $\mathrm{h}-\mathrm{BN}$, can lead to discovering new effects in solid-state systems and are therefore very attractive for potential applications in next-generation technologies. Graphene, for example, features an exceptionally high charge carrier mobility 7,9 and optical transparence $10-12$, which are of prime importance for (opto)electronics. With its very large surface-tovolume ratio, graphene further holds considerable promise as a new anode material in energy-storage devices ${ }^{13}$. On the other hand, $\mathrm{h}-\mathrm{BN}$ has attracted much attention as a dielectric with relation to graphene-based devices. More generally, ultra-thin layered $\mathrm{BCN}$-materials with varying composition are expected to enable a rich variety of electronic properties, notably a tunable bandgap, potentially resulting in new applications 14,15 .

$\mathrm{h}-\mathrm{BN}$ is recognized as an ideal insulating template for graphene based 2D devices due to its excellent properties ${ }^{16}$. Firstly, h-BN monolayers are isostructural to graphene, with a lattice mismatch of $1.7 \%{ }^{17}$. Multilayers of h-BN are structurally similar to graphite, exhibiting a layered honeycomb structure with strong covalent bonds between boron and nitrogen atoms within each layer, and weak van der Waals forces bonding together the neighboring layers 17,18. Such structural properties enable excellent interaction of h-BN with graphene and graphite, and hence it has great potential for various nanoelectronics device applications 7 . Furthermore, h-BN possesses high mechanical hardness and resilience ${ }^{19}$, a wide bandgap of $5.9 \mathrm{eV}^{20}$ and high thermal conductivity ${ }^{21}$ encouraging its applications in transparent membranes 16,17 , gate dielectrics ${ }^{22,23}$ and power devices ${ }^{24}$. For 
example, enhanced mobilities and high current on-off ratios are obtained when graphene field effect transistors are integrated with h-BN 25,26.

Although h-BN is an electrical insulator, inclusion of foreign elements (i.e. carbon) can, in principle, allow to tune its properties (i.e. decrease its bandgap), and is therefore an interesting avenue to explore. Such elements (i) can be located at grain boundaries, (ii) can substitute an atom ${ }^{27}$ or (iii) form separate phase(s) ${ }^{28}$. For example, the catalytic properties of BN can be improved with low levels of phosphorus $(\mathrm{P})$ atoms present as dopants ${ }^{29}$. In addition, p-type conductivity in hBN films has been achieved by doping with beryllium (Be) ${ }^{30}$, magnesium $(\mathrm{Mg})^{31}$ and zinc $(\mathrm{Zn})^{32}$. Further, excess boron (B) incorporation into boron nitride enables tuning the refractive index $(n)^{33,34}$ in a wide range; $n$ increases with the B content due to the presence of B-B bonds. Moreover, higher electrical conductivity is reported when the boron content is increased ${ }^{35}$.

To reiterate, $\mathrm{BCN}$-materials with varying composition (i.e., ratio of the constituting elements) are of particular interest to enable a rich variety of properties. For that reason, synthesis, characterization and possible applications of these materials are widely studied. Experimental $27,36-40$ and theoretical ${ }^{41-45}$ studies showed that BCN-materials have attractive mechanical, electrical and optical properties. For example, Yuki et.al. ${ }^{37}$ reported that the optical bandgap of the BCN film decreased by $\sim 35 \%$ and the electrical resistivity decreased by 3 orders of magnitudes (from $10^{12}$ to $10^{9} \Omega \mathrm{cm}$ ) when the C content increased from $6 \%$ to $30 \%$. Additionally, Ajayan et. al. ${ }^{28}$ reported an increased electrical conductivity with increasing percentage of carbon.

It should be noted that $\mathrm{C}$ and $\mathrm{h}-\mathrm{BN}$ tend to form segregated $\mathrm{C}$ and $\mathrm{BN}$ domains in the $\mathrm{BCN}$ system, making the formation of single-phase $\mathrm{BCN}$ films challenging. Although B-, C- and N-containing materials are often referred to as "BCN" in the literature, the constituting phases are usually not well specified. It remains then a question mark whether such a " $\mathrm{BCN}$ " material is composed of a single phase or multiple phases. The latter can contain for example mixed inclusions of pure carbon and pure boron nitride. The same holds for B-rich BN, 
which can be composed of a pure (elemental) boron (pure-B) and a pure boron nitride phase. Thus, further investigation of the materials, which are generally united under the term "BCN", is certainly required.

The technologies available for fabrication nowadays have, however, clear drawbacks, for example high temperature (high-T) requirements, phase segregation in multicomponent films, reproducibility issues and low conformality, that limit the potential industrial applications of these materials and prevent achieving technological maturity. For that reason, alternative techniques for deposition to achieve the fabrication requirements are needed. To this purpose, atomic layer deposition (ALD) has emerged as an important technique for deposition of ultra-thin layers at relatively low temperatures for industrial applications due to its advantages over other methods.

First (1), high-T processes are more likely to lead to separated phases since this is thermodynamically favorable ${ }^{28,43}$. To synthesize a single-phase material (real BCN or B-rich BN in one phase) low-T methods are preferable. For the chosen precursors in this work, certainly for $\mathrm{BBr}_{3}$ and $\mathrm{TEB}$, ALD occurs at low temperatures ${ }^{46,47}$. Still low-T processes tend to reach chemical equilibrium, which may lead to phase separation. In this case, radical-assisted processes, e.g. hot-wire (hot tungsten filament) and plasma assistance, exhibit a higher chance of obtaining mixed phases, and thus for forming a single phase, as they occur not in equilibrium 48. In addition, they allow lowering the process temperature to room temperature and limit the temperature effects even to a larger extend. Second (2), ALD allows to simplify the deposition chemistry, limiting the study to heterogeneous (surface) processes only. This finally helps to better understand the processes. Altogether, (1) and (2) rationally lead to (i) a pulsed manner of introducing precursors with purges in between, (ii) low-T, and (iii) possible use of HW or plasma. Therefore, thermal or radical enhanced ALD methods become convenient choices.

In this project, we focus on the deposition of boron-nitrogen and boron-carbonnitrogen containing thin films by thermal and radical-enhanced methods. We explore both pulsed-deposition and ALD approaches, with the aim to comparatively study and 
understand the growth mechanisms, observe the occurrence of either single or multiple phases, and study the material properties.

\subsection{Introduction to atomic layer deposition}

Atomic layer deposition is a technique, suitable for the production of thin films with a thickness control down to a fraction of a monolayer ${ }^{49,50}$. It is based on sequential introduction (pulse) of two or more reactive gases (also called precursors) into a reactor, resulting in self-limiting gas-solid reactions occurring at the surface of a suitable substrate 49,51 . Contrary to chemical vapor deposition (CVD), an inert gas purge between pulses of different precursors prevents chemical reactions in the gas phase ${ }^{49-51}$. Thus, an ALD cycle can be expressed as giving (i) precursor A, (ii) purge, (iii) precursor B, and (iv) purge. Ideally, in steps (i) and (iii), the precursors must exhibit self-limiting reactions on the surface. This means that a chemical reaction of a precursor in the gas phase with a surface that is already covered by the same precursor is not possible. Due to the self-limiting nature, ALD has the capability to coat complex shapes (i.e., high aspect ratio structures) with a conformal layer ${ }^{52-55}$. Furthermore, the purging steps (steps (ii) and (iv)) should be long enough to ensure the removal of residual gases from the reactor. As a result of one cycle, a layer of certain thickness is deposited on the surface. This is referred to as the growth per cycle (GPC). ALD cycles are repeated until the desired thickness has been achieved. The reaction temperatures should be chosen such that condensation (i.e., physisorption of multilayers) of the reactants is prevented, whereas their chemisorption leads to the formation of not more than a monolayer. A schematic illustration of one ALD cycle for forming aluminum oxide $\left(\mathrm{Al}_{2} \mathrm{O}_{3}\right)$ by sequential exposures to trimethylaluminum (TMA $\left.\mathrm{Al}\left(\mathrm{CH}_{3}\right)_{3}\right)$ and water $\left(\mathrm{H}_{2} \mathrm{O}\right)^{56}$ is given in Figure 1-1. After a complete cycle, the $\mathrm{OH}$ terminated surface is reproduced; repeating the cycle builds up a film. 


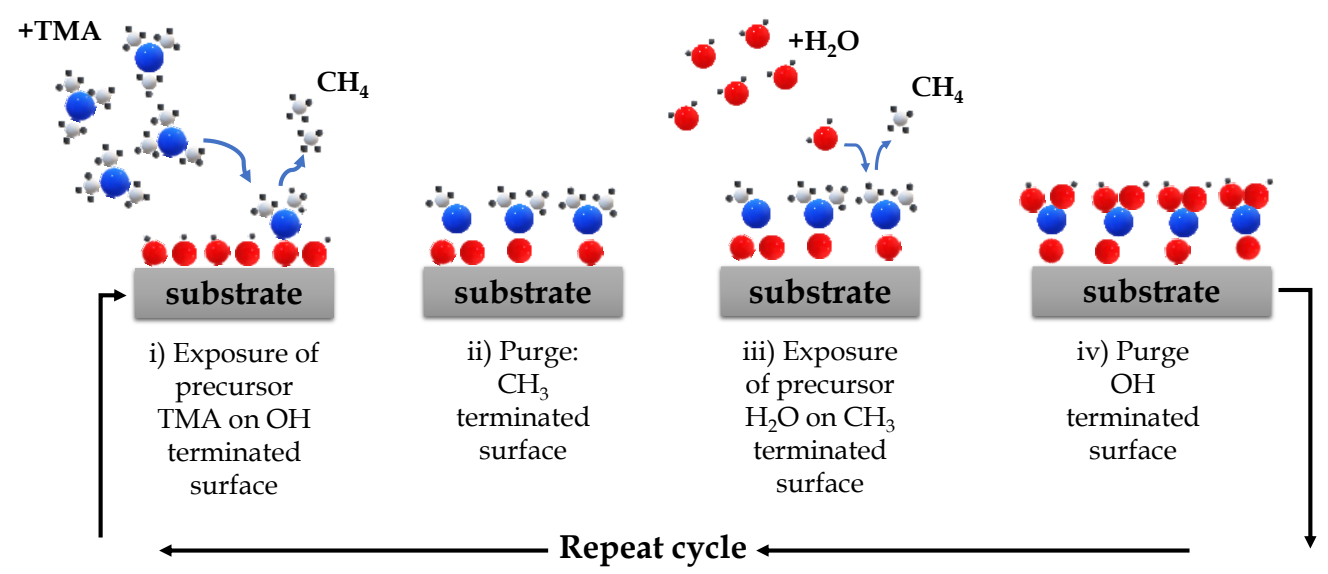

Figure 1-1. Schematic illustration of one ALD reaction cycle. (i) -OH terminated surface exposed to TMA results in $\mathrm{CH}_{4}$ removal and leaves $\mathrm{H}_{3} \mathrm{C}$-terminations; (ii) purge: removal of $\mathrm{CH}_{4}$ and excess TMA; (iii) the $\mathrm{H}_{3} \mathrm{C}$-surface is exposed to $\mathrm{H}_{2} \mathrm{O}$, eliminating $\mathrm{CH}_{4}$ and re-creating-OH terminations; (iv) purge: removal of $\mathrm{CH}_{4}$ and excess $\mathrm{H}_{2} \mathrm{O}{ }^{56}$.

ALD can be performed in thermal and radical-enhanced modes ${ }^{57}$. Thermal ALD processes are commonly used to deposit two-element materials such as oxides and nitrides. Thermal ALD of single-element films (metals or semiconductors), except for notable exceptions, is difficult ${ }^{49}$. A solution can be provided by radical-enhanced ALD (REALD) ${ }^{58}$. Radicals can enable reactions that are not possible in thermal mode. Furthermore, radicals can lower the deposition temperature down to room temperature, as occurs for example for $\mathrm{Al}_{2} \mathrm{O}_{3}$ REALD 59. The radicals can be generated by dissociating one of the (two) precursors by, for example, a plasma source (the so-called plasma-enhanced ALD - PEALD). If ammonia $\left(\mathrm{NH}_{3}\right)$ gas is introduced through plasma, a variety of reactive $\mathrm{NH}_{\mathrm{x}}(\mathrm{x}=0$ 2) radicals as well as atomic hydrogen (at-H) species can be generated 60 . The presence of $\mathrm{NH}_{\mathrm{x}}$ will greatly increase the rate of surface nitridation at low temperatures. The surface bombardment with energetic species (ions, electrons) can additionally provide energy to the surface and thus change film properties. For instance, several groups have observed improved crystallinity upon plasma assistance for aluminum nitride (AlN) ${ }^{61}$, hafnium oxide $\left(\mathrm{HfO}_{2}\right)^{62}$ and vanadium pentoxide $\left(\mathrm{V}_{2} \mathrm{O}_{5}\right) 63$ films. However, detrimental effects may also occur, such as reduced thickness uniformity ${ }^{64,65}$ and possible damage of the film. This makes PEALD less attractive for certain applications. 
Another approach to generate radicals is by utilizing a hot-wire (HW) ${ }^{66,67}$. In this method, a hot tungsten (W) filament, heated up to $\approx 2700 \mathrm{~K}$, can be used to dissociate molecules such as hydrogen $\left(\mathrm{H}_{2}\right)$ and ammonia into atomic hydrogen and $\mathrm{NH}_{\mathrm{x}}{ }^{66-72}$. Compared to plasmas, this method enables purely chemical film growth, since it excludes the presence of energetic charged species and (UV) photons, reducing poorly controlled chemical reactions, possible surface bombardment effects and photo-activation 66,67,73-75.

\subsection{Thin film deposition facilities}

Thin film deposition experiments were performed using two different reactor systems, namely a home-built cluster and a Picuson plasma ALD/CVD (R200) setup. The home-built cluster system (Figure 1-2) consists of two gas distribution networks and three reactors (all equipped with turbo-molecular pumps) connected to a loadlock. The latter minimizes surface/interface deterioration by constantly keeping the reactors under vacuum conditions $\left(10^{-7}\right.$ $10^{-8}$ mbar base pressure). All the reactors allow installation of a spectroscopic ellipsometer (SE) for in-situ (real time) monitoring the film growth. The ellipsometer (Woollam M2000FI) operates in a wavelength range of 245-1688 nm. The reactors are equipped with high-speed ALD valves having a time resolution of $0.1 \mathrm{~s}$. The home-built hot-wire (HW) tool can be installed to provide at-H and $\mathrm{NH}_{x}$ radicals by dissociation of $\mathrm{H}_{2}$ or $\mathrm{NH}_{3}$. The $\mathrm{HW}$ can be mounted either in horizontal (not in line-of-sight with the substrate) or vertical (in line-of-sight with the substrate) position in both Reactor-1 and Reactor-3. 


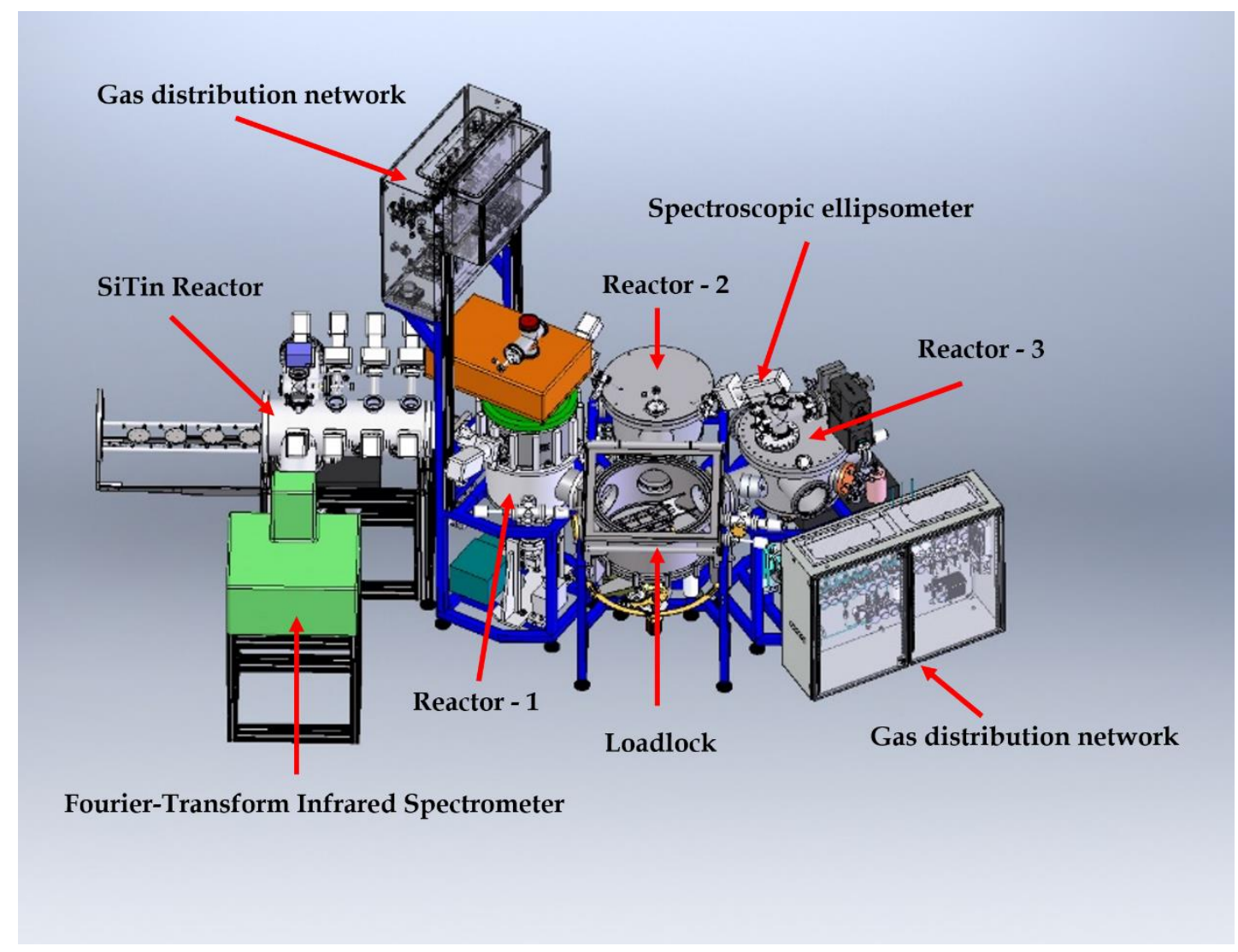

Figure 1-2. A drawing of the home-built cluster system consisting of 2 gas-distribution networks and 3 ALD/CVD reactors connected to a loadlock. A spectroscopic ellipsometer (Woollam M2000FI) can be mounted on all reactors to monitor the film growth in-situ.

A drawing of Reactor-1 (also referred to as the cold-wall reactor), which was employed for the experiments discussed in Chapter 6, is shown in Figure 1-3. In this setup, another chamber equipped with a Fourier Transform Infrared Spectrometer (FTIR) is positioned in the downstream direction (see Figure 1-2), which allows studying the reaction byproducts. Reactor- 1 is rather big and has an effective volume of 70 liters - much larger compared to that of Reactors 2 and 3. Further, it does not contain a small inner chamber, unlike Reactor-2 and Reactor3 (see Figure 1-4 for the latter). Reactor-1 was used for ALD of BN films from boron tribromide $\left(\mathrm{BBr}_{3}\right)$ and $\mathrm{NH}_{3}$, using nitrogen $\left(\mathrm{N}_{2}\right)$ or argon $(\mathrm{Ar})$ as carrier gases. The $\mathrm{NH}_{3}$ was introduced from top (through the so-called cross assembly), whereas the $\mathrm{BBr}_{3}$ supplied via the gas ring located at $10 \mathrm{~cm}$ above the substrate. 


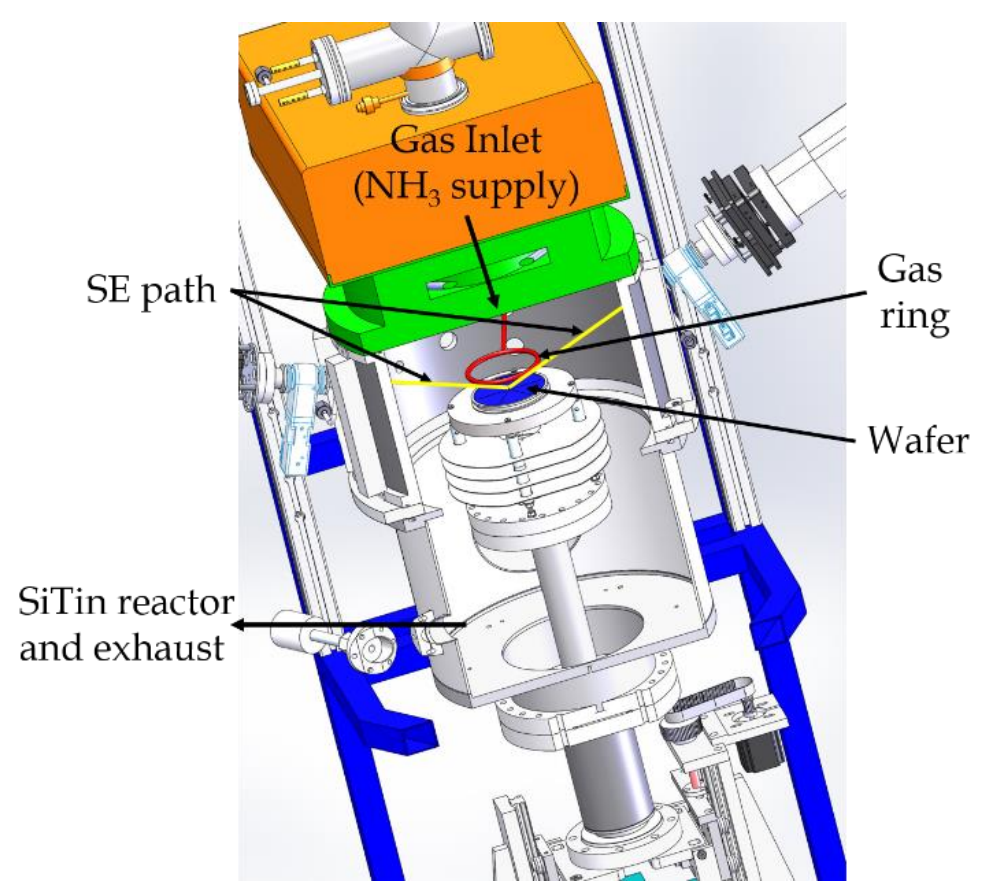

Figure 1-3. A drawing of the cold-wall reactor (Reactor-1) with a volume of $\sim 70$ liters.

The homebuilt hot-wall Reactor-2 was used to deposit amorphous silicon (a-Si) layers from tri-silane $\left(\mathrm{Si}_{3} \mathrm{H}_{8}\right)$ at $400{ }^{\circ} \mathrm{C}$, to passivate $\mathrm{B}(\mathrm{C}) \mathrm{N}$ ALD films. This reactor has a small-volume $(24 \mathrm{ml})$ inner reactor, placed inside a much bigger (several liters) cold-wall outer reactor. Importantly, the walls of the inner reactor were kept at elevated temperatures during deposition.

Reactor-3 (Figure 1-4) was used for the majority of experiments discussed in Chapters 3, 4 and 7. Similar to Reactor-2, the hot-wall small-volume inner reactor is placed inside a big-volume cold-wall outer reactor. Having small volumes is advantageous since, by reducing the precursor delivery- and purge times, it allows to efficiently maintain an ALD mode. The precursors can be supplied both from the top (through the cross-assembly) and the lateral gas inlets located at $2-3 \mathrm{~cm}$ distance above the substrate. 


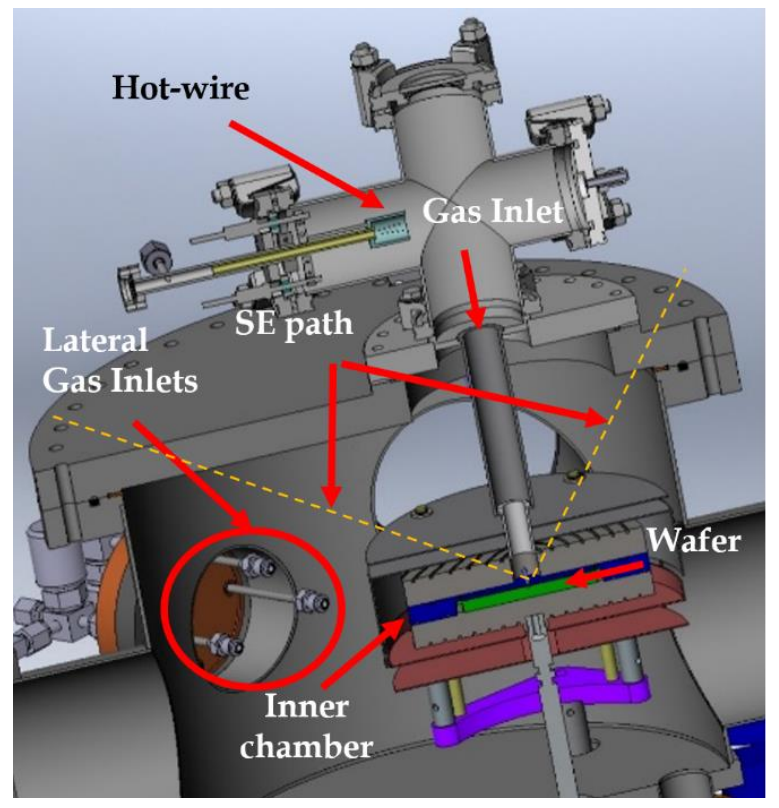

Figure 1-4. A cross-section of Reactor-3. The wafer is placed between the heated top and bottom part of the inner chamber with a volume of $32 \mathrm{ml}$. The hot-wire (tungsten filament), gas inlets and SE optical path are indicated.

The Picosun plasma reactor (Figure 1-5) was used for studying depositions in both thermal and plasma-enhanced ALD (PEALD) modes, as further discussed in Chapters 3, 4, 5 and 6 . The reactor is equipped with a plasma source, to generate a maximum power of $2.5 \mathrm{~kW}$, and an in-situ Woollam M2000XI SE.

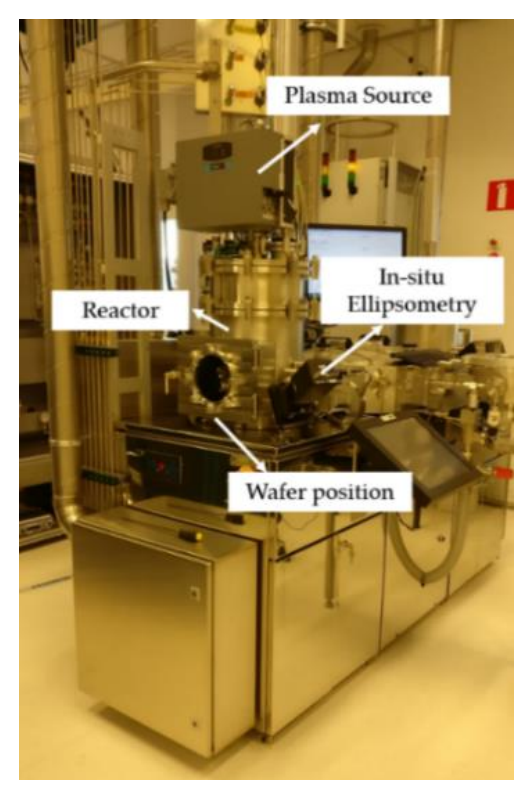

Figure 1-5. Picosun plasma ALD/CVD reactor equipped with a plasma source and spectroscopic ellipsometer. 


\subsection{Thesis outline}

Chapter 2 discusses the application of spectroscopic ellipsometry for determining thickness, optical functions and composition of the films. It further discusses the chemical reaction mechanism. Chapter 3 presents a study of the composite nature of boron rich boron nitride films. It is shown, by using x-ray photoelectron spectroscopy (XPS) and SE, that the films consist of two separate phases, namely pure boron and pure boron nitride. The optical SE model developed in this chapter is further applied in Chapter 4 . Chapter 4 discusses the growth mechanism of $\mathrm{BN}$ films deposited from diborane $\left(\mathrm{B}_{2} \mathrm{H}_{6}\right)$ and $\mathrm{NH}_{3}$ in a pulsed regime, to mimic an ALD process. Further, purely-thermal and radicalenhanced deposition modes are compared by gradually changing the degree of $\mathrm{NH}_{3}$ dissociation, from low by hot-wire to high by plasma-assistance. It is demonstrated that, in thermal mode, the growth and composition of the layers are strongly dependent on the total gas pressure. This allows to hypothesize a growth model via a so-called surface-adduct mechanism (pre-introduced in Chapter 2, Section 2.3). Chapter 5 reports on the applicability of the surface-adduct mechanism to $\mathrm{ALD}$ of $\mathrm{BN}$ from $\mathrm{BBr}_{3}$ and $\mathrm{NH}_{3}$. Chapter 6 compares purely-thermal and radical-assisted methods. It further reports on the effects of reactor design on the film growth aspects, comparing the results obtained with the hot-wall and cold-wall reactors. Chapter 7 investigates thermal deposition of B-C-N films from triethylborane (TEB) and $\mathrm{NH}_{3}$ with various amounts of carbon. Additionally, socalled ALD super-cycles, leading to the incorporation of AlN into BN or B-C-N matrix are studied. Chapter 8 concludes the thesis and gives recommendations for future research. 


\section{References}

${ }^{1}$ R. Haubner, M. Wilhelm, R. Weissenbacher, and B. Lux, in High Perform. NonOxide Ceram. II. Struct. Bond., edited by M. Jansen (2002), pp. 1-45.

2 D.W. Palmer, in Compr. Semicond. Sci. Technol. (Elsevier, 2011), pp. 390-447.

3 T. Oku, N. Koi, and K. Suganuma, J. Phys. Chem. Solids 69, 1228 (2008).

4 S. Wang, Q. Chen, and J. Wang, Appl. Phys. Lett. 99, 063114 (2011).

${ }^{5}$ D. Jin-Xiang, Z. Xiao-Kang, Y. Qian, W. Xu-Yang, C. Guang-Hua, and H. DeYan, Chinese Phys. B 18, 4013 (2009).

${ }^{6}$ W. Liu, T. Yanase, T. Nagahama, and T. Shimada, J. Alloys Compd. 792, 1206 (2019).

7 J. Wang, F. Ma, W. Liang, and M. Sun, Mater. Today Phys. 2, 6 (2017).

8 N.Y. Kim, H.Y. Jeong, J.H. Kim, G. Kim, H.S. Shin, and Z. Lee, ACS Nano 11, 7084 (2017).

${ }^{9}$ J. Wang, F. Ma, and M. Sun, RSC Adv. 7, 16801 (2017).

${ }^{10}$ H. Falomir, M. Loewe, E. Muñoz, and A. Raya, Phys. Rev. B 98, 195430 (2018).

${ }^{11}$ M. Zamani and M. Abbasnejad, Physica C, 554, 19 (2018).

12 R.R. Nair, P. Blake, A.N. Grigorenko, K.S. Novoselov, T.J. Booth, T. Stauber, N.M.R. Peres, and A.K. Geim, Science, 320 (5881), 1308 (2008).

${ }^{13}$ J. Zhu, R. Duan, S. Zhang, N. Jiang, Y. Zhang, and J. Zhu, Springerplus 3, 585 (2014).

14 Q. Peng and S. De, Phys. E Low-Dimensional Syst. Nanostructures 44, 1662 (2012).

15 A. Ramasubramaniam, D. Naveh, and E. Towe, Nano Lett. 11, 1070 (2011).

16 V. Yadav and V. Kulshrestha, Nanoscale 11, 12755 (2019).

17 S.K. Jang, J. Youn, Y.J. Song, and S. Lee, Sci. Rep. 6, 1 (2016).

18 Y. Ding, J. Shi, M. Zhang, X. Jiang, H. Zhong, P. Huang, M. Wu, and X. Cao, RSC Adv. 6, 29190 (2016).

${ }^{19}$ C. Li, Y. Bando, C. Zhi, Y. Huang, and D. Golberg, Nanotechnology 20, (2009).

${ }^{20}$ K. Watanabe, T. Taniguchi, and H. Kanda, Nat. Mater. 3, 404 (2004).

${ }^{21}$ I. Jo, M.T. Pettes, J. Kim, K. Watanabe, T. Taniguchi, Z. Yao, and L. Shi, Nano Lett. 13, 550 (2013).

22 N. Izyumskaya, D.O. Demchenko, S. Das, Ü. Özgür, V. Avrutin, and H. Morkoç, Adv. Electron. Mater. 3, 1 (2017).

${ }^{23}$ K. Zhang, Y. Feng, F. Wang, Z. Yang, and J. Wang, J. Mater. Chem. C 5, 11992 (2017). 
24 G.C. Constantinescu and N.D.M. Hine, Nano Lett. 16, 2586 (2016).

${ }^{25}$ C.R. Dean, A.F. Young, I. Meric, C. Lee, L. Wang, S. Sorgenfrei, K. Watanabe, T. Taniguchi, P. Kim, K.L. Shepard, and J. Hone, Nat. Nanotechnol. 5, 722 (2010).

${ }^{26}$ S.K. Jang, J. Jeon, S.M. Jeon, Y.J. Song, and S. Lee, Solid. State. Electron. 109, 8 (2015).

${ }^{27}$ C.W. Ong, X.A. Zhao, K.F. Chan, Y.M. Ng, P.W. Chan, C.L. Choy, and R.W.M. Kwok, Thin Solid Films 307, 152 (1997).

${ }^{28}$ L. Ci, L. Song, C. Jin, D. Jariwala, D. Wu, Y. Li, A. Srivastava, Z.F. Wang, K. Storr, L. Balicas, F. Liu, and P.M. Ajayan, Nat. Mater. 9, 430 (2010).

${ }^{29}$ J. Zhao, B. Lin, Y. Zhu, Y. Zhou, and H. Liu, Catal. Sci. Technol. 8, 5900 (2018).

30 B. He, W.J. Zhang, Z.Q. Yao, Y.M. Chong, Y. Yang, Q. Ye, X.J. Pan, J.A. Zapien, I. Bello, S.T. Lee, I. Gerhards, H. Zutz, and H. Hofsäss, Appl. Phys. Lett. 95, 2 (2009).

${ }^{31}$ R. Dahal, J. Li, S. Majety, B.N. Pantha, X.K. Cao, J.Y. Lin, and H.X. Jiang, Appl. Phys. Lett. 98, 88 (2011).

32 K. Nose, H. Oba, and T. Yoshida, Appl. Phys. Lett. 89, (2006).

33 S.P. Murarka, C.C. Chang, D.N.K. Wang, and T.E. Smith, J. Electrochem. Soc. 126, 1951 (1979).

34 T.H. Yuzuriha and D.W. Hess, Thin Solid Films 140, 199 (1986).

35 C.W. Ong, K.F. Chan, and C.L. Choy, Thin Solid Films 388, 217 (2001).

36 A. Prakash and K.B. Sundaram, Appl. Surf. Sci. 396, 484 (2017).

37 T. Yuki, S. Umeda, and T. Sugino, Diam. Relat. Mater. 13, 1130 (2004).

38 M.K. Lei, Q. Li, Z.F. Zhou, I. Bello, C.S. Lee, and S.T. Lee, Thin Solid Films 389, 194 (2001).

${ }^{39}$ J. Wang, C. Chen, C. Yang, Y. Fan, D. Liu, and W. Lei, Curr. Graphene Sci. 2, 3 (2017).

40 S. Beniwal, J. Hooper, D.P. Miller, P.S. Costa, G. Chen, S.Y. Liu, P.A. Dowben, E.C.H. Sykes, E. Zurek, and A. Enders, ACS Nano 11, 2486 (2017).

41 J. Zhu, S. Bhandary, B. Sanyal, and H. Ottosson, J. Phys. Chem. C 115, 10264 (2011).

42 E. Hernández, C. Goze, P. Bernier, and A. Rubio, Phys. Rev. Lett. 80, 4502 (1998).

${ }^{43}$ K. Yuge, Phys. Rev. B - Condens. Matter Mater. Phys. 79, 1 (2009).

44 J. Da Rocha Martins and H. Chacham, ACS Nano 5, 385 (2011).

${ }^{45}$ L. Song, Z. Liu, A.L.M. Reddy, N.T. Narayanan, J. Taha-Tijerina, J. Peng, G. Gao, J. Lou, R. Vajtai, and P.M. Ajayan, Adv. Mater. 24, 4878 (2012). 
${ }^{46}$ A. Haider, C. Ozgit-Akgun, E. Goldenberg, A.K. Okyay, and N. Biyikli, J. Am. Ceram. Soc. 97, 4052 (2014).

47 B. Mårlid, M. Ottosson, U. Pettersson, K. Larsson, and J. Carlsson, Thin Solid Films 402, 167 (2002).

${ }^{48}$ H.B. Profijt, S.E. Potts, M.C.M. van de Sanden, and W.M.M. Kessels, J. Vac. Sci. Technol. A Vacuum, Surfaces, Film. 29, 050801 (2011).

${ }^{49}$ M.G. Steven, Chem. Rev. 110, 111 (2010).

50 T. Muneshwar, M. Miao, E.R. Borujeny, and K. Cadien, in Handbook of Thin Film Deposition (2018), pp. 359-377.

${ }^{51}$ R.L. Puurunen, J. Appl. Phys. 97, 121301 (2005).

${ }^{52}$ T. Weiss and W. Ebert, Opt. Photonik 12, 42 (2017).

${ }^{53}$ J.W. Elam, G. Xiong, C.Y. Han, H.H. Wang, J.P. Birrell, U. Welp, J.N. Hryn, M.J. Pellin, T.F. Baumann, J.F. Poco, and J.H. Satcher, J. Nanomater. 2006, 1 (2006).

${ }^{54}$ J.W. Elam, D. Routkevitch, P.P. Mardilovich, and S.M. George, Chem. Mater. 15, 3507 (2003).

55 R. Zazpe, M. Knaut, H. Sopha, L. Hromadko, M. Albert, J. Prikryl, V. Gärtnerová, J.W. Bartha, and J.M. Macak, Langmuir 32, 10551 (2016).

56 G.N. Parsons, S.M. George, and M. Knez, MRS Bull. 36, 865 (2011).

57 C. Detavernier, J. Dendooven, D. Deduytsche, and J. Musschoot, in ECS Trans. (ECS, 2008), pp. 239-246.

${ }^{58}$ H. Kim, J. Vac. Sci. Technol. B Microelectron. Nanom. Struct. 21, 2231 (2003).

${ }^{59}$ S.B.S. Heil, P. Kudlacek, E. Langereis, R. Engeln, M.C.M. Van De Sanden, and W.M.M. Kessels, Appl. Phys. Lett. 89, 1 (2006). 2008).

60 A. Fridman, Plasma Chemistry (Cambridge University Press, Cambridge,

${ }^{61}$ H. Van Bui, F.B. Wiggers, A. Gupta, M.D. Nguyen, A.A.I. Aarnink, M.P. de Jong, and A.Y. Kovalgin, J. Vac. Sci. Technol. A Vacuum, Surfaces, Film. 33, 01A111 (2015).

${ }^{62}$ Y. Lee, S. Kim, J. Koo, I. Kim, J. Choi, H. Jeon, and Y. Won, J. Electrochem. Soc. 153, G353 (2006).

${ }^{63}$ J. Musschoot, D. Deduytsche, H. Poelman, J. Haemers, R.L. Van Meirhaeghe, S. Van den Berghe, and C. Detavernier, J. Electrochem. Soc. 156, P122 (2009).

64 Z. Zhu, P. Sippola, O.M.E. Ylivaara, C. Modanese, M. Di Sabatino, K. Mizohata, S. Merdes, H. Lipsanen, and H. Savin, Nanoscale Res. Lett. 14, 55 (2019).

${ }^{65}$ H. Kim, C. Cabral, C. Lavoie, and S.M. Rossnagel, J. Vac. Sci. Technol. B Microelectron. Nanom. Struct. 20, 1321 (2002).

${ }^{66}$ H. Umemoto, K. Ohara, D. Morita, T. Morimoto, M. Yamawaki, A. Masuda, and H. Matsumura, Jpn. J. Appl. Phys. 42, 5315 (2003). 
${ }^{67}$ Y.J. Shi, B.D. Eustergerling, and X.M. Li, Thin Solid Films 516, 506 (2008).

${ }^{68}$ B. Stannowski, J.K. Rath, and R.E.I. Schropp, Thin Solid Films 395, 339 (2001).

${ }^{69}$ Y. Shi, Acc. Chem. Res. 48, 163 (2015).

70 I. Langmuir, J. Am. Chem. Soc. 34, 860 (1912).

${ }^{71}$ I. Langmuir and G.M.J. Mackay, J. Am. Chem. Soc. 36, 1708 (1914).

72 I. Langmuir, J. Am. Chem. Soc. 37, 417 (1915).

${ }^{73}$ M. Yang, A.A.I. Aarnink, A.Y. Kovalgin, R.A.M. Wolters, and J. Schmitz, Phys. Status Solidi 212, 1607 (2015).

74 V. V. Afanas'ev, J.M.M. de Nijs, P. Balk, and A. Stesmans, J. Appl. Phys. 78, 6481 (1995).

${ }^{75}$ H. Shimizu, K. Sakoda, T. Momose, M. Koshi, and Y. Shimogaki, J. Vac. Sci. Technol. A Vacuum, Surfaces, Film. 30, 01 A144 (2012). 


\title{
2 Studying film growth: spectroscopic ellipsometry and
}

\section{adduct-assisted pathway}

\begin{abstract}
This chapter discusses the issues important for studying thin films by spectroscopic ellipsometry

(SE) and in relation to the specific film-formation mechanism explored in this thesis. The SE optical models, applied for studying optical functions, measuring film thickness and estimating film composition, are explained. The thickness values obtained by SE are compared with those from high-resolution transmission electron microscopy (HRTEM) and $x$-ray reflectometry (XRR). The composition is verified with XPS. The results show a good agreement indicating applicability of the developed SE model. In-situ SE is used to study the growth in real time (to be shown in Chapters 3-7) and determine film composition (to be discussed in Chapters 2-4). Further, the surface reaction mechanism, known from the literature and referred to as the surfaceadduct pathway, is explained. This mechanism is further hypothesized to occur in the processes discussed in Chapters 4-7.
\end{abstract}




\subsection{Introduction}

This chapter reports on the theory and application of spectroscopic ellipsometry (SE) for studying optical functions, measuring thickness and estimating composition of thin films. The relevant optical models will be explained in Section 2.2. Section 2.3 discusses the surface reaction pathway (further referred to as adduct pathway or adduct mechanism) which is proposed to occur for BN films. This mechanism is investigated in Chapters 4-7.

\subsection{SE modelling}

SE is an optical characterization technique which is used to determine a variety of properties (e.g., refractive index $n$, extinction coefficient $k$, thickness) of thin films with high accuracy and in a non-destructive manner ${ }^{1-3}$. SE is widely used for real time (in-situ) studies of film growth. It has been shown that SE is a reliable technique to obtain physical, optical and electrical properties, providing insights into growth mechanism of various materials.

Spectroscopic ellipsometry measures the change in the polarization of light reflected from a sample, as a function of wavelength $\lambda$. The thickness and optical functions ( $n$ and $k$ ) are obtained by fitting the following model (equation 2.1) to the experimental data with the Levenberg-Marquardt algorithm 1,2.

$$
\tan (\Psi) e^{i \Delta}=\frac{r_{p}}{r_{s}}=r
$$

In this equation, $r$ is defined as the ratio of the amplitude reflection coefficients for $p$-polarized light $\left(r_{p}\right)$ to $s$-polarized light $\left(r_{s}\right)$. Psi $(\Psi)$ and delta $(\Delta)$ represent the magnitude of the reflectivity ratio and the phase difference between $r_{p}$ and $r_{s}$, respectively. $\Psi$ and $\Delta$ are the parameters experimentally (directly) measured by SE.

The analysis of the measured psi and delta values for each $\lambda$ or photon energy $(E)$ allows to extract sample properties such as thickness and optical functions. For that, an optical model is required. The entire modeling includes: (i) 
identifying the number and order of contributing sub-layers, (ii) modeling (or measuring) dielectric functions $(\varepsilon)$ of the contributing layers as a function of $\lambda$ or $E$, and (iii) fitting the measured $\Psi$ - and $\Delta$-data for each $\lambda$ or $E{ }^{1}$. The validity of the analysis is mathematically estimated by the mean square error (MSE), $\chi^{2}$, which represents the agreement between the measured and modeled (fitted) data ${ }^{2}$. Since (some of the) optical properties are usually unknown, they become the fitting parameters. Having too many fitting parameters increases the uncertainty; carrying out a correct modelling procedure is thus very crucial for truthful interpretation of the results.

In this study, we used a stacked-layer model (see Figure 2-1) consisting of several sub-layers. Each sub-layer was assigned to have optical functions of the corresponding material. Since silicon (Si) exhibits well-known temperature $(T)$ dependent optical functions $n(\lambda, T)$ and $k(\lambda, T) 1,4$, this was used for in-situ surfacetemperature measurements. For $\mathrm{Si}$ and silicon dioxide $\left(\mathrm{SiO}_{2}\right)$, these functions were taken from the literature 1,5 and fixed in the model. The $\mathrm{SiO}_{2}$ thickness was predetermined by ex-situ SE and subsequently fixed in the model. A capping layer of amorphous $\mathrm{Si}$ (a-Si) was sometimes used to protect the films upon the exposure to oxidizing ambient (air).

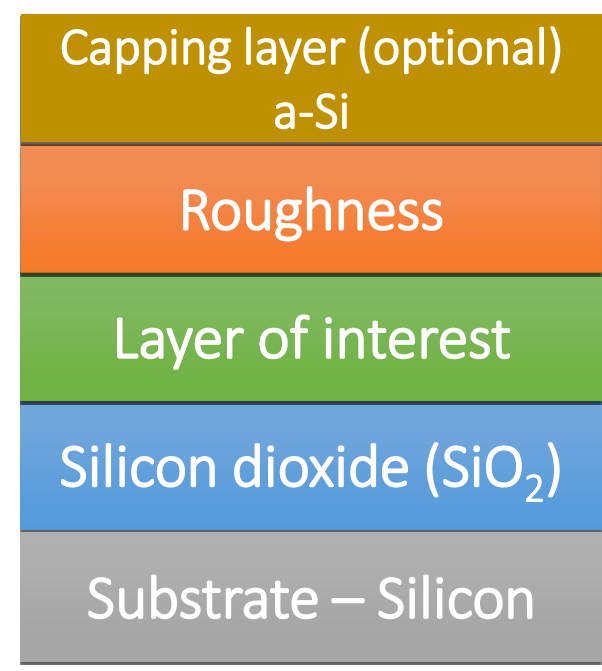

Figure 2-1. Stacked-layer SE model.

Optical functions of the layer of interest (in our case B-, N- and Ccontaining layers) were fitted using Kramers-Kronig consistent (KK-consistent) 
B-spline parameterization (node spacing $0.3 \mathrm{eV}$ ) without assuming a particular spectral shape ${ }^{6}$ for each location (ex-situ wafer mapping) and each time frame (insitu measurements). Following the B-spline parameterization, each film was analyzed using one of the optical models given below.

The Tauc-Lorentz (TL) and Lorentz (L) oscillators were employed to model the optical functions of boron (pure-B) films. The complex dielectric function $(\varepsilon)$ used in these oscillators can be parameterized by equation $2.21,7$.

$$
\varepsilon=\varepsilon_{1 m}+i \varepsilon_{2 m}
$$

In this equation, $\varepsilon_{1 m}$ and $\varepsilon_{2 m}$ are the real and imaginary parts of the dielectric function $-\varepsilon$, respectively, and $m$ is the oscillator number. When $\varepsilon_{2 m}$ is known, $\varepsilon_{1 m}$ can be obtained by Kramers-Kronig integration of $\varepsilon_{2 m}$ as shown in equation 2.3:

$$
\varepsilon_{1 m}=\frac{2}{\pi} P \int_{E g_{m}}^{\infty} \frac{\xi \varepsilon_{2 m}(\xi)}{\xi^{2}-E^{2}} d \xi
$$

with the principle value integral $(P)$ given in ref. ${ }^{1}$ and $E g$ denotes the energy gap. In a Tauc-Lorentz oscillator, $\varepsilon_{2 m}$ is defined by equations 2.4 and 2.5:

$$
\begin{aligned}
& \varepsilon_{2 m}=\left[\frac{A m p_{m} E o_{m} B r_{m}\left(E-E g_{m}\right)^{2}}{\left(E^{2}-E o_{m}^{2}\right)^{2}+B r_{m}^{2} E^{2}} \frac{1}{E}\right] \rightarrow E>E g \\
& \varepsilon_{2 m}=0 \rightarrow E \leq E g_{m}
\end{aligned}
$$

where $A m p_{m}$ is the amplitude and $E o_{m}$ is the central energy of the $m^{\text {th }}$ oscillator, and $\mathrm{Br}_{m}$ is the broadening parameter.

The $\varepsilon_{2 m}$ parametrization for a Lorentz oscillator is given in equation 2.6. The components of the equation have already been described above.

$$
\varepsilon_{2 m}=\frac{A m p_{m} B r_{m} E o_{m}}{\left(E o_{m}^{2}-E^{2}\right)^{2}+E^{2} B r_{m}^{2}}
$$

Each oscillator function describes an electronic transition or, in the case of TL, a series of transitions between two bands. Dielectric functions formed by multiple transitions can be constructed by summation of the relevant oscillator functions. 
To successfully model pure-B films and B/BN composites, it was necessary to include a Lorentz oscillator with a thickness dependent amplitude (see Chapter 3 for details), to describe a feature near the band edge (at $\sim 3.3 \mathrm{eV}$ ). Including this thickness dependence significantly improved the fit accuracy. To note, this feature did not match with any known electronic transitions of $\mathrm{BN}$ according to the theoretical and experimental works surveyed ${ }^{8-12}$.

The refractive index, $n$, was fitted using the Sellmeier model (equation 2.7), limited to the transparent range ${ }^{1,2}$ :

$$
n^{2}(\lambda)=A+B \lambda^{2} /\left(\lambda^{2}-C\right) .
$$

In this equation, $A, B$ and $C$ are Sellmeier coefficients which are obtained by fitting this model to experimental data ${ }^{1,13}$. Consistent thickness values were obtained from both $\mathrm{KK}$-consistent B-spline parameterization (in the entire wavelength range 245-1688 $\mathrm{nm}$ ) and the Sellmeier (transparent region only) model.

Finally, the surface roughness of the layer can be taken into account by using the Bruggeman effective medium approximation (EMA) 1,14,15. The EMA used for this analysis considers the (surface) rough layer to consist of $50 \mathrm{vol}$. \% of (ambient) voids and 50 vol. \% of the corresponding layer material.

The correlation between multiple fit parameters was minimized by variable angle SE (VASE) measurements (ex-situ) and multi-sample analysis (MSA). The former provides more measurement events performed under different angles on the same location (spot) on the wafer. The MSA compares the same material at different film thicknesses, increasing the consistency in determining optical functions. Further details on VASE and MSA can be found in ref. 5,16-22.

Sensitivity tests were performed to confirm that the fits represented unique and global solutions rather than local or shallow minima, and to estimate errors in fitting the parameters ${ }^{23}$. The sensitivity analysis delivers an MSE value for a range of values of one fit parameter. 


\subsubsection{Comparison of the thicknesses measured by SE, TEM and XRR}

In order to verify the applicability of the SE optical model to determine the film thickness, we measured thicknesses of several stoichiometric-BN samples deposited at various conditions, by high-resolution transmission electron microscopy (HRTEM) and X-ray reflectometry (XRR), as given in Tables 2-1 and 2-2.

Table 2-1. A comparison of BN film thicknesses as determined by SE and HRTEM.

\begin{tabular}{|c|c|c|c|}
\hline Sethod & $\mathbf{1}$ & $\mathbf{2}$ & $\mathbf{3}$ \\
\hline SE & $15 \mathrm{~nm}$ & $8 \mathrm{~nm}$ & $18 \mathrm{~nm}$ \\
\hline HRTEM & $12 \mathrm{~nm}$ & $8 \mathrm{~nm}$ & $14 \mathrm{~nm}$ \\
\hline
\end{tabular}

Table 2-2. A comparison of BN film thicknesses as determined by SE and XRR.

\begin{tabular}{|c|c|c|c|c|c|}
\hline Sample & $\mathbf{1}$ & $\mathbf{2}$ & $\mathbf{3}$ & $\mathbf{4}$ & $\mathbf{5}$ \\
\hline SE & $30 \mathrm{~nm}$ & $15 \mathrm{~nm}$ & $13 \mathrm{~nm}$ & $15 \mathrm{~nm}$ & $13 \mathrm{~nm}$ \\
\hline XRR & $28 \mathrm{~nm}$ & $14 \mathrm{~nm}$ & $13 \mathrm{~nm}$ & $15 \mathrm{~nm}$ & $13 \mathrm{~nm}$ \\
\hline
\end{tabular}

The comparison indicates all the thicknesses to be in agreement. This verifies the applicability of the developed optical model and provides a solid platform for further characterization of the deposited thin films.

\subsubsection{Compositional analysis by SE}

The EMA model was originally developed to predict the effect of inclusions of a given material into another material by using the materials dielectric functions 1,2,24,25. The model can adequately describe optical functions of a layer consisting of two uniformly mixed components (similar to the roughness determination). In case of a two-phase material, the EMA gives the following complex dielectric function $\varepsilon_{E M A}$ of the composite ${ }^{1,15}$ : 


$$
\varepsilon_{E M A}=\frac{\varepsilon_{a} \varepsilon_{b}+\kappa \varepsilon_{E M A}\left(f_{a} \varepsilon_{a}+f_{b} \varepsilon_{b}\right)}{\kappa \varepsilon_{E M A}\left(f_{a} \varepsilon_{b}+f_{b} \varepsilon_{a}\right)}
$$

In this equation, $f_{a}$ and $f_{b}$ are the volume fractions of the " $\mathrm{a}$ " and " $\mathrm{b}$ " component, respectively, and $\varepsilon_{a}$ and $\varepsilon_{b}$ are their corresponding dielectric functions. Further, $\kappa$ is defined as $\kappa=(1-q) / q$ using the screening factor $q$ ranging between 0 and $1^{1,15}$. The screening factor is given by $q=1 / 3$ for the EMA model used in this work.

To use the EMA model, individual optical functions of the contributing " $a$ " and " $b$ " components have to be known. For that, we used the Sellmeier model optimized for stoichiometric BN since this material possesses transparency in the entire range of our ellipsometer. Further, we used a combination of Tauc-Lorentz and Lorentz (with a thickness dependent amplitude - see Chapter 3) oscillator models developed for pure-B. Substituting the optical functions of stoichiometric $\mathrm{BN}$ and pure-B into equation 2.8 revealed pure boron volume fractions in the $\mathrm{B} / \mathrm{BN}$ composites. This methodology showed good agreement with XPS measurements, as will be discussed in Chapter 3. The EMA model was employed to determine the composition of samples discussed in Chapter 4 as well.

\subsection{Adduct-assisted pathway}

It is well known that so-called Lewis-acids and Lewis-bases can react with each other, resulting in the formation of an adduct ${ }^{26}$. Examples of Lewis acids are group III metal-organic compounds (e.g., trimethylaluminum - TMA) and the corresponding halides (e.g., $\mathrm{AlCl}_{3}, \mathrm{BBr}_{3}{ }^{27,28}$ ), whereas group $\mathrm{V}$ hydrides (e.g., $\mathrm{NH}_{3}$ ) belong to Lewis bases. Reaction 2.1 gives an example of such adduct formation in gas phase from TMA and $\mathrm{NH}_{3} 29,30$ :

$$
\mathrm{Al}\left(\mathrm{CH}_{3}\right)_{3}+\mathrm{NH}_{3} \rightarrow \mathrm{H}_{3} \mathrm{~N}: \mathrm{Al}\left(\mathrm{CH}_{3}\right)_{3},
$$

(reaction 2.1)

where $\mathrm{H}_{3} \mathrm{~N}: \mathrm{Al}\left(\mathrm{CH}_{3}\right)_{3}$ is the adduct.

The adducts can decompose at certain temperatures and form gaseous compounds. Formation of a gas-phase $\mathrm{H}_{3} \mathrm{~N}: \mathrm{Al}\left(\mathrm{CH}_{3}\right)_{3}$ (also referred to as 
TMA: $\mathrm{NH}_{3}$ ) adduct was shown by Sauls et. al. ${ }^{29}$ and Interrante et. al. ${ }^{31}$. For AIN growth, occurrence of a surface adduct was confirmed in ref. ${ }^{30,32}$. A similar surface adduct was further hypothesized to play an important role in gallium nitride $(\mathrm{GaN})$ ALD at low temperatures 22,33-35.

For AlN ALD from TMA and $\mathrm{NH}_{3}$, a two-step process has been suggested 30. Namely, it includes (see Figure 2-2) (i) formation of the surface adduct by a reaction between the chemisorbed TMA and gas-phase- $\mathrm{NH}_{3}$, and (ii) subsequent reaction of the adduct- $\mathrm{NH}_{3}$ group with a neighboring $-\mathrm{CH}_{3}$ group of the chemisorbed TMA. This mechanism finally results in $-\mathrm{NH}_{2}-$ bridges between neighboring aluminum atoms, forming units of $\mathrm{AlN}$. After each $\mathrm{NH}_{3}$ exposure, the growth surface becomes $\mathrm{NH}_{2}$-terminated and thereby chemically activated for the subsequent TMA exposure. A schematic representation of the adduct pathway for AlN is given below.

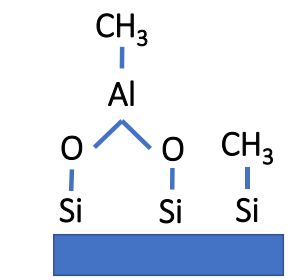

Phase I: TMA pulse and chemisorption

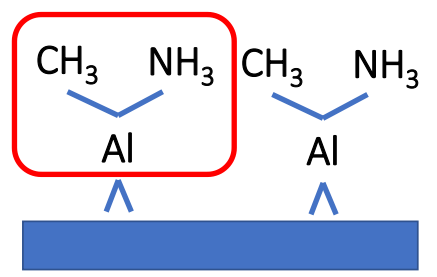

Phase II: Surface Adduct formation

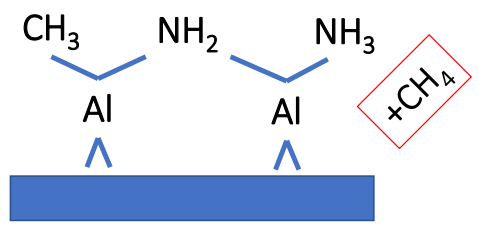

Phase III: Surface Amide formation

(the first $\mathrm{Al}-\mathrm{N}-\mathrm{Al}$ linkage)

Figure 2-2. Surface-adduct assisted formation of AlN ${ }^{30}$.

Hypothesizing the occurrence of a similar two-step mechanism for growing GaN from trimethylgallium (TMG) and ammonia, Banerjee et.al. successfully realized polycrystalline GaN films by purely thermal ALD at $400{ }^{\circ} \mathrm{C} 22,33,34$. Similarly to AlN, beyond a specific temperature, the TMG: $\mathrm{NH}_{3}$ surface adduct was assumed to convert into $\mathrm{Ga}-\mathrm{NH}_{2}-\mathrm{Ga}$ linkages with the elimination of methane (see Figure 2-3), forming a $\mathrm{NH}_{2}$-terminated $\mathrm{GaN}$ surface in a self-limiting fashion. The adduct-formation reaction will proceed until all available chemisorbed-TMG sites are occupied. It has been reported that the rate of occupation could be enhanced by increasing the partial pressure of $\mathrm{NH}_{3}\left(P_{\mathrm{NH} 3}\right)$. The $P_{\mathrm{NH} 3}$ either shifts the surface reactions towards the adduct formation (assuming the adduct formation to be a 
reversible reaction in equilibrium) or just provides more $\mathrm{NH}_{3}$ for occupying the available surface sites (regardless whether the reaction is reversible or not).

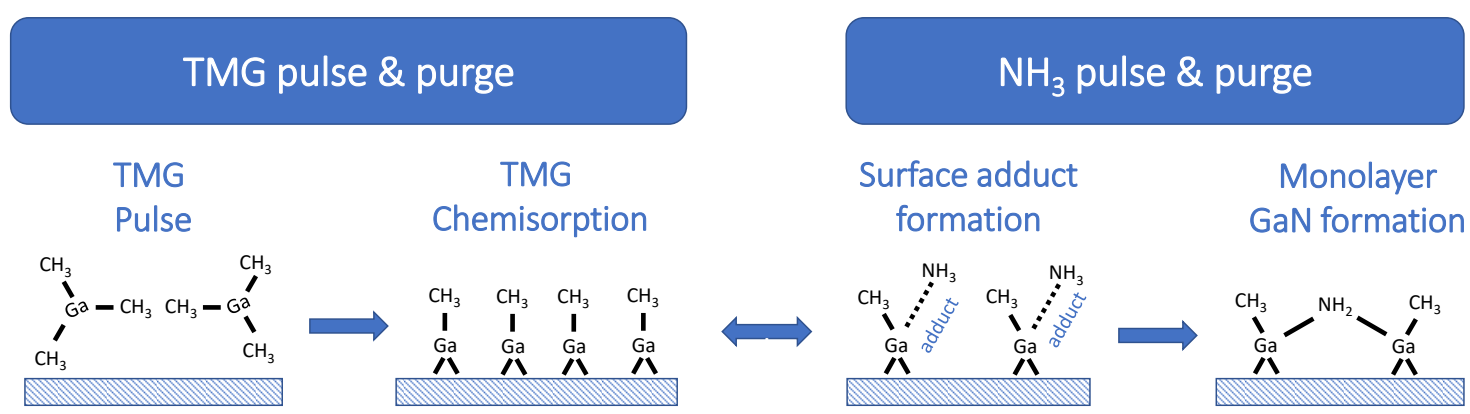

Figure 2-3. The proposed mechanism of thermal-GaN ALD ${ }^{34}$.

The described surface-adduct pathway may be applicable to other precursor systems as well. This thesis investigates the growth mechanism of BN films from diborane $\left(\mathrm{B}_{2} \mathrm{H}_{6}\right)$ and $\mathrm{NH}_{3}$, boron tribromide $\left(\mathrm{BBr}_{3}\right)$ and $\mathrm{NH}_{3}$, as well as triethylborane (TEB) and $\mathrm{NH}_{3}$ precursors. These precursor systems will be discussed one by one in Chapters from 4 to 7. A similar mechanism involving surface-adduct formation can be suggested to explain the experimental observations.

\subsection{Conclusions}

First part of this chapter shortly presented the approach used in this thesis to obtain the thicknesses, optical functions and composition of thin films by spectroscopic ellipsometry. The thicknesses from SE were in good agreement with those obtained by HRTEM and XRR. The SE analysis was further extended to estimating the factions of different phases present in the layers, i.e., enabling the analysis of composite materials. Altogether, this indicated the applicability of the SE approach chosen.

Second part of this chapter outlined the surface-adduct film-growth mechanism, earlier approved for AIN ALD and recently hypothesized for GaN ALD. The mechanism will be taken as a basis to explain the BN deposition results presented in Chapters 4-7 for various precursor systems and deposition methodologies. 


\section{References}

${ }^{1}$ H. Fujiwara, Spectroscopic Ellipsometry: Principles and Applications (John Wiley \& Sons, Ltd, Chichester, UK, 2007).

2 H.G. Tompkins and E.A. Irene, Handbook of Ellipsometry (William Andrew, Norwich, NY, 2005).

${ }^{3}$ E. Langereis, S.B.S. Heil, H.C.M. Knoops, W. Keuning, M.C.M. van de Sanden, and W.M.M. Kessels, J. Phys. D. Appl. Phys. 42, 073001 (2009).

4 P. Lautenschlager, M. Garriga, L. Vina, and M. Cardona, Phys. Rev. B 36, 4821 (1987).

5 C.M. Herzinger, B. Johs, W.A. McGahan, J.A. Woollam, and W. Paulson, J. Appl. Phys. 83, 3323 (1998).

${ }^{6}$ B. Johs and J.S. Hale, Phys. Status Solidi 205, 715 (2008).

7 J.A. Woollam Co, (2011).

8 J.A. Zapien, R.W. Collins, and R. Messier, Thin Solid Films 364, 16 (2000).

9 J.A. Zapien, R. Messier, and R.W. Collins, Diam. Relat. Mater. 10, 1304 (2001).

10 J.A. Zapien, R.W. Collins, and R. Messier, J. Vac. Sci. Technol. A Vacuum, Surfaces, Film. 20, 1395 (2002).

11 S. Lousinian, N. Kalfagiannis, and S. Logothetidis, Solid State Sci. 11, 1801 (2009).

12 S.L. Ren, A.M. Rao, P.C. Eklund, and G.L. Doll, Appl. Phys. Lett. 62, 1760 (1993).

13 J. Mistrik, S. Kasap, H.E. Ruda, C. Koughia, and J. Singh, in Springer Handb. Electron. Photonic Mater. (Springer International Publishing, Cham, 2017), pp. 1-1.

14 D.E. Aspnes, J.B. Theeten, and F. Hottier, Phys. Rev. B 20, 3292 (1979).

15 H. Fujiwara, J. Koh, P.I. Rovira, and R.W. Collins, Phys. Rev. B 61, 10832 (2000).

16 J.N. Hilfiker, N. Singh, T. Tiwald, D. Convey, S.M. Smith, J.H. Baker, and H.G. Tompkins, Thin Solid Films 516, 7979 (2008).

17 W.A. McGahan, B. Johs, and J.A. Woollam, Thin Solid Films 234, 443 (1993).

18 K. Järrendahl and H. Arwin, Thin Solid Films 313-314, 114 (1998).

${ }^{19}$ C.M. Herzinger, P.G. Snyder, F.G. Celii, Y. -C. Kao, D. Chow, B. Johs, and J.A. Woollam, J. Appl. Phys. 79, 2663 (1996).

${ }^{20}$ C.M. Herzinger, H. Yao, P.G. Snyder, F.G. Celii, Y. -C. Kao, B. Johs, and J.A. Woollam, J. Appl. Phys. 77, 4677 (1995).

21 H.G. Tompkins, T. Zhu, and E. Chen, J. Vac. Sci. Technol. A Vacuum, Surfaces, Film. 16, 1297 (1998). 
22 S. Banerjee, A.J. Onnink, S. Dutta, A.A.I. Aarnink, D.J. Gravesteijn, and A.Y. Kovalgin, J. Phys. Chem. C 122, 29567 (2018).

${ }^{23}$ D.-M. Rosu, E. Ortel, V.-D. Hodoroaba, R. Kraehnert, and A. Hertwig, Appl. Surf. Sci. 421, 487 (2017).

24 G. Bruno, E. Irene, K. Hingerl, J. Humlicek, M. Losurdo, D.E. Aspnes, P. Zeppenfeld, H. Wormeester, C. Cobet, E. Speiser, F. Bechstedt, C. Rockstuhl, F.L. Christoph Menzel, T. Novikova, A. De Martino, S.A. Little, R.W. Collins, S. Marsillac, M. Cardona, and M.L. Sadowski, Defining and Analysing the Optical Properties of Materials at the Nanoscale: A Collection of Thoughts, Opinions, Ideas and Data That Have Matured over Years on Exploiting Ellipsometry for a Range of Characteristic Needs, NanoCharM, (2010).

25 D.A.G. Bruggeman, Ann. Phys. 416, 636 (1935).

26 K. Seshan, Handbook of Thin-Film Deposition Processes and Techniques, 2nd ed. (Noyes Publications, Norwich, NY, 2002).

27 C.D. Hunt, in Chem. Elem. (Elsevier, 1997), pp. 139-215.

28 K. Possemiers, P. Van Der Voort, and E.F. Vansant, J. Chem. Soc. Faraday Trans. 92, 679 (1996).

${ }^{29}$ F.C. Sauls, L. V. Interrante, and Z. Jiang, Inorg. Chem. 29, 2989 (1990).

30 M.E. Bartram, T.A. Michalske, J.W. Rogers, and R.T. Paine, Chem. Mater. 5, 1424 (1993).

${ }^{31}$ L. V. Interrante, L.E. Carpenter, C. Whitmarsh, W. Lee, M. Garbauskas, and G.A. Slack, MRS Proc. 73, 359 (1986).

32 T.M. Mayer, J.W. Rogers, and T.A. Michalske, Chem. Mater. 3, 641 (1991).

33 S. Banerjee and A.Y. Kovalgin, ECS Trans. 86, 21 (2018).

34 S. Banerjee, From Radical-Enhanced to Pure Thermal ALD of Aluminium and Gallium Nitrides, University of Twente, 2019.

${ }^{35}$ D. Sengupta, S. Mazumder, W. Kuykendall, and S.A. Lowry, J. Cryst. Growth 279, 369 (2005). 


\title{
3 Studying B/BN composite material by XPS and SE
}

\begin{abstract}
This work investigates boron-rich boron nitride (BN) thin films deposited using sequential pulses of diborane $\left(\mathrm{B}_{2} \mathrm{H}_{6}\right)$ and ammonia $\left(\mathrm{NH}_{3}\right)$ with argon $(\mathrm{Ar})$ purge in between, in the substrate temperature range of $275-375^{\circ} \mathrm{C}$. We observe two different phases in these films, namely pure boron (pure-B) and boron nitride (BN). Refractive indices ( $n$ ) of the $B / B N$ composites are found to be consistently higher than $n$ of stoichiometric $B N$, and lower than $n$ of a pure-B reference. Namely, $n$ obtained at $632 \mathrm{~nm}$ gradually increases from 1.7 to 2.9 by tuning the composition from stoichiometric BN to pure-B. Further, the boron rich samples reveal an absorption behavior between 1 and $5 \mathrm{eV}$, which is assigned to the pure-B phase. The developed SE optical model adequately estimates the relative amounts of pure- $B$ and $B N$ phases as well as reveals the optical functions of pure- $B$, stoichiometric $B N$, and the $B / B N$ composites. The relative amounts of the phases are in agreement with X-ray photoelectron spectroscopy (XPS) measurements, thereby verifying the SE model for determining composition of the B/BN composite films. As compared to a sharp $B$ 1s peak of pure- $B$, the XPS analysis shows broadening of the $B$ 1s peak towards higher binding energies (i.e., towards those of $B N$ ) for $B / B N$, resulting in a clear asymmetry due to the appearance of two separate peaks. It is shown that single-peak fitting of XPS data fails to represent the experimentally obtained data. On the other hand, the $N$ 1s peak allows good fitting with one stoichiometric-BN peak only, indicating a well-defined BN phase. Spatial distribution of the phases is investigated by planar view energy filtered transmission electron microscopy (EFTEM). The corresponding cross-correlation maps of elemental B and N show laterally homogeneous distribution of the elements within the measurement error.
\end{abstract}




\subsection{Introduction}

The possibility of including other elements (e.g., carbon) into boron nitride $(\mathrm{BN})$, to tailor its properties, motivates further exploration of boron nitride containing films. For example, low-amount additives of phosphorus can improve the catalytic properties of $\mathrm{BN}^{1}$ while beryllium (Be), magnesium (Mg) or zinc ( $\left.\mathrm{Zn}\right)$ doping leads to p-type conductivity ${ }^{2-4}$. Moreover, making BCN by adding carbon (C) to BN noticeably influences the mechanical, electronic and optical properties ${ }^{5-}$ 11.

Further, boron (B) incorporation into boron nitride was investigated by several groups. Theoretical work ${ }^{12}$ conducted to explore the local structure (shortor long-range order), electronic structure and mechanical properties, predicted a phase segregation in amorphous $\mathrm{B} / \mathrm{BN}$ material with boron fractions higher than $\mathrm{BN}$. The same work proposed interesting applications of $\mathrm{B} / \mathrm{BN}$ in the field of nanoglass ceramics. Experimental works ${ }^{13-16}$ reported (i) tunable optical and altered electronic properties and (ii) the presence of both B-B and B-N bonding environments. These works however did not explicitly identify the material as phase-segregated (i.e., a composite).

This chapter investigates whether a composite nature of $\mathrm{B} / \mathrm{BN}$ can be experimentally confirmed and quantitatively addressed by modeling. We confirm the multi-phase nature of the B/BN films by spectroscopic ellipsometry (SE) and x-ray photoelectron spectroscopy (XPS). We further investigate the distribution of phases using energy filtered transmission electron microscopy (EFTEM) analysis. The optical SE model developed in this chapter for B/BN composites will further be applied in Chapter 4 to clarify composition of the films deposited from $\mathrm{B}_{2} \mathrm{H}_{6}$ and $\mathrm{NH}_{3}$ precursors.

\subsection{Experimental details}

The B/BN films were deposited in Reactor-3 of the home-built ALD/CVD cluster system from sequentially introduced diborane $\left(\mathrm{B}_{2} \mathrm{H}_{6}, 5 \%\right.$ in $\left.\mathrm{Ar}\right)$ and 
ammonia $\left(\mathrm{NH}_{3}\right)$ pulses. A detailed description of the reactor can be found in Chapter 1 and ref. 17,18. The variously-composed films were obtained either in purely thermal deposition mode or by assistance with a hot-wire (HW).

A stoichiometric-BN reference sample was deposited on silicon dioxide $\left(\mathrm{SiO}_{2}\right)$ in a Picosun R-200 ALD reactor (see Chapter 1 ) from the same precursors and in the same manner, but by adding a plasma assistance. The reference layers of pure-B were deposited on silicon (Si) by chemical vapor deposition (CVD) from $\mathrm{B}_{2} \mathrm{H}_{6}(5 \%$ in $\mathrm{Ar})$ at $220-300{ }^{\circ} \mathrm{C}$.

Prior to deposition, Si (100) wafers underwent a three-step wafer cleaning procedure. This included (i) removal of native oxide by a 1-min dip into $1 \% \mathrm{HF}$, (ii) rinsing in deionized (DI) water, and (iii) ozone-steam cleaning followed by another HF dip and rinsing. Further, a $100 \mathrm{~nm}$ thick silicon dioxide $\left(\mathrm{SiO}_{2}\right)$ layer was grown by thermal oxidation at $1050{ }^{\circ} \mathrm{C}$ in dry oxygen.

The $\mathrm{B} / \mathrm{BN}$ films were obtained in the pressure range of $10^{-3}-5 \times 10^{-2} \mathrm{mbar}$, at substrate temperatures between 270 and $360{ }^{\circ} \mathrm{C}$. The precursors were introduced via alternating pulses with Ar-purge in between, to avoid gas phase reactions. The typical pulse- and purge-durations were: $0.5-2.5 \mathrm{~s}$ of $\mathrm{B}_{2} \mathrm{H}_{6}, 4-6 \mathrm{~s}$ of post- $\mathrm{B}_{2} \mathrm{H}_{6}$ purge, 2.5-3 s of $\mathrm{NH}_{3}$ and 4-6 s of post- $\mathrm{NH}_{3}$ purge.

The SE measurements were carried out using a Woollam M2000UI spectroscopic ellipsometer, operating in the wavelength range of 246-1689 $\mathrm{nm}$ (0.72-5.05 eV), in combination with CompleteEASE 5.19 modeling software. The XPS spectra were acquired with a Quantera SCM (scanning XPS microprobe from Physical Electronics) instrument using monochromatic Al Ka radiation at 1486.6 $\mathrm{eV}$. The $\mathrm{C}$ 1s peak due to ambient hydrocarbon contamination was calibrated at $284.8 \mathrm{eV}^{19}$. Binding energies of the photoelectron lines of the samples were chargereferenced to this $\mathrm{C}$ 1s line. For compositional analysis, XPS sputter depth profiling was performed using Ar ions. A Philips CM300ST-FEG transmission electron microscope (TEM) was used to perform the EFTEM measurements. 


\subsection{Results and discussion}

\subsubsection{Spectroscopic ellipsometry analysis}

\subsubsection{Tunable refractive index ( $n$ ) of $\mathrm{B} / \mathrm{BN}$ composites}

The refractive indices of the B/BN samples with various amounts of pure$\mathrm{B}$ (in the range of 30-65 vol.\%, as determined by XPS) were found to be consistently higher compared to the stoichiometric $\mathrm{BN}$ and lower compared to the pure- $\mathrm{B}$ references. The stoichiometric $\mathrm{BN}$ exhibited $n=1.7$ at $632 \mathrm{~nm}$ and $n=1.68$ at 1500 $\mathrm{nm}$, which reasonably agreed with the reported values ${ }^{20-22}$. To account for the effect of pure-B incorporation in the presumably composite material, the $n$ was modelled by including EMA in the SE model (see Figure 3-1.a). This implied that the samples were considered to be composed of uniformly mixed pure-B and stoichiometric-BN phases with a certain fraction $\left(f_{B}\right)$ of the pure-B phase $\left(0 \leq f_{B} \leq\right.$ $1)$.

Performing KK-consistent B-spline parameterization reveals $n$, whereas the pure-B fraction can be calculated from XPS:

$$
f_{B}=N_{B}-N_{N}
$$

In this equation, $N_{B}$ is the fraction of $\mathrm{B}$ atoms (atomic percentage of $\mathrm{B}$ divided by $100 \%$ ) and $N_{N}$ is the share of $\mathrm{N}$ atoms. To note, this equation only holds for $N_{B}>N_{N}$. Assuming that all $\mathrm{N}$ atoms to bond with $\mathrm{B}$ atoms to form a stoichiometric-BN phase with a B:N ratio of 1:1, equation 3.1 can be re-written for a mixture of $\mathrm{B}$ and $\mathrm{BN}$ and the atomic fraction can be converted into pure-B volume fraction $f_{\mathrm{V}, \mathrm{B}}$ :

$$
f_{V, B}=\frac{\left(N_{B}-N_{N}\right) \frac{a_{B}}{\rho_{B}}}{\left(N_{B}-N_{N}\right) \frac{a_{B}}{\rho_{B}}+N_{N} \frac{a_{B}+a_{N}}{\rho_{B N}}}
$$

In this equation, $\rho_{B}$ and $\rho_{B N}$ are the mass densities of the boron and boron nitride phases, respectively, and $a_{B}$ and $a_{N}$ are the atomic masses of B and N. Since $\rho_{B}$ and $\rho_{B N}$ have very similar values $\left(\rho_{B}=2.35 \mathrm{~g} / \mathrm{cm}^{3}{ }^{23}\right.$ and $\left.\rho_{B N}=2.28 \mathrm{~g} / \mathrm{cm}^{324}\right)$, it follows that: 


$$
f_{V, B}=\frac{\left(N_{B}-N_{N}\right) a_{B}}{\left(N_{B}-N_{N}\right) a_{B}+N_{N}\left(a_{B}+a_{N}\right)}=\frac{N_{B}-N_{N}}{N_{B}+N_{N} \frac{a_{N}}{a_{B}}} .
$$

With $a_{N} / a_{B} \approx 1.3$, within the error margin the fractions $f_{B}$ and $f_{\mathrm{V}, \mathrm{B}}$ can be assumed to be equal:

$$
\frac{N_{B}-N_{N}}{N_{B}+N_{N} \frac{a_{N}}{a_{B}}} \approx \frac{N_{B}-N_{N}}{N_{B}+N_{N}}=N_{B}-N_{N}
$$

Therefore, $f_{B}$ is further mentioned without specifically attributing it to either atomic or volume fraction.

On one hand, fractions $f_{B}$ can be practically calculated from the XPS results by equation 3.4 and then used as input data to the EMA model; the latter reveals $n$. On the other hand, $n$ can be directly calculated from B-spline fitting without assuming any particular spectral shape of $n(\lambda)$. A comparison of the as-calculated $n$-values is given below. Figure 3-1.a shows the EMA predicted refractive index assuming certain $f_{B}$, as simulated by SE. In Figure 3-1.b, the n-values obtained directly from B-spline fitting are compared with the EMA prediction; a good agreement within $\sim 10 \%$ can be seen.
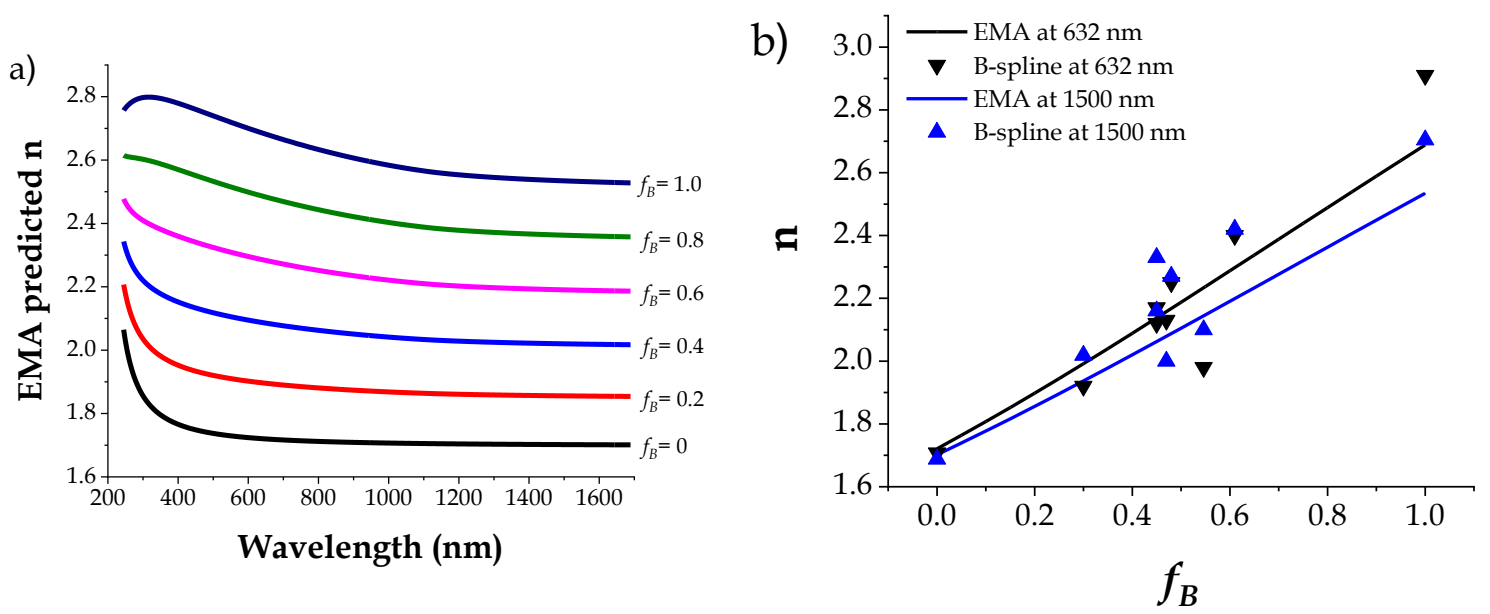

Figure 3-1. (a) The evolution of the refractive index $n(\lambda)$ with $f_{B}$, as calculated by the EMA for a composite of pure-B and stoichiometric-BN (b) Comparison of experimental (symbols; the corresponding $f_{B}$-values are calculated from XPS) and calculated (lines; the corresponding $f_{B}$-values are taken from (a)) refractive indices.

Clearly, changing the $f_{B}$ significantly affects the refractive index. The layers with no pure-B $\left(f_{B}=0\right)$ exhibit a value of $n$ that agrees with literature for $\mathrm{BN} 20,21$. 
Similar observations have been reported by other research groups for boron-rich boron nitride, as well as for carbon containing boron nitride and gallium nitride ${ }^{25-}$ ${ }^{29}$. Varying pure-B share enables tuning the refractive index between 1.7-2.9 at 632 $\mathrm{nm}$ and 1.7-2.7 at $1500 \mathrm{~nm}$. The experimentally obtained B-spline n-values are fairly consistent (within $~ 10 \%$ ) with the $n$ calculated by EMA. This may be a first indication of the co-existence of uniformly mixed pure-B and stoichiometric-BN phases, i.e., the formation of a composite. To further verify this hypothesis, the SE model was further developed in detail.

\subsubsection{Development of SE model for a $\mathrm{B} / \mathrm{BN}$ composite}

Accurate SE modelling requires knowing optical functions of pure-B and stoichiometric-BN components of the composite. The parameterization used for fine-tuning the optical functions is described below.

\subsection{Parameterization approaches}

The KK-consistent B-spline functions fitted to the spectra of the films revealed an absorption behavior that did not match with any electronic transitions of boron nitride in the theoretical and experimental works that have been surveyed 30-33. A further comparison with the SE data of the pure-B films revealed the similar absorption behavior, suggesting the formation of a pure-B phase and thus a $\mathrm{B} / \mathrm{BN}$ mixture. A comparison of the optical functions is given in Figure 3-2. One should keep in mind that a pure-B film exhibits thickness dependent optical functions; this will be discussed below.

The determination of the thickness dependent optical functions of pure-B was thus a first step. The Tauc-Lorentz oscillator model was employed to represent the optical functions. For layers thinner than $5 \mathrm{~nm}$, the $\sim 3.3 \mathrm{eV}$ absorption peak (see Figure 3-4) was described by a Lorentz oscillator. Next, the Sellmeier model was employed to describe $n$ of stoichiometric $\mathrm{BN}$, for which $k=0$ in the measurement range of 245 - 1689 nm. Finally, the EMA was applied to adequately describe optical functions of a layer consisting of the two uniformly mixed components. Details of all models have been given in Chapter 2. 


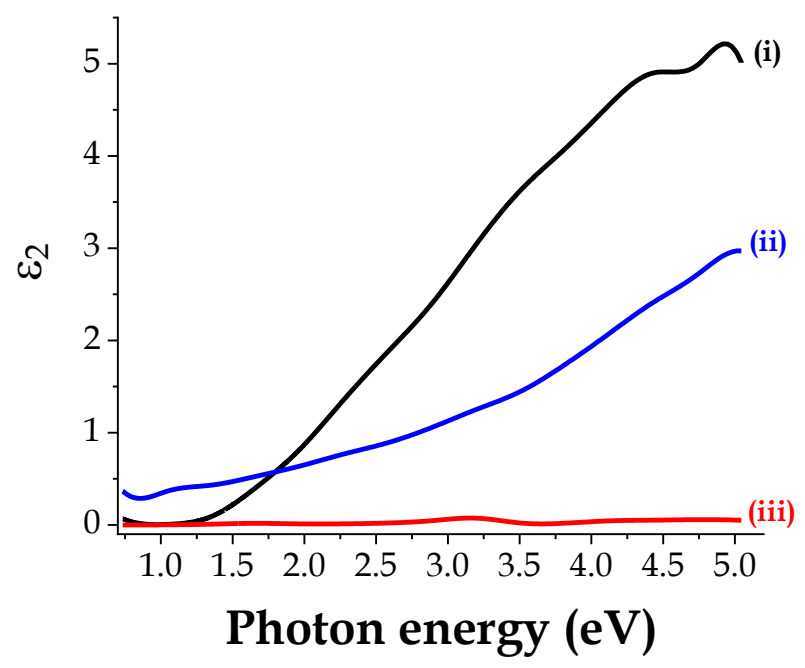

Figure 3-2. Imaginary part ( $\left.\varepsilon_{2}\right)$ of the complex dielectric function ( $(\varepsilon)$ of (i) CVD-grown boron reference (thickness 6-113 nm), (ii) 50 vol.\% of pure-B into B/BN composite (thickness 12-43 $\mathrm{nm}$ ), and (iii) plasma-grown (see the experimental) stoichiometric-BN reference (thickness 10-27 nm). The indicated pure-B share is determined from XPS.

\subsection{Optical function determination*}

For stoichiometric BN, a B-spline fit (MSA) to a combined dataset of in-situ (25 frames) and ex-situ (25 points) SE measurements found an absorption coefficient less than $7000 \mathrm{~cm}^{-1}(k<0.025)$ over the entire $\lambda$ range $(246<\lambda<1689$ $\mathrm{nm}$ ). Since the sensitivity limit of SE to $k$ is in this order of magnitude ${ }^{34}$, the layer was approximated as transparent. This allowed to model $n(\lambda)$ with the Sellmeier equation, $n^{2}(\lambda)=A+B \lambda^{2} /\left(\lambda^{2}-C\right)$. A fit on the dataset described above yields values 2.17, 0.72 and $0.04 \mu^{2}$ for A, B and C, respectively, for the peak centered at $199 \mathrm{~nm}$, i.e., at $6.24 \mathrm{eV}$. Figure 3-3 shows the as-obtained dielectric function of BN $\left(\varepsilon_{\mathrm{BN}}\right)$.

For pure-B, a B-spline fit to a combined dataset of in-situ (18 frames) and ex-situ (18 points) SE from 8 depositions of pure-B (see Section 3.2 for experimental conditions) revealed an absorption spectrum comparable to the literature ${ }^{35-43}$, that could be modeled by a Tauc-Lorentz (TL) oscillator. Including a Lorentz (L) oscillator with a thickness-dependent amplitude significantly improved the fits

\footnotetext{
* Contributed by A.J. Onnink, University of Twente. This section concerns a joint publication of R.O. Apaydin and A.J. Onnink, see the list of publications at the end of this thesis.
} 
due to a better description of the feature near the band edge. The feature is only significant in ultrathin $(<5 \mathrm{~nm})$ layers. Namely, the $\mathrm{r} \chi^{2}$ (reduced chi square) decreased from 78.8 to 9.6. (To bear in mind, $\mathrm{r} \chi^{2}$ represents the agreement between the measured data and the data simulated by the optical model.) Figure 3-4 shows the resulting $\varepsilon(\lambda)$ for pure-B. The Lorentzian feature at $3.3 \mathrm{eV}$ may correspond to the effective optical response of B nano-islands ${ }^{44}$.

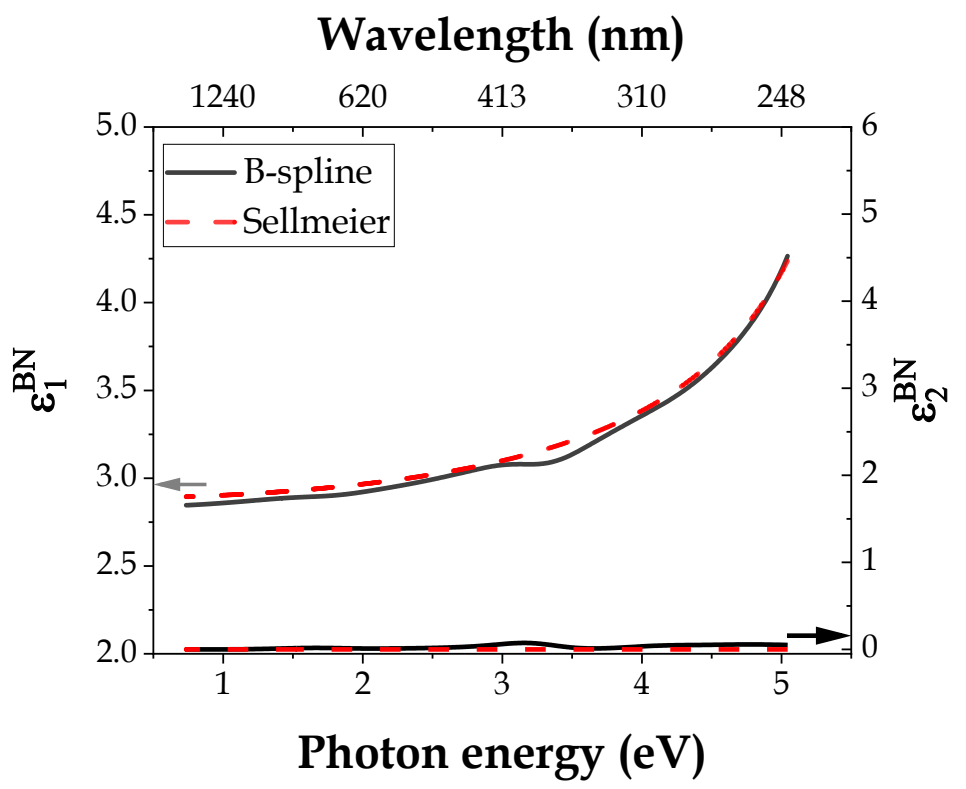

Figure 3-3. Real $\left(\varepsilon_{1}^{B N}\right)$ and imaginary $\left(\varepsilon_{2}{ }^{B N}\right)$ part of the dielectric function of a layer (10 to $27 \mathrm{~nm}$ thick) of stoichiometric BN deposited on $100 \mathrm{~nm} \mathrm{SiO}$ by plasma-assistance. A single dielectric function could describe this range of thicknesses, indicating that the thickness dependence of $\varepsilon^{B N}$ could be neglected above $10 \mathrm{~nm}$.

\footnotetext{
$\dagger$ This graph is contributed by A.J. Onnink (University of Twente) and included into the joint publication of R.O. Apaydin and A.J. Onnink, see the list of publications at the end of this thesis.
} 


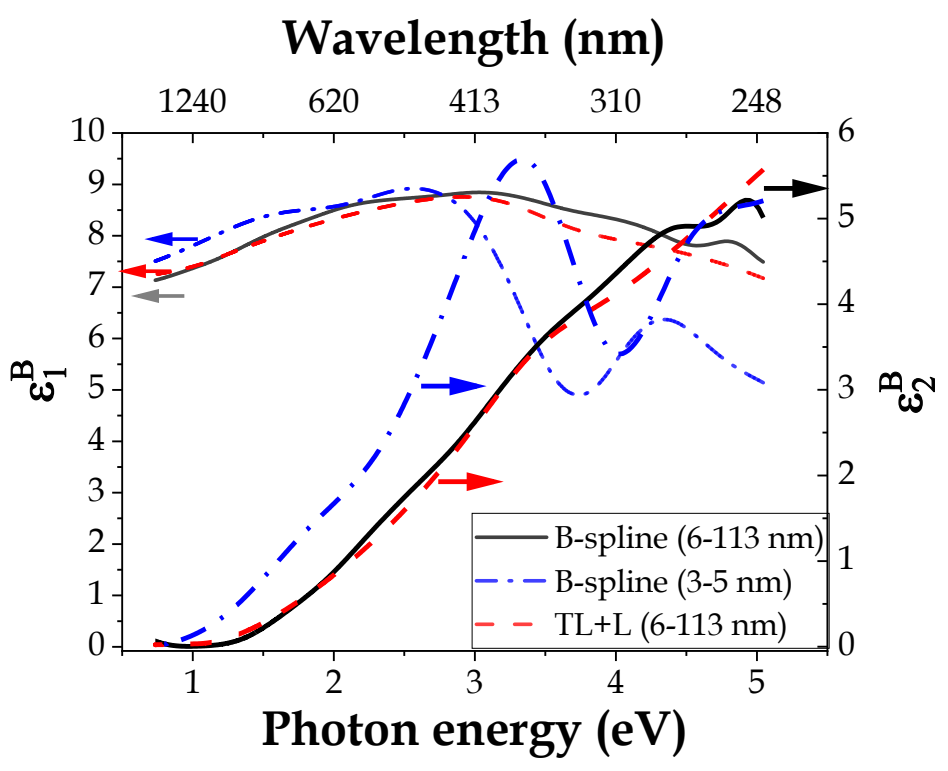

Figure 3-4. Real $\left(\varepsilon_{1} B\right)$ and imaginary $\left(\varepsilon_{2}{ }^{B}\right)$ part of the dielectric function of pure- $B$ deposited on Si by CVD. For the 6-113 $\mathrm{nm}$ dataset, the fitted Lorentz amplitude is zero within the error margin. The TL-parameters are: $A m p=100, B r=11.646 \mathrm{eV}, E_{0}=8.282$ $\mathrm{eV}$, and $E_{g}=1.086 \mathrm{eV} \ddagger$

Figure 3-5 illustrates that the $\varepsilon_{2}(\lambda)$-shape from B-spline fits resembles that of $\varepsilon_{2}(\lambda)$ for pure- $B$, suggesting that the EMA may apply. To test, $f_{B}$ was determined by SE for 23 samples and compared to that determined by XPS under the assumption of having stoichiometric BN phases. Figure 3-6 shows the results for one wafer (5 points of comparison). The values of $f_{\mathrm{B}}$ from SE agree with $f_{\mathrm{B}}$ from XPS within the error margin $(<10 \%)$; the latter is determined from the SE parameter sensitivity analysis. Thus, SE allows quantitative estimation of $f_{B}$ in these $B / B N$ films, although less precisely than XPS. The agreement with XPS verifies the validity of the developed SE model in this particular case, and suggests a composite material which contains a mixture of pure-B and stoichiometric-BN phases. The SE model is particularly sensitive to $f_{\mathrm{B}}$ because of the prominent increase in the film's absorption coefficient, between 1 and $5 \mathrm{eV}$, attributed to the $\mathrm{B}$ enrichment.

\footnotetext{
$\$$ This graph is contributed by A.J. Onnink (University of Twente) and included into the joint publication of R.O. Apaydin and A.J. Onnink, see the list of publications at the end of this thesis.
} 


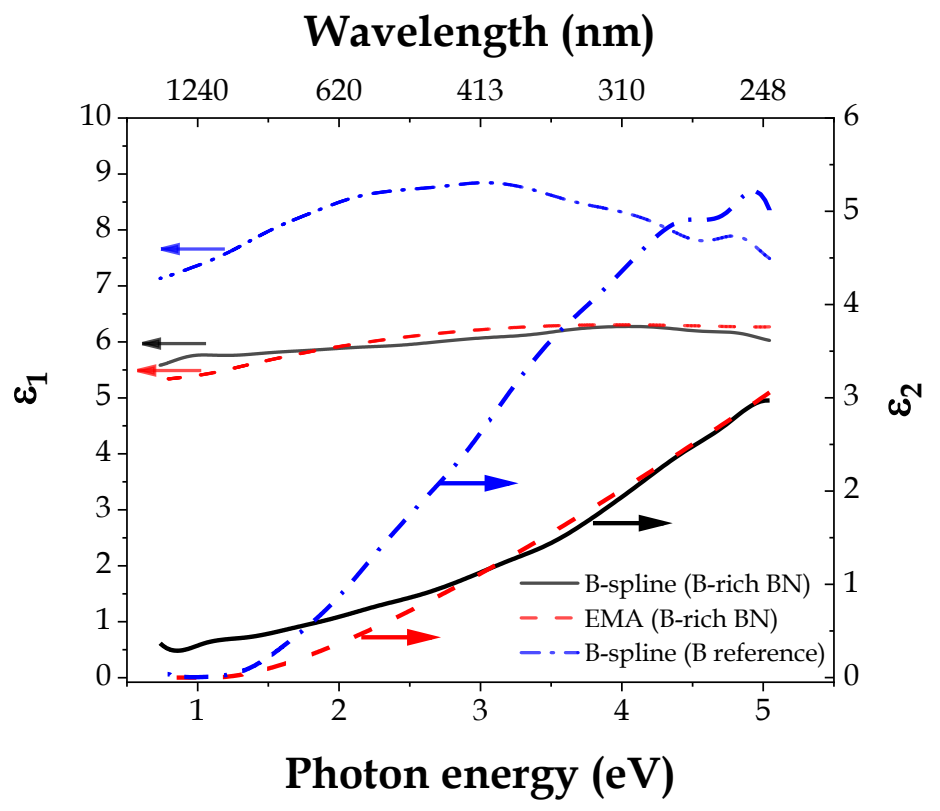

Figure 3-5. Real $\left(\varepsilon_{1}\right)$ and imaginary $\left(\varepsilon_{2}\right)$ parts of the dielectric function of a $B / B N$ film on $S i$, compared to $\varepsilon_{1}{ }^{B}$ and $\varepsilon_{2}{ }^{B}$ of the pure-B reference shown in Figure 3-4. The B/BN data were obtained by MSA of a sample with thickness of 12-46 nm and $f_{B}=0.50$ as determined by XPS §.

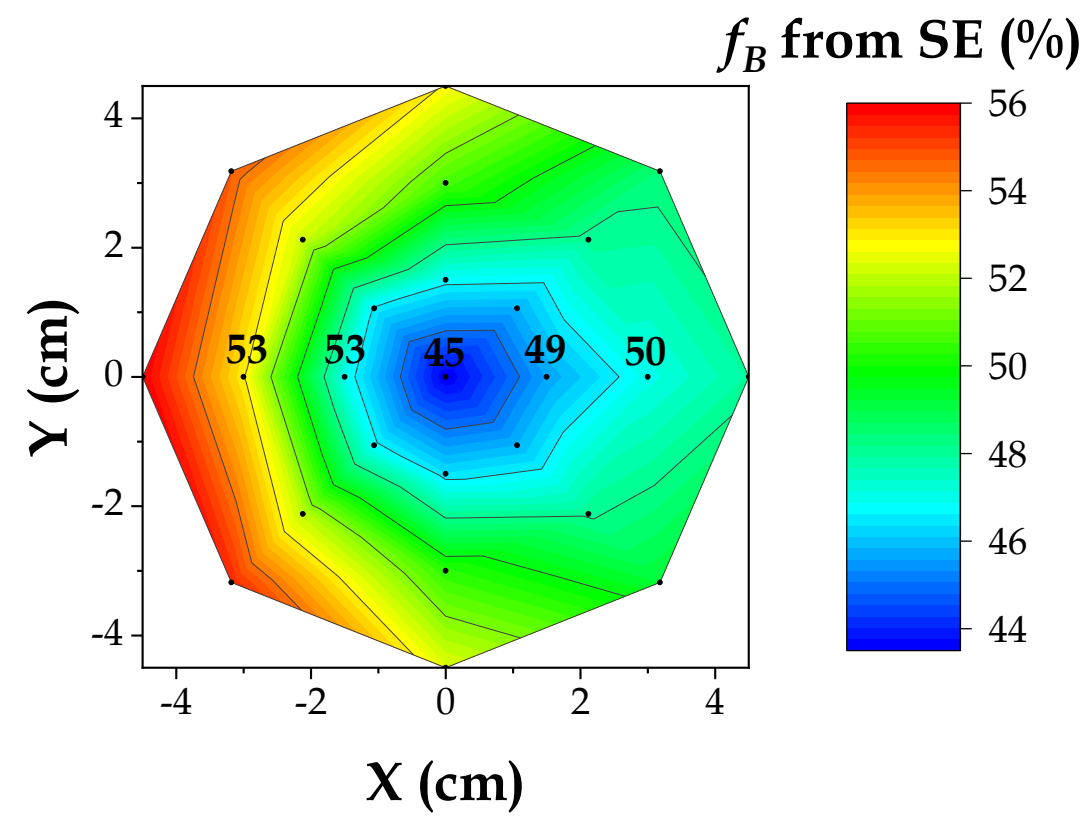

Figure 3-6. Wafer mapping of the SE-determined pure-B share (given by the colors, in vol.\%) in a B/BN composite. The bold numbers on the map correspond to the B-shares from XPS.

\footnotetext{
$\S$ This graph is contributed by A.J. Onnink (University of Twente) and included into the joint publication of R.O. Apaydin and A.J. Onnink, see the list of publications at the end of this thesis.
} 


\subsubsection{Confirmation of the composite nature by XPS}

The overall film composition can be estimated from the total area of elemental XPS peaks (B 1s and N 1s). Peak fitting of the B 1s region may further allow a categorization of the population of B atoms by chemical environment. This can aid in distinguishing 2-phase amorphous B/BN composite films in which the chemical environment of B atoms is widely distributed. Section 3.3.2.1 below discusses the peak fitting results of $\mathrm{B} / \mathrm{BN}$ films, clearly indicating 2 bonding environments of B atoms.

\subsubsection{XPS data of $\mathrm{B} / \mathrm{BN}$ films}

The composition was deduced from B 1s and N 1s spectra acquired during sputter-depth profiling. It was observed that the B 1s spectra broadened towards higher binding energies, compared to the pure-B reference, causing asymmetry (Figure 3-7.a). However, the $\mathrm{N}$ 1s spectra match quite well with that of the stoichiometric BN reference (Figure 3-7.b), showing no broadening.
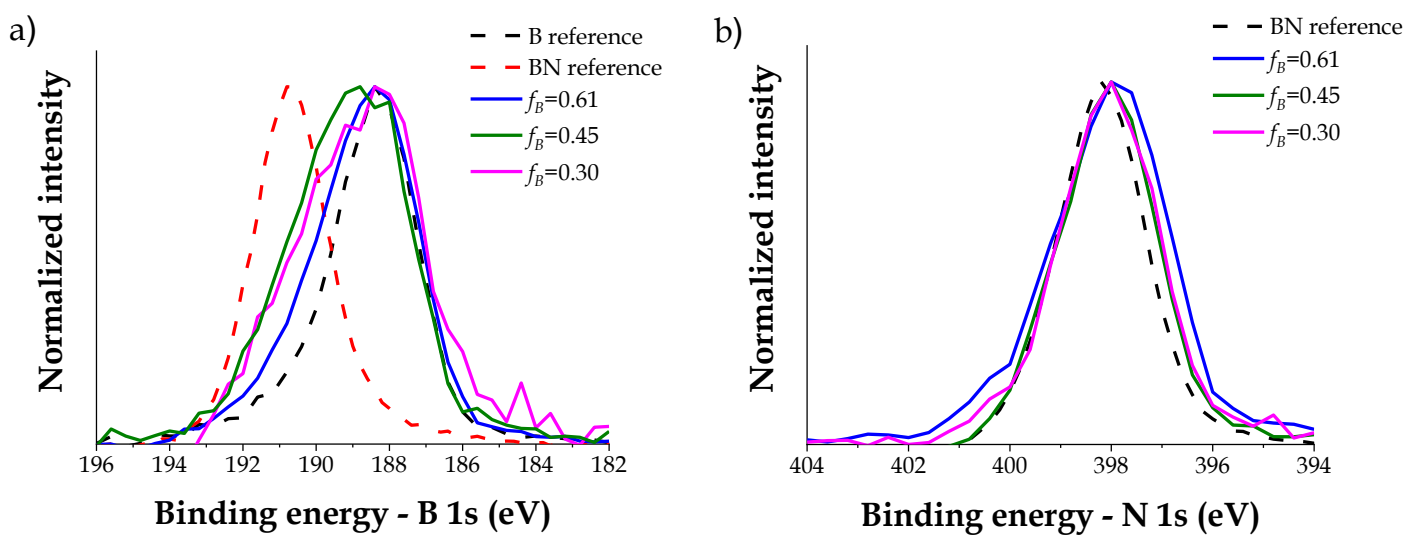

Figure 3-7. Comparison of (a) B 1s and (b) N 1s spectra of samples containing different fractions of pure- $B$, as indicated in the figure legend. To be noted: the shown samples contain less than 4 at. \% of oxygen in the bulk, therefore, possible contribution of oxygen to the broadening can be excluded. The indicated $f_{B}$ values are determined from XPS.

On the one hand, the lack of broadening of the $\mathrm{N}$ 1s spectra of the $\mathrm{B} / \mathrm{BN}$ samples as well as the similar-to-BN FWHM indicate a well-defined BN phase. On the other hand, the observed asymmetry in the B 1s spectra may point to the 
existence of two B 1s peaks, namely of pure-B and of stoichiometric BN. Confirming this would support the co-existence of the two phases.

The B 1s spectra were further investigated by deconvolution of the experimental peak using a double-peak model (Figure 3-8). All spectra were fitted by Gaussian peaks after subtracting an iteratively determined Shirley background 45. We neglected the Lorentzian lifetime broadening of the B $1 \mathrm{~s}(71 \mathrm{meV})$ and $\mathrm{N}$ 1s peaks $(130 \mathrm{meV}){ }^{46}$. The fitting analysis was performed by setting the B 1s peak positions at $188.4 \mathrm{eV}$ (pure-B component) and $190.6 \mathrm{eV}$ (BN component), as determined from the reference samples and the literature $6,24,47,48$. The shot noise in the spectrum was calculated as the square root of the background counts and included into the error bars ${ }^{49}$. Single-peak fitting was additionally performed for a comparison.

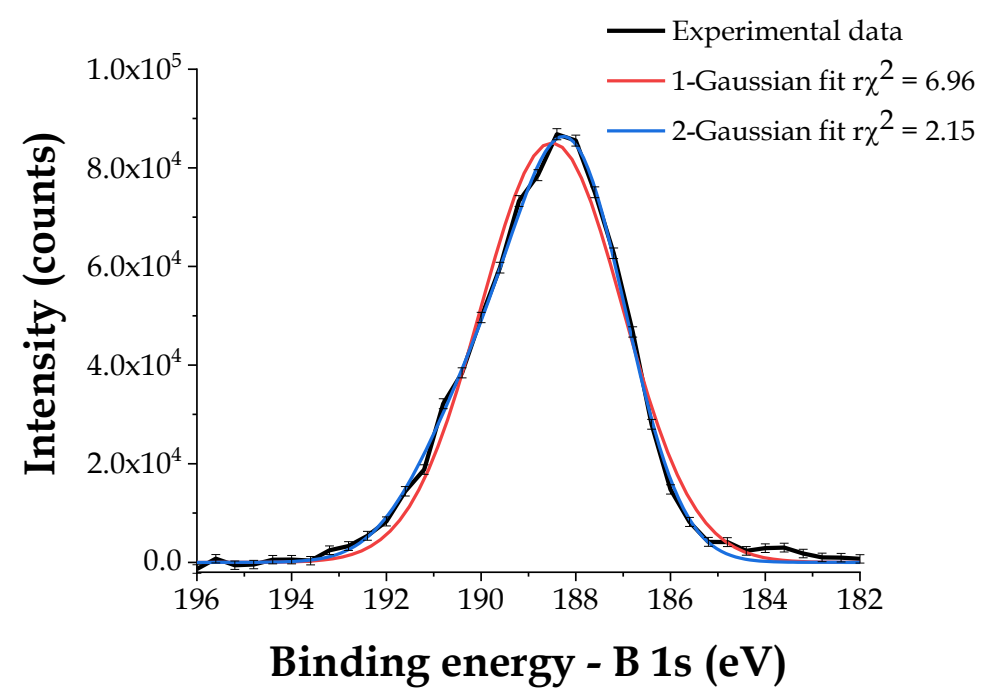

Figure 3-8. Deconvolution of the B 1s XPS peak by single-peak (1-Gaussian) and doublepeak (2-Gaussian) fitting, after subtracting of a Shirley background. From XPS, the sample contains $\sim 55$ vol. $\%$ of pure-B.

From Figure 3-8, it is evident that the 1-Gaussian fitting fails to describe the experimental B 1s data, giving more than 3 times higher $r \chi^{2}$ compared to that of the 2-Gaussian fitting. In addition, for the single-peak fitting, the fitted and experimental peak maxima do not match. This confirms that at least 2 components are required to adequately describe the experimental B 1s spectra, confirming once again a composite nature of the films. 


\subsubsection{EFTEM analysis}

Planar-view EFTEM measurements (see Figure 3-9) were performed on a representative $\mathrm{B} / \mathrm{BN}$ sample with $f_{B}=0.5$ (from $\mathrm{SE}$ ). To obtain the elemental maps of $\mathrm{B}$ and $\mathrm{N}$, the area of interest was limited to a certain range of pixels (marked by red rectangles in the figure) in order to exclude the contribution of perforation in the TEM grid used. After calculating the pixel sizes, intensities of the pixels corresponding to B were plotted versus $\mathrm{N}$-pixel intensities in a cross correlation graph (Figures 3-9.c and 3-9.d).

It can be seen that both $\mathrm{B}$ and $\mathrm{N}$ are homogeneously distributed within the measurement error. One cannot observe any lateral clustering of pure-B and BN phases. Although both XPS and SE clearly indicate about 50 vol.\% of pure-B, EFTEM does not reveal any lateral inhomogeneity. This conclusion is rather expected from the methodology used for growing the films. To bear in mind, the films were obtained from sequential pulses of $\mathrm{B}_{2} \mathrm{H}_{6}$ and $\mathrm{NH}_{3}$, with Ar-purges in between. Such a process would naturally lead to a vertical inhomogeneity of the elemental distribution rather than a lateral inhomogeneity, due to incomplete nitridation of a the pure- $\mathrm{B}$ phase formed by $\mathrm{B}_{2} \mathrm{H}_{6}$ pulses during corresponding $\mathrm{NH}_{3}$ pulses. 
a)
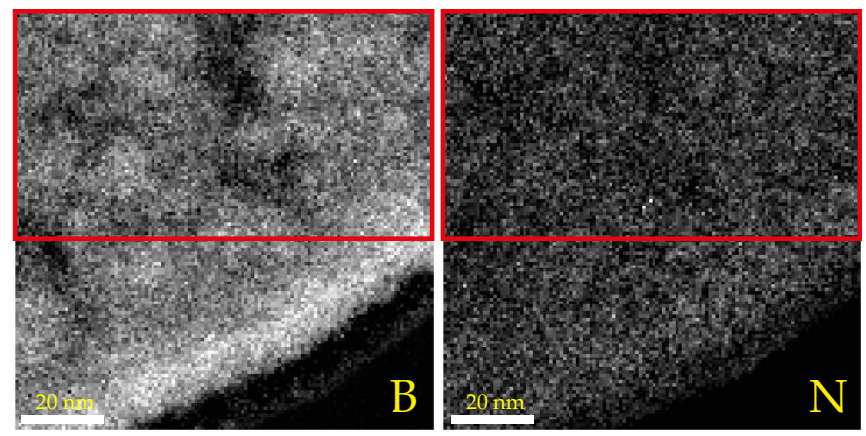

b)
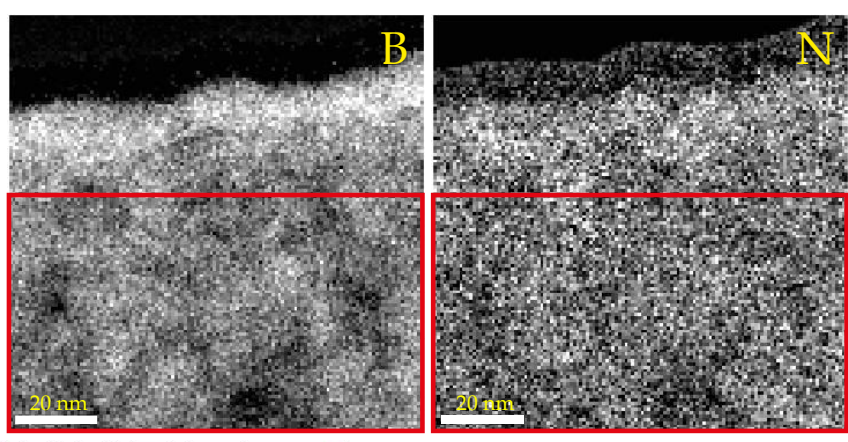
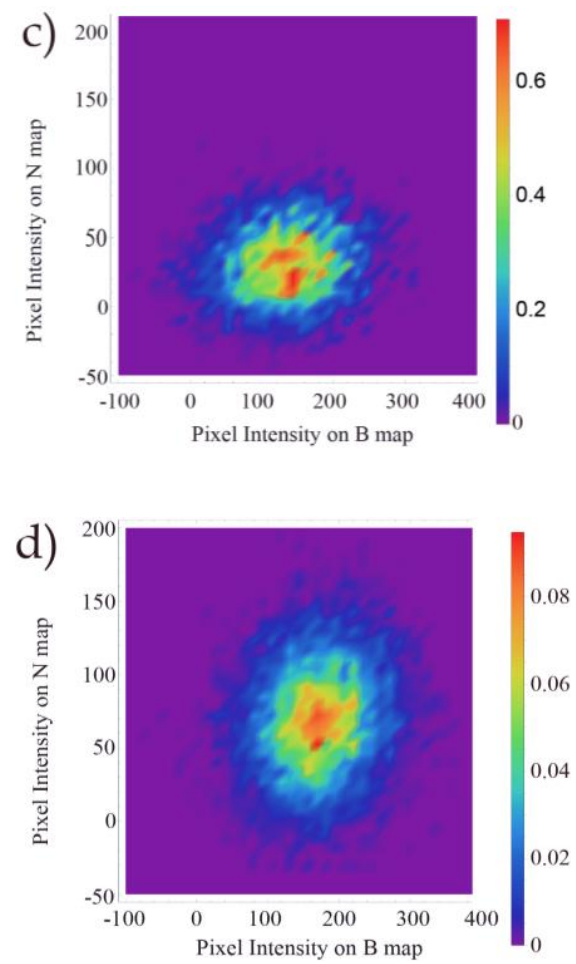

Figure 3-9. Images $(\boldsymbol{a})$ and $(\boldsymbol{b})$ show elemental maps of $B$ and $N$ obtained from two different areas of a sample consisting of $50 \mathrm{vol} . \%$ of pure-B and $50 \mathrm{vol} \%$ of stoichiometric-BN phase, as determined by in-situ SE. Images (c) and (d) give the B-vs-N cross correlation maps obtained from the red-boxed areas of $(a)$ and $(b)$, respectively. No clear lateral inhomogeneity (clustering) of pure-B and BN phases can be seen.

\subsection{Conclusions}

This work investigated the multi-phase (composite) nature of $\mathrm{B} / \mathrm{BN}$ thin films. It has been shown that the refractive index $(n)$ of the films was strongly dependent on the pure boron fraction: a gradual increase of $n$ from 1.7 (stoichiometric BN) to 2.9 (pure-B) was achieved by tuning the pure-B share. The film composition and optical properties were successfully modelled by spectroscopic ellipsometry. The developed SE model could quantitatively describe the experimental $n$-values as well as the co-existence of pure-B and stoichiometric$\mathrm{BN}$ phases in the films. The SE data revealed absorption behavior between 1 and 5 $\mathrm{eV}$, matching that of a pure-B phase.

The composite nature of the films was further supported by XPS. The B 1s peak revealed broadening towards higher binding energies and a clear asymmetry 
compared to the pure-B or stoichiometric-BN reference. No N 1s-peak broadening was observed; the peak showed good matching with that of the stoichiometric-BN reference. This further confirmed the presence of a well-defined BN phase. The cross-correlation maps of elemental B and N, obtained from planar-view EFTEM, indicated laterally homogeneous distribution of these elements, suggesting their vertical inhomogeneity. 


\section{References}

1 J. Zhao, B. Lin, Y. Zhu, Y. Zhou, and H. Liu, Catal. Sci. Technol. 8, 5900 (2018).

2 B. He, W.J. Zhang, Z.Q. Yao, Y.M. Chong, Y. Yang, Q. Ye, X.J. Pan, J.A. Zapien, I. Bello, S.T. Lee, I. Gerhards, H. Zutz, and H. Hofsäss, Appl. Phys. Lett. 95, 2 (2009).

${ }^{3}$ R. Dahal, J. Li, S. Majety, B.N. Pantha, X.K. Cao, J.Y. Lin, and H.X. Jiang, Appl. Phys. Lett. 98, 88 (2011).

${ }^{4}$ K. Nose, H. Oba, and T. Yoshida, Appl. Phys. Lett. 89, (2006).

${ }^{5}$ C.W. Ong, X.A. Zhao, K.F. Chan, Y.M. Ng, P.W. Chan, C.L. Choy, and R.W.M. Kwok, Thin Solid Films 307, 152 (1997).

${ }^{6}$ L. Ci, L. Song, C. Jin, D. Jariwala, D. Wu, Y. Li, A. Srivastava, Z.F. Wang, K. Storr, L. Balicas, F. Liu, and P.M. Ajayan, Nat. Mater. 9, 430 (2010).

7 A. Prakash and K.B. Sundaram, Appl. Surf. Sci. 396, 484 (2017).

8 T. Yuki, S. Umeda, and T. Sugino, Diam. Relat. Mater. 13, 1130 (2004).

${ }^{9}$ M.K. Lei, Q. Li, Z.F. Zhou, I. Bello, C.S. Lee, and S.T. Lee, Thin Solid Films 389, 194 (2001).

10 J. Wang, C. Chen, C. Yang, Y. Fan, D. Liu, and W. Lei, Curr. Graphene Sci. 2, 3 (2017).

11 S. Beniwal, J. Hooper, D.P. Miller, P.S. Costa, G. Chen, S.Y. Liu, P.A. Dowben, E.C.H. Sykes, E. Zurek, and A. Enders, ACS Nano 11, 2486 (2017).

12 A. Çetin and M. Durandurdu, J. Am. Ceram. Soc. 101, 1929 (2018).

13 J.J. Pouch, S.A. Alterovitz, K. Miyoshi, and J.O. Warner, MRS Proc. 93, 323 (1987).

14 C.W. Ong, K.F. Chan, and C.L. Choy, Thin Solid Films 388, 217 (2001).

${ }^{15}$ M.D. Wiggins, C.R. Aita, and F.S. Hickernell, J. Vac. Sci. Technol. A Vacuum, Surfaces, Film. 2, 322 (1984).

16 J.G. Kho, K.T. Moon, G. Nouet, P. Ruterana, and D.P. Kim, Thin Solid Films 389, 78 (2001).

17 A.Y. Kovalgin, M. Yang, S. Banerjee, R.O. Apaydin, A.A.I. Aarnink, S. Kinge, and R.A.M. Wolters, Adv. Mater. Interfaces 4, 1700058 (2017).

18 M. Yang, Hot-Wire Assisted Atomic Layer Deposition of Tungsten Films, University of Twente, 2018.

19 T.L. Barr and S. Seal, J. Vac. Sci. Technol. A Vacuum, Surfaces, Film. 13, 1239 (2002).

${ }^{20}$ M.J. Rand and J.F. Roberts, J. Electrochem. Soc. 115, 423 (1968).

21 S. Weissmantel, G. Reisse, B. Keiper, and S. Schulze, Diam. Relat. Mater. 8, 377 (1999). 
${ }^{22}$ H. Dumont, B. Bayle, and B. Bonnetot, Phys. Status Solidi 2473, 2470 (2003).

23 C.P. Talley, L.E. Line, and Q.D. Overman, in Boron Synth. Struct. Prop. (Springer US, Boston, MA, 1960), pp. 94-104.

${ }^{24}$ N.R. Glavin, C. Muratore, M.L. Jespersen, J. Hu, P.T. Hagerty, A.M. Hilton, A.T. Blake, C.A. Grabowski, M.F. Durstock, M.E. McConney, D.M. Hilgefort, T.S. Fisher, and A.A. Voevodin, Adv. Funct. Mater. 26, 2640 (2016).

25 S. Banerjee, R.O. Apaydin, and A.Y. Kovalgin, in ECS 234 Meet. (ECS 234 meeting, Oral presentation, Cancun, 2018).

${ }^{26}$ V.O. Todi and K.B. Sundaram, Electrochem. Solid-State Lett. 14, G49 (2011).

27 V.S. Sulyaeva, Y.M. Rumyantsev, V.G. Kesler, and M.L. Kosinova, Thin Solid Films 581, 59 (2015).

${ }^{28}$ S.P. Murarka, J. Electrochem. Soc. 126, 1951 (1979).

${ }^{29}$ T.H. Yuzuriha and D.W. Hess, Thin Solid Films 140, 199 (1986).

30 J.A. Zapien, R.W. Collins, and R. Messier, Thin Solid Films 364, 16 (2000).

31 J.A. Zapien, R.W. Collins, and R. Messier, J. Vac. Sci. Technol. A Vacuum, Surfaces, Film. 20, 1395 (2002).

32 S.L. Ren, A.M. Rao, P.C. Eklund, and G.L. Doll, Appl. Phys. Lett. 62, 1760 (1993).

33 S. Lousinian, N. Kalfagiannis, and S. Logothetidis, Solid State Sci. 11, 1801 (2009).

${ }^{34}$ B. von Blanckenhagen, D. Tonova, and J. Ullmann, Appl. Opt. 41, 3137 (2002).

${ }^{35}$ C. Feldman and K. Moorjani, Johns Hopkins APL Tech. Dig. 7, 2 (1968).

${ }^{36}$ N. Morita and A. Yamamoto, Jpn. J. Appl. Phys. 14, 825 (1975).

${ }^{37}$ F.H. Cocks, P.L. Jones, and L.J. Dimmey, Appl. Phys. Lett. 36, 970 (1980).

38 L.J. Dimmey, H. Park, P.L. Jones, and F.H. Cocks, J. Electron. Mater. 10, 111 (1981).

${ }^{39}$ K. Nakamura, J. Electrochem. Soc. 131, 2691 (1984).

${ }^{40}$ K. Shirai and S. Gonda, J. Phys. Chem. Solids 53, 1081 (1992).

${ }^{41}$ U. Kuhlmann, H. Werheit, T. Lundström, and W. Robers, J. Phys. Chem. Solids 55, 579 (1994).

42 M. Terauchi, Y. Kawamata, M. Tanaka, M. Takeda, and K. Kimura, J. Solid State Chem. 133, 156 (1997).

${ }^{43}$ H. Akazawa, J. Vac. Sci. Technol. A Vacuum, Surfaces, Film. 28, 411 (2010).

${ }^{44}$ D. Bedeaux and J. Vlieger, Optical Properties of Surfaces, 2nd ed. (Imperial College Press, London, 2004).

${ }^{45}$ D.A. Shirley, Phys. Rev. B 5, 4709 (1972). 
${ }^{46}$ C. Nicolas and C. Miron, J. Electron Spectros. Relat. Phenomena 185, 267 (2012).

47 L. Chen, T. Goto, T. Hirai, and T. Amano, J. Mater. Sci. Lett. 9, 997 (1990).

48 K.K. Kim, A. Hsu, X. Jia, S.M. Kim, Y. Shi, M. Hofmann, D. Nezich, J.F. Rodriguez-Nieva, M. Dresselhaus, T. Palacios, and J. Kong, Nano Lett. 12, 161 (2012).

49 J.F. Moulder, W.F. Stickle, P.E. Sobol, and K.D. Bomben, Handbook of X-Ray Photoelectron Spectroscopy (Perkin-Elmer Corporation, Physical Electronics Division, Minnesota, 1992). 


\title{
4 Comparative study of $\mathrm{B} / \mathrm{BN}$ deposition in purely
}

\section{thermal and radical-enhanced modes}

\begin{abstract}
This chapter studies the deposition of boron/boron nitride (B/BN) composite films at 275-375 ${ }^{\circ} \mathrm{C}$ of the substrate temperature by giving alternating pulses of diborane $\left(\mathrm{B}_{2} \mathrm{H}_{6}\right)$ and ammonia $\left(\mathrm{NH}_{3}\right)$ with argon (Ar)-purges in between, to avoid gas-phase reactions of the precursors. This allows to mimic an atomic layer deposition (ALD) process, ensuring merely surface reactions and presumably simplifying the growth mechanism. This work further compares purely thermal and radical-enhanced deposition modes, by gradually changing the degree (and mechanism) of $\mathrm{NH}_{3}$ dissociation, from low by hot-wire (HW) to high by plasma-assistance. It is demonstrated that, in purely thermal mode, the growth of the layers and their composition are strongly dependent on total gas pressure. By changing the pressure, the pure boron (pure-B) content (not to be confused with the total boron content) in the B/BN composites could be varied in the range of $\sim 6-70$ vol. $\%$.

The pressure dependence is consistent with a growth model via the so-called surface-adduct mechanism. The plasma-assisted deposition results in polycrystalline BN with near stoichiometric

$B / N$ ratio at $310^{\circ} \mathrm{C}$. These films exhibit crystal planes stacked perpendicular to the substrate surface with an interplane distance of $3.57 \AA$ corresponding to hexagonal boron nitride (h-BN).

The films are stable in air up to at least six months after their deposition.
\end{abstract}




\subsection{Introduction}

Several methods have been used to deposit boron nitride, including molecular beam epitaxy (MBE) 1,2, ion beam assisted deposition (IBAD) 3,4, magnetron sputtering ${ }^{5}$, RF sputtering ${ }^{6}$, pulsed laser deposition ${ }^{7}$ and chemical vapor deposition (CVD) ${ }^{8-12}$. Among these, CVD is the most intensively studied method, commonly utilizing diborane $\left(\mathrm{B}_{2} \mathrm{H}_{6}\right)$ and ammonia $\left(\mathrm{NH}_{3}\right)$ gas mixtures as precursors. However, the high growth temperatures (close to $1000{ }^{\circ} \mathrm{C}$ ) required to form crystalline films, limit many (potential) applications of $\mathrm{BN} 13,14$. In addition, different thermal expansion coefficients of the substrate and of the deposited film negatively affect the processing at high temperatures. Boron nitride films deposited at temperatures below $800{ }^{\circ} \mathrm{C}$ are usually amorphous 14,15 .

To reduce the growth temperature, several radical-enhanced deposition methods have been employed. Radicals can be generated by dissociating $\mathrm{NH}_{3}$ with, for example, a plasma source (the so-called plasma-enhanced CVD or PECVD), thereby producing a variety of nitrogen-containing $\left(\mathrm{NH}_{\mathrm{x}}, \mathrm{x}=0-2\right)$ radicals. Another approach to generate radicals is by utilizing a hot-wire (HW). Further details on the radical-assisted methods can be found in Chapter 1.

This chapter compares purely thermal and radical-enhanced deposition methods, by gradually changing the degree (and mechanism) of $\mathrm{NH}_{3}$ dissociation, from low by HW- to high by plasma-assistance. It demonstrates that, in purely thermal mode, the growth of the layers and their composition are strongly dependent on total gas pressure. By changing the pressure, the pure boron content ( $\mathrm{B}$ bonded to $\mathrm{B}$ instead of to $\mathrm{N}$ ) in the $\mathrm{B} / \mathrm{BN}$ composites can be varied in the range of $\sim 6-70$ vol. \%. The pressure dependence will be discussed in line with a growth model via the so-called surface-adduct pathway (see Chapter 2).

\subsection{Experimental details}

The deposition experiments were performed in both home-built cluster and Picosun plasma ALD/CVD reactor. The details were already given in Chapter 1. 
The experiments were conducted in the total pressure range of $10^{-3}-12 \mathrm{mbar}$. The substrate temperature was kept between $275-375{ }^{\circ} \mathrm{C}$. Diborane $\left(\mathrm{B}_{2} \mathrm{H}_{6}\right)$ and ammonia $\left(\mathrm{NH}_{3}\right)$ gases were used as boron and nitrogen sources, respectively.

Prior to deposition, silicon (Si) (100) and $\mathrm{SiO}_{2}$ substrates were processed following the procedure explained in Chapter 3. The deposited films were characterized by x-ray photoelectron spectroscopy (XPS) and in-situ (real time) and ex-situ spectroscopic ellipsometer (SE) (see previous chapter for equipment details). In-situ spectroscopic ellipsometer (SE) was used to monitor the actual surface temperature ${ }^{16}$. Films deposited with plasma were further characterized by transmission electron microscopy (TEM), energy filtered TEM (EFTEM), grazing incidence angle $x$-ray diffraction (GIXRD) and x-ray reflectivity (XRR) techniques. Details for TEM equipment can be found in Chapter 3. GIXRD and XRR analyses were carried out with a X'pert Powder XRD system from Malvern Panalytical.

Spectroscopic ellipsometry analysis were performed using EMA, Sellmeier, Tauc Lorentz and Lorentz models, as explained in Chapters 2 and 3. The pure-B shares (in volume \%, vol.\%) given in this chapter were obtained solely from SE.

\subsection{Results and discussion}

\subsubsection{Purely thermal deposition}

Thermal decomposition of $\mathrm{B}_{2} \mathrm{H}_{6}$ occurs continuously, therefore, selflimiting reactions in the studied temperature $(T)$ range are not expected. This was confirmed experimentally and shown in Figure 4-1.a, clearly demonstrating the ongoing deposition of pure boron on $\mathrm{SiO}_{2}$ from $\mathrm{B}_{2} \mathrm{H}_{6}$. An incubation time is observed (Figure 4-1.b); temperature clearly promotes the nucleation of $\mathrm{B}$ on $\mathrm{SiO}_{2}$ decreasing the incubation time. No incubation was observed on silicon wafers at all temperatures studied. 

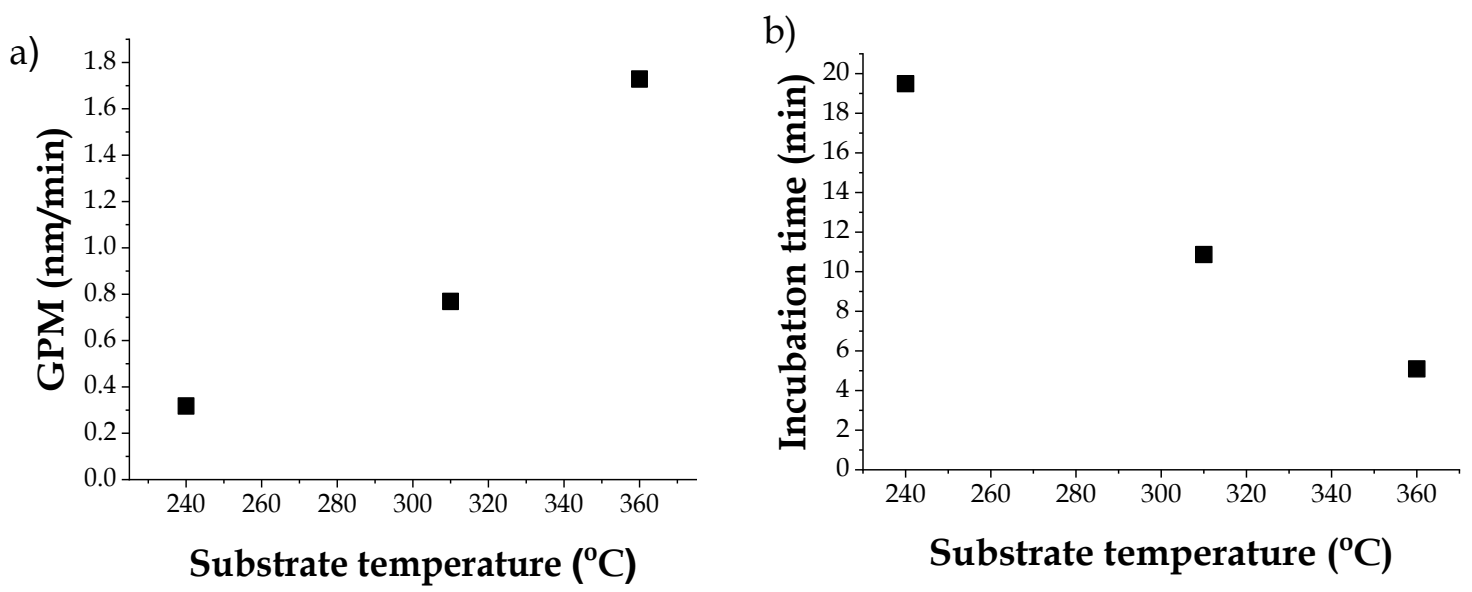

Figure 4-1. The temperature dependence of growth per minute (GPM) (a) and incubation time (b) of pure boron films on $\mathrm{SiO}_{2}$, measured by SE. The incubation time is defined as the growth time required to obtain a constant GPM. Conditions: CVD at 1 mbar of total pressure, $200 \mathrm{sccm}$ of $\mathrm{B}_{2} \mathrm{H}_{6}$ (5\% in Ar) and $500 \mathrm{sccm}$ of Ar flow ${ }^{* *}$.

The demonstrated non-self-limiting nature of boron deposition implies two co-existing processes in the $\mathrm{BN}$ formation mechanism:

$\checkmark$ process (1) - non self-limiting thermal decomposition of $\mathrm{B}_{2} \mathrm{H}_{6}$, leading to the formation of a pure- $\mathrm{B}$ phase, presumably $\mathrm{BH}_{\mathrm{x}}(\mathrm{x}=0-3)$ terminated, and

$\checkmark$ process (2) - reaction of this pure-B with $\mathrm{NH}_{3}$, thereby incorporating nitrogen in the layers (i.e., nitridation of the pure-B).

Process (2) is self-limiting in the sense that the nitrogen content cannot exceed a certain share.

In the subsequent experiments, the effects of substrate temperature, total pressure (ranging from $5 \times 10^{-3}$ mbar to 12 mbar) and diborane dose on the growth rate per cycle (GPC), as well as on the amount of pure-B, were investigated. It was observed that the nitrogen content slightly increases with lowering the substrate temperature from $375{ }^{\circ} \mathrm{C}$ to $290{ }^{\circ} \mathrm{C}$, whereas the GPC decreases from 0.045 $\mathrm{nm} /$ cycle to $0.021 \mathrm{~nm} /$ cycle. These results suggest that the temperature rather affects the $\mathrm{B}_{2} \mathrm{H}_{6}$ chemisorption (process 1 ) and its subsequent decomposition than

\footnotetext{
** Courtesy of Xingyu Liu, University of Twente
} 
the nitridation reaction (process 2). A strong enhancement of the GPC with increasing the $\mathrm{B}_{2} \mathrm{H}_{6}$ pulse time, as shown in Figure 4-2.a, implies that the GPC is limited by the $\mathrm{B}_{2} \mathrm{H}_{6}$ dose. The $\mathrm{B}_{2} \mathrm{H}_{6}$ pulse time also crucially determines the pureB share in the layers (Figure 4-2.b).
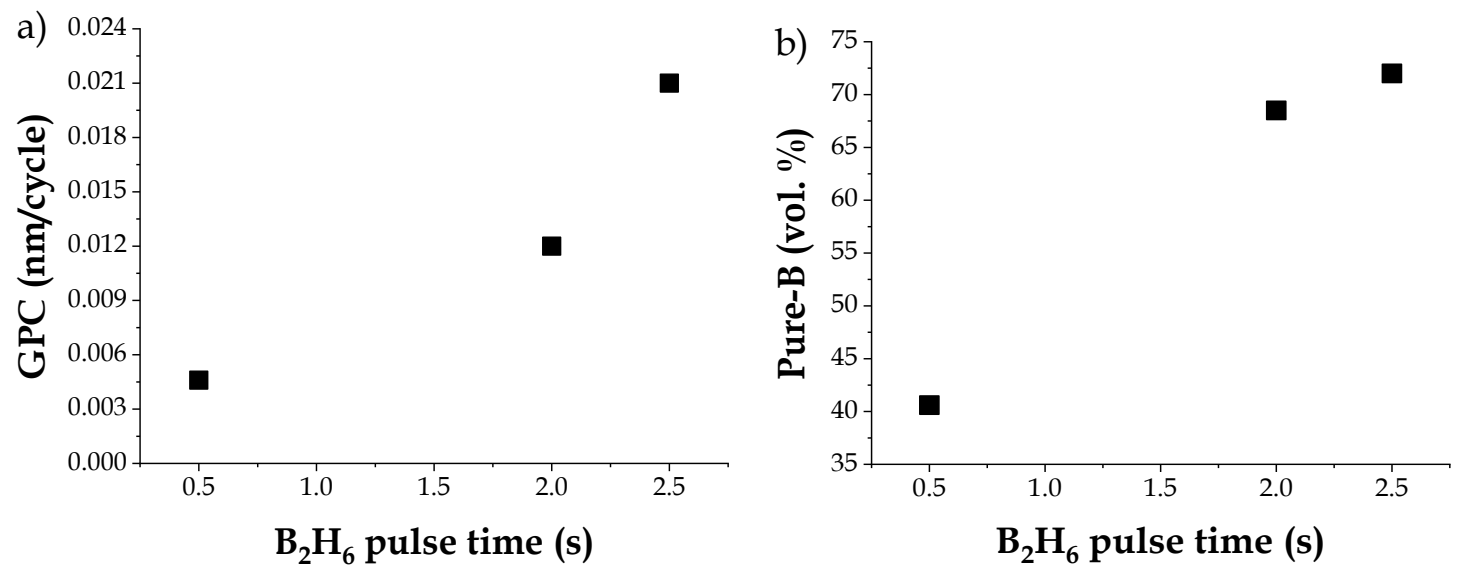

Figure 4-2. Dependence of GPC (a) and pure-B share in vol.\% (b) on $B_{2} H_{6}$ pulse duration, both measured by SE. Conditions: 4- 6 s of Ar for post- $B_{2} H_{6}$ purge /2.5-3 s of $\mathrm{NH}_{3}$ pulse / 4-6 s of Ar for post-NH3 purge, at a substrate temperature of $280 \pm 10{ }^{\circ} \mathrm{C}$ and a total pressure of $2 \times 10^{-3}$ mbar.

Further, increasing the total pressure $\left(P_{\text {tot }}\right)$ leads to a higher nitrogen content (share) and a correspondingly lower amount of pure-B (Figure 4-3.a). This will be further discussed in Section 4.1, in view of the proposed adduct-assisted reaction pathway. However, a gradual decrease of the GPC was observed with increasing the $P_{\text {tot }}$ (Figure 4-3.b). This rather unusual result can be explained by a decreased delivery of $\mathrm{B}_{2} \mathrm{H}_{6}$ to the wafer surface at a higher pressure (i.e., lower diffusion rate of $\mathrm{B}_{2} \mathrm{H}_{6}$ ) or a suppressed (dissociative) chemisorption of $\mathrm{B}_{2} \mathrm{H}_{6}$ (the rate limiting step) on the as-nitridized surface in comparison to a surface terminated by $\mathrm{B}_{2} \mathrm{H}_{6}$ decomposition products. 

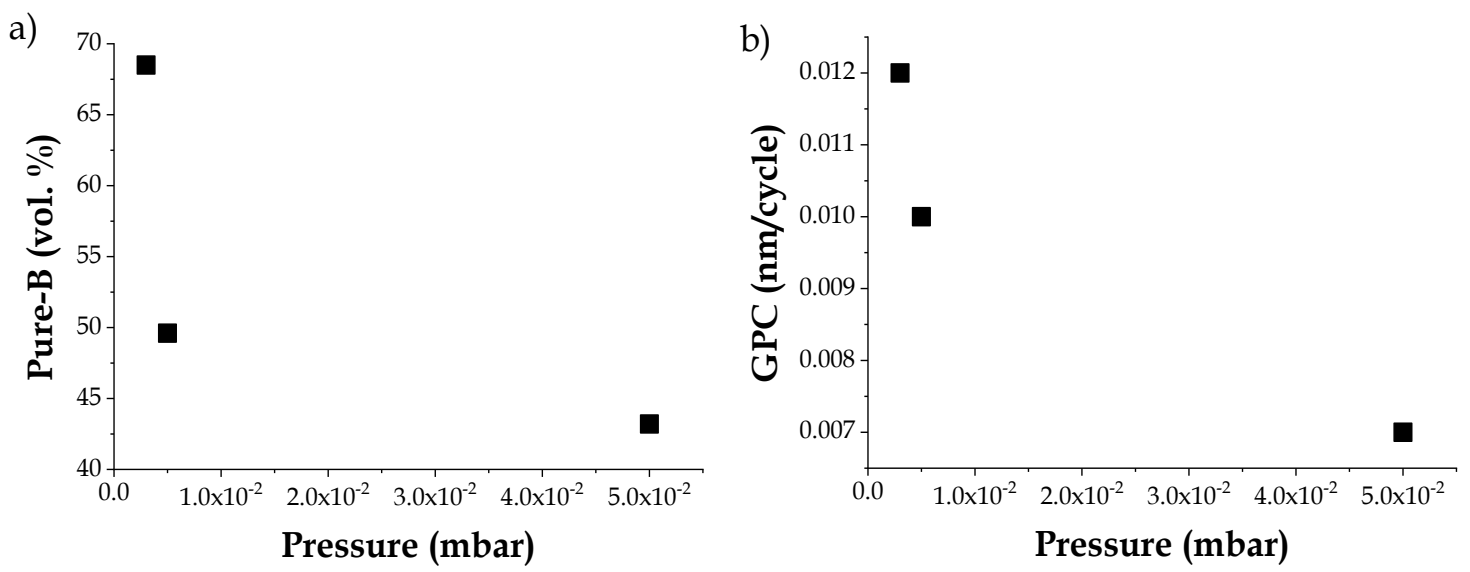

Figure 4-3. SE measurements of the pure-B share in vol.\% (a) and GPC (b) as a function of the total gas pressure. Conditions: $2 \mathrm{~s}$ of $\mathrm{B}_{2} \mathrm{H}_{6}$ pulse / $6 \mathrm{~s}$ of Ar for post- $\mathrm{B}_{2} \mathrm{H}_{6}$ purge $/ 3$ $s$ of $\mathrm{NH}_{3}$ pulse / $6 \mathrm{~s}$ of Ar for post- $\mathrm{NH}_{3}$ purge, at a substrate temperature of $280 \pm 10{ }^{\circ} \mathrm{C}$.

Since the $P_{\text {tot }}$ has a large impact on both GPC and pure-B share, we further expand the pressure range up to 12 mbar (see Figure 4-4). These experiments were carried out using the Picosun reactor, in purely thermal mode.
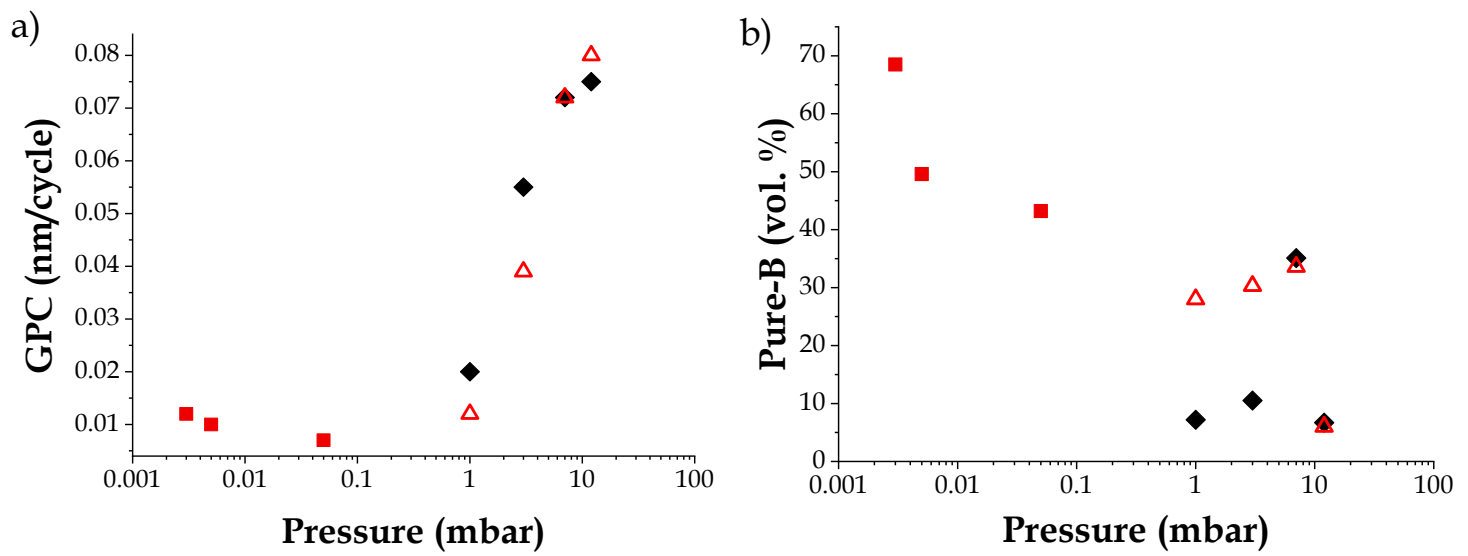

Figure 4-4. SE measurements of GPC (a) and pure-B share in vol.\% (b) as a function of the total gas pressure. Conditions: 0.1-2.5 s of $B_{2} H_{6}$ pulse / 4- 6 s of Ar post- $B_{2} H_{6}$ purge / 2.5-11.5 s of $\mathrm{NH}_{3}$ pulse/ 4-10 s of Ar for post- $\mathrm{NH}_{3}$ purge, at a substrate temperature of $290 \pm 20^{\circ} \mathrm{C}$. Symbols: squares for $P_{\text {tot }}<1$ mbar, diamonds for $P_{\text {tot }} \geq 1$ mbar with $0.2 \mathrm{~s}$ $B_{2} H_{6}$-pulse duration, triangles for $P_{\text {tot }} \geq 1$ mbar with $0.1 s B_{2} H_{6}$-pulse duration. Showing the cumulative datasets from different reactors, substrates and pulse times allows to generalize the pressure effect.

Although all obtained at different $\mathrm{B}_{2} \mathrm{H}_{6}$-pulse, Ar-purge and $\mathrm{NH}_{3}$-pulse durations (see Figure 4-4 caption), the measurements in Figure 4-4.a exhibit the same trend of the GPC versus $P_{\text {tot. }}$ Namely, the GPC slightly decreases with increasing the pressure for $P_{\text {tot }}<0.1$ mbar and starts to increase rapidly for $P_{\text {tot }}$ 
exceeding 1 mbar. The pure boron share gradually decreases with increasing the $P_{\text {tot, }}$ being as high as $\sim 70$ vol. $\%$ in the low-pressure range and as low as $\sim 6$ vol. $\%$ in the high-pressure range (Figure 4-4.b). This figure exhibits a consistent and clear effect of $P_{\text {tot }}$. Showing the cumulative datasets from different reactors, substrates and pulse times allows to generalize the pressure effect.

Obviously, changing $P_{\text {tot }}$ would affect partial pressure of both diborane $\left(P_{\mathrm{B} 2 \mathrm{H} 6}\right)$ and ammonia $\left(P_{\mathrm{NH} 3}\right)$. It should however be noted that the difference between $P_{\mathrm{B} 2 \mathrm{H} 6}$ and $P_{\mathrm{NH} 3}$ was at least one order of magnitude. Namely, for $P_{\text {tot }}>1$ mbar, the $P_{B 2 H 6}$ was kept in the range of $10^{-3}-10^{-2}$ mbar, whereas the $P_{N H 3}$ was changing between $10^{-2}$ and $10^{-1}$ mbar. Considering the large difference in the partial pressures, in combination with the significant decay of the pure-B share with increasing $P_{\text {tot, }}$ a dominant role of the $P_{\mathrm{NH} 3}$ in the growth process might be suggested.

As proposed above, the film growth may occur via processes (1) and (2). Assuming the dependence of their rates on $P_{\text {tot, }}$ it is evident that the strong increase of the GPC at $P_{\text {tot }} \geq 1$ mbar can hardly occur if process (1) dominates. If the latter was the case, this would not match with the gradually decreasing amount of the pure-B phase. We therefore conclude that the sharp rise of GPC is caused by process (2); the latter controls the growth at $P_{\text {tot }} \geq 1$ mbar. Process (2) may in turn enhance process (1) by changing the surface nitridation state. The proposed effect of $\mathrm{NH}_{3}$ on the chemisorption of $\mathrm{B}_{2} \mathrm{H}_{6}$ is still to be explored. For example, it is reported that presence of $\mathrm{H}_{2}$ may increase the activation energy required for diborane decomposition ${ }^{17}$.

Summarizing, the experiments performed in purely thermal mode indicate the importance of $\mathrm{B}_{2} \mathrm{H}_{6}$ in the growth rate and the film composition at $P_{\text {tot }}<0.1$ mbar, whereas the impact of nitridation by $\mathrm{NH}_{3}$ dominates at $P_{\text {tot }} \geq 1$ mbar. Clearly, higher $P_{\text {tot }}$ increases the GPC and lowers the pure-B share. Decreasing the pure-B share below 6 vol.\% is however problematic in purely thermal mode and at low temperatures. Sections 4.3.2 and 4.3.3 address the effectiveness of two radicalenhanced approaches towards growing stoichiometric $\mathrm{BN}$ from $\mathrm{B}_{2} \mathrm{H}_{6}$ and $\mathrm{NH}_{3}$. 


\subsubsection{Hot-wire-assisted deposition}

The impact of a $\mathrm{HW}$ on the dissociation of $\mathrm{NH}_{3}$ has been investigated by several groups, confirming the formation of mainly $\mathrm{NH}_{2}$ radicals ${ }^{18,19}$. This also means providing a corresponding flux of atomic hydrogen (at-H) to the substrate. Importantly, the at-H flux is expected to be even larger compared to that of $\mathrm{NH}_{2}$, due to a higher recombination probability of the latter. The generation, recombination and delivery of the radicals to the growth surface were previously studied in our experiments on tellurium etching (for at-H) and silicon nitridation (for $\left.\mathrm{NH}_{2}\right)^{20}$.

The HW-assisted deposition led to a dramatic decrease in the GPC with increasing the HW temperature $\left(T_{\mathrm{HW}}\right)$. Namely, being $\sim 0.01 \mathrm{~nm} /$ cycle for the HWoff mode (i.e., HW at room temperature), the GPC decreased to $\sim 0.001 \mathrm{~nm} /$ cycle at $T_{\mathrm{HW}}=2100 \mathrm{~K}$ (see Figure 4-5). (To note, an efficient dissociation of $\mathrm{NH}_{3}$ was already observed for $T_{\mathrm{HW}}>1600 \mathrm{~K}{ }^{20}$ ). In spite of the lower GPC, more nitrogen was incorporated into the layers with increasing the $T_{\mathrm{HW}}$. For the specific conditions (see Figure 4-3 caption), the pure-B share decreased from $\sim 50$ vol. $\%$ at $T_{\mathrm{HW}}=300 \mathrm{~K}$ to $\sim 37$ vol. $\%$ at $T_{\mathrm{HW}}=1800 \mathrm{~K}$. This was determined by SE and confirmed by XPS. Furthermore, a clear shift of the XPS B 1s peak position from that of pure-B towards that of stoichiometric-BN was observed with increasing the $T_{\mathrm{HW}}$ (to be discussed in Section 4.3.4.1). 


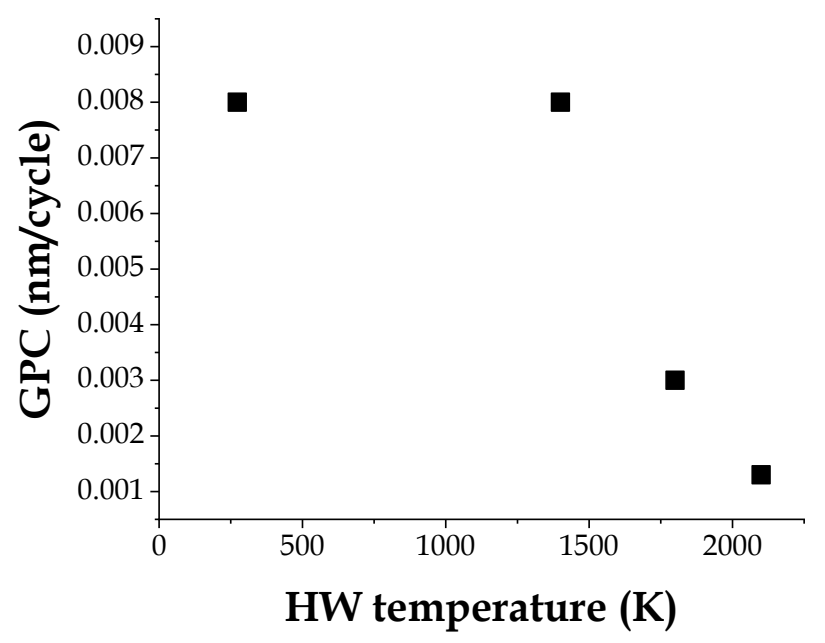

Figure 4-5. Dependence of GPC on $T_{H W}$. Conditions: $2 s$ of $B_{2} H_{6}$ pulse/ $6 s$ of Ar for post$B_{2} \mathrm{H}_{6}$ purge / $3 \mathrm{~s}$ of $\mathrm{NH}_{3}$ pulse/ $6 \mathrm{~s}$ of Ar for post- $\mathrm{NH}_{3}$ purge, at a substrate temperature of $275^{\circ} \mathrm{C}$ and a total pressure of $2 \times 10^{-3} \mathrm{mbar}$.

Although utilizing the HW has a clear effect on both GPC and stoichiometry, the concentration of as-generated $\mathrm{N}$-containing radicals seems to be not high enough to effectively nitridize the growing film. The competing interaction of at- $\mathrm{H}$ with the surface was hypothesized to decrease the GPC. This will be discussed in Section 4.4.2. We further proceed with a plasma radical source, as it is expected to provide a higher degree of $\mathrm{NH}_{3}$ dissociation.

\subsubsection{Plasma-assisted deposition}

The depositions were performed with the Picosun reactor on an $\mathrm{SiO}_{2}$ layer $(100 \mathrm{~nm})$ at $310^{\circ} \mathrm{C}$. To bear in mind, the previously-described experiments were performed at comparable substrate temperatures of $290 \pm 20{ }^{\circ} \mathrm{C}$. The total gas pressure was kept at $1 \mathrm{mbar}$ for all plasma experiments, corresponding to the pureB share of $\sim 6$ vol.\% of the purely thermal mode (recall Figure $4-4 . b)$. The other process conditions were kept identical to the thermal counterpart. Remarkably, the GPC with plasma (0.017 nm/cycle) was hardly changed compared to that of the thermal mode $(0.020 \mathrm{~nm} /$ cycle), meaning that the plasma merely enhanced the nitridation process. The latter was confirmed by both SE and XPS. The XPS revealed near stoichiometric BN films at the surface (see Figure 4-6); the difference 
between the $\mathrm{B}$ and $\mathrm{N}$ shares increased with sputter depth, possibly due to preferential sputtering ${ }^{21}$.

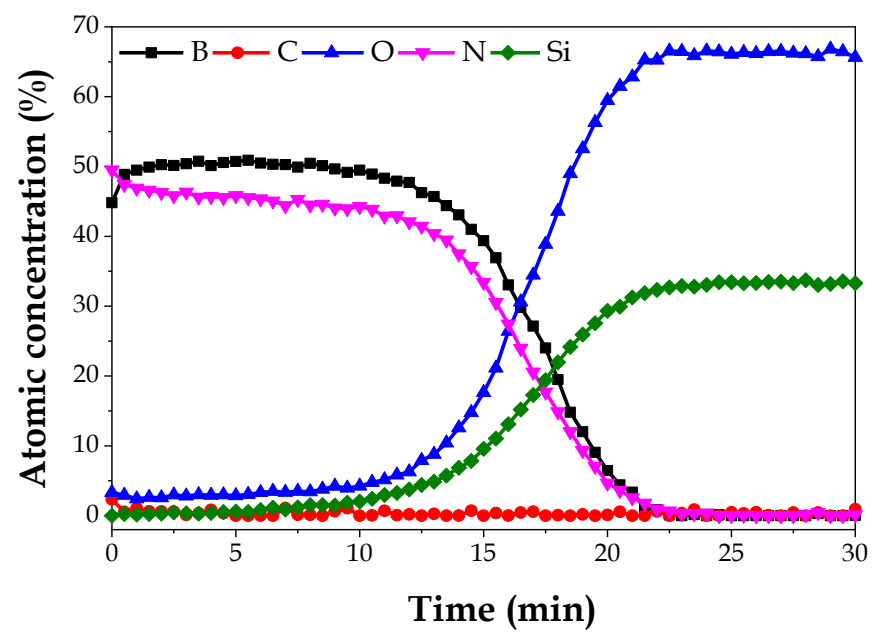

Figure 4-6. XPS sputter depth profile of a plasma deposited BN film. Conditions: $0.2 \mathrm{~s}$ of $B_{2} \mathrm{H}_{6}$ pulse / $5 \mathrm{~s}$ of Ar for post $\mathrm{B}_{2} \mathrm{H}_{6}$ purge / $11.5 \mathrm{~s}$ of $\mathrm{NH}_{3}$ pulse/ $10 \mathrm{~s}$ of Ar for post- $\mathrm{NH}_{3}$ purge, at a substrate temperature of $310^{\circ} \mathrm{C}$ and a total pressure of $1 \mathrm{mbar}$.

\subsubsection{Comparative analysis of the film properties}

\subsubsection{XPS analysis}

A comparison of the B 1s and N 1s spectra showed a significant influence of the growth methods. The amount of pure-B, estimated by SE and verified by XPS, decreased from $\sim 50$ to $\sim 37$ vol.\% for the thermally- and HW-deposited films, respectively. The plasma enhancement resulted in 46 at. $\%$ of N, 50 at. $\%$ of $B$, and 4 at. $\%$ of oxygen.

The B 1s spectra were taken after sputtering the top 0.5-1 nm of the film surface, to prevent the contribution of various surface contaminants. A comparison of the B 1s spectra of pure-B as well as thermally-, HW- and plasma-deposited $\mathrm{B} / \mathrm{BN}$ films is given in Figure 4-7. 

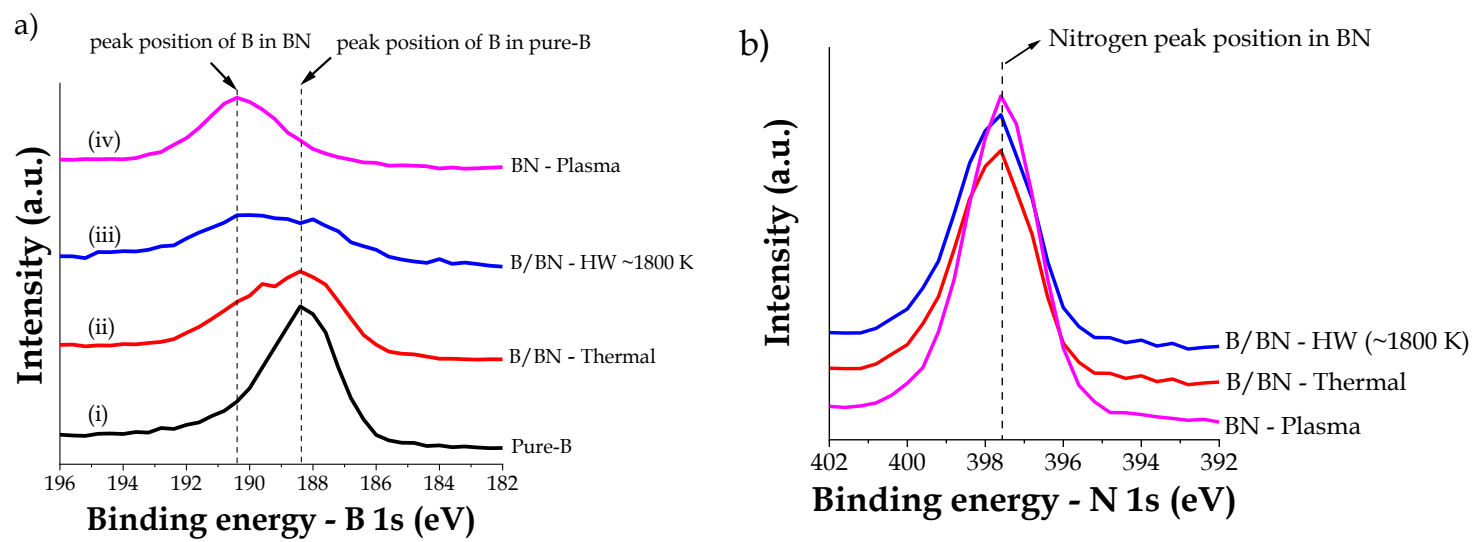

Figure 4-7. (a) XPS B 1s spectra of pure-B (i), thermally-and HW-deposited B/BN (ii)(iii), and plasma-deposited BN films (iv). (b) XPS N 1s spectra of films (ii)-(iv) from (a). For deposition conditions see the captions of Figures 4-4, 4-5 and 4-6.

Going from thermal through HW- to plasma-assisted deposition, one can clearly see that the B 1s peak broadens towards higher binding energies, and that the binding energy of the main peak gradually shifts from $188.4 \mathrm{eV}$ (i.e., B-B bonding ${ }^{22}$ ) to $190.6 \mathrm{eV}$ (i.e., B-N bonding 10,11,23). This confirms that effective nitridation is enabled by the external energy sources. In addition to the B 1s spectra, we analyzed the $\mathrm{N}$ 1s-peak binding energies (Figure 4-7.b). For all the samples, the $\mathrm{N}$ 1s peak positions corresponded to stoichiometric-BN; no shift towards higher or lower binding energies was observed.

To investigate the gradual shift of the B 1s peak with increasing a degree of nitridation (Figure 4-7), B 1s peak deconvolution was performed (Figure 4-8). It was concluded that the broad features seen for the thermally- and HW-deposited films could adequately be described by two Gaussian peaks at binding energies of pure-B and stoichiometric-BN. On the other hand, the B 1s peak of the plasmadeposited film was fitted by a single Gaussian peak at the B-N binding energy. These results are consistent with the formation of mixed pure-B and stoichiometric-BN phases in the thermally- and HW-deposited films, whereas plasma assistance leads to growing near-stoichiometric BN. More discussion on the existence of these two phases mixed in the as-made films can be found in Chapter 3. 

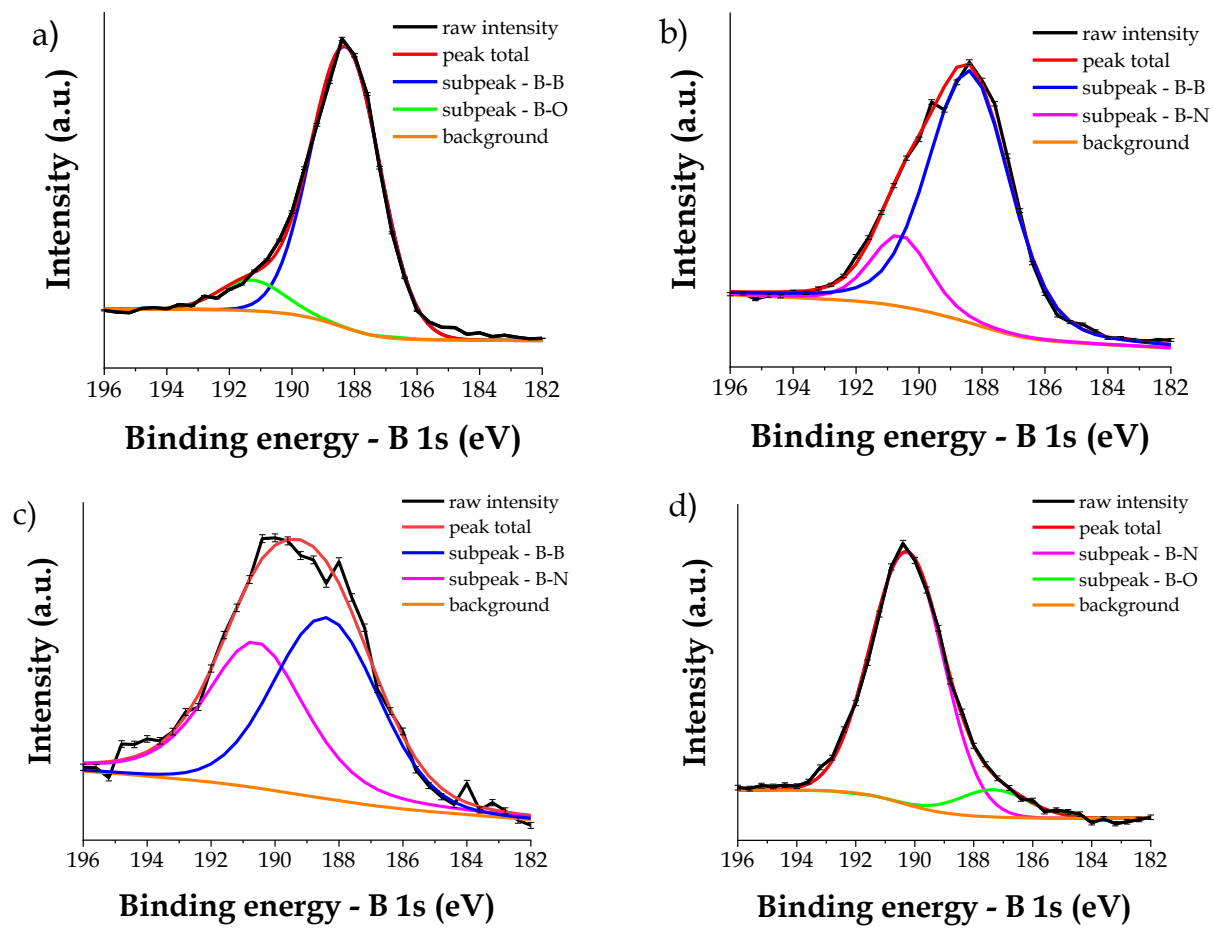

Figure 4-8. B 1s peak deconvolution for (a) pure-B, (b) thermally-and (c) HW-deposited $B / B N$, and $(d)$ plasma-deposited $B N$. Contributions of several chemical bonding environments $(B-O 24,25, B-B 22$ and $B-N 10,11,23)$ are included in the fits. For deposition conditions see the captions of Figures 4-4, 4-5 and 4-6.

\subsubsection{Stability in air}

Environmental stability of $\mathrm{BN}$ is of prime importance for practical applications and occurs for films with a sufficient degree of crystallinity. It is known that (partially) amorphous and low-crystal-order BN films can quickly degrade in air due to their interaction with oxidizing species ${ }^{14}$, whereas h-BN layers are chemically inert in many environments ${ }^{26}$. Degradation in air is therefore a measure of the film crystallinity.

The degradation can be investigated by ex-situ SE. The measurements we performed on as-deposited (i.e., measured within 20 minutes) samples and after their exposure to air for more than 6 months. To draw conclusions regarding the degradation of the films, a comparison of the delta-values (see Chapter 2) was carried out, since delta is rather sensitive to changes in thickness and optical functions ${ }^{16}$. It can be concluded from Figure 4-9 that the thermally- and HWdeposited samples significantly changed their optical responses after this long exposure, presumably due to their oxidation, whereas the plasma-deposited 
samples showed no change. The latter might be a first indication of a crystalline structure 13,14 .
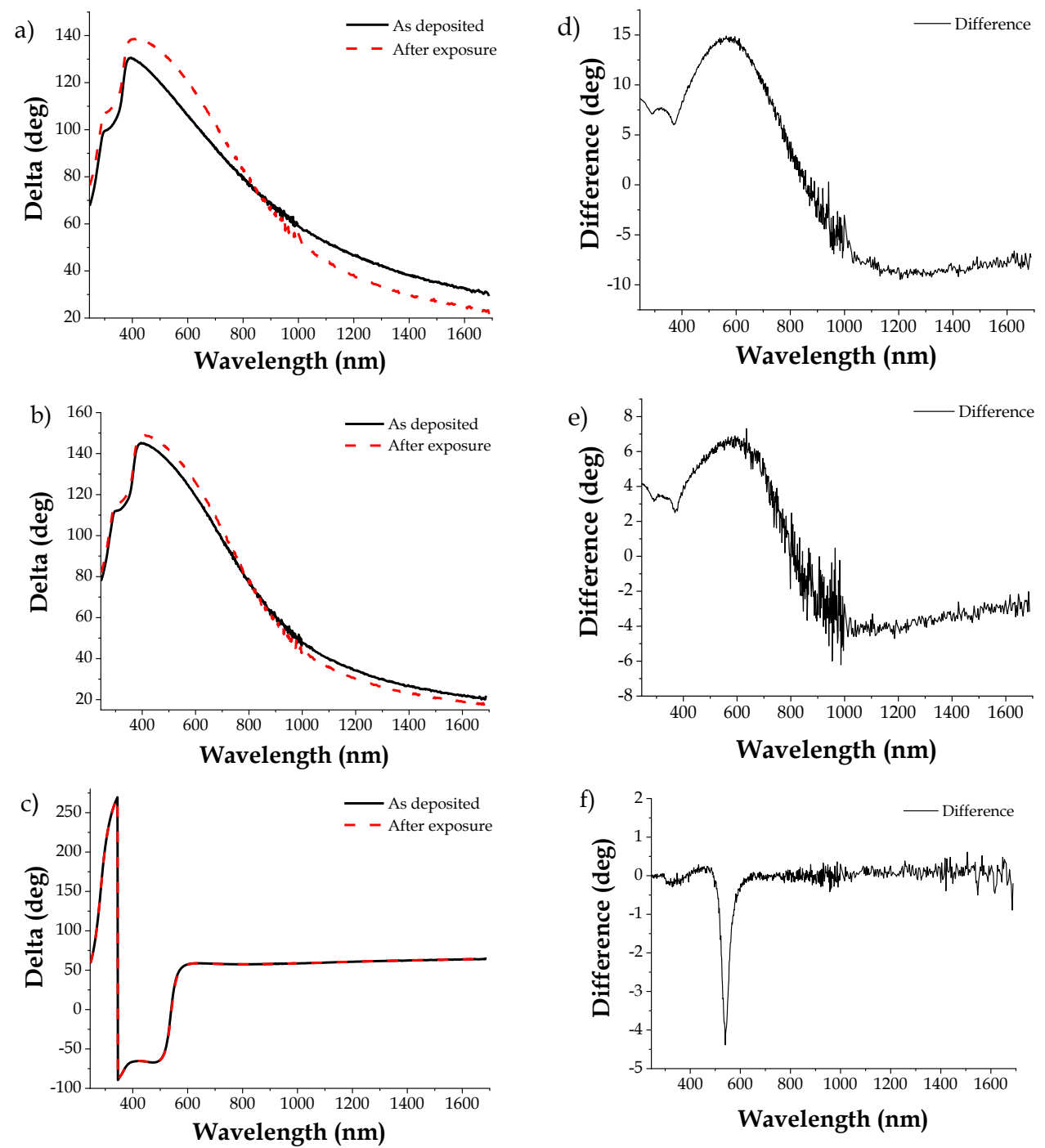

Figure 4-9. Delta-values of (a) thermally-, (b) HW- and (c) plasma-deposited layers, for as-deposited samples and after their exposure to air for 6 months. Graphs (d-f) show the difference between the corresponding delta-values in $(a-c)$, respectively. The sharp difference observed in $(f)$ is a measurement artefact.

\subsubsection{Crystallinity from HRTEM}

A crystalline structure of the plasma-deposited films is confirmed by HRTEM. Figure 4-10.a shows a lamellar-type structure with crystal planes perpendicular to the substrate surface. Line profile analysis (the inset) performed on the FFT1 area reveals interplane distances ( $d$-spacing) ranging between 3.4 and $3.8 \AA$. These values fall in the range previously reported for hexagonal boron nitride (3.3-3.7 $\AA$ ) 8,9,12,15,27-29. 
A detailed analysis of the interplane distance was further conducted by using radial profile analysis with ImageJ $1.52 \mathrm{i}^{30}$ and Radial Profile Extended 31 software. Fast Fourier Transform (FFT) analysis of the 3 boxed areas in Figure 410.a revealed an average interplane distance of $3.57 \AA$, with a second periodicity at $2.16 \AA$, as depicted in Figure 4-10.b. The former matches with the (002) $d$-spacing of h-BN (3.3-3.7 $\AA$ ), while the latter corresponds to the (100) $d$-spacing of h-BN $(2.17$ $\AA)$. This is close to the values in sphalerite $\beta$-BN $(2.09 \AA){ }^{32}$ and wurtzite $\gamma$-BN $(2.20$ $\AA$ and $2.10 \AA$ ) ${ }^{33}$. These two structures however do not have any $d$-spacing above $2.2 \AA$, and so cannot cause the broad peak centered at 3.57 $\AA$. In the 3.3-3.7 $\AA$ range reported for $\mathrm{BN}$, the larger spacing shifts have been attributed to curved ${ }^{34}$ and turbostratic ${ }^{35} \mathrm{BN}$. The $d$-spacing may increase due to the presence of $\mathrm{NH}_{\mathrm{x}}(\mathrm{x}=1-2)$ groups in $\mathrm{BN}$, similar to the effect of hydroxyl or carboxyl groups reported for graphite 36,37 .
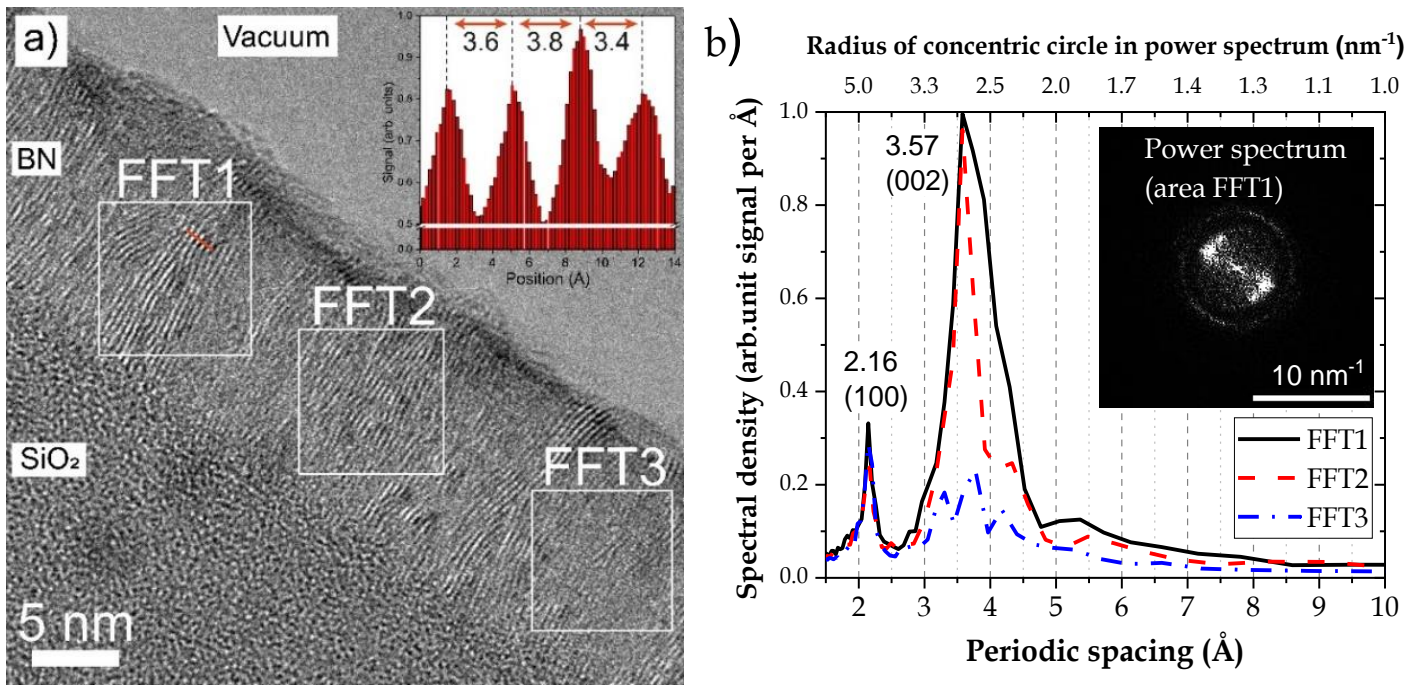

Figure 4-10. (a) HRTEM image of a plasma-deposited BN layer (after 4 months being stored in air) on thermally grown $\mathrm{SiO}_{2}$. The 3 boxes indicate the areas for Fast Fourier Transform (FFT) analysis. Inset: line profile inside area FFT1, showing the interlayer distance ranging between 3.4 and $3.8 \AA$ (with a pixel size of $0.2 \AA$ ). (b) Radial profiles of the FFT power spectra of the 3 boxed areas in (a) $t+$.

i† Contributed by A.J. Onnink (University of Twente) and included into the joint publication of R.O. Apaydin and A.J. Onnink, see the list of publications at the end of this thesis. 


\subsubsection{Other analyses}

The plasma-deposited samples showed no detectable amount of pure-B, as additionally confirmed by EFTEM. The elemental maps indicated only nitrogen and boron with some trace amounts of oxygen (see Figure 4-11).
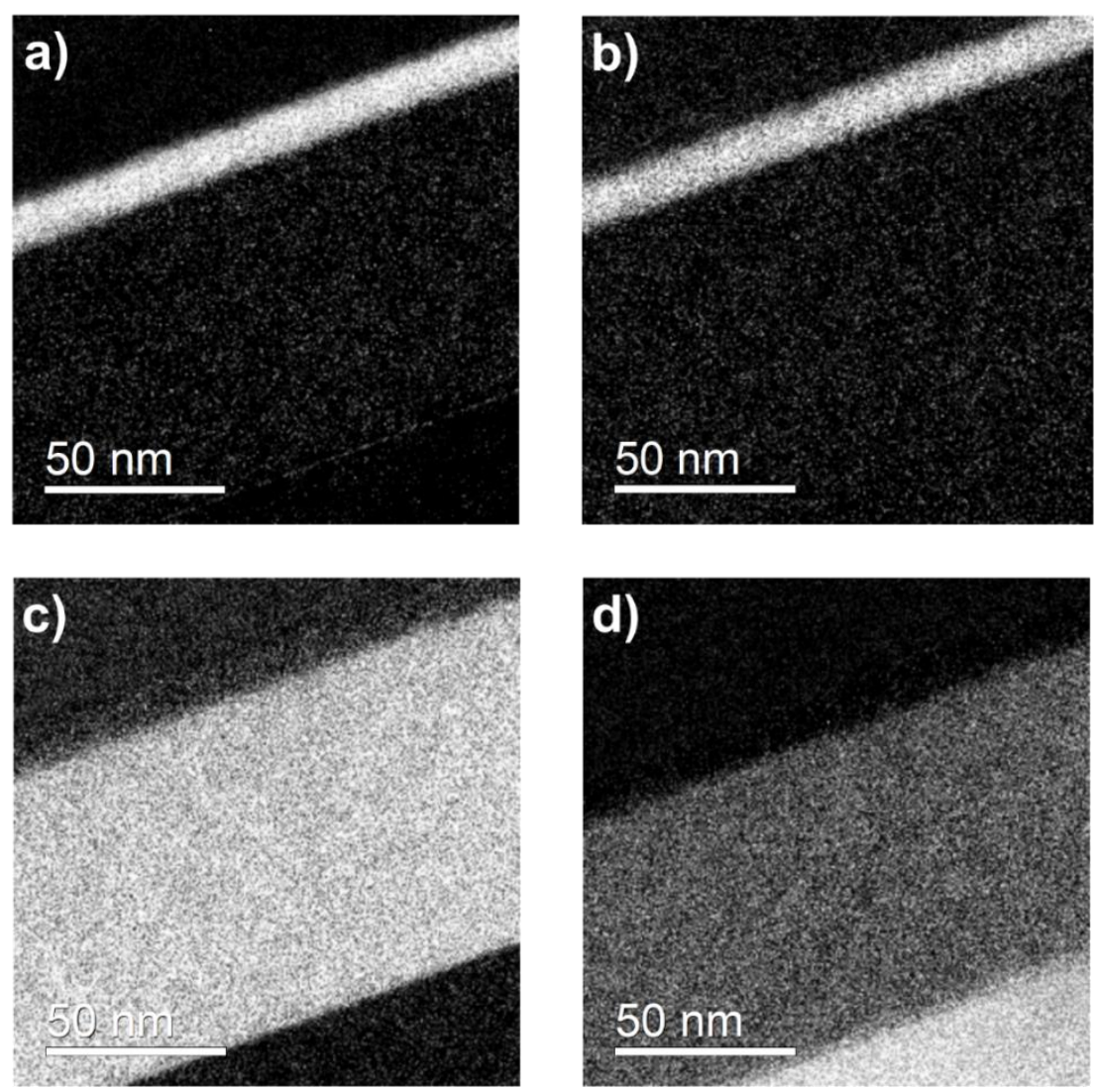

Figure 4-11. EFTEM element-maps of the plasma-deposited BN sample of Figure 4-10: (a) boron, (b) nitrogen, (c) oxygen and $(\boldsymbol{d})$ silicon.

GIXRD analysis of the plasma-deposited film of Figure 4-10 confirmed the occurrence of an h-BN phase in that film. The diffraction-peak positions in Figure 4-12 coincide well with the values reported for h-BN 38 . Fitting the mass density by XRR revealed $1.82 \mathrm{~g} / \mathrm{cm}^{3}$ - close to $1.89 \mathrm{~g} / \mathrm{cm}^{3}$ reported for h-BN films ${ }^{39}$. 


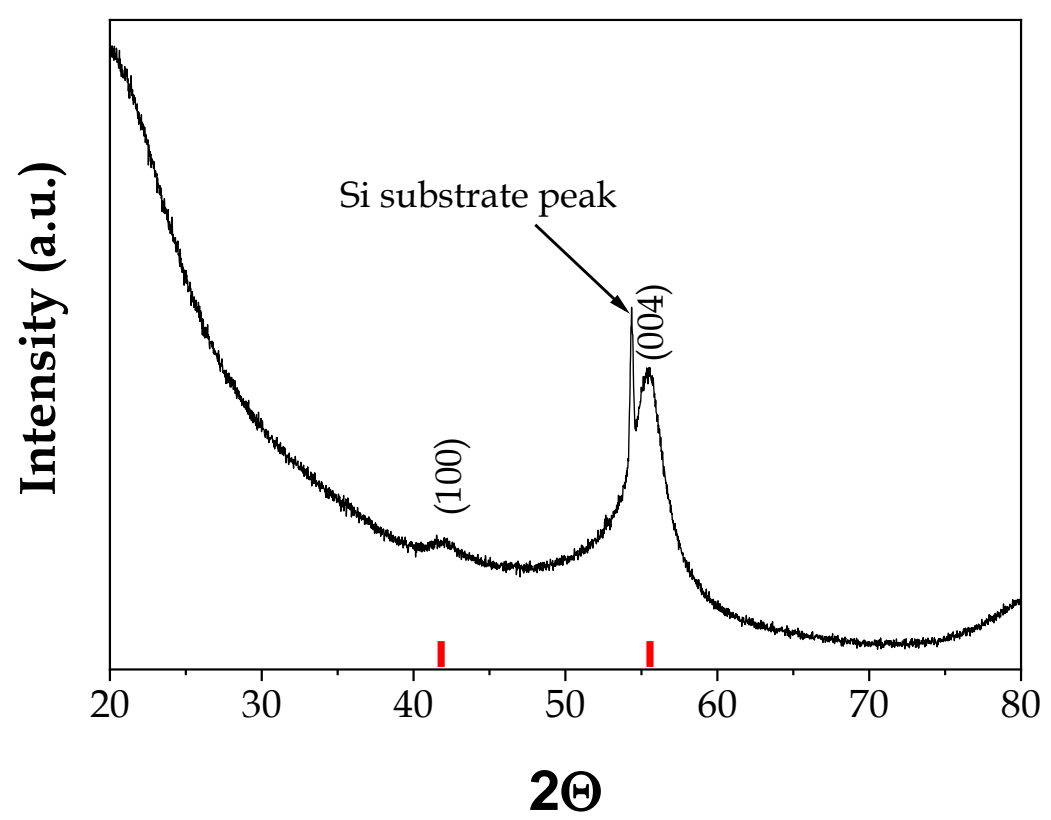

Figure 4-12. GIXRD pattern of the plasma-deposited BN sample of Figure 4-10. Miller indices are given in the image. The peaks coincide well with the corresponding positions (indicated by vertical red bars) reported for $h-B N{ }^{38}$.

\subsection{Suggested deposition mechanisms}

The demonstrated dependence of both GPC and pure-B share on $P_{\text {tot }}$ (recall Figure 4-4) allows to hypothesize the so-called surface-adduct pathway (see Section 2.3) for the formation of $\mathrm{BN}$ layers from $\mathrm{B}_{2} \mathrm{H}_{6}$ and $\mathrm{NH}_{3}$ at high pressures.

\subsubsection{Surface-adduct pathway for purely thermal deposition}

$\mathrm{B}_{2} \mathrm{H}_{6}$ and $\mathrm{BH}_{3}$ gases are Lewis acids ${ }^{40,41}$ whereas $\mathrm{NH}_{3}$ is a Lewis base ${ }^{42}$. Such acids and bases can readily react and form corresponding adducts. The basics of the adduct formation were already given in Chapter 2 .

We start with an overview of previous reports, among others by Carpenter et.al. ${ }^{43}$, Gómez- Aleixandre et.al. ${ }^{44}$, Rand et.al. ${ }^{45}$ and Gerry et.al. ${ }^{46}$. The essential reactions between diborane and ammonia are summarized elsewhere ${ }^{47}$. It should be noted that the formation of a gas phase $\mathrm{H}_{6} \mathrm{~B}_{2}: \mathrm{NH}_{3}$ adduct from $\mathrm{B}_{2} \mathrm{H}_{6}$ and $\mathrm{NH}_{3}$ has been suggested to be the most energetically favorable reaction, based on the calculations performed by Nguyen et.al. ${ }^{48}$. Further, through a subsequent release 
of $\mathrm{H}_{2}$ and $\mathrm{BH}_{3}$, first $\mathrm{H}_{2} \mathrm{~B}=\mathrm{NH}_{2}$ and then $\mathrm{HB}=\mathrm{NH}$ species can be produced. As the reaction temperature increases, the adduct complex progressively loses hydrogen and, at temperatures above $500{ }^{\circ} \mathrm{C}$, boron nitride can finally be obtained 43-46,49-51. Gómez-Aleixandre et.al. ${ }^{4}$ showed that, as a result of the limited (partial) dissociation of ammonia at temperatures lower than $850{ }^{\circ} \mathrm{C}$, the interaction between diborane and ammonia, leading to $\mathrm{BN}$, is strongly temperature dependent.

The gas-phase decomposition of $\mathrm{B}_{2} \mathrm{H}_{6}$ was studied by many researchers ${ }^{52-}$ 58,59 . On a surface, $\mathrm{B}_{2} \mathrm{H}_{6}$ is known to cause non-self-limiting formation of solid boron 17,59-61. The studies of Fehlner ${ }^{62-65}$, Mappes ${ }^{66}$, and Sarubbi et.al. ${ }^{67}$ suggested $\mathrm{BH}_{3}$ species to dominate in the gas phase. Mohammedi et.al. ${ }^{17}$ proposed a growth model based on chemisorption of $\mathrm{BH}_{3}$ and the subsequent elimination of $\mathrm{H}_{2}$. A similar mechanism for the interaction of $\mathrm{B}_{2} \mathrm{H}_{6}$ with silicon oxide surfaces has been proposed by Gillis-D'Hamers 68,69. The authors showed that, upon the chemisorption, diborane forms $\mathrm{BH}$ - or $\mathrm{BH}_{2}$-terminated surface sites. To simplify the reaction schematic in our case, we only draw BH-terminations in Figure 4-13.

Thus, the initial step in thermal deposition of $\mathrm{BN}$ from $\mathrm{B}_{2} \mathrm{H}_{6}$ and $\mathrm{NH}_{3}$ is likely the decomposition of $\mathrm{B}_{2} \mathrm{H}_{6}$ (in gas phase or on the surface), forming $\mathrm{BH}$ terminations accompanied by a release of $\mathrm{H}_{2}$. In the next step, we hypothesize the $\mathrm{NH}_{3}$ adsorption and the occurrence of a surface adduct, analogous to the known 70 gas-phase $\mathrm{H}_{3} \mathrm{~B}: \mathrm{NH}_{3}$ adduct. This and the following steps are proposed to occur similarly to the formation of AlN and GaN films (see Chapter 2). Further, a reaction of the adduct- $\mathrm{NH}_{3}$ with hydrogen of a neighboring - $\mathrm{BH}$ termination occurs, releasing $\mathrm{H}_{2}$ (Figure 4-13.a). This forms $-\mathrm{NH}_{2}$ - bridges between neighboring $\mathrm{B}$ atoms (i.e., B-NH2-B linkages), analogous to Al-NH $2-A l$ linkages in AlN ALD ${ }^{71}$. Such B- $\mathrm{NH}_{2}-\mathrm{B}$ linkages laterally expand over the entire growth surface in a selflimiting fashion. Exposure to $\mathrm{B}_{2} \mathrm{H}_{6}$ during the subsequent precursor pulse restores the required $\mathrm{BH}$-terminations (not a self-limiting process), again with releasing $\mathrm{H}_{2}$. It should be noted that direct thermal nitridation of a pure-B phase is thermodynamically inhibited at temperatures below $900{ }^{\circ} \mathrm{C} 72$. However, via the 
proposed adduct-assisted pathway, nitrogen can still be effectively incorporated at much lower temperatures.

a) Thermal: reacting species $-\mathrm{NH}_{3}$

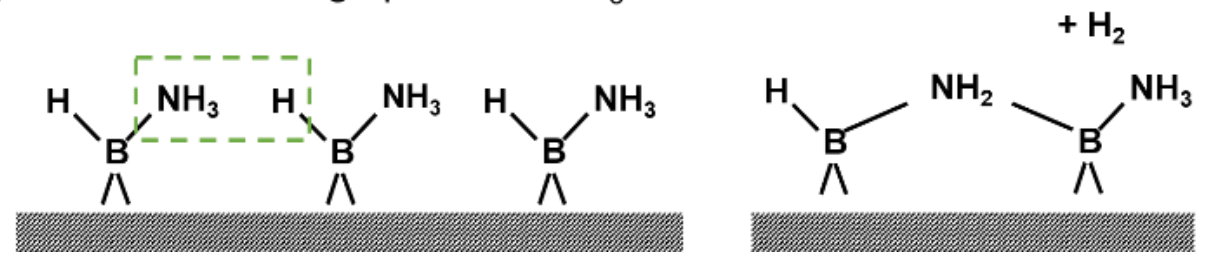

b) Plasma: reacting species $-\mathrm{NH}_{3}, \mathrm{NH}_{2}, \mathrm{NH}, \mathrm{N}$ and $\mathbf{H}$

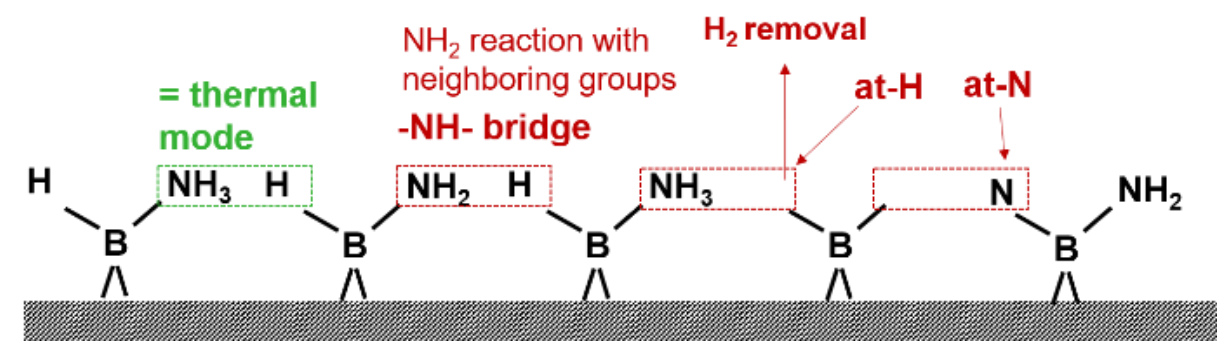

Figure 4-13. Proposed schematic of $B N$ formation from $\mathrm{B}_{2} \mathrm{H}_{6}$ and $\mathrm{NH}_{3}$. (a) In thermal mode: via the formation of a surface adduct and then its conversion into $B-\mathrm{NH}_{2}-\mathrm{B}$ linkages. (b) In radical-enhanced mode (HW or plasma): via additional removal of surface species by atomic hydrogen (at- $H)$ and involvement of $\mathrm{NH}_{x}(x=1-2)$ radicals, as well as via direct nitridation by atomic nitrogen (for plasma only).

\subsubsection{A comparison of pure-thermal and radical-enhanced modes}

Applying radical-enhanced methods (HW or plasma) is expected to alter the growth mechanism. The dissociation of $\mathrm{NH}_{3}$ into $\mathrm{NH}_{\mathrm{x}}(\mathrm{x}=0-2)$ radicals $18,73-75$ and at-H may facilitate alternative chemical routes and thus suppress the adductassisted pathway. First, the generated at- $\mathrm{H}$ can remove hydrogen of the $\mathrm{BH}-$ terminations (so-called hydrogen abstraction 76,77 ), thereby decreasing the number of H-B surface sites required to maintain the adduct-assisted mechanism (Figure 4-13.b). On the other hand, the presence of reactive $\mathrm{NH}_{\mathrm{x}}$ radicals in sufficient quantities can still support the formation of $\mathrm{B}-\mathrm{NH}_{2}-\mathrm{B}$ and/or B-NH-B linkages. Atomic nitrogen can further directly nitridize elemental boron. For optimized process conditions, radical-enhanced methods increase the nitrogen-share (see Sections 4.3.2 and 4.3.3), still having diborane chemisorption as the rate limiting step. On the other hand, non-optimized conditions may lead to a lower GPC (see 
Figure 4-5) and an increased B-share. The latter is due to a decreased efficiency of nitrogen incorporation via the surface-adduct mechanism, as schematically shown in Figure 4-13.b. A deficiency of $\mathrm{NH}_{x}$ radicals at the growth surface, for example due to a low-power radical source or because of their recombination on the way to the substrate 18 , results in boron rich samples. Our experiments show that the highest degree of nitrogen incorporation is provided by plasma-assisted growth; this gives near-stoichiometric, crystalline and air-stable BN films at a substrate temperature of $310^{\circ} \mathrm{C}$.

\subsection{Conclusions}

This chapter studied the formation of $\mathrm{B} / \mathrm{BN}$ composites using purely thermal, hot-wire- and plasma-assisted deposition methods by sequentially pulsing $\mathrm{B}_{2} \mathrm{H}_{6}$ and $\mathrm{NH}_{3}$ precursors. It has been demonstrated that, in purely thermal mode, increasing the total gas pressure considerably enhances the GPC, incorporating a bigger share of nitrogen in the layers and thereby reducing the pure-B content from $\sim 70$ vol. $\%$ to $6-7$ vol. \%. However, a further decrease of the pure-B share, to obtain a stoichiometric $\mathrm{BN}$ in thermal mode, is challenging. To improve both stoichiometry and crystallinity, HW- and plasma-assisted methods have been explored. Utilizing the HW had a clear effect on both GPC and film composition, although the concentration of $\mathrm{NH}_{2}$ radicals was not sufficiently high to strongly decrease the pure-B share. Switching to plasma provided nearstoichiometric, crystalline and air-stable BN films at just $310{ }^{\circ} \mathrm{C}$.

Concerning the growth mechanism in purely thermal mode, we hypothesized a surface-adduct-assisted reaction pathway, analogous to the earlier suggested surface-adduct mechanisms for growing AlN and GaN by thermal ALD at low temperatures. Namely, BH-terminated surface sites react with $\mathrm{NH}_{3}$, forming surface adducts. The adduct- $\mathrm{NH}_{3}$ consequently reacts with hydrogen of a neighboring $\mathrm{BH}$-termination, forming $\mathrm{B}-\mathrm{NH}_{2}-\mathrm{B}$ linkages and releasing $\mathrm{H}_{2}$. A subsequent $\mathrm{B}_{2} \mathrm{H}_{6}$ pulse restores the original $\mathrm{BH}$-terminations, once more eliminating $\mathrm{H}_{2}$. The adduct-assisted pathway is proposed to enable effective 
incorporation of nitrogen into BN films at low temperatures. Applying HW or plasma may provide additional reaction pathways and alter the growth mechanism. 


\section{References}

1 S. Nakhaie, J.M. Wofford, T. Schumann, U. Jahn, M. Ramsteiner, M. Hanke, J.M.J. Lopes, and H. Riechert, Appl. Phys. Lett. 106, 213108 (2015).

2 T.Q.P. Vuong, G. Cassabois, P. Valvin, E. Rousseau, A. Summerfield, C.J. Mellor, Y. Cho, T.S. Cheng, J.D. Albar, L. Eaves, C.T. Foxon, P.H. Beton, S. V. Novikov, and B. Gil, 2D Mater. 4, 021023 (2017).

${ }^{3}$ J. Ying, X.W. Zhang, Y.M. Fan, H.R. Tan, and Z.G. Yin, Diam. Relat. Mater. 19, $1371(2010)$.

${ }^{4}$ C. Ronning, A.D. Banks, B.L. McCarson, R. Schlesser, Z. Sitar, R.F. Davis, B.L. Ward, and R.J. Nemanich, J. Appl. Phys. 84, 5046 (1998).

${ }^{5}$ Y. Panayiotatos, S. Logothetidis, A. Laskarakis, A. Zervopoulou, and M. Gioti, Diam. Relat. Mater. 11, 1281 (2002).

6 S. Kotake, T. Hasegawa, K. Kamiya, Y. Suzuki, T. Masui, Y. Kangawa, K. Nakamura, and T. Ito, Appl. Surf. Sci. 216, 72 (2003).

${ }^{7}$ M. Xie, J. Wang, and Y.K. Yap, J. Phys. Chem. C 114, 16236 (2010).

8 S.K. Jang, J. Youn, Y.J. Song, and S. Lee, Sci. Rep. 6, 30449 (2016).

9 Y. Shi, C. Hamsen, X. Jia, K.K. Kim, A. Reina, M. Hofmann, A.L. Hsu, K. Zhang, H. Li, Z.-Y. Juang, M.S. Dresselhaus, L.-J. Li, and J. Kong, Nano Lett. 10, 4134 (2010).

10 K.K. Kim, A. Hsu, X. Jia, S.M. Kim, Y. Shi, M. Hofmann, D. Nezich, J.F. Rodriguez-Nieva, M. Dresselhaus, T. Palacios, and J. Kong, Nano Lett. 12, 161 (2012).

11 N.R. Glavin, C. Muratore, M.L. Jespersen, J. Hu, P.T. Hagerty, A.M. Hilton, A.T. Blake, C.A. Grabowski, M.F. Durstock, M.E. McConney, D.M. Hilgefort, T.S. Fisher, and A.A. Voevodin, Adv. Funct. Mater. 26, 2640 (2016).

12 K.H. Lee, H.-J. Shin, J. Lee, I. Lee, G.-H. Kim, J.-Y. Choi, and S.-W. Kim, Nano Lett. 12, 714 (2012).

13 J.L. Andújar, E. Bertran, and M.C. Polo, J. Vac. Sci. Technol. A Vacuum, Surfaces, Film. 16, 578 (1998).

14 C. Gómez-Aleixandre, A. Essafti, M. Fernández, J.L.G. Fierro, and J.M. Albella, J. Phys. Chem. 100, 2148 (1996).

15 A. Ismach, H. Chou, D.A. Ferrer, Y. Wu, S. McDonnell, H.C. Floresca, A. Covacevich, C. Pope, R. Piner, M.J. Kim, R.M. Wallace, L. Colombo, and R.S. Ruoff, ACS Nano 6, 6378 (2012).

${ }^{16}$ H. Fujiwara, Spectroscopic Ellipsometry: Principles and Applications (John Wiley \& Sons Ltd, 2007).

17 V. Mohammadi, W.B. de Boer, and L.K. Nanver, Appl. Phys. Lett. 101, 111906 (2012). 
${ }^{18}$ H. Umemoto, K. Ohara, D. Morita, T. Morimoto, M. Yamawaki, A. Masuda, and H. Matsumura, Jpn. J. Appl. Phys. 42, 5315 (2003).

19 G. Yuan, H. Shimizu, T. Momose, and Y. Shimogaki, J. Vac. Sci. Technol. A Vacuum, Surfaces, Film. 32, 01A104 (2014).

20 A.Y. Kovalgin, M. Yang, S. Banerjee, R.O. Apaydin, A.A.I. Aarnink, S. Kinge, and R.A.M. Wolters, Adv. Mater. Interfaces 4, 1700058 (2017).

21 T. Ichiki and T. Yoshida, Appl. Phys. Lett. 64, 851 (1994).

22 L. Chen, T. Goto, T. Hirai, and T. Amano, J. Mater. Sci. Lett. 9, 997 (1990).

${ }^{23}$ L. Ci, L. Song, C. Jin, D. Jariwala, D. Wu, Y. Li, A. Srivastava, Z.F. Wang, K. Storr, L. Balicas, F. Liu, and P.M. Ajayan, Nat. Mater. 9, 430 (2010).

${ }^{24}$ M. Belyansky, M. Trenary, and C. Ellison, Surf. Sci. Spectra 3, 147 (1994).

${ }^{25}$ C. Kimura, H. Sota, H. Aoki, and T. Sugino, Diam. Relat. Mater. 18, 478 (2009).

${ }^{26}$ G.R. Bhimanapati, N.R. Glavin, and J.A. Robinson, in Semicond. Semimetals, edited by C.J. Francesca Iacopi, John J. Boeckl (Elsevier Ltd, 2016), pp. 101-147.

27 O. Cometto, B. Sun, S.H. Tsang, X. Huang, Y.K. Koh, and E.H.T. Teo, Nanoscale 7, 18984 (2015).

28 J. Wang, F. Ma, and M. Sun, RSC Adv. 7, 16801 (2017).

29 S.M. Kim, A. Hsu, M.H. Park, S.H. Chae, S.J. Yun, J.S. Lee, D.-H. Cho, W. Fang, C. Lee, T. Palacios, M. Dresselhaus, K.K. Kim, Y.H. Lee, and J. Kong, Nat. Commun. 6, 8662 (2015).

30 C.A. Schneider, W.S. Rasband, and K.W. Eliceiri, Nat. Methods 9, 671 (2012).

31 P. Carl, Radial profile extended, plugin to ImageJ, (2017).

32 R.W.G. Wyckoff, Crystal Structures Vol. 1, 2nd ed. (Interscience Publishers, New York, 1963).

33 Y.-N. Xu and W.Y. Ching, Phys. Rev. B 48, 4335 (1993).

34 P. Ahmad, M.U. Khandaker, N. Muhammad, F. Rehman, G. Khan, M.A. Rehman, S.M. Ahmed, M. Gulzar, A. Numan, and A.S. Khan, Ceram. Int. 43, 7358 (2017).

35 S. Chen, P. Li, S. Xu, X. Pan, Q. Fu, and X. Bao, J. Mater. Chem. A 6, 1832 (2018).

36 M. Cabello, X. Bai, T. Chyrka, G.F. Ortiz, P. Lavela, R. Alcántara, and J.L. Tirado, J. Electrochem. Soc. 164, A3804 (2017).

37 L. Zhechkov, Simulations of the Hydrogen Storage Capacities of Carbon Materials, TU Dresden, 2007.

38 S. Yuan, S. Linas, C. Journet, P. Steyer, V. Garnier, G. Bonnefont, A. Brioude, and B. Toury, Sci. Rep. 6, 20388 (2016).

${ }^{39}$ S. V. Nguyen, J. Electrochem. Soc. 141, 1633 (1994). 
40 Y. Katsuma, L. Wu, Z. Lin, S. Akiyama, and M. Yamashita, Angew. Chemie 131, 323 (2019).

41 R.H. Petrucci, F.G. Herring, J.D. Madura, and C. Bissonnette, General Chemistry Principles and Modern Applications, 11th ed. (Pearson Canada Inc., 2017).

42 S. Sakai, J. Phys. Chem. 99, 9080 (1995).

43 J.D. Carpenter and B.S. Ault, J. Phys. Chem. 96, 7913 (1992).

${ }^{44}$ C. Gomez-Aleixandre, D. Diaz, F. Orgaz, and J.M. Albella, J. Phys. Chem. 97, 11043 (1993).

${ }^{45}$ M.J. Rand and J.F. Roberts, J. Electrochem. Soc. 115, 423 (1968).

46 M.C.L. Gerry, W. Lewis-Bevan, A.J. Merer, and N.P.C. Westwood, J. Mol. Spectrosc. 110, 153 (1985).

47 D. Franz, M. Hollenstein, and C. Hollenstein, Thin Solid Films 379, 37 (2000).

48 V.S. Nguyen, M.H. Matus, M.T. Nguyen, and D.A. Dixon, J. Phys. Chem. A 112, 9946 (2008).

${ }^{49}$ S. Frueh, R. Kellett, C. Mallery, T. Molter, W.S. Willis, C. King' ondu, and S.L. Suib, Inorg. Chem. 50, 783 (2011).

50 M.G. Hu, R.A. Geanangel, and W.W. Wendlandt, Thermochim. Acta 23, 249 (1978).

51 V.I. Simagina, N.V. Vernikovskaya, O.V. Komova, N.L. Kayl, O.V. Netskina, and G.V. Odegova, Chem. Eng. J. 329, 156 (2017).

52 L.H. Long, J. Inorg. Nucl. Chem. 32, 1097 (1970).

53 N.N. Greenwood and R. Greatrex, Pure Appl. Chem. 59, 857 (1987).

54 N.N. Greenwood, Chem. Soc. Rev. 21, 49 (1992).

55 A.B. Baylis, G.A. Pressley, E.J. Sinke, and F.E. Stafford, J. Am. Chem. Soc. 86, 5358 (1964).

56 L. V. McCarty and P.A. Di Giorgio, J. Am. Chem. Soc. 73, 3138 (1951).

57 S.A. Fridmann and T.P. Fehlner, Inorg. Chem. 11, 936 (1972).

58 T.P. Fehlner and S.A. Fridmann, J. Am. Chem. Soc. 93, 2824 (1971).

${ }^{59}$ H. Habuka, S. Akiyama, T. Otsuka, and W.F. Qu, J. Cryst. Growth 209, 807 (2000).

60 V. Mohammadi, N. Golshani, K.R.C. Mok, W.B. de Boer, J. Derakhshandeh, and L.K. Nanver, Microelectron. Eng. 125, 45 (2014).

${ }^{61}$ M.L. Yu, D.J. Vitkavage, and B.S. Meyerson, J. Appl. Phys. 59, 4032 (1986).

62 T.P. Fehlner and W.S. Koski, J. Am. Chem. Soc. 86, 2733 (1964).

63 T.P. Fehlner, J. Am. Chem. Soc. 87, 4200 (1965).

64 T.P. Fehlner and G.W. Mappes, J. Phys. Chem. 73, 873 (1969). 
65 T.P. Fehlner and S.A. Fridmann, Inorg. Chem. 9, 2288 (1970).

66 A.B. Baylis, G.A. Pressley, and F.E. Stafford, J. Am. Chem. Soc. 88, 2428 (1966).

67 F. Sarubbi, T.L.M. Scholtes, and L.K. Nanver, J. Electron. Mater. 39, 162 (2010).

68 I. Gillis-D’Hamers, K.C. Vrancken, P. Van Der Voort, E.F. Vansant, and G. De Roy, J. Chem. Soc. Faraday Trans. 88, 1459 (1992).

69 I. Gillis-D'Hamers, P. Van Der Voort, K.C. Vrancken, G. De Roy, and E.F. Vansant, J. Chem. Soc. Faraday Trans. 88, 65 (1992).

70 J.D. Carpenter and B.S. Ault, J. Phys. Chem. 95, 3507 (1991).

${ }^{71}$ M.E. Bartram, T.A. Michalske, J.W. Rogers, and R.T. Paine, Chem. Mater. 5, 1424 (1993).

72 F. Ye, L. Zhang, Y. Liu, S. Li, M. Su, X. Yin, and L. Cheng, Prog. Nat. Sci. Mater. Int. 22, 433 (2012).

73 Y.J. Shi, B.D. Eustergerling, and X.M. Li, Thin Solid Films 516, 506 (2008).

74 R. D'Agostino, F. Cramarossa, S. De Benedictis, and G. Ferraro, Plasma Chem. Plasma Process. 1, 19 (1981).

75 G.P. Miller and J.K. Baird, J. Phys. Chem. 97, 10984 (1993).

76 S. Agarwal, A. Takano, M.C.M. van de Sanden, D. Maroudas, and E.S. Aydil, J. Chem. Phys. 117, 10805 (2002).

77 H.A. Kazmi and D.J. Le Roy, Can. J. Chem. 42, 1145 (1964). 


\title{
$5 \underline{\text { Thermal deposition of } \mathrm{BN} \text { from } \mathrm{BBr}_{3} \text { and } \mathrm{NH}_{3}}$
}

\begin{abstract}
In this chapter thermal deposition of boron nitride thin films by sequential introduction of boron tribromide $\left(\mathrm{BBr}_{3}\right)$ and ammonia $\left(\mathrm{NH}_{3}\right)$ precursors with an Ar purge in between is investigated.

We further continue exploring the role of the surface adducts (see also Chapter 4) and thus hypothesize the existence of an analogous $\mathrm{BBr} 3: \mathrm{NH}_{3}$ surface adduct which facilitates the growth of $B N$ layers. The reaction kinetics is simulated using a Mathcad code. The results are in agreement with the assumption that the adduct surface coverage may depend on the ammonia partial pressure $\left(P_{\mathrm{NH} 3}\right)$ in the reactor, assuming the reaction to occur in equilibrium. In accordance with the expectations, the growth per cycle (GPC) exhibit a reasonable dependence on $P_{N H 3}$ : the GPC increases at least by factor 2 in the $P_{N H 3}$ range studied. The SE analysis reveals the refractive index (n) similar to that reported for $a-B N$ and $h-B N$. The XPS results indicate stoichiometric $B N$ films with $O$ contamination less than 5 at.\%; the films are however found to be environmentally instable. The GIXRD results reveal nanocrystalline structure of the films.
\end{abstract}




\subsection{Introduction}

This chapter discusses the growth of boron nitride (BN) layers by a sequential introduction of boron tribromide $\left(\mathrm{BBr}_{3}\right)$ and ammonia $\left(\mathrm{NH}_{3}\right)$ precursors, with Ar-purges in between, in thermal ALD mode. We show that BN growth can take place with reasonably high $(\sim 0.08 \mathrm{~nm} /$ cycle $)$ growth per cycle (GPC) values. The suggested mechanism relies on the speculated existence of a $\mathrm{BBr} 3: \mathrm{NH}_{3}$ surface adduct and its conversion into BN. The formation of the surface adduct is enhanced by the partial pressure of $\mathrm{NH}_{3}\left(P_{\mathrm{NH} 3}\right)$, directly affecting the GPC.

Section 5.2 reviews the previously reported surface reactions in relation to BN growth. Section 5.3 proposes the BN growth model, based on a similar model reported in the literature, as explained in Sections 2.3 and 5.2. Section 5.4 deals with the expected reaction kinetics of BN growth. Section 5.5 reports the experimental results, in line with the proposed deposition mechanism. Section 5.6 concludes this chapter.

\subsection{Surface reactions in relation to $\mathrm{BN}$ growth}

Various gas-phase and surface reactions (including the adduct formation) in relation to ALD of aluminum nitride $(\mathrm{AlN})$ and gallium nitride $(\mathrm{GaN})$ films have been discussed in Chapter 2. Here, we extend that knowledge towards a possible formation of halide-based adducts with boron included. Boron trihalides $\left(B X_{3}, X=\right.$ $\mathrm{Br}, \mathrm{Cl}, \mathrm{F})$ are known to be typical Lewis acids. These halides show a strong affinity for sharing a pair of electrons with Lewis bases, such as $\mathrm{NH}_{3}$, to satisfy the octet rule ${ }^{1}$. In this way, stable donor-acceptor complexes having a B-N bond can be formed. Such boron halide complexes have been investigated in both experimental 2-11 and theoretical works ${ }^{12-19}$. The studies showed that, once introduced into the system, boron halides react with Lewis bases to form adducts. This may suggest a similar growth mechanism as reported for AIN and GaN ALD. 
Gas phase adducts of boron halides were experimentally observed by many researchers, see for example Refs. ${ }^{2-4,6}$. In addition, theoretical studies have been performed in order to obtain understanding of the gas phase reactions. Reinhardt et.al. 12,13 suggested the formation of a gas phase adduct (reaction 5.1), that decomposes to aminodichloroborane (reaction 5.2) by the elimination of hydrogen chloride $(\mathrm{HCl})$. One should keep in mind that $\mathrm{HCl}$ can react with available $\mathrm{NH}_{3}$ molecules and form $\mathrm{NH}_{4} \mathrm{Cl}$ 8,9,20.

$$
\begin{array}{ll}
\mathrm{BCl}_{3}+\mathrm{NH}_{3} \leftrightarrow \mathrm{BCl}_{3}: \mathrm{NH}_{3} & \text { (reaction 5.1) } \\
\mathrm{BCl}_{3}: \mathrm{NH}_{3} \leftrightarrow \mathrm{BCl}_{2} \mathrm{NH}_{2}+\mathrm{HCl} & \text { (reaction 5.2) }
\end{array}
$$

Possemiers et.al. 8,9,21 further studied the reactions between $\mathrm{BCl}_{3}$ and $\mathrm{NH}_{3}$ on silica surfaces. In their studies, they introduced $\mathrm{BCl}_{3}$ and $\mathrm{NH}_{3}$ gases onto silica surfaces in a sequential manner, preventing gas phase reactions. They reported that $\mathrm{NH}_{3}$ exposure on the $\mathrm{BCl}_{3}$ pre-treated surface results in an increased $\mathrm{NH}_{3}$ sorption capacity of the surface. Upon sorption, surface boron species react with $\mathrm{NH}_{3}$, forming chemisorbed $=\mathrm{BNH}_{2}$ groups and $\mathrm{NH}_{4} \mathrm{Cl}$ (sublimes above $100{ }^{\circ} \mathrm{C}$ ). Above $200^{\circ} \mathrm{C}$, secondary amines $(=\mathrm{B}-\mathrm{NH}-\mathrm{B}=)$ ) are being formed via a consecutive reaction mechanism, completely covering the surface at $300{ }^{\circ} \mathrm{C}$. Subsequent introduction of precursors results in a cross-linked borazine-like B-N polymeric structure, which finally forms $\mathrm{BN}$ with $\mathrm{NH}_{4} \mathrm{Cl}$ released as the reaction by-product. The main reactions of the $\mathrm{BCl}_{3}$-treated surface with ammonia are summarized below:

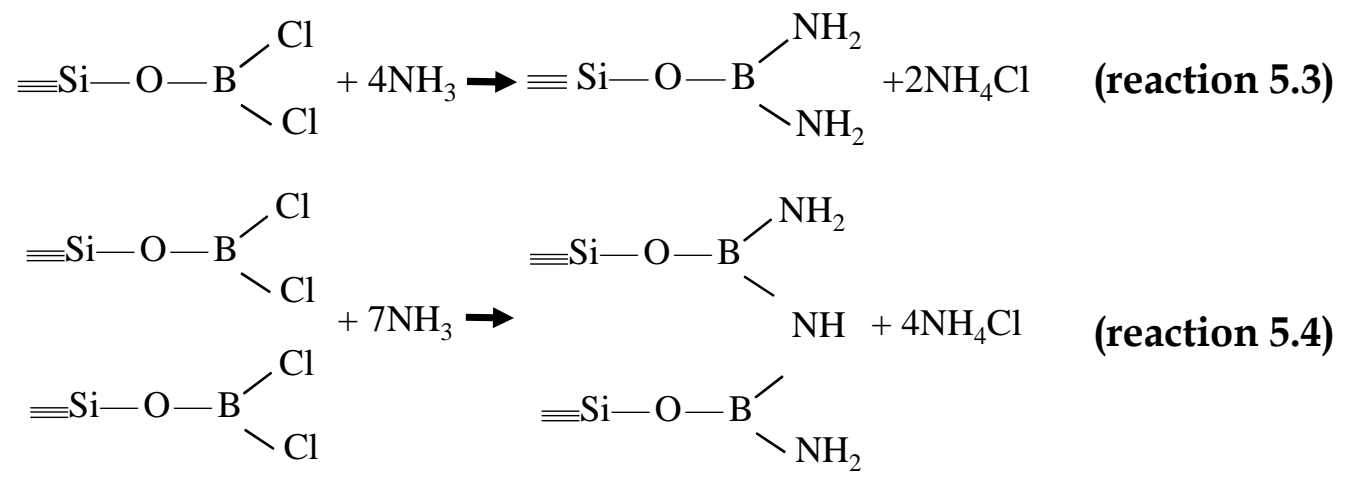

Formation of the compounds reported by Possemiers et al. was also studied by George et al. ${ }^{10}$. They investigated the formation of BN on zirconium dioxide $\left(\mathrm{ZrO}_{2}\right)$ particles by sequential exposures to $\mathrm{BCl}_{3}$ and $\mathrm{NH}_{3}$. Upon the delivery of 
$\mathrm{NH}_{3}$ molecules onto the $\mathrm{BCl}_{3}$-treated surface, absorption bands attributed to $\mathrm{BNH}_{2}$ and $-\mathrm{B}_{2} \mathrm{NH}$ surface species were observed by Fourier transform infrared spectroscopy (FTIR), indicating the $-\mathrm{NH}_{2}$ - bridge formation analogous to that reported for AlN growth ${ }^{22}$.

As can be deduced from the above-mentioned studies, BN deposition reactions proceed in a similar manner compared to the reactions reported for AIN ALD $^{22}$ (recall Figure 2-2).

\subsection{Proposed BN growth mechanisms}

\subsubsection{Thermal-BN deposition via surface adduct pathway}

Based on the known mechanisms of AlN ALD ${ }^{22}$, Banerjee et.al. ${ }^{23}$ recently hypothesized a similar mechanism for GaN ALD. In this work, we further extend the mechanism to $\mathrm{BN}$ growth from $\mathrm{BBr}_{3}$ and $\mathrm{NH}_{3}$. Namely, the $\mathrm{BN}$ growth is proposed to occur in two stages (see Figure 5-1): (i) formation of a $\mathrm{BBr}_{3}: \mathrm{NH}_{3}$ 'surface adduct' complex (reversible or irreversible), and (ii) conversion of this complex into B-NH $2-\mathrm{B}$ linkage (irreversible), resulting in a unit of BN. From this model, the GPC is expected to depend on $\mathrm{NH}_{3}$ partial pressure $\left(P_{\mathrm{NH}}\right)$ and $\mathrm{NH}_{3}$ pulse time $\left(t_{N H 3}\right)$. The latter is usually the case, but the former is not typical for ALD. If the surface adduct formation is reversible, a higher $P_{N H 3}$ increases the surface density of the adduct by shifting the equilibrium in the direction of adduct formation. This further leads to enhancing the $\mathrm{B}-\mathrm{NH}_{2}-\mathrm{B}$ linkage formation, thereby increasing the GPC. The formation of BN units will proceed until bridging all neighboring sites via $-\mathrm{NH}_{2}$ - linkages is complete, provided that a sufficient amount of $\mathrm{NH}_{3}$ is present in the reactor. 


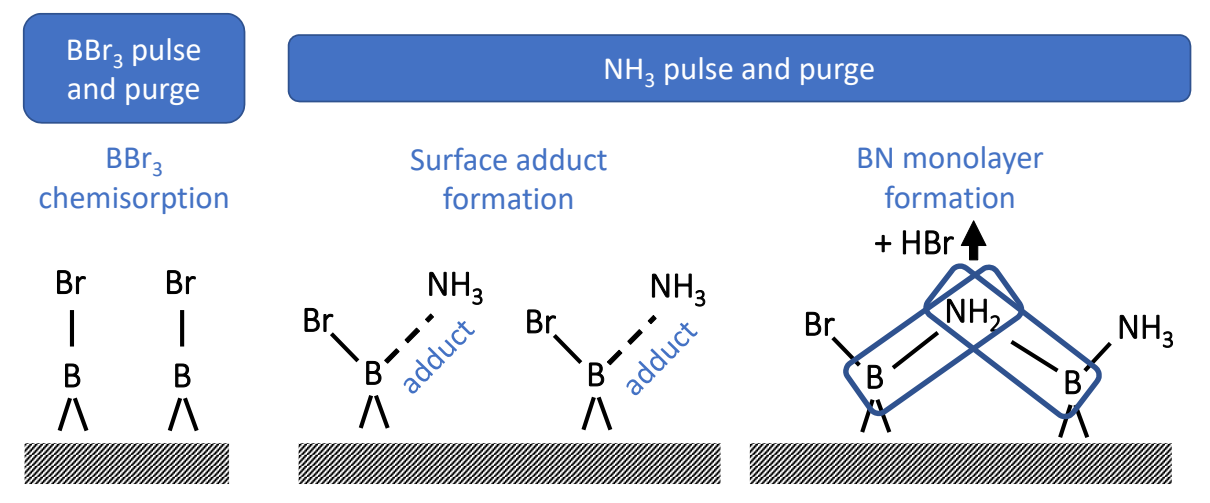

Figure 5-1. Proposed mechanism of BN growth by two-step reaction. First, formation of surface adducts; second conversion of the adducts into $\mathrm{B}-\mathrm{NH}_{2}-\mathrm{B}$ linkages. Although the chemisorption of $B B r_{3}$ can result in a variety of $B B r_{x}(x=1-3)$ surface species, here, for simplicity, we limit that to $B-B r$ terminated surface only. The exact nature of the $\mathrm{BBr}_{3}$ chemisorption is beyond the scope of this work.

\subsection{Modeling the thermal-BN growth}

The first step in the proposed mechanism, i.e., the $\mathrm{BBr}_{3}: \mathrm{NH}_{3}$ surface-adduct formation, is assumed to be reversible. This is analogous to the reversible formation of the $\mathrm{BCl}_{3}: \mathrm{NH}_{3}$ gas-phase adduct known from the literature ${ }^{24}$. Briefly, Kapralova et. al. ${ }^{24}$ reported pressure dependent reaction rates for the $\mathrm{BCl}_{3}-\mathrm{NH}_{3}$ system $\left(\right.$ at $\left.72{ }^{\circ} \mathrm{C}\right)$ and attributed a decrease of the reaction rate of $\mathrm{HCl}$ elimination, in a certain pressure range, to the reversible adduct formation. Reinhardt et.al. 12,13 theoretically investigated the $\mathrm{BCl}_{3}-\mathrm{NH}_{3}$ reactions and showed that the adduct formation is an exothermic reaction yielding approximately $25 \mathrm{kcal} / \mathrm{mol}$ energy. Since first $\mathrm{HCl}$ release requires just a bit higher energy of $\sim 32 \mathrm{kcal} / \mathrm{mol}$, the adduct may start decomposing by releasing $\mathrm{HCl}$ and thus yielding $\mathrm{Cl}_{2} \mathrm{BNH}_{2}$. Kingsmill et.al. ${ }^{25}$ reported that the $\mathrm{BBr}_{3}: \mathrm{NH}_{3}$ adduct occurs already at room temperature; however, the removal of first $\mathrm{HBr}$ molecule requires a temperature of $240{ }^{\circ} \mathrm{C}$.

The assumed reversibility of the $\mathrm{BBr}_{3}: \mathrm{NH}_{3}$ surface-adduct formation implies that, once physisorbed as adduct, before establishing a stable $\mathrm{B}-\mathrm{NH}_{2}-\mathrm{B}$ linkage, $\mathrm{NH}_{3}$ can desorb back into the gas phase. The linkage irreversibly forms from reaction of an adduct- $\mathrm{NH}_{3}$ with $-\mathrm{Br}$ of an adjacent $\mathrm{B}-\mathrm{Br}_{x}$ site. For TMA: $\mathrm{NH}_{3}$ and $\mathrm{BCl}_{3}: \mathrm{NH}_{3}$ surface adducts, such reactions have been reported ${ }^{8,9,22}$. Although chemisorption of $\mathrm{BBr}_{3}$ can result in a variety of $\mathrm{BBr}_{x}(x=1-3)$ surface species, here, 
for simplicity, we limit the discussion to B-Br (i.e., $\mathrm{x}=1$ ) terminated surfaces only. The exact mechanism of the $\mathrm{BBr}_{3}$ chemisorption is beyond the scope of this work.

The reversible adsorption of $\mathrm{NH}_{3}$ on the chemisorbed $\mathrm{B}-\mathrm{Br}$ sites can be described by the Langmuir adsorption-desorption kinetics ${ }^{26}$. Equation 5.1 shows the adduct surface coverage $\theta$ expressed via the concentration of $\mathrm{NH}_{3}\left(C_{\mathrm{NH}}\right)$. In this equation, $\mathrm{NH}_{3}$ adsorption and desorption rate constants are given by $k_{a}$ and $k_{d}$, respectively. From equation 5.1, the surface coverage is a function of $t_{N H 3}$ and $C_{N H 3}$. The latter corresponds to the partial pressure $\left(P_{N H 3}\right)$ via $C_{N H 3}=P_{N H 3} / k_{B} T$, where $\mathrm{k}_{\mathrm{B}}$ is the Boltzmann constant and $T$ is the temperature.

$$
\theta\left(t_{N H 3}\right)=\left(\frac{k_{a} C_{N H 3}}{k_{a} C_{N H 3}+k_{d}}\right)\left[1-e^{-\left(k_{a} C_{N H 3}+k_{d}\right) t_{N H 3}}\right]
$$

$\theta$ is further plotted versus $t_{N H 3}$ and $P_{N H 3}$ in Figure 5-2.a, after choosing reasonable (i.e., physically solid) values for $k_{a}\left(10^{-11} \mathrm{~cm}^{3} \mathrm{~s}^{-1}\right)$ and $k_{d}\left(10^{6} \mathrm{~s}^{-1}\right)^{\ddagger \ddagger} 26-29$. It can be seen that the adduct surface coverage is $P_{\mathrm{NH} 3}$ dependent and increases with the total pressure. According to Langmuir kinetics, $\theta$ approaches to 1 at infinitely high pressure. $\theta$ saturates within a few microseconds at low $P_{\mathrm{NH} 3}$; this time shortens at higher pressures. The time required to reach the equilibrium coverage can be affected by changing the $k_{a}$ and $k_{d}$ values over several orders of magnitudes. For example, $k_{a}=10^{-18} \mathrm{~cm}^{3} \mathrm{~s}^{-1}$ and $k_{d}=10^{-2} \mathrm{~s}^{-1}$ cause an equilibrium within tens of seconds. Such rates are however hardly physical, since one is too low and the other is too high.

Since the adduct formation is assumed to be reversible, physisorbed $\mathrm{NH}_{3}$ molecules can either desorb back to the gas phase or form irreversible $-\mathrm{NH}_{2}$ bridges by reacting with neighboring - $\mathrm{BBr}$ sites thereby eliminating $\mathrm{HBr}$. These considerations were applied in the Mathcad code and the $-\mathrm{NH}_{2}$ - coverage was calculated as a function of $t_{\mathrm{NH} 3}$ and $P_{\mathrm{NH} 3}$. Since the adduct-to- $\mathrm{NH}_{2}$ - conversion rate

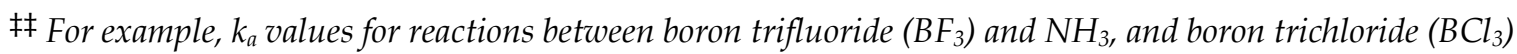
and $\mathrm{NH}_{3}$ range between $10^{-10}$ and $10^{-14} \mathrm{~cm}^{3} / \mathrm{s}$. Due to the lack of information, we were not able to find any $k_{d}$ values reported for reactions of boron halide with $\mathrm{NH}_{3}$ and therefore used the values reported for GaN deposition, ranging between $10^{6}-10^{8} \mathrm{~s}^{-1}$ 26-29.
} 
constant is unknown, it was varied between $10^{-14}$ and $10^{-16} \mathrm{~cm}^{2} \mathrm{~s}^{-1}$, yielding time scales similar to those experimentally obtained for GPC (see Figure 5-3.b). As Figure 5-2.b and 5-2.c show, up to several minutes of $t_{N H 3}$ is required to convert all surface adduct sites into $-\mathrm{NH}_{2}$ - linkages. A complete $-\mathrm{NH}_{2}$ - coverage indicates the formation of a BN monolayer.

a)

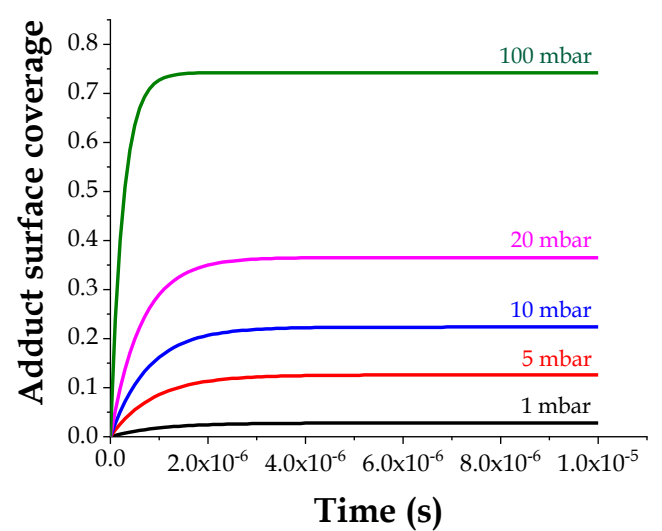

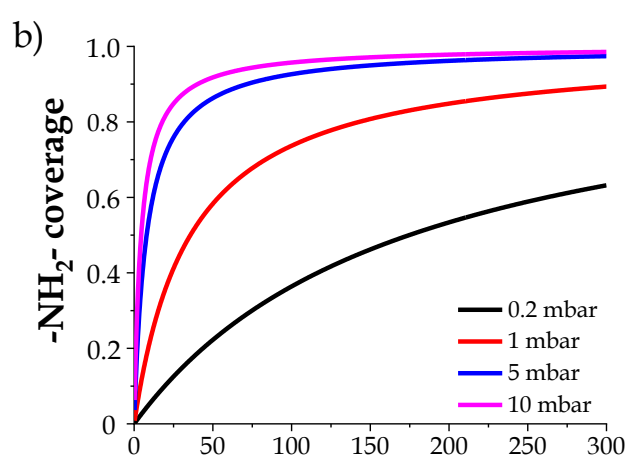

Time (s)

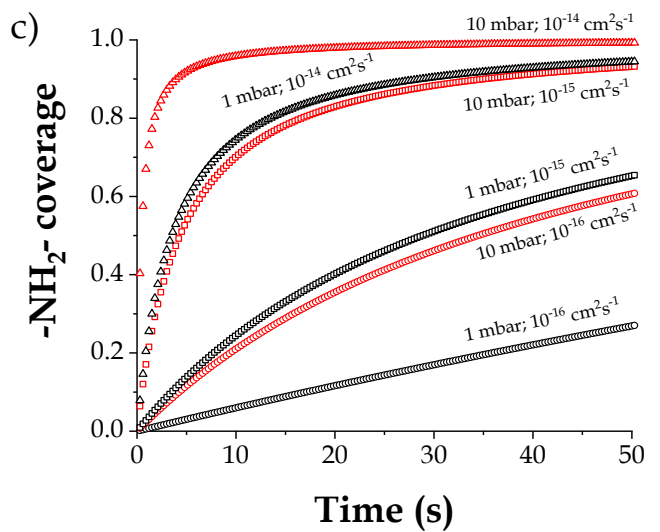

Figure 5-2. Simulated surface coverage with (a) adduct for $k_{a}=10^{-11} \mathrm{~cm}^{3} \mathrm{~s}^{-1}$ and $k_{d}=10^{6}$ $\mathrm{s}^{-1}$, (b) $-\mathrm{NH}_{2-}$ for $k_{B N}=10^{-15} \mathrm{~cm}^{2} \mathrm{~s}^{-1}$, (c) $-\mathrm{NH}_{2}$ for $k_{B N}$ of $10^{-14}, 10^{-15}$ and $10^{-16} \mathrm{~cm}^{2} \mathrm{~s}^{-1}$.

Indicated pressures correspond to $P_{\mathrm{NH}}$. $k_{\mathrm{BN}}$ represents the rate of $-\mathrm{NH}_{2}$ - bridge formation.

From Figure 5-2, the BN deposition is clearly affected by $P_{N H 3}$. A low $P_{N H 3}$ would result in a low adduct surface coverage and very long $t_{\mathrm{NH} 3}$ would be required to complete the surface coverage with $-\mathrm{NH}_{2}$ - linkages. On the other hand, a high $P_{N H 3}$ would result in a larger adduct surface coverage, requiring a short $t_{N H 3}$ to establish the linkages. The next sections will experimentally confirm these findings. 


\subsection{Experimental results}

\subsubsection{Experimental setup}

Boron nitride films were deposited on $100 \mathrm{~nm}$ thick thermally grown $\mathrm{SiO}_{2}$ layers by sequentially pulsing $\mathrm{BBr}_{3}$ and $\mathrm{NH}_{3}$. An inert (argon - Ar) gas purge was applied between the pulses in order to achieve atomic layer deposition (ALD) conditions. The depositions were performed in a Picosun Plasma R-200 reactor. The total reactor gas-pressure was kept in the range of 1-12 mbar, while the substrate temperatures $\left(T_{s}\right)$ were varied between 240 and $370{ }^{\circ} \mathrm{C}$. The typical pulse and purge times were set to $0.1 \mathrm{~s}$ for $\mathrm{BBr}_{3}, 30 \mathrm{~s}$ for post-BBr3 $\mathrm{Ar}$-purge, 5-40 s for $\mathrm{NH}_{3}$, and 20-60 s for post- $\mathrm{NH}_{3}$ Ar-purge. The details of the ALD window determination are addressed in Section 5.5.2.1.

The film growth was monitored in-situ by a Woollam M-2000XI spectroscopic ellipsometer (SE) served with a J.A. Woollam CompleteEASE software, to determine film thickness and optical constants. The approach and the SE models have been explained in Chapter 2. The XPS sputter depth profiles were obtained with a Thermo theta probe spectrometer of a Quantera SXM microprobe system, using monochromatic Al-Ka $(1486.6 \mathrm{eV})$ radiation. The XRR and XRD data were acquired using a Panalytical Empyrean system and analyzed by a Qualx2.0 software ${ }^{30}$.

\subsubsection{Kinetics of thermal-BN deposition}

\subsubsection{The BN ALD window}

The thermal-ALD (t-ALD) experiments were carried out at different $t_{\mathrm{NH} 3}(5$ $\left.\leq t_{N H 3} \leq 40 \mathrm{~s}\right)$ and $P_{N H 3}\left(0.1 \leq P_{N H 3} \leq 1.5\right.$ mbar $)$ values. To minimize gas phase reactions and promote surface reactions only, long (30-60 s) Ar-purges were necessary (see caption of Figure 5-3) to efficiently remove $\mathrm{BBr}_{3}$ and especially $\mathrm{NH}_{3}$. Figure 5-3 clearly shows that the GPC varies with both the $P_{\mathrm{NH} 3}$ (Figure 5-3.a) and $t_{\mathrm{NH} 3}$ (Figure 5-3.b). One can clearly notice an enhancement by at least a factor of two (i.e., from 0.04 to $0.08 \mathrm{~nm} /$ cycle) of the GPC with increasing the $P_{N H 3}$. A 
towards-saturation GPC trend can still be observed while changing the $t_{\mathrm{NH} 3}$, for each $P_{N H 3}$ value (Figure 5-3.b), pointing to an "effective" ALD window. The observed pressure-dependence of the towards-saturation region is rather atypical for ALD. One can see in Figure 5-3.b that the GPC does not quite saturate even at very long pulse durations (20 s, $40 \mathrm{~s}$ ), indicating still ongoing surface reactions. This could involve the ongoing formation of the surface adduct and its conversion into $-\mathrm{NH}_{2}$ - linkages. Such reaction(s) is(are) presumably rather slow in view of the time range indicated. The actual saturation of the GPC, typical for ALD in general and the particular precursors used, is expected at a longer $t_{N H 3}$, after completing the $\mathrm{B}-\mathrm{NH}_{2}-\mathrm{B}$ surface coverage. The sharp increase in the GPC (see the values within the green circle in Figure 5-3.a), which corresponds to the purge time of 20$30 \mathrm{~s}$, only occurs for $P_{\mathrm{NH} 3}>1$ mbar. This may indicate an insufficient removal of the $\mathrm{NH}_{3}$ by the 20-30 s long post- $\mathrm{NH}_{3}$ purges, due to its adsorption on the reactor walls at such high $P_{N H 3}$. The insufficient purge presumably caused gas phase reactions, significantly enhancing the growth.
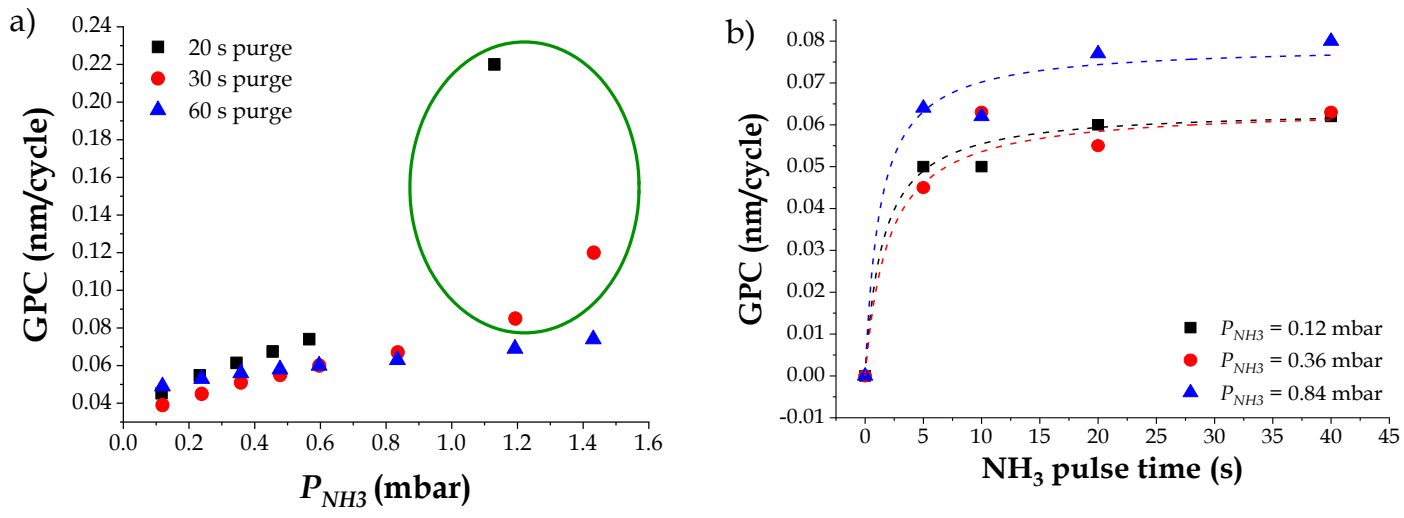

Figure 5-3. Variation of GPC as a function of $(\boldsymbol{a}) P_{\mathrm{NH}}$ and post-NH3 $\mathrm{Nurge}$ time and (b) $t_{N H 3}$, as-measured by in-situ SE. Conditions for (a): $0.1 \mathrm{~s}$ of BBr3 pulse / $30 \mathrm{~s}$ of Ar for post-BBr 3 purge / 10 s of $\mathrm{NH}_{3}$ pulse / 20-60 s of Ar for post- $\mathrm{NH}_{3}$ purge. The indicated $0.1<P_{\mathrm{NH}_{3}}<1.5$ mbar corresponds to $1 \leq P_{\text {tot }} \leq 12 \mathrm{mbar}$. Conditions for $(b): 0.1 \mathrm{~s}$ of $\mathrm{BBr}_{3}$ pulse / $30 \mathrm{~s}$ of Ar for post-BBr 3 purge/ 5-40 s of $\mathrm{NH}_{3}$ pulse/ $60 \mathrm{~s}$ of Ar for post-NH3 purge. The given $P_{\mathrm{NH} 3}$ values correspond to a total pressure in the range of 1-12 mbar. All depositions were performed at $T_{s}=240 \pm 10^{\circ} \mathrm{C}$ on $100 \mathrm{~nm}$ thermally grown $\mathrm{SiO}_{2}$.

The dashed lines in (b) are given to guide the eye.

Regarding the influence of substrate temperature, it has been observed that the GPC decreased from 0.05 to $0.033 \mathrm{~nm} /$ cycle and from 0.075 to $0.052 \mathrm{~nm} /$ cycle at $\mathrm{P}_{\mathrm{NH} 3}$ of 0.12 mbar and 1.43 mbar, respectively, with increasing substrate 
temperature from 240 to $365^{\circ} \mathrm{C}$ (Figure 5-4). Although the GPC of a perfect ALD process should be nearly temperature independent within the ALD window, there are exceptions to this rule. For example, in a recent study on GaN ALD ${ }^{29}$, a gradual increase of the GPC with increasing $T_{\mathrm{s}}$ has been observed. Indications of an ALD process in such cases would be the following: (i) still self-limiting (although temperature dependent) surface reactions and (ii) the right material stoichiometry (i.e., the effective removal of byproducts). The decrease in GPC might indicate a decreased surface-adduct coverage at a higher $T_{\mathrm{s}}$, in terms of the model proposed in Section 5.3, due to the desorption of $\mathrm{NH}_{3}$. The later would mean that the adduct formation is favorable at lower temperatures. A change of the growth mechanism with temperature is less likely, since both graphs in Figure 5-4 reveal similar activation energies for $P_{\mathrm{NH} 3}$ of 0.12 and 1.43 mbar $\left(P_{\text {tot }}\right.$ of 1 and $12 \mathrm{mbar}$ respectively).
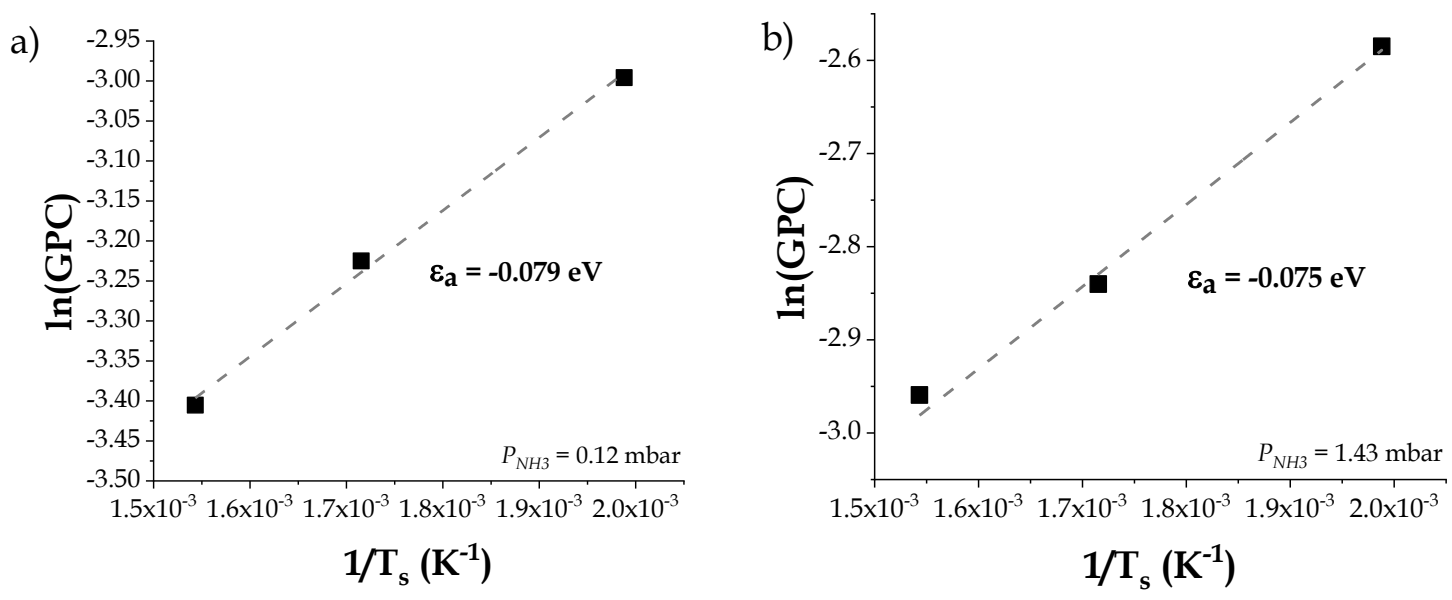

Figure 5-4. Arrhenius plot of GPC against reciprocal temperature for samples deposited at $P_{\mathrm{NH} 3}$ of $(\boldsymbol{a}) 0.12$ and $(\boldsymbol{b}) 1.43$ mbar ( $P_{\text {tot }}$ of 1 and $12 \mathrm{mbar}$, respectively). The dashed lines are the linear fits. The as-obtained activation energies $\left(\varepsilon_{a}\right)$ are given inside the graphs. Conditions: 0.1 s of $\mathrm{BBr}_{3}$ pulse / 30 s of Ar for post-BBr 3 purge/ $10 \mathrm{~s}$ of $\mathrm{NH}_{3}$ pulse/ 60 s of Ar for post-NH3 purge.

The BN deposition was further studied by analyzing the shape evolution of individual growth cycles. The GPC curve obtained by in-situ SE consisted of welldefined steps (Figure 5-5.a). Before proceeding further, it is important to emphasize the following. The extremely small variations in thickness within an ALD cycle, are due to the changes in signal, as interpreted by the SE optical model. 
Apart from the actual thickness variations, changing the surface optical properties upon the corresponding chemical reactions may also be sufficient to cause this effect. Only the starting and ending points of each cycle correspond to the real thickness values, since they compose the entire growth curve and result in the final film thickness. The latter can be independently verified by other ex-situ measurement techniques (as discussed in Chapter 2 - Section 2.2.1).

The first step of a cycle, interpreted by $\mathrm{SE}$ as a thickness increase, corresponds to the introduction of $\mathrm{BBr}_{3}$ and presumably indicates its successful chemisorption. Figure 5-5.b compares the shapes of individual ALD cycles obtained by in-situ SE for different $P_{\mathrm{NH}}$. The corresponding step height $\$ \$$ evolutions are quantified in Figure 5-5.c and 5-5.d. The gradual (with $P_{\mathrm{NH} 3}$ ) increase of the step height after each $\mathrm{BBr}_{3}$ pulse (Figure 5-5.c) and the smaller decrease after each $\mathrm{NH}_{3}$ pulse (Figure 5-5.d) may indicate a higher concentration of- $\mathrm{NH}_{2}$ - linkages as a result of applying a higher $P_{\mathrm{NH}}$. These linkages serve as $\mathrm{BBr}_{3}$ chemisorption sites for the subsequent cycle, increasing the surface coverage of the chemisorbed -B-Br (recall Figure 5-1), and resulting in a larger step. On the contrary, a lower $P_{\mathrm{NH} 3}$ leads to lower $-\mathrm{NH}_{2}$ - coverage, therefore leaving unreacted $\mathrm{B}-\mathrm{Br}$ sites on the surface from the previous $\mathrm{BBr}_{3}$ pulse and resulting in a weaker step. The fact that a higher $P_{N H 3}$ leads to a larger step after introducing $\mathrm{BBr}_{3}$ supports the necessity of having $\mathrm{NH}_{\mathrm{x}}$ groups to enhance the $\mathrm{BBr}_{3}$ chemisorption. In other words, increasing the $-\mathrm{NH}_{2}$ - coverage leads to a large $\mathrm{BBr}_{3}$ uptake. Similarly, increasing the -B-Br coverage leads to a large $\mathrm{NH}_{3}$ uptake, in line with the effect observed earlier and mentioned in the literature. See the earlier literature review given in this chapter.

The same effect comes into play when $t_{\mathrm{NH} 3}$ is altered (Figure 5-5.e). A higher $t_{\mathrm{NH} 3}$ causes more nitridation of the -B-Br-chemisorbed surface, leading to enhanced surface coverage with - $\mathrm{NH}_{2}$ - linkages. This in turn, may result in a higher surface

$\S \S$ Step height and thickness decrease reported in the text and in Figure 5-5 represent the increase in thickness
(as interpreted by SE) following a BBrs pulse and the decrease in thickness upon an $\mathrm{NH}_{3}$ pulse, respectively. 
coverage in the subsequent $\mathrm{BBr}_{3}$ pulse, leading to a larger step and therefore a higher GPC (recall Figure 5-3.b).
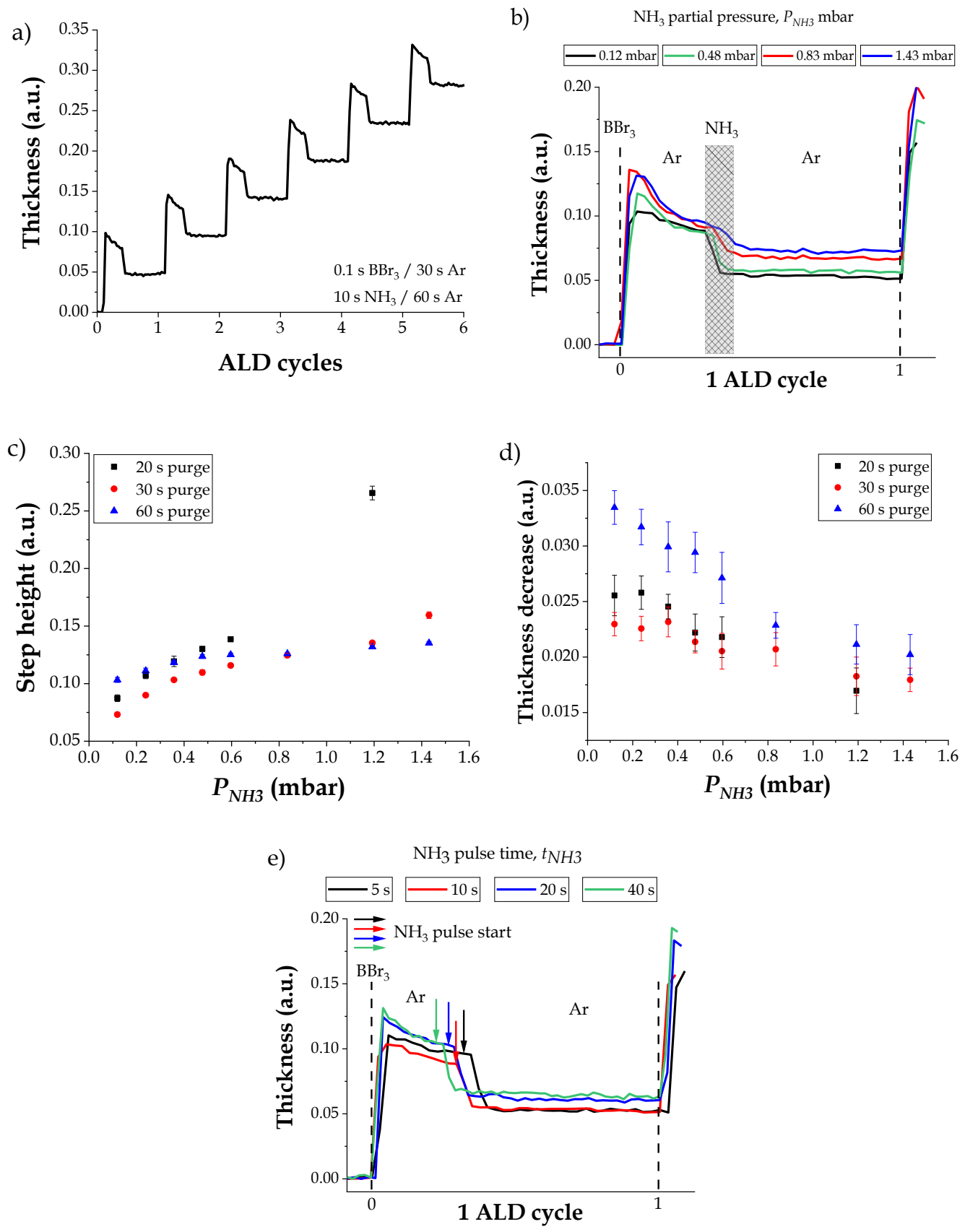

Figure 5-5. Thickness evolution (as interpreted by in-situ SE) within individual ALD cyles. (a) Representative step-wise growth in every ALD cycle; (b) Influence of $P_{\mathrm{NH} 3}$ (at $P_{N H 3}=0.12-1.43$ mbar, $P_{t o t}=1-12$ mbar $),(c, d)$ Quantification of the step increase / decrease during one ALD cycle versus $P_{N H 3}$ and for different post- $\mathrm{NH}_{3}$ purge durations (see the legend), and (e) the effect of $t_{\mathrm{NH} 3}$ at $P_{\mathrm{NH} 3}=0.12 \mathrm{mbar}\left(P_{\text {tot }}=1 \mathrm{mbar}\right)$. 


\subsubsection{Characterization of the BN layers}

The BN films were deposited at a substrate temperature of 240, 320 and 365 ${ }^{\circ} \mathrm{C}$ and $P_{N H 3}$ ranging from 0.12 to $1.43 \mathrm{mbar}\left(P_{t o t}=1-12 \mathrm{mbar}\right)$. The pulse durations used for all samples discussed in this section were: $0.1 \mathrm{~s}$ of $\mathrm{BBr}_{3}, 30 \mathrm{~s}$ of Ar for post$\mathrm{BBr}_{3}$ purge, $10 \mathrm{~s}$ of $\mathrm{NH}_{3}$ and $60 \mathrm{~s}$ of Ar for post-NH 3 purge. A GaN layer on top of the $\mathrm{BN}$ is in-situ deposited to diminish the aging effect.

\subsection{Refractive index ( $n$ ) by $S E$}

The refractive indices obtained at $632 \mathrm{~nm}$ and $1500 \mathrm{~nm}$ wavelengths (Figures 5-6.a and 5-6.b, respectively) reasonably agree with the values reported for stoichiometric boron nitride films having amorphous (a-BN), nanocrystalline or hexagonal (h-BN) structure ${ }^{31,32}$. To bear in mind, extinction coefficients were below the sensitivity limits of the measurements system, therefore considered as zero. Further, $n$ of an a-BN has been reported between 1.65 and $1.931,33,34 ; n$ of a h$\mathrm{BN}$, falls in the range between 1.55 and 2.17 35-38. From the figures, the $n$ at $632 \mathrm{~nm}$ prominently decreases with increasing $T_{\mathrm{s}}$ for $P_{\mathrm{NH} 3}=0.12 \mathrm{mbar}$, whereas for $P_{\mathrm{NH} 3}=$ $1.43 \mathrm{mbar}$ it increases. The trends of $n$ at $1500 \mathrm{~nm}$ are less evident. The behavior of $n$ at $632 \mathrm{~nm}$ can be explained by the Urbach rule ${ }^{39-41}$ since this wavelength is in the spectral region of the Urbach tail for the interband transitions of BN ${ }^{37}$. It could also be related to impurities and defect states. For example, Hoffman et.al. ${ }^{42}$ reported absorptions in the photon energy range of 1-5 eV and attributed this to impurities and defect states. However, the observed behavior of $n$ requires additional investigation which is out of the scope of this work.
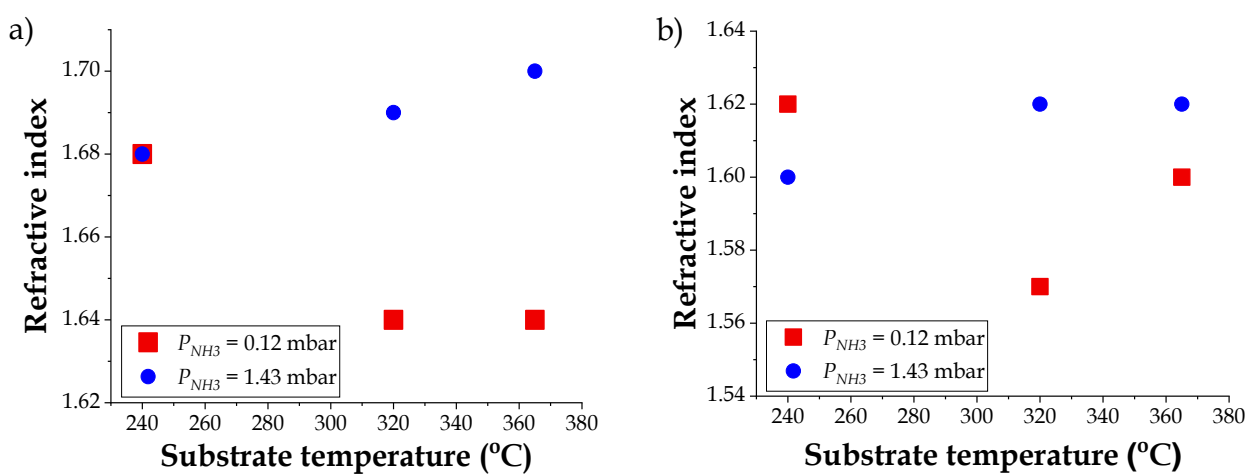

Figure 5-6. Variation of the refractive index of as-deposited BN $(15 \pm 3 \mathrm{~nm})$ as a function of $T_{s}$ and $P_{N H 3}$ at (a) $632 \mathrm{~nm}$ and (b) $1500 \mathrm{~nm}$. 


\subsection{XPS analyses}

Sputter-depth profiling was performed using 0.5-1 kV Ar+ ions to obtain bonding environments from the bulk. The surface carbon peak position was referenced to the $\mathrm{C} 1 \mathrm{~s}$ line of adventitious hydrocarbons at $284.8 \mathrm{eV}{ }^{43}$. B 1s and $\mathrm{N} 1 \mathrm{~s}$ spectra were analyzed to obtain the bonding environments in the bulk. All the spectra were deconvoluted by Gaussian peaks after assuming an iterated Shirley background. We neglected the lifetime broadening of the B 1 s and $N$ 1s peaks ${ }^{44}$. It was observed that the B 1s and N 1s spectra fitted very well with those of a boron nitride reference ${ }^{45}$, providing a strong indication of the occurrence of (near) stoichiometric BN films.

It was observed that the as-deposited layers contained less than 5 at.\% of oxygen in the bulk (see Figure 5-7.a). However, after aging in air for several months, the layers revealed an oxygen amount of $\sim 10$ at.\% (see Figure 5-7.b), indicating their atmospheric instability and thus amorphous or nanocrystalline nature ${ }^{46,47}$.

a)

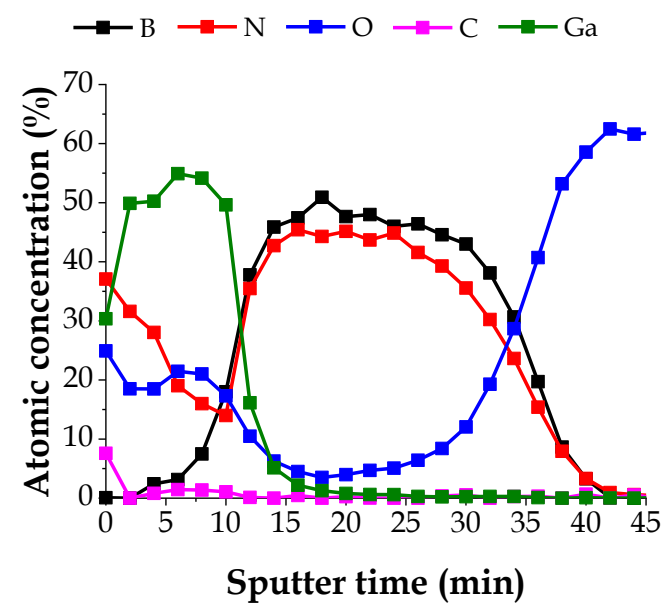

b)

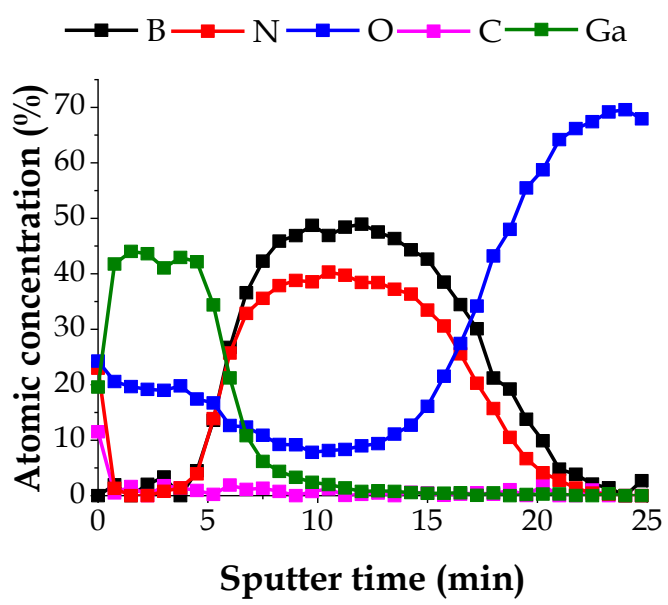

Figure 5-7. Sputter depth profiles of a $\mathrm{GaN} / \mathrm{BN} / \mathrm{SiO}_{2} / \mathrm{Si}$ stack (a) as-deposited and (b) after aging in air for several months. The near stoichiometric $B N$ layer inhibits an increase of the oxygen amount from $\sim 5$ at. \% (as-deposited) to $>10$ at.\% (after aging). Conditions: $T_{s}=240^{\circ} \mathrm{C}, P_{\mathrm{NH} 3}=0.12 \mathrm{mbar}, P_{\text {tot }}=1 \mathrm{mbar}, 0.1 \mathrm{~s}$ of BBr 3 pulse $/ 30 \mathrm{~s}$ of $\mathrm{Ar}$ for post-BBr 3 purge/ 10 s of $\mathrm{NH}_{3}$ pulse/ $60 \mathrm{~s}$ of Ar for post-NH3 purge. The GaN layer on top of the BN is in-situ deposited to diminish the aging effect; apparently, oxygen is still able to diffuse through. 


\subsection{XRD analyses}

The grazing incidence angle XRD (GIXRD) spectra of the samples deposited at $T_{s}=360{ }^{\circ} \mathrm{C}$ and $\mathrm{P}_{\mathrm{NH} 3}$ of 0.12 and 1.43 mbar ( $\mathrm{P}_{\text {tot }}$ of 1 and $12 \mathrm{mbar}$, respectively) showed 2 broad BN-derived peaks located at $21^{\circ}$ and $54^{\circ}$ of 2 theta $(2 \Theta)$ values with very low intensities, indicating a poor crystallinity. Peaks due to the GaN capping layer can also be observed. It can be concluded that changing the pressure did not affect the crystalline structure significantly.

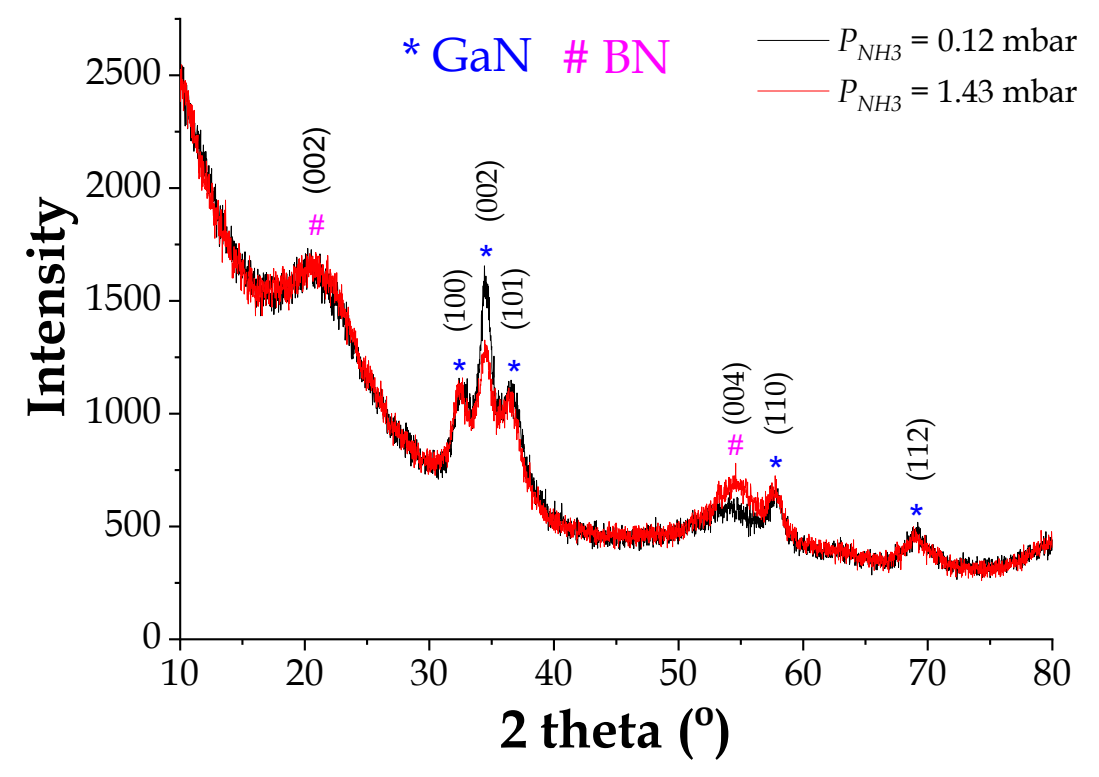

Figure 5-8. GIXRD patterns of the thermal-BN samples ( $15 \mathrm{~nm}$ thick). The corresponding Miller indices are indicated above the peaks for BN (\#) and GaN (*). The peak positions coincide with those reported for $h-B N{ }^{48,49}$. The GaN peak positions are taken from ref. ${ }^{23}$.

\subsection{Conclusions}

This chapter studied ALD of BN in view of the hypothesized role of $\mathrm{BBr}_{3}: \mathrm{NH}_{3}$ surface adduct in the film formation process. The proposed ALD model involved (i) formation of a $\mathrm{BBr}_{3}: \mathrm{NH}_{3}$ surface adduct complex (presumably reversible), and (ii) conversion of this complex into $\mathrm{B}-\mathrm{NH}_{2}-\mathrm{B}$ linkage (irreversible), resulting in a unit of BN. The proposed ALD mechanism could also be viewed as the replica of the adduct pathway reported for AlN 22,50 and proposed for GaN 23,29 ALD. 
The kinetics of the surface adduct formation and its conversion into $-\mathrm{NH}_{2}-$ linkages were calculated using a Mathcad code. The results showed that the adduct surface coverage depends primarily on ammonia partial pressure. The experimental observations of the strong dependence of GPC on both partial pressure and $\mathrm{NH}_{3}$-pulse duration were in qualitative agreement with the simulations. The pressure dependence, atypical for ALD, was indeed the novelty of this work.

The ex-situ layer characterization revealed (i) refractive index (n) similar to that reported for a-BN and h-BN, (ii) stoichiometric BN films with O contamination less than 5 at.\%, (iii) environmental instability of the films and (iv) their nanocrystalline / amorphous structure. 


\section{References}

${ }^{1}$ H. Hirao, K. Omoto, and H. Fujimoto, J. Phys. Chem. A 103, 5807 (1999).

2 A.C. Legon and H.E. Warner, J. Chem. Soc. Chem. Commun. 1397, 1397 (1991).

${ }^{3}$ K. Iijima and S. Shibata, Bull. Chem. Soc. Jpn. 53, 1908 (1980).

${ }^{4}$ K. Iijima and S. Shibata, Bull. Chem. Soc. Jpn. 56, 1891 (1983).

${ }^{5}$ R.E. McCoy and S.H. Bauer, J. Am. Chem. Soc. 78, 2061 (1956).

6 P. Cassoux, R.L. Kuczkowski, and A. Serafini, Inorg. Chem. 16, 3005 (1977).

7 E.W. Hughes, J. Am. Chem. Soc. 78, 502 (1956).

8 K. Possemiers, P. Van Der Voort, and E.F. Vansant, J. Chem. Soc. Faraday Trans. 92, 679 (1996).

9 K. Possemiers, N.R.E.N. Impens, and E.F. Vansant, J. Chem. Soc. - Faraday Trans. 93, 2309 (1997). (2002).

10 J.D. Ferguson, A.W. Weimer, and S.M. George, Thin Solid Films 413, 16

11 S. Prouhet, G. Vignoles, F. LanglaisS, A. Guette, and R. Naslain, ChemInform 25, (2010). (2000).

${ }^{12}$ S. Reinhardt, M. Gastreich, and C.M. Marian, Phys. Chem. Chem. Phys. 2, 955

13 S. Reinhardt, C.M. Marian, and I. Frank, Angew. Chemie Int. Ed. 40, 3683 (2001).

14 P.R.R. Barreto, A.E. Kull, and M.A. Cappelli, MRS Proc. 750, Y5.13 (2002).

15 A. Haaland, Angew. Chemie Int. Ed. English 28, 992 (1989).

16 V. Jonas, G. Frenking, and M.T. Reetz, J. Am. Chem. Soc. 116, 8741 (1994).

17 V. Jonas and G. Frenking, J. Chem. Soc., Chem. Commun. 1489 (1994).

${ }^{18}$ M.D. Allendorf and C.F. Melius, J. Phys. Chem. A 101, 2670 (1997).

${ }^{19}$ H. Anane, A. Boutalib, I. Nebot-Gil, and F. Tomás, J. Phys. Chem. A 102, 7070 (1998).

20 F.M. Tao, J. Chem. Phys. 110, 11121 (1999).

${ }^{21}$ K. Possemiers, K.C. Vrancken, P. Van Der Voort, and E.F. Vansant, J. Chem. Soc. Faraday Trans. 91, 2173 (1995).

22 M.E. Bartram, T.A. Michalske, J.W. Rogers, and R.T. Paine, Chem. Mater. 5, 1424 (1993).

23 S. Banerjee and A.Y. Kovalgin, ECS Trans. 86, 21 (2018).

24 G.A. Kapralova, T. V. Suchkova, and A.M. Chaikin, Mendeleev Commun. 3, 118 (2004). 
${ }^{25}$ C.A. Kingsmill, N.H. Werstiuk, and N.P.C. Westwood, J. Am. Chem. Soc. 109, 2870 (1987).

26 R.I. Masel, Principles of Adsorption and Reaction on Solid Surfaces (John Wiley \& Sons, 1996).

27 X. Ou, R. Wallace, and A.F. Janzen, Can. J. Chem. 71, 51 (1993).

28 C. Theodoropoulos, T.J. Mountziaris, H.K. Moffat, and J. Han, J. Cryst. Growth 217, 65 (2000).

29 S. Banerjee, A.A.I. Aarnink, D.J. Gravesteijn, and A.Y. Kovalgin, J. Phys. Chem. C 123, 23214 (2019).

${ }^{30}$ A. Altomare, N. Corriero, C. Cuocci, A. Falcicchio, A. Moliterni, and R. Rizzi, J. Appl. Crystallogr. 48, 598 (2015).

${ }^{31}$ M.J. Rand and J.F. Roberts, J. Electrochem. Soc. 115, 423 (1968).

32 S. Weissmantel, G. Reisse, B. Keiper, and S. Schulze, Diam. Relat. Mater. 8, 377 (1999).

33 J.J. Pouch, S.A. Alterovitz, K. Miyoshi, and J.O. Warner, MRS Proc. 93, 323 (1987).

${ }^{34}$ A. Abdellaoui, A. Bath, B. Bouchikhi, and O. Baehr, Mater. Sci. Eng. B 47, 257 (1997).

35 T. Takahashi, H. Itoh, and M. Kuroda, J. Cryst. Growth 53, 418 (1981).

36 T. Ishii and T. Sato, J. Cryst. Growth 61, 689 (1983).

37 D. Jin-Xiang, Z. Xiao-Kang, Y. Qian, W. Xu-Yang, C. Guang-Hua, and H. DeYan, Chinese Phys. B 18, 4013 (2009).

38 D.C. Cameron, M.Z. Karim, and M.S.J. Hashmi, Thin Solid Films 236, 96 (1993).

${ }^{39}$ F. Urbach, Phys. Rev. 92, 1324 (1953).

40 I. Studenyak, M. Kranj, and M. Kurik, Int. J. Opt. Appl. 4, 76 (2014).

${ }^{41}$ M. V. Kurik, Phys. Status Solidi 8, 9 (1971).

42 D.M. Hoffman, G.L. Doll, and P.C. Eklund, Phys. Rev. B 30, 6051 (1984).

43 T.L. Barr and S. Seal, J. Vac. Sci. Technol. A Vacuum, Surfaces, Film. 13, 1239 (1995).

44 C. Nicolas and C. Miron, J. Electron Spectros. Relat. Phenomena 185, 267 (2012).

45 J.F. Moulder, W.F. Stickle, P.E. Sobol, and K.D. Bomben, Handbook of X-Ray Photoelectron Spectroscopy (Perkin-Elmer Corporation, Physical Electronics Division, Minnesota, 1992).

46 C. Gómez-Aleixandre, A. Essafti, M. Fernández, J.L.G. Fierro, and J.M. Albella, J. Phys. Chem. 100, 2148 (1996). 
47 T.A. Anutgan, M. Anutgan, I. Atilgan, and B. Katircioglu, Thin Solid Films 518, 419 (2009).

${ }^{48}$ Q. Li, W. Luo, L. Su, J. Chen, K.-C. Chou, and X. Hou, RSC Adv. 6, 92748 (2016).

${ }^{49}$ S. Yuan, S. Linas, C. Journet, P. Steyer, V. Garnier, G. Bonnefont, A. Brioude, and B. Toury, Sci. Rep. 6, 20388 (2016).

${ }^{50}$ T.M. Mayer, T.A. Michalske, and J.W. Rogers, Chem. Mater. 3, 641 (1991). 


\title{
6 The effects of using alternative approaches to growing
}

\section{$\underline{\mathrm{BN} \text { from } \mathrm{BBr}_{3} \text { and } \mathrm{NH}_{3}}$}

\begin{abstract}
In this chapter the effects of using alternative approaches, namely plasma assistance and switching to a cold wall reactor, on the deposition of boron nitride thin films are investigated. The films are obtained by a sequential introduction of boron tribromide $\left(\mathrm{BBr}_{3}\right)$ and ammonia $\left(\mathrm{NH}_{3}\right)$ precursors with an Ar purge in between. Using plasma assisted growth, to switch from pure thermal to radical enhanced deposition mode, leads to lower GPC values compared to the thermal process. Furthermore, the appearance of a pure-B phase is observed by SE, presumably indicating a different growth mechanism than for thermal deposition. Indeed, the GPC does not follow the Arrhenius behavior typical for a purely thermal process. Next, switching to a cold wall reactor reveals results similar to those obtained with a hot-wall reactor (see Chapter 5). We observe (i) pressure dependence of GPC, (ii) lower GPC in the case of the radical (hot-wire) enhancement, (iii) environmentally instable layers with (iv) amorphous/nanocrystalline structure. Studying the ammonium bromide $\left(\mathrm{NH}_{4} \mathrm{Br}\right.$ ) formation is suggested for differentiating between ALD and CVD modes as well as for clarifying the deposition mechanism.
\end{abstract}




\subsection{Introduction}

This chapter gives insights into additional aspects of $\mathrm{BN} \mathrm{ALD} \mathrm{from} \mathrm{BBr}_{3}$ and $\mathrm{NH}_{3}$ precursors. First, the results of the thermal-BN deposition discussed in Chapter 5 are compared with the plasma-enhanced ALD. In-situ SE results presumably indicate a different-from-thermal growth mechanism for plasmaassisted ALD. Second, two types of deposition reactors are compared, namely a hot wall versus a cold wall reactor. The latter is especially interesting for studying a reaction byproduct (ammonium bromide - $\mathrm{NH}_{4} \mathrm{Br}$ ), which is suggested for optimizing the ALD process.

Section 6.2 discusses the proposed growth mechanism based on a similar model reported in the literature and discussed earlier in Chapters 4 and 5. Section 6.3 reports the experimental results, comparing radical-enhanced and thermal deposition modes in line with the proposed deposition mechanism. Section 6.4 briefly highlights the observations made when changing the hardware from a hotwall to a cold-wall reactor. Finally, Section 6.5 concludes this chapter.

\subsection{Proposed BN growth mechanism in a radical-enhanced mode}

As discussed in Chapter 1, radicals or other reactive species produced via radical enhancement methods (e.g., plasma or hot-wire) are much more reactive than their molecular counterparts, thus enabling reactions that may not be possible in thermal mode ${ }^{1}$. This means enabling new chemical routes compared to thermal mode. Specifically, applying a radical enhancement to deposit BN is expected to alter the growth mechanism since dissociation of $\mathrm{NH}_{3}$ into $\mathrm{N}$ - or $\mathrm{H}$ - containing radicals $2-6$, may enable different chemical routes, which could suppress the dominating effect of adduct assisted routes. Firstly, $\mathrm{N}$ - containing radicals $\left(\mathrm{NH}_{\mathrm{x}}\right.$ $x=0-2$ ) can react with the surface species, causing nitridation without involving adduct formation as the intermediate step. Additionally, generated atomic hydrogen (at-H) radicals can react with surface species, e.g., with -Br, leading to their removal. This will decrease the number of available B-Br sites required for 
the linkage formation via the adduct mechanism. This may imply a reduced involvement of the $-\mathrm{NH}_{2}$ - bridges (linkages) into the $\mathrm{BN}$ growth mechanism. A schematic representation of the proposed alternations is given in Figure 6-1.

PLASMA: reacting species $-\mathrm{NH}_{3}, \mathrm{NH}_{2}, \mathrm{NH}, \mathrm{N}$ and $\mathrm{H}$

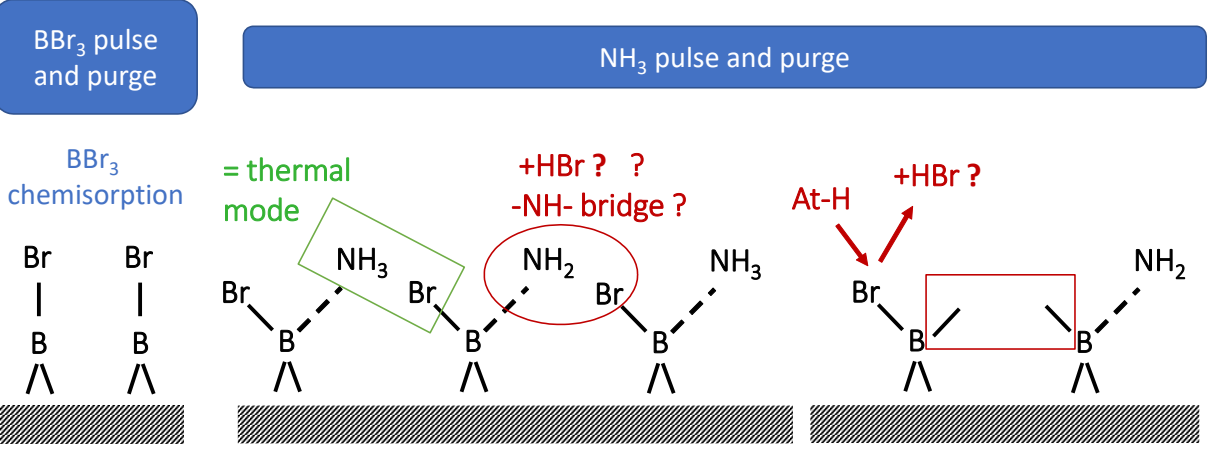

Figure 6-1. Proposed alternation of the BN growth with radicals involved: thermal route, reaction with $\mathrm{NH}_{x}$ radicals, removal of surface species by at- $H$.

It should be noted that, under optimized conditions, the use of plasma can improve film crystallinity 7,8 . On the other hand, non-optimized conditions (i.e., insufficient concentration of $\mathrm{NH}_{\mathrm{x}}$ radicals, too much at-H, etc.) may lead to a lower GPC and an increased B share in the layers. Section 6.3.2 will address this issue in detail.

\subsection{Plasma-enhanced ALD of $\mathrm{BN}$ in a hot-wall reactor}

For plasma assisted deposition, in addition to pure radical enhancement, surface bombardment with energetic species (i.e., ions) can altered film properties or the growth mechanism. For example, plasma assistance has been reported to improve crystallinity, electrical behavior, and densify the layers ${ }^{8-10}$.

\subsubsection{Experimental setup}

Boron nitride films were deposited on $100 \mathrm{~nm}$ thermally grown $\mathrm{SiO}_{2}$ layers on Si wafers by sequentially pulsing $\mathrm{BBr}_{3}$ and $\mathrm{NH}_{3}$ with Ar purges in between. During the plasma-enhanced ALD (PEALD) experiments, only the $\mathrm{NH}_{3}$ was supplied such that it passed through the plasma-generation region, the $\mathrm{BBr}_{3}$ precursor was introduced far below and just above the substrate holder. The 
depositions were performed in a Picosun Plasma R-200 reactor. Due to the technical limitations of the plasma source, it was impossible to perform the plasma-experiments at total pressures higher than 1 mbar (i.e., $P_{\mathrm{NH} 3}=0.12$ mbar). The total reactor gas-pressure was thus kept at 1 mbar, while the substrate temperatures $\left(T_{s}\right)$ were varied between 240 and $370{ }^{\circ} \mathrm{C}$. The typical pulse and purge times were set to $0.1-1.2 \mathrm{~s}$ for $\mathrm{BBr}_{3}, 10-30 \mathrm{~s}$ for post-BBr 3 Ar-purge, 5-25 s for $\mathrm{NH}_{3}$, and 20-80 s for post- $\mathrm{NH}_{3}$ Ar-purge.

The film growth was monitored in-situ by a Woollam M-2000XI spectroscopic ellipsometer (SE) served with J.A. Woollam CompleteEASE software. The approach and the SE models have been explained in Chapter 2.

\subsubsection{BN ALD window and the effect of non-optimized conditions}

Varying the $\mathrm{NH}_{3}$ (Figure 6-2.a) and $\mathrm{BBr}_{3}$ (Figure 6-2.b) pulse and purge duration caused only a slight GPC variation without any conclusive trend, consistent with an ALD growth mode.
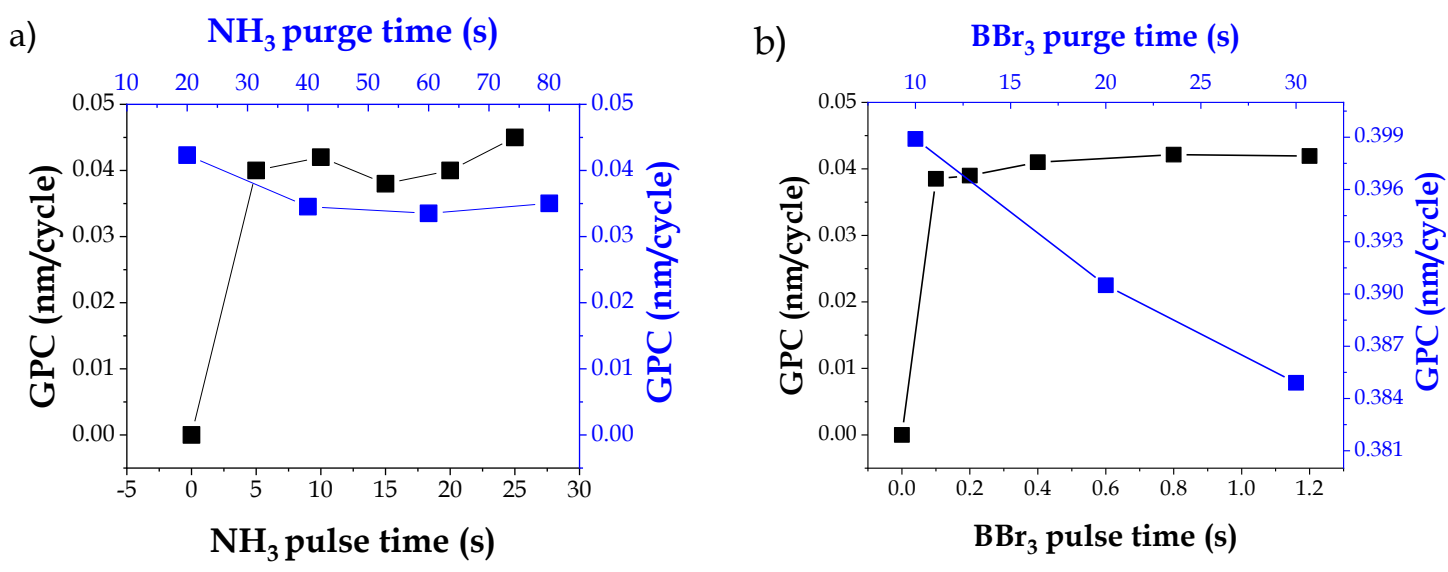

Figure 6-2. Variation of GPC with (a) $\mathrm{NH}_{3}$ and (b) $\mathrm{BBr}_{3}$ pulse and purge times measured by in-situ SE. Other conditions $T_{s}=240^{\circ} \mathrm{C}$ and $P_{\mathrm{NH} 3}=0.12 \mathrm{mbar}\left(P_{\text {tot }}=1\right.$ mbar).

From the figure, using the shortest pulse and purge times $\left(0.1 \mathrm{~s}\right.$ of $\mathrm{BBr}_{3}$ pulse, $10 \mathrm{~s}$ of post-BBr 3 purge, $5 \mathrm{~s}$ of $\mathrm{NH}_{3}$ pulse and $20 \mathrm{~s}$ of post- $\mathrm{NH}_{3}$ purge) seems to be long enough to achieve similar GPC values. However, an intense spectral absorption band at $\sim 3.4 \mathrm{eV}$ was observed for the shortest $t_{\mathrm{NH} 3}$ of $5 \mathrm{~s}$ (see Figure 63.a), which was earlier attributed to the appearance of a pure-B phase, as discussed 
in Chapter 3. This indicated an insufficient nitridation of the surface during such short $\mathrm{NH}_{3}$ pulses. Figure 6-3.b compares the optical function $\left(\varepsilon_{2}\right)$ of the plasma and thermal sample deposited using $5 \mathrm{~s}$ of $t_{\mathrm{NH} 3}$. It can be seen that the absorption band is absent in the case of thermal deposition and present if plasma assistance is used. This confirms that, in line with the expectations, plasma enhancement significantly alters the $\mathrm{BN}$ growth mechanism (see Figure 6-1 and the corresponding text).

a)

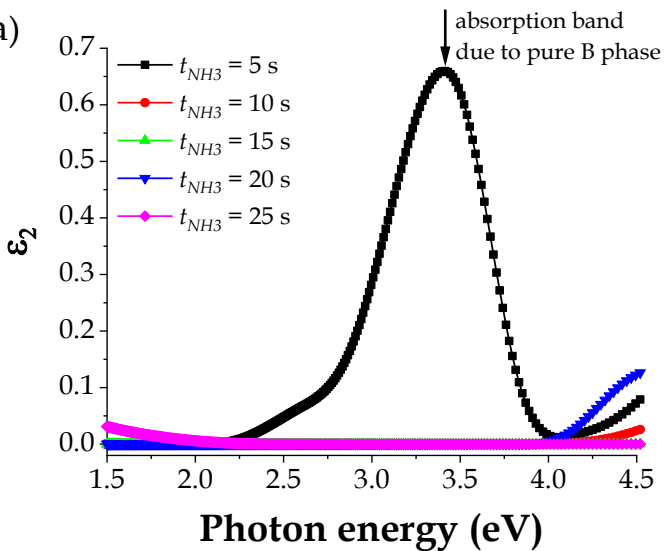

b) ${ }^{0.7}$. plasma

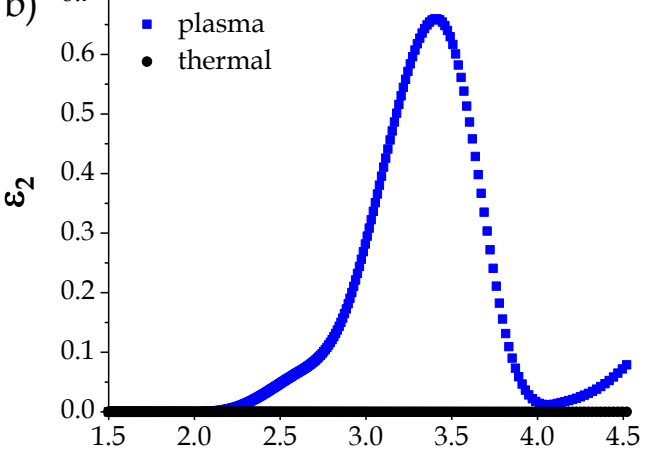

Photon energy (eV)

Figure 6-3. The adsorption-related optical function ( $\left.\varepsilon_{2}\right)$ as determined by in-situ SE for (a) various $t_{\mathrm{NH} 3}$ and (b) plasma-vs-thermal mode. The absorption band observed at $\sim 3.4$ $\mathrm{eV}$ is attributed to pure-B phase (see Chapter 3) and absent for thermal deposition.

The GPC vs substrate temperature exhibits no Arrhenius behavior (see Figure 6-4) in contrast with the thermal mode (recall Figure 5-4). This is another indication of altering the growth mechanism in comparison to thermal ALD and/or possibly co-existence of several parallel mechanisms with a different dependence on temperature. 


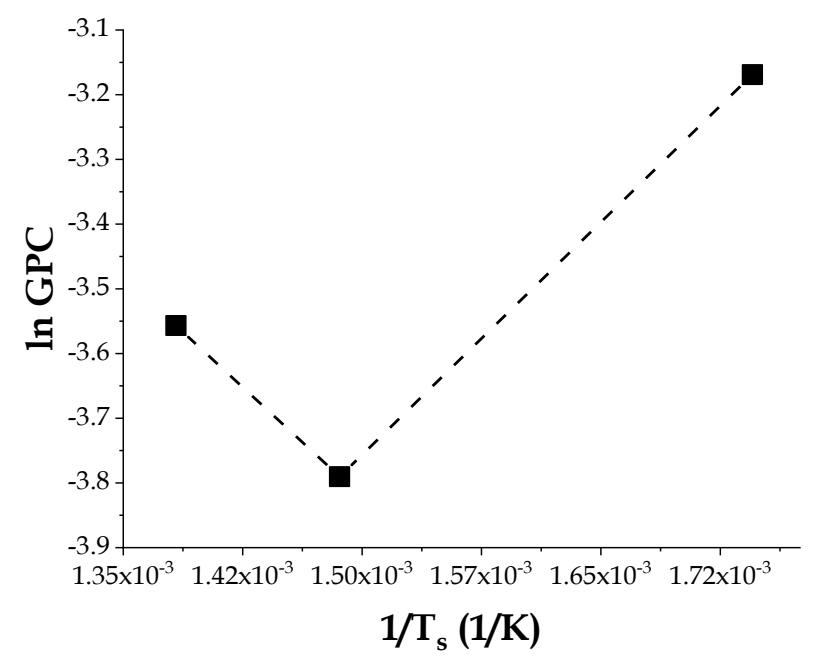

Figure 6-4. Arrhenius plot for the plasma-samples. Conditions: $0.1 \mathrm{~s}$ of $\mathrm{BBr} 3 \mathrm{pulse} / 30 \mathrm{~s}$ of $\mathrm{Ar}$ for post-BBr 3 purge/ $10 \mathrm{~s}$ of $\mathrm{NH}_{3}$ pulse/ $20 \mathrm{~s}$ of Ar for post-NH3 purge. The dashed lines are given as a guide to the eye.

\subsection{BN deposition in a cold-wall reactor}

All the reported earlier experiments concern deposition of BN films in a hotwall reactor. The latter provides a vertical heating zone with a uniform temperature distribution and furnishes a good temperature control. However, due to the (large) hot surfaces, the precursors might react on the walls which could result in their depletion as well as particle/film formation on the walls ${ }^{11-15}$. Such effects are not desired since they can affect both reaction mechanism and material properties.

A cold-wall reactor can suppress the mentioned effects. A more efficient precursor use can be expected since the reactants are not depleted by the walls. On the other hand, heating only the substrate normally results in substrate surface temperature distribution and a strong temperature gradient. The temperature difference between the hot stage $\left(T \approx 1000{ }^{\circ} \mathrm{C}\right.$ ) and the cold walls (few tens of ${ }^{\circ} \mathrm{C}$ ) can be so high ${ }^{14}$ that it is uncertain which reaction pathways will determine the growth. In addition, cold walls will allow increased adsorption or even condensation of precursors, water vapor or reaction byproducts. All these issues can affect the growth mechanism and film properties. The next section aims to 
investigate the differences in film growth using hot-wall or cold-wall reactor designs.

\subsubsection{Experimental setup}

The experiments were performed in a cold-wall reactor of the home-built cluster system, using $\mathrm{BBr}_{3}$ and $\mathrm{NH}_{3}$ precursor pulses with Ar purges in between. For a schematic of the reactor assembly, refer to Figure 1-3. Briefly, the assembly consists of 2 reactors in series with the exhaust of the first (deposition) reactor connected to the inlet of the second (analysis) reactor. Both reactors are pumped by a shared turbo-molecular pump connected to the exhaust of the second reactor. The latter is equipped with an in-situ Fourier transform infrared spectrometer (FTIR), enabling characterization of byproducts coming from the first reactor.

\subsubsection{Purely thermal mode}

The depositions were conducted on $\mathrm{Si}(100)$ substrates at a $T_{S}$ of $300{ }^{\circ} \mathrm{C}$ (as determined by in-situ SE). Initial test experiments (not shown here) were performed to verify the ALD window in terms of pulse/purge durations. XPS analysis revealed approximately 45 at. \% of B, 38 at. \% of N, 15 at. \% of $\mathrm{O}$ and 2 at. \% of $\mathrm{C}$ in the films. The relatively high oxygen share might be due to the (i) oxidation of the films upon exposure to air or (ii) oxygen being incorporated during the growth process. To differentiate between (i) and (ii), two equivalent samples were further deposited with one being in-situ capped with an a-Si protection layer and the other without capping. The XPS depth profiling (Figure 6-5), carried out on both samples after 3 days of their exposure to air, revealed 20 at. \% of oxygen in the uncapped sample and 3-4 at. \% of oxygen in the capped sample. This clearly confirms that the deposited layers were instable in air, presumably indicating their amorphous or nanocrystalline nature ${ }^{16}$. 

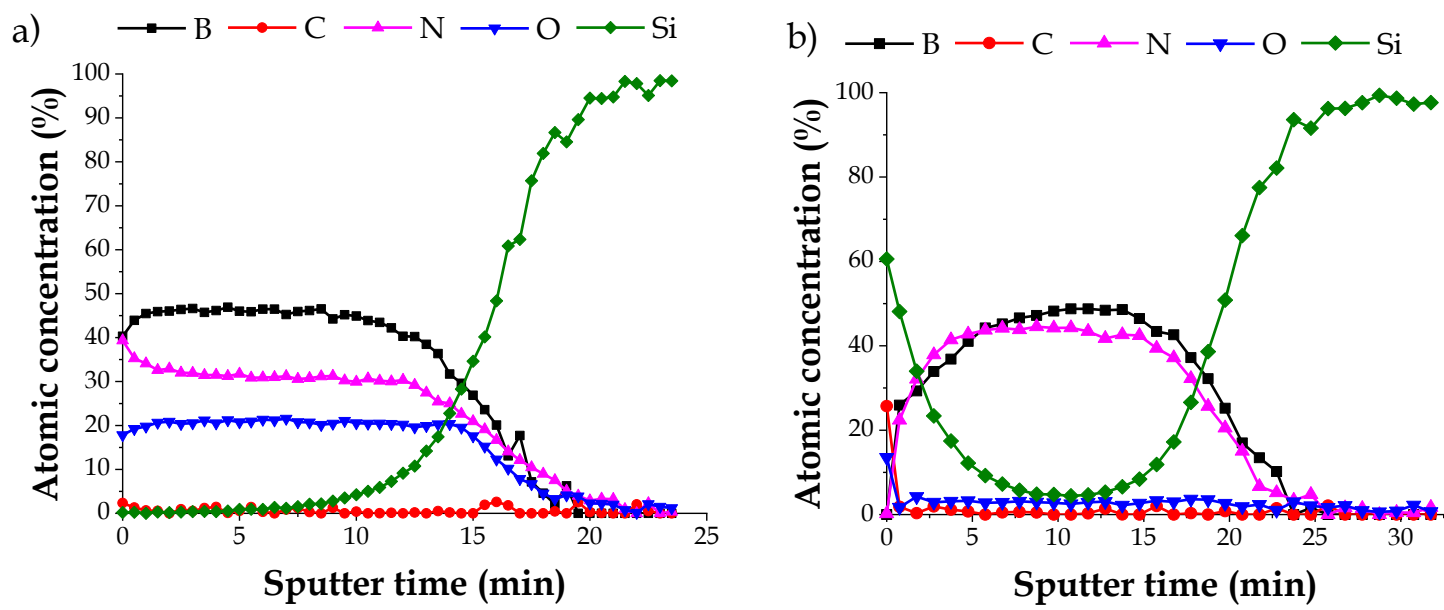

Figure 6-5. XPS sputter depth profiles of samples deposited in purely thermal mode, (a) uncapped and $(\boldsymbol{b})$ with a-Si capping layer. Conditions: $P_{\text {tot }}=0.5$ mbar $\left(P_{\mathrm{NH} 3} \approx 0.2\right.$ mbar $)$, $T_{s}=300^{\circ} \mathrm{C}, 0.1 \mathrm{~s}$ of $\mathrm{BBr}_{3}$ pulse, $30 \mathrm{~s}$ of Ar for post-BBr 3 purge, $5 \mathrm{~s}$ of $\mathrm{NH}_{3}$ pulse and 20 s of Ar for post-NH3 purge.

\subsubsection{Hot-wire-assisted mode}

Further experiments were performed in the same reactor but additionally using a hot-wire $(\mathrm{HW})$ radical source heated up to max. $T_{H W}=1850 \mathrm{~K}$. Interaction of ammonia molecules with the hot tungsten surface of the HW facilitates the formation of atomic hydrogen (at-H) and $\mathrm{NH}_{\mathbf{x}}$ (mainly $\mathrm{NH}_{2}$ ) radicals 2,3. Generating $\mathrm{NH}_{2}$ implies providing a corresponding flux of at- $\mathrm{H}$ to the surface. One should keep in mind that the at-H flux arriving at the growing surface is expected to be relatively high, due to the higher recombination rate of $\mathrm{NH}_{2}$ compared to that of at-H. The generation, recombination and delivery of these radicals to the substrate surface were experimentally confirmed and discussed in our previous work ${ }^{1}$, demonstrating the effective dissociation of $\mathrm{NH}_{3}$ at $\mathrm{HW}$ temperatures above $1600 \mathrm{~K}$.

The HW-assisted deposition led to a significant decrease in the GPC with increasing the HW temperature. Namely being $0.08 \mathrm{~nm} /$ cycle for the $\mathrm{HW}$-off mode (i.e., HW at room temperature), the GPC decreased to $0.05 \mathrm{~nm} /$ cycle for the HW at $2100 \mathrm{~K}$. Such a decrease was in line with the expected suppression of the adduct assisted (thermal) route while activating new chemical routes in the BN growth mechanism (see Figure 6-1 and the corresponding text). 
Specifically, the experiments were performed with the HW-state changing from off to on ( $T_{H W} \sim 1850 \mathrm{~K}$, out of the line-of-sight with the substrate) during deposition, otherwise using the same ALD conditions as for the purely thermal mode. The deposition started with the HW off, then setting the $T_{H W}$ in steps first to $\sim 800 \mathrm{~K}, \sim 1400 \mathrm{~K}$ and finally to $\sim 1850 \mathrm{~K}$. A clear effect of the $T_{H W}$ on the GPC was observed for the $T_{H W}$ beyond $1400 \mathrm{~K}$ (see Figure 6-6.a). The step-height (i.e., first increase after introducing a $\mathrm{BBr}_{3}$ pulse) was only slightly affected ( $15 \%$ change) by $T_{H W}$ while the entire GPC was changed by $\sim 50 \%$. The latter is due to a pronounced decrease of the "thickness" caused by the $\mathrm{NH}_{3}$ pulses ${ }^{* * *}$ : the higher the $T_{H W}$, the larger the decrease (Figure 6-6.b). This effect can be explained by increasing the dissociation degree of ammonia with $T_{H W}$ and altering the growth mechanism due to e.g. the presence of atomic hydrogen, as discussed in Section 6.2. In this light, the use of the mentioned position of the HW, i.e. not in the lineof-sight with the substrate, ensures an effective delivery of at- $\mathrm{H}$ to the film surface, however preventing delivery of $\mathrm{NH}_{2}$ radicals (see ref. ${ }^{1}$ for further details).

\footnotetext{
*** Thickness decrease after introducing an $\mathrm{NH}_{3}$ pulse as can be seen in Figure 6-6.b for $\mathrm{T}_{\mathrm{HW}}$ at $1400 \mathrm{~K}$ and $1850 \mathrm{~K}$.
} 


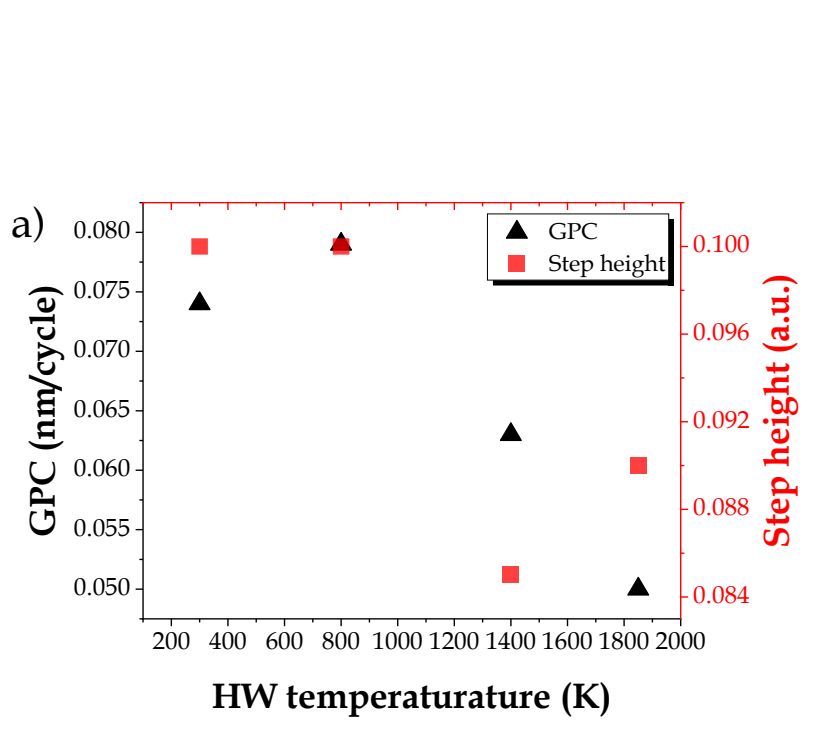

b)

$\mathrm{NH}_{3}$ pulse

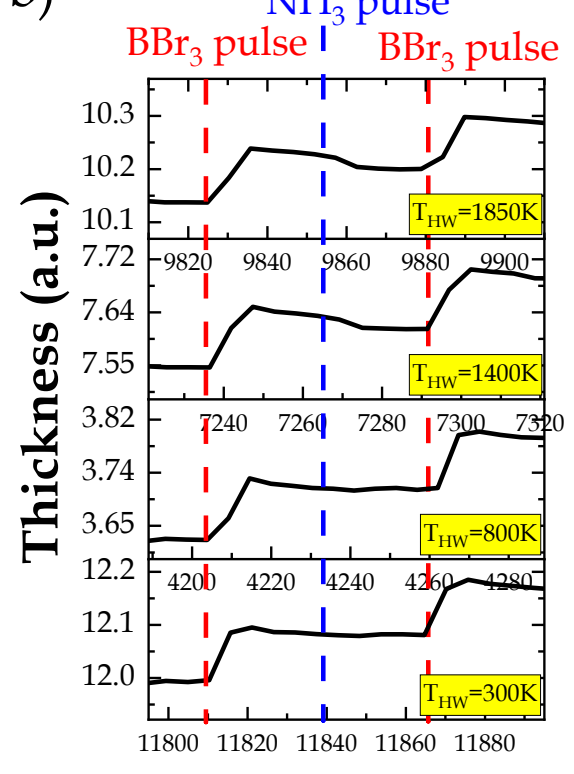

Time (s)

Figure 6-6. (a) GPC and (b) step-shape evolution with changing HW temperature. All measurements are performed by in-situ SE. It is important to bear in mind the considerations mentioned in Section 5.5.2 w.r.t. to the small step-variations interpreted by $S E$ as the thickness changes.

XPS sputter-depth profiling of the HW-deposited films (see Figure 6-7) reveals (similar to the thermally deposited layers - recall Figure 6-5) near stoichiometric boron nitride with less than 3 at.\% of oxygen. It can be concluded that the HW does not affect the composition, as there is no clear in-depth change observed.

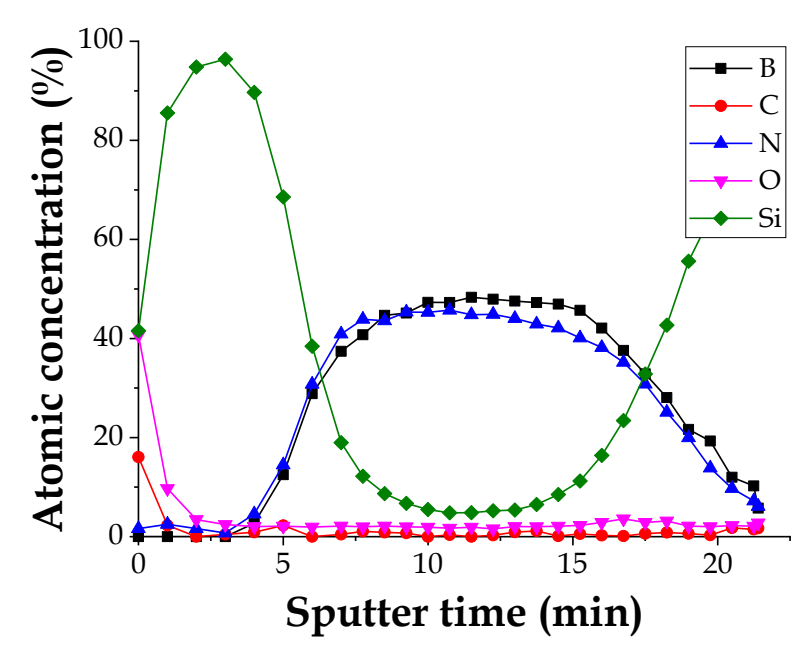

Figure 6-7. XPS sputter-depth profiling of the HW-deposited sample shown in Figure 66.a. 
It is however known that structural properties can be improved by activating radical-assisted routes. It has been reported that plasma assistance can help to improve crystallinity, electrical properties, and density of the layers ${ }^{8-10}$. Utilizing a hot-wire may be another approach to influence film properties. Importantly, a HW-process is purely chemical opposite to plasma, since energetic and charged species are excluded from the gas-surface interactions. Comparing plasma with HW in this aspect can further clarify the mechanism(s) behind the changes of the film properties.

Specifically, ref. ${ }^{17}$ reported on an improved crystallinity of silicon obtained by HWCVD. In expectation of a possible effect, transmission electron microscopy (TEM) analysis of the purely thermal and HW-deposited samples was performed. Both samples exhibited an amorphous structure of the layers. The thermal-BN easily delaminated from the substrate surface (Figure 6-8.a), indicating its poor adhesion. However, a better adhesion was observed for the HW-sample, showing no delamination (Figure 6-8.b). Both films exhibited similar densities, $2.06 \mathrm{~g} / \mathrm{cm}^{3}$ for the thermal and $1.98 \mathrm{~g} / \mathrm{cm}^{3}$ for the HW-deposited sample (determined by $\mathrm{x}$ ray reflectometry). These values are within the range of $1.8-2.3 \mathrm{~g} / \mathrm{cm}^{3}$ reported for amorphous $\mathrm{BN} 18,19$.
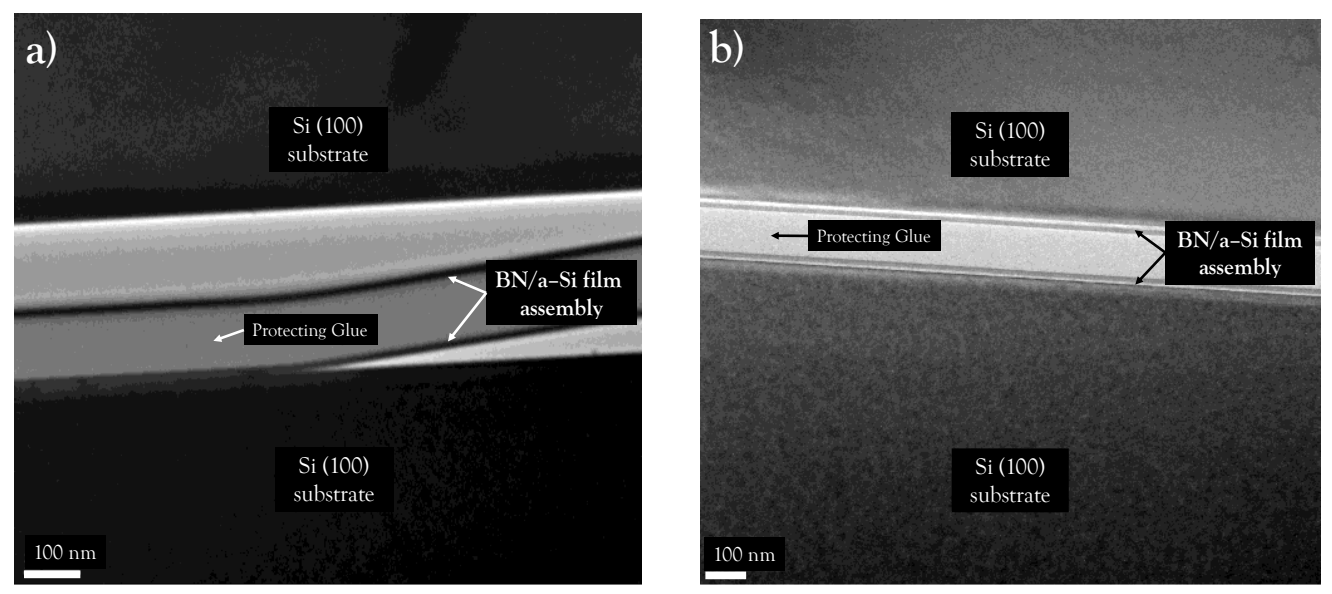

Figure 6-8. TEM images of the films deposited in (a) purely-thermal and (b) HWassisted modes. For the thermal sample, adhesion of the BN/a-Si stack to the protective glue layer is much larger than that to the Si substrate. This leads to the easy delamination of the complete BN/a-Si/protecting glue/a-Si/BN stack from the Si. There is no delamination observed for the HW-sample. 


\subsubsection{Studying the byproduct formation}

Ammonium bromide $\left(\mathrm{NH}_{4} \mathrm{Br}\right)$ forms as a byproduct of the $\mathrm{BN}$ formation reaction and further deposits on all cold parts of the two-reactor assembly (recall Figure 1-3) Such parts include the reactor walls, room-temperature substrates and the internal FTIR mirrors of the second downstream reactor. In ref. ${ }^{20}$, we propose to study deposition of $\mathrm{NH}_{4} \mathrm{Br}$ for differentiating between ALD and CVD modes. This can further assist in (i) optimizing the deposition conditions and (ii) clarifying the deposition mechanism.

Briefly, rather important conclusions can be drawn from measuring the ratio of the produced amounts of $\mathrm{NH}_{4} \mathrm{Br}$ and $\mathrm{BN}$. In view of the proposed adduct formation mechanism discussed in Sections 5.3.1 and 6.2, deposition of 1 mole of $\mathrm{BN}$ should result in the production of 1 mole of $\mathrm{NH}_{4} \mathrm{Br}$, if working in an ALD mode. The $\mathrm{NH}_{4} \mathrm{Br}$ solely appears because of the reaction between $\mathrm{NH}_{3}$ (of the pulse) and $\mathrm{HBr}$ (of the byproduct). For CVD, when all the precursors are mixed, at least 3 moles of $\mathrm{NH}_{4} \mathrm{Br}$ will be produced per 1 mole of $\mathrm{BN}$. Therefore, the relativeto-BN amount of produced $\mathrm{NH}_{4} \mathrm{Br}$ can indicate the growth mode. It can further shine light on the deposition mechanism, since the relative $\mathrm{NH}_{4} \mathrm{Br}$-amount can be pressure and/or temperature dependent. These issues however require further investigation and are out of the scope of this work. Further details can be found in Appendix 6.3.

The removal of ammonia from the cold-wall reactor is analyzed in Appendix 6.1. Additional results on the formation and identification of $\mathrm{NH}_{4} \mathrm{Br}$ can be found in Appendix 6.2. The migration of $\mathrm{NH}_{4} \mathrm{Br}$ and its removal from the reactor are briefly discussed in Appendix 6.4.

\subsection{Conclusions}

The effects of switching to radical enhanced modes were investigated in comparison to purely thermal deposition. The experimental results could be adequately explained by the proposed growth mechanism which involved 
activating the additional-to-thermal chemical routes. The radical enhancement lead to lower GPC values and the existence of a pure-B phase. Unlike the thermal mode, the absence of Arrhenius behavior could be considered as another evidence of the altered reaction mechanism.

Further, the effects of performing depositions with a cold wall reactor (instead of a hot-wall reactor) were investigated. The material characterization revealed results similar to those obtained with a hot-wall reactor. We namely observed (i) pressure dependence of the GPC, (ii) a lower GPC in the case of the radical (HW) enhancement, (iii) environmentally instable layers with (iv) amorphous/nanocrystalline structure. Studying the ammonium bromide $\left(\mathrm{NH}_{4} \mathrm{Br}\right)$ formation is suggested for differentiating between ALD and CVD modes as well as for clarifying the deposition mechanism. 


\section{Appendix 6.1: Ammonia-decay analysis}

Ammonia decay analysis were performed using Perkin-Elmer Frontier FTIR equipment. For this analysis, $\mathrm{NH}_{3}$ was introduced into the reactor for $5 \mathrm{~s}$. The other parameters were kept similar $\left(T_{s}=300{ }^{\circ} \mathrm{C}\right.$ and $\left.P_{t o t}=0.5 \mathrm{mbar}\right)$ to the experimental conditions discussed in Section 6.4.

Although ammonia has its most intense peaks located at $965 \mathrm{~cm}^{-1}$ and 931 $\mathrm{cm}^{-1}$ and many other peaks with various intensities in the wavenumber range of $550-1250 \mathrm{~cm}^{-1}$, it is not easy to perform reliable baseline correction analysis in these ranges due to the limitations of the equipment. Therefore, to calculate the partial pressure of ammonia decay in the reactor, we selected the wavenumber range of $1300-1900 \mathrm{~cm}^{-1}$. It should be noted that this calculation is only valid for this particular reactor. The calculations were performed as follows:

1- Background recorded to eliminate the effects of existing molecules (i.e. water) and ammonia introduced into the reactor while FTIR signal continuously recorded.

2- Multiple, representative spectrum files were selected at different times

3- Transmittance $(T)$ data converted to Absorbance $(A)$ using the following equation (equation A-6.1), where $I$ and $I_{o}$ represents the intensity in the sample spectrum and intensity of the background spectrum, respectively.

$$
A=-\ln (T), \text { where } \mathrm{T}=\frac{I}{I_{o}}
$$

4- Peak areas were calculated by integration $\left(\int A-\right.$ unit $\left.\mathrm{cm}^{-1}\right)$.

5- The absorption cross section (ACS - unit $\mathrm{cm}^{2} /$ molecule) is calculated using the HITRAN database ${ }^{21}$ as a reference and multiplied with the optical pathlength of our setup.

6- To convert the integrated absorbance $\left(\int A\right)$ to a concentration $(n / V$ - unit molecules $/ \mathrm{cm}^{3}$ ) the following equation (equation A-6.2) is used.

$$
n / V=\int A / A C S
$$

7- The result obtained from equation A-6.2 is converted to molecules $/ \mathrm{m}^{3}$. 
8- Following ideal gas law (equation A-6.3) pressure is calculated. In this equation $P$ is pressure, $T$ is temperature and $k_{B}$ is the Boltzmann constant.

$$
P=n / V k_{B} T
$$

As evident from Figure A-6-1, it requires several minutes to purge ammonia below the FTIR detection limit. A complete removal of $\mathrm{NH}_{3}$ (meaning that ammonia is not detectable by FTIR in the full range of $600-4000 \mathrm{~cm}^{-1}$ ) requires tens of minutes, making BN ALD impractical in this reactor.

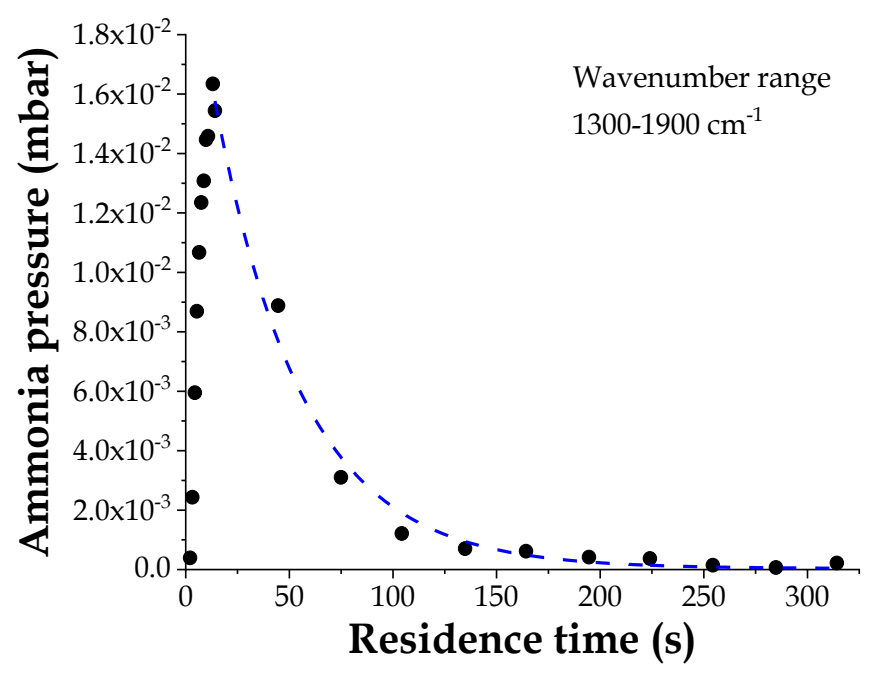

Figure A-6-1. Ammonia pressure decay measured by FTIR by analyzing corresponding absorption bands in the range of $1300-1900 \mathrm{~cm}^{-1}$. 


\section{Appendix 6.2. Ammonium bromide identification ttt}

Migration of solid (but volatile) species in cold-wall reactors is a known problem for CVD and ALD processes, especially if Lewis acids and Lewis bases are used as precursors 22,23 . These compounds tend to deposit on all available surfaces that have temperatures lower than the decomposition temperature of the solids. For the cold-wall reactor employed in Section 6.4, this includes the reactor walls and the FTIR mirrors. The latter allows the detection of the solid reaction byproduct (Figure A-6-2), which is identified as ammonium bromide $\left(\mathrm{NH}_{4} \mathrm{Br}\right)$.

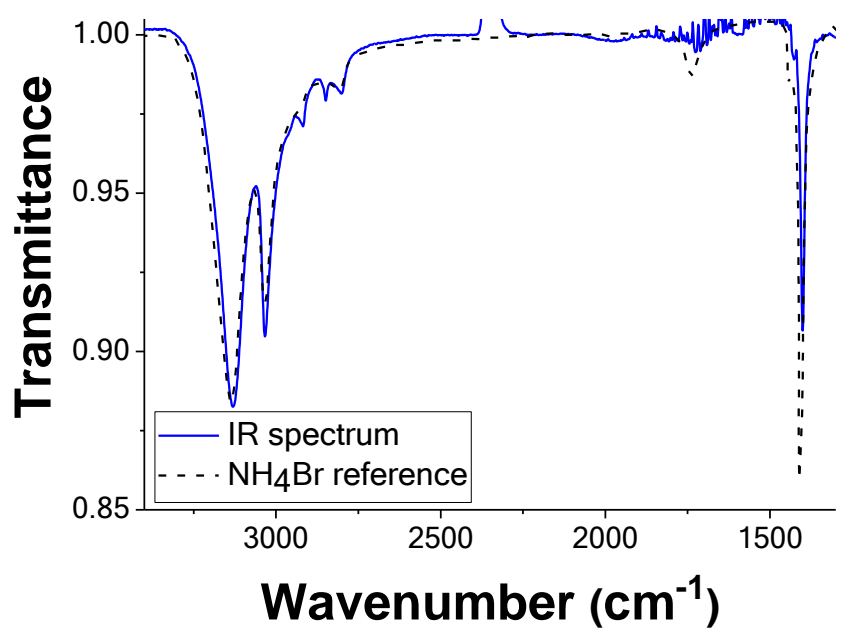

Figure A-6-2. In-situ FTIR spectrum of the solid byproduct and its comparison with a reference ${ }^{24}$.

In boron nitride deposition from boron halides (i.e., $\mathrm{BBr}_{3}$ and $\mathrm{BCl}_{3}$ ), ammonium halide powders are being formed via the reaction of ammonia with available hydrogen halides (i.e., $\mathrm{HCl}, \mathrm{HBr}$ ). In this work, $\mathrm{NH}_{4} \mathrm{Br}$ is being formed by reaction of $\mathrm{HBr}$ (byproduct of the reactions between $\mathrm{BBr}_{3}$ and $\mathrm{NH}_{3}$ ) and $\mathrm{NH}_{3}$ :

$$
\mathrm{HBr}+\mathrm{NH}_{3} \leftrightarrow \mathrm{NH}_{4} \mathrm{Br}
$$

Reaction A-6.1 requires simultaneous presence of the reactants $\mathrm{HBr}$ and $\mathrm{NH}_{3}$. In an ideal ALD process, both $\mathrm{HBr}$ and $\mathrm{NH}_{3}$ are available during an $\mathrm{NH}_{3}$ pulse only. As shown in Appendix 6.1, even with very long purge durations

\footnotetext{
††门 Joint work of R.O. Apaydin and A.J. Onnink (University of Twente).
} 
(minutes), the high sticking coefficient of ammonia at room temperature ${ }^{25}$ results in $\mathrm{NH}_{3}$ adsorption on the reactor cold walls. 


\section{Appendix 6.3. In-situ study of ammonium bromide formation for optimizing boron nitride $\mathrm{ALD}$ from $\mathrm{BBr}_{3}$ and $\mathrm{NH}_{3}$}

The deposition of $\mathrm{BN}$ from boron tribromide $\left(\mathrm{BBr}_{3}\right)$ and ammonia $\left(\mathrm{NH}_{3}\right)$ was studied by in-situ real-time monitoring of the reactive gases and reaction byproducts, using Fourier Transform infrared (FTIR) spectroscopy and spectroscopic ellipsometry (SE) as schematically shown in Figure A-6-3.a. Depending on the chosen conditions, the deposition of BN varies between an ALD mode and a pulsed chemical vapor deposition (CVD) mode. Figures A-6-3.b and A-6-3.c show a layer of particles deposited on a cold (293 K) substrate near the exhaust, identified as ammonium bromide $\left(\mathrm{NH}_{4} \mathrm{Br}\right)$ by the FTIR reflectance spectrum. Such a salt is a known byproduct in CVD from $\mathrm{NH}_{3}$ and halide precursors 26 , forming from $\mathrm{NH}_{3}$ and the gaseous hydrogen halide byproduct (here, $\mathrm{HBr}$ ) and spreading through the reactor by sublimation, dissociation 27 to $\mathrm{HBr}+\mathrm{NH}_{3}$, and redeposition.

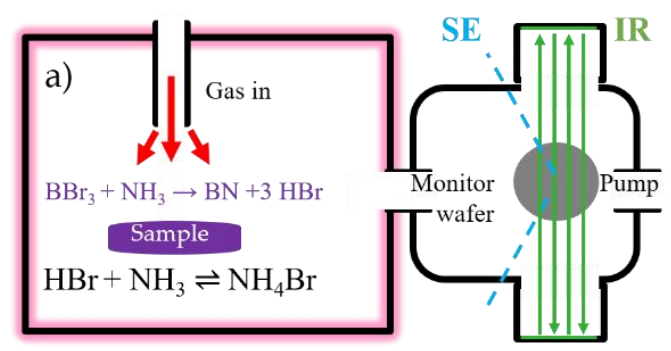

b)

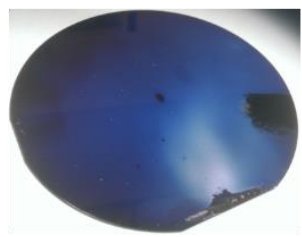

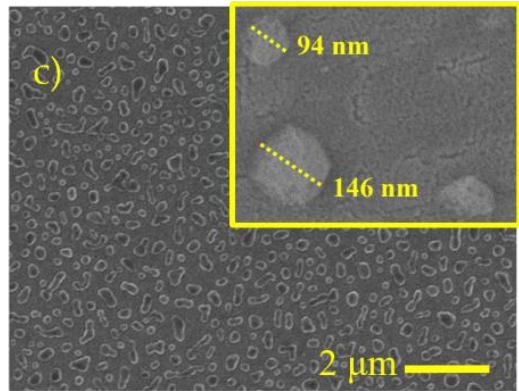

Figure A-6-3. (a) Schematic overview of the studied reactions and the reactor (not to scale), comprising a BN deposition compartment (345 K walls) and an attachment (293 $K)$ with in-situ spectroscopic ellipsometer (SE) and infrared (IR) spectrometer. The IR beam reflects between aluminum mirrors to a total path length of $26 \mathrm{~m}$. (b) Photo of monitor wafer with a $\mathrm{NH}_{4} \mathrm{Br}$ film (partially cleaned for contrast). (c) Scanning electron micrographs of $\mathrm{NH}_{4} \mathrm{Br}$ nanoparticles on $(b)$.

To optimize an ALD recipe, the precursor-pulse and purge durations are typically increased until the growth per cycle (GPC) saturates. This work explores a new method to optimize BN ALD based on in-situ monitoring by FTIR and SE of

Ht This section is a joint work presented at EuroCVD22-Baltic ALD16 conference by A.J. Onnink, see the list of publications at the end of this thesis. 
the precursors and reaction byproducts. The idea is as follows. First, FTIR monitoring detects precursor mixing (PM) in real-time and thus assists in minimizing that effect. Second, the quantity of $\mathrm{NH}_{4} \mathrm{Br}$ formed per cycle is expected to indicate a degree of PM. Figure A-6-4.a demonstrates the concept, which is understood by the model given below.

In absence of PM, only the fraction of $\mathrm{HBr}$ that is produced in the $\mathrm{NH}_{3}$ pulse forms $\mathrm{NH}_{4} \mathrm{Br}$. BN ALD will thus form less $\mathrm{NH}_{4} \mathrm{Br}$ than CVD; the amount depends on the mechanism. Based on the known mechanism of thermal ALD of aluminum nitride and the recently proposed similar pathway for gallium nitride from $\mathrm{NH}_{3}$ and trimethylgallium ${ }^{28}$, we hypothesize that ALD of BN involves formation of a $\mathrm{BBr}: \mathrm{NH}_{3}$ 'surface adduct' complex, subsequently converted to B- $\mathrm{NH}_{2}-\mathrm{B}$ links. This reaction produces $1 \mathrm{~mol}$ of $\mathrm{HBr}$ per mol of $\mathrm{BN}$ in the $\mathrm{NH}_{3}$ pulse, and so $1 \mathrm{~mol}$ of $\mathrm{NH}_{4} \mathrm{Br}$. The remaining hydrogen atoms of the $-\mathrm{NH}_{2}$-termination are released in the $\mathrm{BBr}_{3}$ pulse (i.e., $-\mathrm{NH}_{2}+\mathrm{BBr}_{3} \rightarrow 2 \mathrm{HBr}+-\mathrm{N}-\mathrm{B}-\mathrm{Br}$ ) in absence of $\mathrm{NH}_{3}$. Alternative ALD mechanisms may yield higher $\mathrm{NH}_{4} \mathrm{Br}$ production, but not exceeding 3 mol per mol BN. With PM, at least $3 \mathrm{~mol} \mathrm{NH}_{4} \mathrm{Br}$ is made per mol $\mathrm{BN}$, or more if $\mathrm{BBr}_{3}$ reacts with gases such as $\mathrm{H}_{2} \mathrm{O}$ to form additional $\mathrm{HBr}$. Therefore, the monitoring of $\mathrm{NH}_{4} \mathrm{Br}$ production can yield information on the mode and mechanism of pulsed BN deposition.

The conditions that minimize PM in a BN deposition can be predicted by a model that describes the rise (pulse), decay (purge), and fall (reaction) in the precursor partial pressures. Figure A-6-4.b shows such a model, that also incorporates $\mathrm{HBr}$ and the growth of $\mathrm{NH}_{4} \mathrm{Br}$ through parameters determined from combined in-situ SE and FTIR data (e.g., Figure A-6-4.a). Process 2 approaches the $\mathrm{NH}_{4} \mathrm{Br}$ GPC of ALD, whereas process 1 is in CVD mode. An extensive purge is required to prevent PM fully; the duration may be shortened by minimizing the pulse dose and reactor volume, and maximizing the pump speed. 
a)

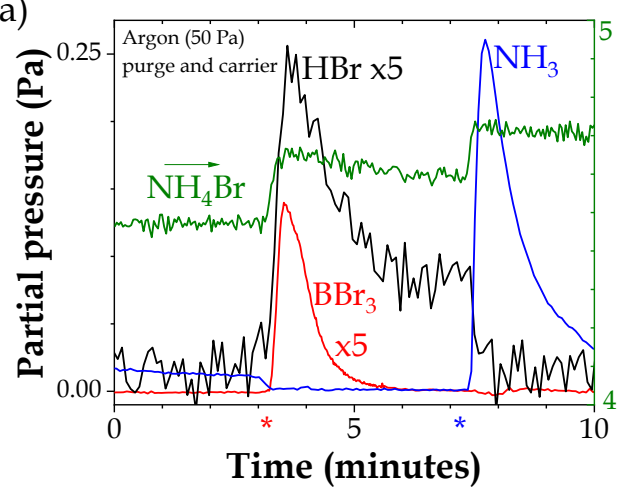

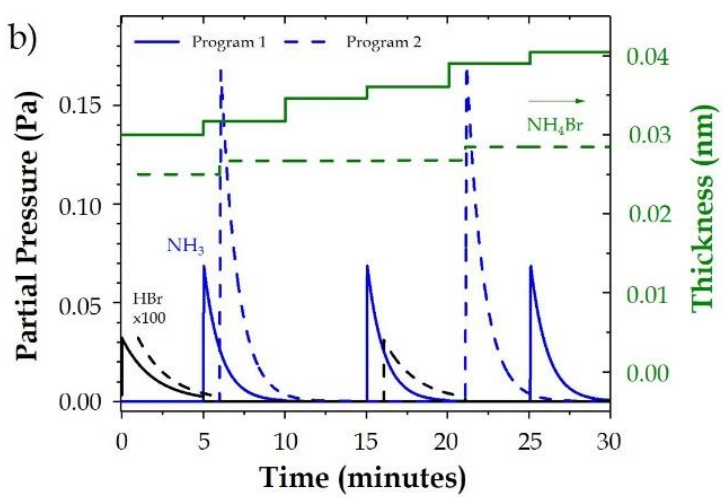

Figure A-6-4. (a) In-situ monitoring of partial pressures of gases (FTIR) and the effective thickness of $\mathrm{NH}_{4} \mathrm{Br}$ (SE) near the exhaust during pulsed BN deposition. A pulse of $\mathrm{BBr}_{3}(30 \mathrm{~s})$ is started at $t=3 \mathrm{~min}$ with $0.01 \mathrm{~Pa}$ of $\mathrm{NH}_{3}$ still present, leading to production of $\mathrm{NH}_{4} \mathrm{Br}$ and $\mathrm{HBr}$ and rapid decay of $\mathrm{P}_{\mathrm{NH}}$. A subsequent pulse of $\mathrm{NH}_{3}(5 \mathrm{~s})$ in the presence of $\mathrm{HBr}$ similarly leads to $\mathrm{NH}_{4} \mathrm{Br}$ production. (Partial pressures were calculated from the integrated absorbance of peaks in FTIR spectra. The effective $\mathrm{NH}_{4} \mathrm{Br}$ thickness is calculated as layer thickness $\times$ (1-void fraction) from fits to SE data.) (b) Simulated pulsed depositions with different pulse and purge durations. Program 1 leads to significant PM and high $\mathrm{NH}_{4} \mathrm{Br}$ GPC. Program 2 approaches $A L D$, as most $\mathrm{HBr}$ produced in the $\mathrm{BBr}_{3}$ pulse is pumped off rather than reacting with $\mathrm{NH}_{3}$ to form $\mathrm{NH}_{4} \mathrm{Br}$.

The model calculates the $\mathrm{NH}_{4} \mathrm{Br}$ production assuming instantaneous reactions (not treating transport or kinetics): experimentally, when either $\mathrm{HBr}$ or $\mathrm{NH}_{3}$ is present in excess, the other species is not detected by in-situ FTIR, consistent with full conversion to $\mathrm{NH}_{4} \mathrm{Br}$. Durations in seconds (BBr 3 pulse, Ar purge, $\mathrm{NH}_{3}$ pulse, Ar purge), program 1: 0.1-300-2-300, program 2: 0.1-300-5-600.

The monitoring of experimental trends in the $\mathrm{NH}_{4} \mathrm{Br}$ production can further clarify the $\mathrm{BN}$ growth mechanism. If $\mathrm{BN}$ growth occurs via reversible formation of -BBr: $\mathrm{NH}_{3}$ surface adducts, then the equilibrium concentration of these adducts should increase with the partial pressure of $\mathrm{NH}_{3}\left(P_{\mathrm{NH}}\right)$, enhancing the formation of B-NH${ }_{2}-\mathrm{B}$ links. Our separately submitted results ${ }^{29}$, which is also discussed in Chapter 5, indeed show the expected dependence of the BN GPC on $P_{N H 3}$, which is rather atypical for ALD. In support of this result, Figure A-6-5.a demonstrates that the $\mathrm{NH}_{4} \mathrm{Br}$ production per cycle is also pressure-dependent. A lower pressure results in increased $\mathrm{NH}_{4} \mathrm{Br}$ production, presumably because the $\mathrm{BN}$ growth mechanism transitions from adduct-dominated to a different regime in which more than 1 unit of $\mathrm{HBr}$ is produced per unit of $\mathrm{BN}$ during the $\mathrm{NH}_{3}$ pulse.

Figure A-6-5 displays the surprising observation that $\mathrm{NH}_{4} \mathrm{Br}$ deposition on the monitor wafer can be delayed to over an hour after the end of BN deposition. 
Based on the absence of $\mathrm{HBr}$ (Figure A-6-5.a, inset) at the exhaust during the delay, we suggest that free $\mathrm{HBr}$ has a short lifetime when chamber surfaces have a high density of adsorbed $\mathrm{NH}_{3}$. Then, all $\mathrm{NH}_{4} \mathrm{Br}$ produced after the first cycle initially deposits on cold surfaces near the deposition compartment only. Any decomposition to $\mathrm{HBr}+\mathrm{NH}_{3}$ is quickly followed by redeposition, until the density of $\mathrm{NH}_{3}$ is sufficiently reduced to allow migration (Figure A-6-5.b).
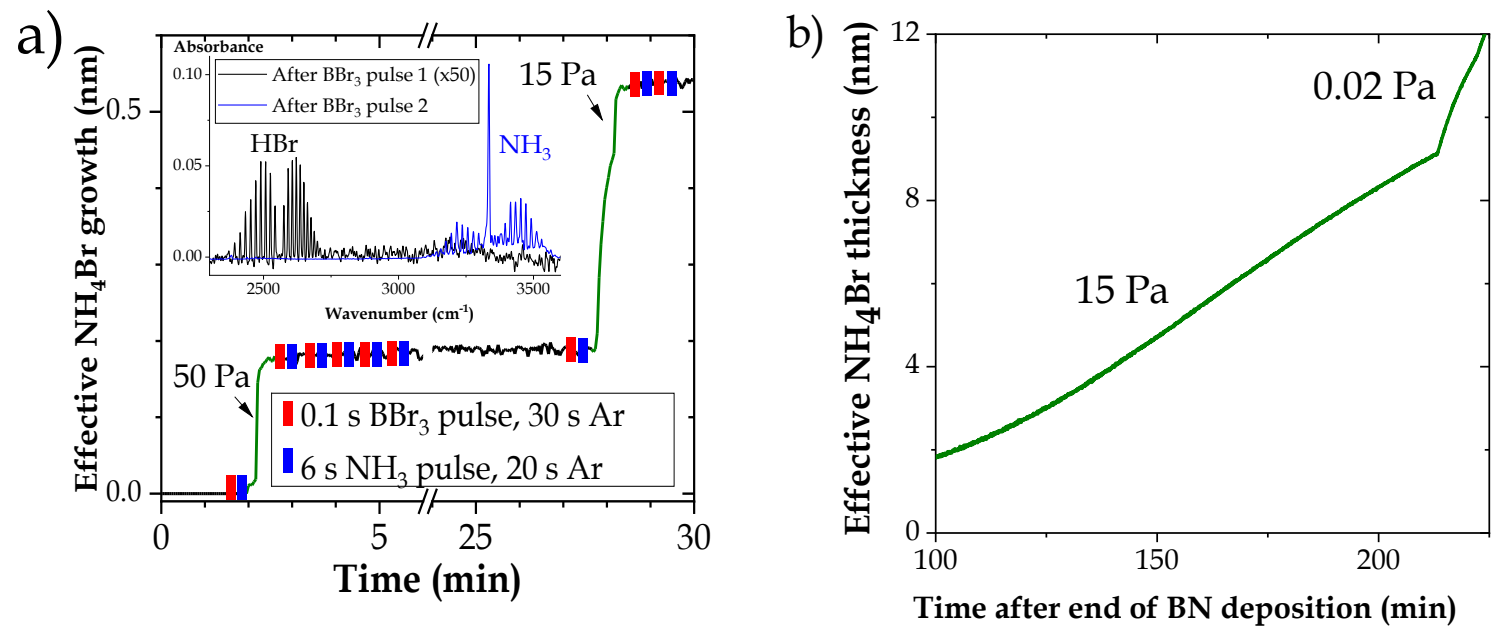

Figure A-6-5. (a) During pulsed BN deposition with purge duration $<1$ minute, $\mathrm{NH}_{4} \mathrm{Br}$ only deposits on the monitor wafer in the first pulse-purge cycle. In subsequent cycles and until a 10-minute purge, in-situ FTIR monitoring (inset) detects $\mathrm{NH}_{3}$ but not $\mathrm{HBr}$. This figure also shows that the $\mathrm{NH}_{4} \mathrm{Br} G P C$ on the monitor wafer increases as pressure is decreased. (b) After the BN deposition started in (a) is completed, $\mathrm{NH}_{4} \mathrm{Br}$ migrates from the deposition chamber to the monitor wafer. 


\section{Appendix 6.4. Ammonium bromide migration and removal issues $§ \S \S$}

Once deposited, ammonium bromide causes multiple problems, mainly contaminating the reactor as well as the FTIR mirrors and the pumping system. One (and possibly the best) way of minimizing such contaminants is to keep the temperature of the system (including reactor walls and pumping system) above the sublimation temperature of $\mathrm{NH}_{4} \mathrm{Br}$. However, heating the entire system may be a difficult task. Consequently, other effective cleaning procedures must be found.

In this work, we studied multiple approaches including wet scrubbing, heating or mobilization by hot-wire and plasma. It was observed that wet scrubbing of contaminated surfaces is an efficient method on removing the contaminants. Yet, considering the complex geometries of the deposition systems, it is not possible to reach all the deposits of $\mathrm{NH}_{4} \mathrm{Br}$ in this way. Additionally, partial cleaning of the reactor and waiting for migration of the molecules is not an effective method due to the possibility of agglomeration into bigger molecules, which makes it harder to estimate the time required for complete removal of the molecules from the reactor. In addition, because this procedure requires exposure of the reactor to ambient conditions, cleaning via wet scrubbing is impractical.

Secondly, we studied heating the reactor walls to favor the sublimation and migration of $\mathrm{NH}_{4} \mathrm{Br}$. It was observed that heating the walls up to $80{ }^{\circ} \mathrm{C}$ enhanced the $\mathrm{NH}_{4} \mathrm{Br}$ migration. The relatively high activation energy $(\sim 0.65 \mathrm{eV})$ required for sublimation of $\mathrm{NH}_{4} \mathrm{Br}{ }^{30}$ and the low wall temperature results in a long waiting time, up to tens of days to remove all the contaminants from the reactor.

The possibility of $\mathrm{NH}_{4} \mathrm{Br}$ removal by introducing $\mathrm{Ar}$ and an $\mathrm{Ar} / \mathrm{H}_{2}$ mixture through HW and a microwave plasma sources has been further investigated. For this, a clean monitor wafer was placed in the downstream direction and SE was installed to follow the thickness changes on the wafer. It was observed that HW

$\S \S \S$ Joint work of R.O. Apaydin and A.J. Onnink (University of Twente). 
did not cause any removal, presumably due to a low concentration of at-H generated. On the other hand, plasma resulted in sharp thickness changes over the monitor wafer, indicating a plasma-enhanced removal. It can be seen from Figure A-6-6.a that the effect of plasma in the case of pure-Ar compared to $\mathrm{Ar} / \mathrm{H}_{2}$ mixture is much less pronounced. Interestingly, a removal of $\mathrm{NH}_{4} \mathrm{Br}$ under $\mathrm{UV} /$ Visible light exposure (provided by SE beam) was also observed (see Figure A-6-6.b), presumably due to the local heating or photocatalytic effects.

a)

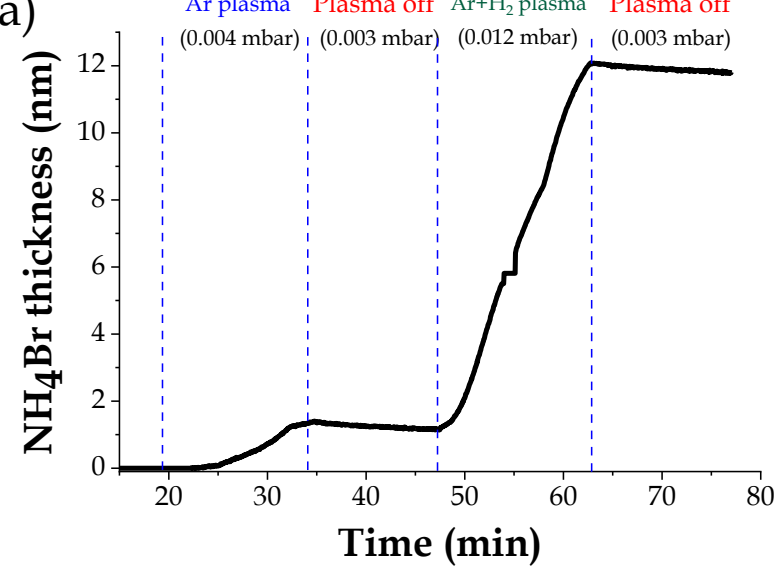

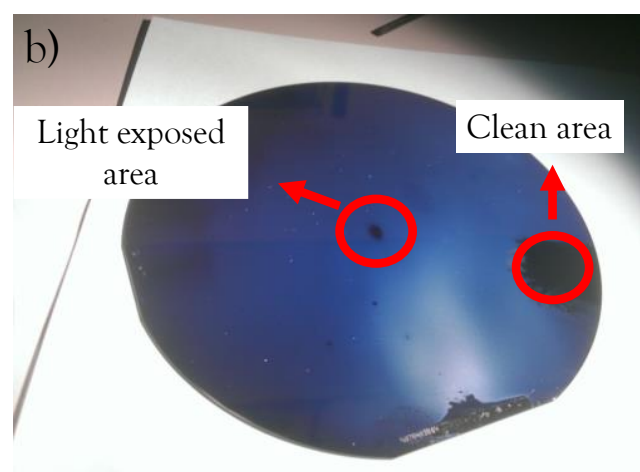

Figure A-6-6. (a) SE measurements of $\mathrm{NH}_{4} \mathrm{Br}$ thickness change by Ar and $\mathrm{Ar}+\mathrm{H}_{2}$ plasma. Rapid change in thickness in case of $\mathrm{Ar}+\mathrm{H}_{2}$ introduction (b) a picture of monitor wafer after $\mathrm{NH}_{4} \mathrm{Br}$ deposition.

Concluding, effective cleaning can be achieved by simultaneous heating of walls and exposure to $\mathrm{Ar} / \mathrm{H}_{2}$ plasma. Detailed investigation of $\mathrm{NH}_{4} \mathrm{Br}$ cleaning is however out of the scope of this work. 


\section{References}

${ }^{1}$ A.Y. Kovalgin, M. Yang, S. Banerjee, R.O. Apaydin, A.A.I. Aarnink, S. Kinge, and R.A.M. Wolters, Adv. Mater. Interfaces 4, 1700058 (2017).

2 H. Umemoto, K. Ohara, D. Morita, T. Morimoto, M. Yamawaki, A. Masuda, and H. Matsumura, Jpn. J. Appl. Phys. 42, 5315 (2003).

3 Y.J. Shi, B.D. Eustergerling, and X.M. Li, Thin Solid Films 516, 506 (2008).

${ }^{4}$ R. d'Agostino, F. Cramarossa, S. De Benedictis, and G. Ferraro, Plasma Chem. Plasma Process. 1, 19 (1981).

${ }^{5}$ G.P. Miller and J.K. Baird, J. Phys. Chem. 97, 10984 (1993). 2008).

6 A. Fridman, Plasma Chemistry (Cambridge University Press, Cambridge,

7 M. Losurdo, M.M. Giangregorio, A. Sacchetti, P. Capezzuto, G. Bruno, G. Malandrino, and I.L. Fragalà, Superlattices Microstruct. 42, 40 (2007).

${ }^{8}$ H. Van Bui, F.B. Wiggers, A. Gupta, M.D. Nguyen, A.A.I. Aarnink, M.P. de Jong, and A.Y. Kovalgin, J. Vac. Sci. Technol. A Vacuum, Surfaces, Film. 33, 01A111 (2015).

${ }^{9}$ Y. Lee, S. Kim, J. Koo, I. Kim, J. Choi, H. Jeon, and Y. Won, J. Electrochem. Soc. 153, 353 (2006).

10 H.B. Profijt, S.E. Potts, M.C.M. van de Sanden, and W.M.M. Kessels, J. Vac. Sci. Technol. A Vacuum, Surfaces, Film. 29, 050801 (2011).

11 M. Yang, Hot-Wire Assisted Atomic Layer Deposition of Tungsten Films, University of Twente, 2018.

12 H. Habuka, J. Cryst. Growth 223, 145 (2001).

13 N. Bondestam and S. Lindfors, US6939579B2 (2005).

14 H. Arjmandi-Tash, N. Lebedev, P.M.G. van Deursen, J. Aarts, and G.F. Schneider, Carbon N. Y. 118, 438 (2017).

15 A.R. Barron, editor, Chemistry of Electronic Materials (Andrew R. Barron, Houston, Texas, 2013).

16 C. Gómez-Aleixandre, A. Essafti, M. Fernández, J.L.G. Fierro, and J.M. Albella, J. Phys. Chem. 100, 2148 (1996).

17 J.H. Song, B. Du Ahn, S.D. Shin, N.M. Hwang, and H.J. Kim, Sol. Energy Mater. Sol. Cells 93, 324 (2009).

18 S. V. Nguyen, T. Nguyen, H. Treichel, and O. Spindler, J. Electrochem. Soc. 141, 1633 (1994).

19 N.R. Glavin, C. Muratore, M.L. Jespersen, J. Hu, P.T. Hagerty, A.M. Hilton, A.T. Blake, C.A. Grabowski, M.F. Durstock, M.E. McConney, D.M. Hilgefort, T.S. Fisher, and A.A. Voevodin, Adv. Funct. Mater. 26, 2640 (2016). 
20 A.J. Onnink, R.O. Apaydin, J. Schmitz, and A.Y. Kovalgin, in EuroCVD 22Baltic ALD 16 Conf. (Luxembourg, 2019).

${ }^{21}$ C. Hill, I.E. Gordon, R. V. Kochanov, L. Barrett, J.S. Wilzewski, and L.S. Rothman, J. Quant. Spectrosc. Radiat. Transf. 177, 4 (2016).

22 V. Pavlović, H.-R. Kötter, and C. Meixner, J. Mater. Res. 6, 2393 (1991).

${ }^{23}$ K. Possemiers, N.R.E.N. Impens, and E.F. Vansant, J. Chem. Soc. - Faraday Trans. 93, 2309 (1997).

24 E.L. Wagner and D.F. Hornig, J. Chem. Phys. 18, 305 (1950).

${ }^{25}$ A. de Castro, D. Alegre, and F.L. Tabarés, Nucl. Mater. Energy 9, 1 (2016).

26 B.J. Choi, D.W. Park, and D.R. Kim, J. Mater. Sci. Lett. 14, 452 (1995).

27 R.S. Zhu, J.H. Wang, and M.C. Lin, J. Phys. Chem. C 111, 13831 (2007).

28 S. Banerjee, A.J. Onnink, S. Dutta, A.A.I. Aarnink, D.J. Gravesteijn, and A.Y. Kovalgin, J. Phys. Chem. C 122, 29567 (2018).

29 R.O. Apaydin, A.A.I. Aarnink, M.P. de Jong, D.J. Gravesteijn, and A.Y. Kovalgin, in EuroCVD 22-Baltic ALD 16 Conf. (Luxembourg, 2019).

${ }^{30}$ R.F. Chaiken, D.J. Sibbett, J.E. Sutherland, D.K. Van de Mark, and A. Wheeler, J. Chem. Phys. 37, 2311 (1962). 


\title{
7 Growing BCN and AlBCN films from TEB and TMA
}

\section{precursors}

\begin{abstract}
This chapter studies the deposition of BCN and AlBCN films at $250-400{ }^{\circ} \mathrm{C}$ substrate temperatures $\left(T_{s}\right)$ by giving alternating pulses of triethylborane (TEB), ammonia $\left(\mathrm{NH}_{3}\right)$ and trimethylaluminum (TMA) with argon (Ar)-purges in between. We observe that the GPC of $B C N$ deposition increases with increasing $T_{s}$ and TEB pulse time $\left(t_{T E B}\right)$ which indicates ongoing thermal decomposition of TEB. The latter is also supported by the large thickness non-uniformity, increasing with $T_{s}$. The films deposited at different $T_{s}$ exhibit similar compositions with atomic concentrations of 42 at.\% of $B, 41$ at. $\%$ of $C$ and 15 at. \% of $N$. In order to enable manipulating

the composition, hot-wire (HW) assistance is introduced. This results in increased $C$ - and decreased $N$-shares indicating inefficient nitridation and different-to-thermal chemical routes. The attempt to increase the $N$-share by elongating $t_{\mathrm{NH} 3}$ has no conclusive effect on the composition whereas resulted in different chemical bonding environments of $N$ atoms as determined by XPS.

Namely, $s p^{2}$ hybridized carbon-nitrogen bonds are obtained at longer $t_{\mathrm{NH} 3}(30-60 \mathrm{~s})$ whereas shorter $t_{\mathrm{NH} 3}(5 \mathrm{~s})$ yielded $s p$ or $s p^{3}$ carbon-nitrogen bonds. The changes in the chemical bonding environments lead to a decrease in refractive index by $\sim 10 \%$. Changing other process parameters hardly has any effect.
\end{abstract}

Deposition of AlBCN films was enabled via replacing selected TEB/NH $\mathrm{H}_{3}$ cycles by TMA/NH cycles or, in other words, realizing so-called super-cycles. The effects of the total pressure $\left(P_{\text {tot }}\right.$ of 0.2 and 10 mbar) were investigated. It was shown that the deposition kinetics is slightly pressure dependent; high $P_{\text {tot }}$ resulted in $\sim 10 \%$ higher GPC. The kinetics of deposition at 10 mbar was found to be thickness dependent; the GPC increased from $0.11 \mathrm{~nm} / c y c l e$ to $0.14 \mathrm{~nm} / \mathrm{cycle}$ above $\sim 10 \mathrm{~nm}$ of the film thickness. From XPS, the elemental compositions were determined as $A_{34} B_{13} C_{3} N_{49}$ and $A l_{2} B_{41} C_{36} N_{15}$ at 0.2 and 10 mbar, respectively. Merely based on the XPS peak fitting analysis, the appearance of $B_{x} C, C_{y} N$, pure $C$ and stoichiometric $B N$ phases, as well as a contribution of single $B_{x} C_{y} N_{z}$ can be speculated for the samples. As for $A l_{34} B_{13} C_{3} N_{49}$, co-existence of stoichiometric AlN and BN with some small incorporations of carbon can be speculated. 


\subsection{Introduction}

The first part of this chapter discusses the growth of boron (B), carbon (C) and nitrogen $(\mathrm{N})$ containing layers from triethylborane (TEB) and ammonia $\left(\mathrm{NH}_{3}\right)$ precursors. This allowed to obtain the so-called $\mathrm{BCN}$ films. In the second part, the so-called super-cycles were additionally implemented by replacing selected TEB/ $\mathrm{NH}_{3}$ cycles by trimethylaluminum (TMA) and $\mathrm{NH}_{3}$ cycles. This allowed to incorporate aluminum (Al) into the films and thus realize $\mathrm{AlBCN}$ material. If not explicitly specified in the text, abbreviations BCN and AlBCN neither denote any quantitative elemental composition (i.e., give no actual shares of $A l, B, C$ and $N$ in the films and thus do not indicate stoichiometry) nor represent any phase information. The depositions were performed either in thermal or hot-wire (HW) assisted modes; the latter was explored in view of possible radical enhancement.

The purpose of this work is manifold. First, considering the rather low temperature required for thermal decomposition of TEB $\left(\sim 250{ }^{\circ} \mathrm{C}\right.$, see Section 7.2.3), it is scientifically interesting to investigate whether ammonia is still able to react with a TEB-terminated surface at such low temperatures and thus provide its efficient nitridation. In this view, it is important to confirm / disprove the occurrence of a surface-adduct pathway for forming $\mathrm{BN}$ from $\mathrm{TEB}$ and $\mathrm{NH}_{3}$ at low temperatures. Second, it is important to verify the existence of an efficient mechanism to remove carbon (of TEB) from the layers; the surface-adduct pathway may also play a role there (see, for example, ref. ${ }^{1}$ ). Third, if carbon removal is confirmed to be incomplete at low temperatures, this can be beneficial for adding $\mathrm{C}$ impurities to $\mathrm{BN}$ and thus forming $\mathrm{BCN}$. Fourth, using $\mathrm{TEB} / \mathrm{NH}_{3}$ and TMA/ $\mathrm{NH}_{3}$ super-cycles may open a route to realize AlBN or AlBCN compounds with, depending on the elemental shares, tunable electrical and optical properties.

This chapter is organized as follows. Section 7.2 reviews the previously reported reactions between TEB and $\mathrm{NH}_{3}$. Next, the interaction between TEB: $\mathrm{NH}_{3}$ adducts and TMA: $\mathrm{NH}_{3}$ adducts is discussed followed by the literature reports on decomposition of TEB in relation to $\mathrm{BN}$ growth. Section 7.3 discusses the experimental details and determination of an ALD window for the TEB/ $\mathrm{NH}_{3}$ 
precursor system. Section 7.4 reports the results of deposition of BCN films and Section 7.5 discusses the AlBCN films obtained by super-cycles. Section 7.6 concludes this chapter.

\subsection{Reactions in relation to $\mathrm{BCN}$ growth}

\subsubsection{Reactions between TEB and $\mathrm{NH}_{3}$}

Since TEB $\left(\left(\mathrm{C}_{2} \mathrm{H}_{5}\right)_{3} \mathrm{~B}\right)$ shares similar coordination characteristics with TMA $\left.\left(\mathrm{CH}_{3}\right)_{3} \mathrm{Al}\right)$, calculations predict that it forms an adduct already at room temperature by reacting with $\mathrm{NH}_{3}{ }^{2,3}$. The key importance of these adducts depends on the relative magnitude of the energy barrier to eliminate a single molecule (SM), e.g., methane $\left(\mathrm{CH}_{4}\right)$ or ethane $\left(\mathrm{C}_{2} \mathrm{H}_{6}\right)$.

Several experimental ${ }^{4-10}$ and theoretical 3,11,12 works have been reported on the decomposition of TEB and growth of BN films. Among them, Freitas et.al. ${ }^{3}$ studied the ethane elimination from a TEB: $\mathrm{NH}_{3}$ adduct in the gas phase in relation to BN deposition by metal-organic CVD. The temperature was not specified but it is expected to be high because MOCVD was used. The adduct was considered to be the starting compound for three different reaction pathways: (i) unimolecular, (ii) ammonia assisted and (iii) adduct assisted. The corresponding chemical reactions are shown below ${ }^{3}$ :

$$
\begin{gathered}
\left(\mathrm{C}_{2} \mathrm{H}_{5}\right)_{3} \mathrm{~B}: \mathrm{NH}_{3} \rightarrow \mathrm{TS}(1) \rightarrow\left(\mathrm{C}_{2} \mathrm{H}_{5}\right)_{2} \mathrm{BNH}_{2}+\mathrm{C}_{2} \mathrm{H}_{6} \\
\left(\mathrm{C}_{2} \mathrm{H}_{5}\right)_{3} \mathrm{~B}: \mathrm{NH}_{3}+\mathrm{NH}_{3} \rightarrow \mathrm{TS}(2) \rightarrow\left(\mathrm{C}_{2} \mathrm{H}_{5}\right)_{2} \mathrm{BNH}_{2}: \mathrm{NH}_{3}+\mathrm{C}_{2} \mathrm{H}_{6} \\
\left(\mathrm{C}_{2} \mathrm{H}_{5}\right)_{3} \mathrm{~B}: \mathrm{NH}_{3}+\left(\mathrm{C}_{2} \mathrm{H}_{5}\right)_{3} \mathrm{~B}: \mathrm{NH}_{3} \rightarrow \mathrm{TS}(3) \rightarrow \\
\left(\mathrm{C}_{2} \mathrm{H}_{5}\right)_{3} \mathrm{BNH}_{2} \mathrm{~B}\left(\mathrm{C}_{2} \mathrm{H}_{5}\right)_{2}: \mathrm{NH}_{3}+\mathrm{C}_{2} \mathrm{H}_{6}
\end{gathered}
$$

(reaction 7.3)

where TS(1), TS(2) and TS(3) stand for the transitional states.

It was reported that the ethane elimination through transitional states (reactions 7.1-7.3) might enable adduct-derived species which could potentially evolve further and eventually form BN. However, the high energies required to overcome the energy barriers of ethane elimination (see Figure 7-1) may prevent 
the formation of the adduct-derived species and thus $\mathrm{BN}^{3}$. In this case, the deposition process may be dominated by decomposition of the initial precursors close to the growth surface. To note, thermal decomposition of TEB occurs just above $250{ }^{\circ} \mathrm{C}^{5}$.

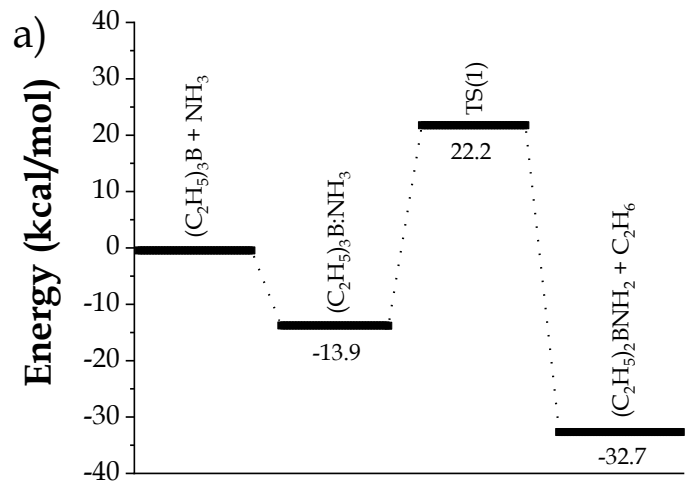

Reaction progress

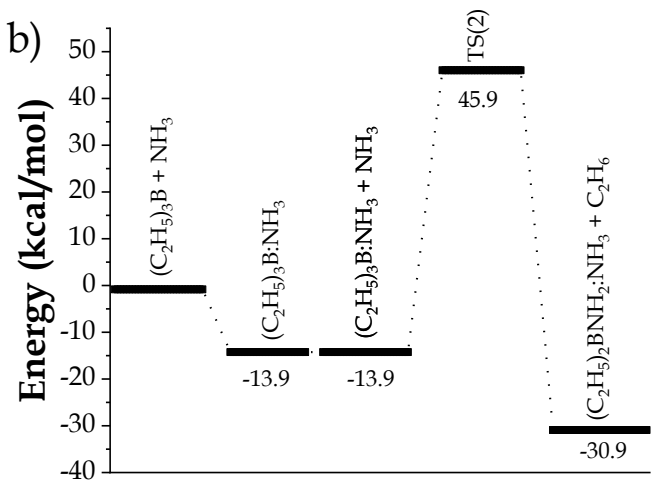

Reaction progress

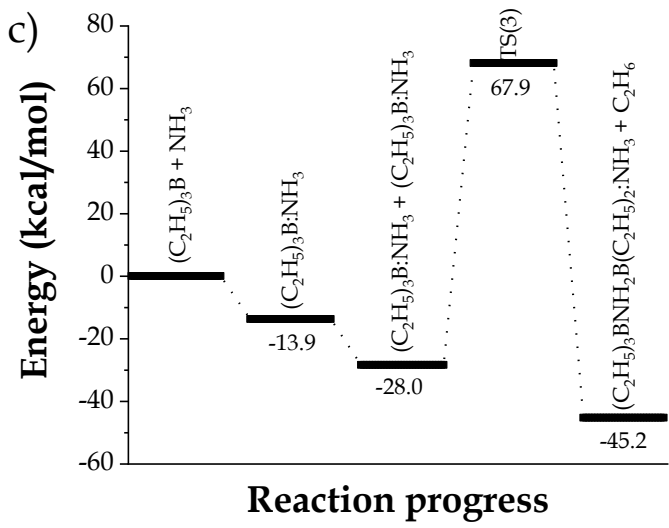

Figure 7-1. Schematic diagrams of sequences of gas-phase reactions starting with the formation of the $\left(\mathrm{C}_{2} \mathrm{H}_{5}\right)_{3} \mathrm{~B}: \mathrm{NH}_{3}$ adduct and proceeding with the removal of $\mathrm{C}_{2} \mathrm{H}_{6}$ via $(\mathrm{a})$

reaction 7.1 - unimolecular reaction pathway, (b) reaction 7.2 - ammonia-assisted reaction pathway and (c) reaction 7.3 - adduct-assisted reaction pathway ${ }^{3}$. Energy values relative to that of the starting compound are given in the images.

It is known that TEB is subjected to a so-called $\beta$-hydride elimination, meaning elimination of the $\beta-\mathrm{H}$ bond resulting in the formation of borane $\left(\mathrm{BH}_{3}\right)$ and B-containing radicals ${ }^{10}$. The as-dehydrogenated TEB will further (dissociatively) adsorb on the surfaces as B atoms or B-containing radicals, regardless the substrate ${ }^{3,13}$. Therefore, the adsorption and decomposition of $\mathrm{NH}_{3}$ on the deposition surface, which is terminated by B-containing molecules, will play a key role for the growth of $\mathrm{BN}$. Since thermal dissociation of $\mathrm{NH}_{3}$ occurs at high temperatures $\left(\mathrm{T}>1000{ }^{\circ} \mathrm{C}\right){ }^{14}$, lower shares of incorporated $\mathrm{N}$ can be expected 
within the investigated temperature window of 300-400 ${ }^{\circ} \mathrm{C}$. This will lead to high B- and C-shares and low N-share. For that reason, utilizing non-thermal means of energy (i.e., by a HW) can enhance $\mathrm{N}$-incorporation. This will be addressed in Section 7-4.

\subsubsection{Reactions between TEB: $\mathrm{NH}_{3}$ and TMA: $\mathrm{NH}_{3}$ adducts}

ALD of AlN is known to occur via the surface adduct and $-\mathrm{NH}_{2}$ - linkages ${ }^{15}$. To form AlBCN compounds, interactions between corresponding adduct species may play a role. Freitas et.al 3 investigated interactions between TEB: $\mathrm{NH}_{3}$ and TMA: $\mathrm{NH}_{3}\left(\left(\mathrm{CH}_{3}\right)_{3} \mathrm{Al}: \mathrm{NH}_{3}\right)$ adducts and showed that the energy barrier to the SM elimination is reduced when one of the TEB: $\mathrm{NH}_{3}$ species is replaced by a TMA:NH adduct (see Figure 7-2), compared to the adduct assisted reaction pathway shown in Figure 7-1.c. Although reduced, the energy barrier to obtain a complex compound consisting of TEB: $\mathrm{NH}_{3}$ and TMA: $\mathrm{NH}_{3}$ derivatives remains high ( $~ 56$ $\mathrm{kcal} / \mathrm{mol})$. For that reason, the formation of such intermediate species is still unlikely; other reaction pathways may therefore be expected, presumably involving thermal decomposition of TEB.

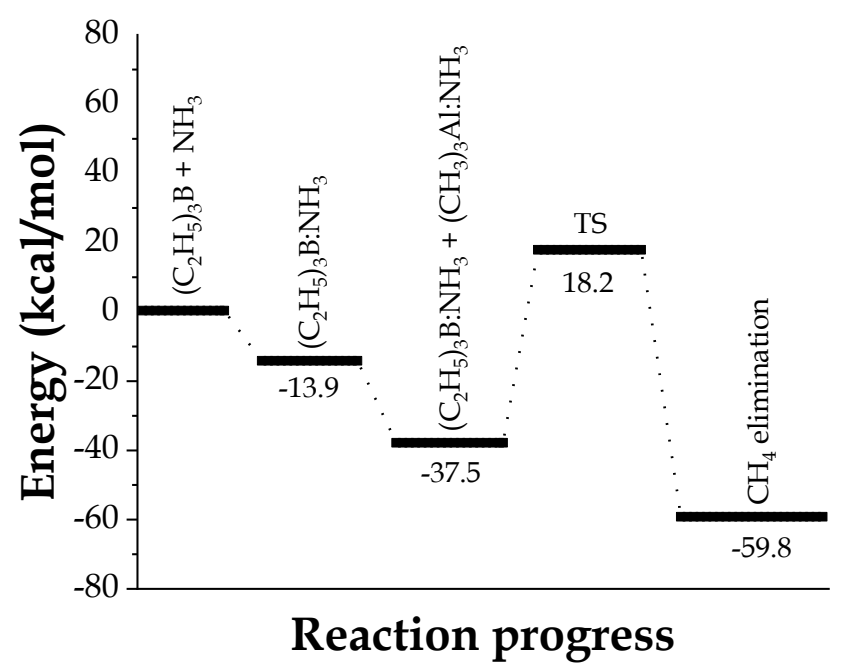

Figure 7-2. Schematic diagram of a sequence of gas-phase reactions, starting with the formation of the $\left(\mathrm{C}_{2} \mathrm{H}_{5}\right)_{3} \mathrm{~B}: \mathrm{NH}_{3}$ adduct from the initial $\left(\mathrm{C}_{2} \mathrm{H}_{5}\right)_{3} \mathrm{~B}$ and $\mathrm{NH}_{3}$ precursors and proceeding with the removal of $\mathrm{CH}_{4}$ via an $\left(\mathrm{CH}_{3}\right)_{3} \mathrm{Al}: \mathrm{NH}_{3}$ adduct-assisted reaction pathway ${ }^{3}$. Energy values relative to that of the starting compound are given in the image. 


\subsubsection{Thermal decomposition of TEB}

It is known that metalorganic precursors with alkyl groups thermally decompose at low temperatures ${ }^{7}$. For example, TMA starts decomposing at $\mathrm{T}>330$ ${ }^{\circ} \mathrm{C}$ 16. TEB starts decomposing at $250{ }^{\circ} \mathrm{C}$ through the so-called $\beta$-elimination reactions (reactions 7.4 - 7.6) 5,10,11,17, eliminating ethylene $\left(\mathrm{C}_{2} \mathrm{H}_{4}\right)$ in Ar ambient and ethane $\left(\mathrm{C}_{2} \mathrm{H}_{6}\right)$ in $\mathrm{H}_{2}$ ambient. The $\mathrm{C}_{2} \mathrm{H}_{6}$ elimination occurs via reactions 7.7 - 7.9 11,17. The $\mathrm{C}_{2} \mathrm{H}_{4}$ elimination (reaction 7.4) was reported to occur at $300{ }^{\circ} \mathrm{C}$. Above 400 ${ }^{\circ} \mathrm{C}, \mathrm{BH}_{3}$ formation was suggested via elimination of the other two ethyl groups 11,17 . One may thus expect an increased coverage of the growth surface with TEB dissociation products, of which $\mathrm{BH}_{3}$ is an important component, at temperatures around $400{ }^{\circ} \mathrm{C}$ or higher. If this occurs, such a process can hardly be self-limiting and will not lead to an ALD mode while depositing BN from TEB and $\mathrm{NH}_{3}$ at $\mathrm{T}_{\mathrm{s}}>400{ }^{\circ} \mathrm{C}$. As earlier proposed, the occurrence of $\mathrm{BH}_{3}$ may lead to the formation of $\mathrm{BN}$ via the adduct assisted pathway. It should be noted that $\mathrm{BH}_{3}$ can also lead to pure boron (pure-B) deposition. For further information, see Chapter 4.

$$
\begin{aligned}
& \mathrm{B}\left(\mathrm{C}_{2} \mathrm{H}_{5}\right)_{3} \rightarrow \mathrm{B}\left(\mathrm{C}_{2} \mathrm{H}_{5}\right)_{2} \mathrm{H}+\mathrm{C}_{2} \mathrm{H}_{4} \\
& \mathrm{~B}\left(\mathrm{C}_{2} \mathrm{H}_{5}\right)_{2} \mathrm{H} \rightarrow \mathrm{B}\left(\mathrm{C}_{2} \mathrm{H}_{5}\right)_{\mathrm{H}_{2}}+\mathrm{C}_{2} \mathrm{H}_{4} \\
& \mathrm{~B}\left(\mathrm{C}_{2} \mathrm{H}_{5}\right)_{\mathrm{H}_{2}} \rightarrow \mathrm{BH}_{3}+\mathrm{C}_{2} \mathrm{H}_{4} \\
& \mathrm{~B}\left(\mathrm{C}_{2} \mathrm{H}_{5}\right)_{3}+\mathrm{H}_{2} \rightarrow \mathrm{B}\left(\mathrm{C}_{2} \mathrm{H}_{5}\right)_{2} \mathrm{H}+\mathrm{C}_{2} \mathrm{H}_{6} \\
& \mathrm{~B}\left(\mathrm{C}_{2} \mathrm{H}_{5}\right)_{2} \mathrm{H}+\mathrm{H}_{2} \rightarrow \mathrm{B}\left(\mathrm{C}_{2} \mathrm{H}_{5}\right) \mathrm{H}_{2}+\mathrm{C}_{2} \mathrm{H}_{6} \\
& \mathrm{~B}\left(\mathrm{C}_{2} \mathrm{H}_{5}\right)_{\mathrm{H}_{2}}+\mathrm{H}_{2} \rightarrow \mathrm{BH}_{3}+\mathrm{C}_{2} \mathrm{H}_{6}
\end{aligned}
$$$$
\text { (reaction 7.6) }
$$$$
\text { (reaction 7.7) }
$$$$
\text { (reaction 7.8) }
$$$$
\text { (reaction 7.9) }
$$

Below $400{ }^{\circ} \mathrm{C}$, the intermediate products of the $\beta$-hydride elimination reactions, namely the $\mathrm{B}\left(\mathrm{C}_{2} \mathrm{H}_{5}\right)_{2} \mathrm{H}$ and $\mathrm{B}\left(\mathrm{C}_{2} \mathrm{H}_{5}\right) \mathrm{H}_{2}$ species, are expected to lead to $\mathrm{BN}$ deposition. Specifically, BN may form through amine formation reactions similar to AlN and GaN (see Chapter 2). Carbon incorporation into the films can possibly originate from $\mathrm{C}_{2} \mathrm{H}_{4}$ or $\mathrm{C}_{2} \mathrm{H}_{2}$, since these hydrocarbons can enable carbon deposits at comparable temperatures ${ }^{10}$. The $\mathrm{C}_{2} \mathrm{H}_{2}$ is being formed via $\mathrm{H}_{2}$ elimination from ethylene ${ }^{11,18}$. Incorporation of C bonded to B may occur due to unbroken C-B 
bonds in TEB fragments in combination with the absence of an effective chemical reaction to remove the carbon at low deposition temperatures. An example of such a reaction is the proposed removal of $\mathrm{CH}_{3}$ groups from TMG by the surface-adduct assisted pathway while forming $\mathrm{GaN}$ at $400{ }^{\circ} \mathrm{C} 1$.

\subsection{Experimental details}

\subsubsection{Deposition methodology}

The BCN films were deposited in Reactor-3 of the home-built ALD/CVD cluster system from sequentially introduced TEB and $\mathrm{NH}_{3}$ precursors. A detailed description of the reactor can be found in Chapter 1 and ref. 19,20. The same reactor was used to additionally realize the super-cycles by replacing selected TEB/ $\mathrm{NH}_{3}$ cycles by TMA/ $\mathrm{NH}_{3}$ cycles. This allowed to incorporate $\mathrm{Al}$ and thus realize $\mathrm{AlBCN}$ films.

Prior to deposition, the substrates (i.e., $\mathrm{Si}(100)$ wafers) underwent the standard three-step wafer cleaning procedure detailed in Chapter 3. The films were obtained in the total pressure range of $0.2-10 \mathrm{mbar}$, at substrate temperatures between 250 and $400{ }^{\circ} \mathrm{C}$. The precursors were introduced via alternating pulses with Ar-purges in between, to avoid gas phase reactions. The typical pulse- and purge-durations were: $0.5-2.0 \mathrm{~s}$ of TEB, $0.5 \mathrm{~s}$ of TMA, $5 \mathrm{~s}$ of post-TEB and $5 \mathrm{~s}$ of post-TMA purge, 2.0-60 s of $\mathrm{NH}_{3}$ and 2-80 s of post- $\mathrm{NH}_{3}$ purge.

The layers were characterized by in-situ (real time) and ex-situ spectroscopic ellipsometry (SE) (see Chapters 2 / Section 2.2 for details) and x-ray photoelectron spectroscopy (XPS) (see Chapter 3 / Section 3.2 for the equipment identification).

\subsubsection{Tuning the deposition conditions}

Figure 7-3 shows the effects of substrate temperature and TEB pulse time on the growth rate per cycle (GPC). There are rather small changes of the GPC for $T_{s}<325^{\circ} \mathrm{C}$, whereas beyond this temperature the GPC shows a sharp increase. This 
is possibly due to the enhanced thermal dissociation of TEB if the $T_{\mathrm{s}}$ is approaching to $400{ }^{\circ} \mathrm{C}$, as expected from the literature ${ }^{5}$. Figure $7-4$ shows that the GPC is not significantly affected by the $\mathrm{NH}_{3}$-exposure $\left(t_{\mathrm{NH}}\right)$ and post- $\mathrm{NH}_{3}$ purge times in the range studied. Analyzing the step-wise growth per cycle by in-situ SE (see Appendix 7.1) revealed that post- $\mathrm{NH}_{3}$ purge times longer than $20 \mathrm{~s}$ were required to minimize possible gas phase reactions between TEB and $\mathrm{NH}_{3}$ at a total pressure $\left(P_{t o t}\right)$ of 5 mbar. Increasing the $P_{t o t}$ to 10 mbar required at least $60 \mathrm{~s}$ of the post- $\mathrm{NH}_{3}$ purge time. The $t_{T E B}$ was fixed at $0.5 \mathrm{~s}$ based on Figure 7-3.

To investigate the temperature effect on the reaction with $\mathrm{NH}_{3}$ and the removal of carbon, $T_{\mathrm{s}}$ in the range of $325-375^{\circ} \mathrm{C}$ was selected. There is only a little decomposition of TEB at the lowest $T_{\mathrm{s}}$, whereas the highest $T_{\mathrm{s}}$ results in a significant decomposition.

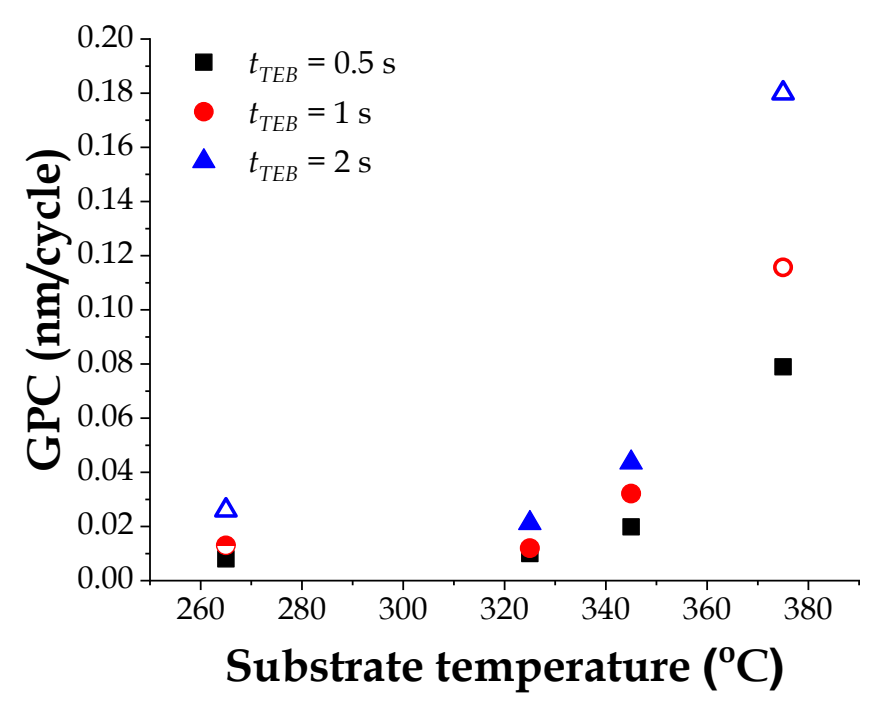

Figure 7-3. Variation of GPC as a function of $T_{s}$ and $t_{T E B}$ (see the legend) at $P_{t o t}=5 \mathrm{mbar}$. Durations: post-TEB of $5 \mathrm{~s}, t_{\mathrm{NH}}$ of $5 \mathrm{~s}$ for the solid and open symbols and $2 \mathrm{~s}$ for the halfopen symbols, post-NH of $40 \mathrm{~s}$ for the solid and $10 \mathrm{~s}$ for open and half-open symbols. To note: the $t_{\mathrm{NH}}$ and post-NH3 purge durations have only a little effect on the GPC, as concluded from Figure 7-4. 


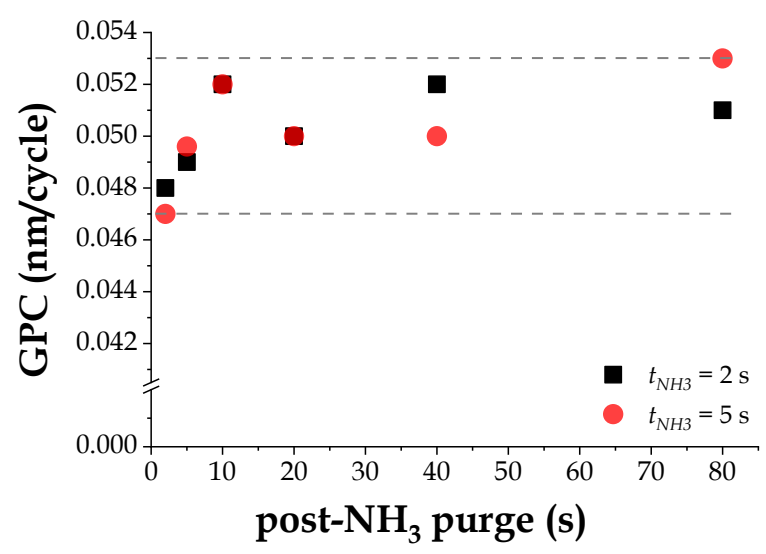

Figure 7-4. Variation of GPC as a function of $t_{\mathrm{NH}}$ (see the legend) and post-NH3 purge time at $P_{\text {tot }}=5$ mbar. Between the horizontal dashed lines, the GPC varies within 0.006 $\mathrm{nm} / \mathrm{cycle}$.

Total pressure can influence both GPC and material (i.e., optical) properties, as discussed in the earlier chapters. No film growth was observed at $P_{\text {tot }}$ of $10^{-3}$ mbar. From Figure 7-5, it can be concluded that the GPC noticeably increases at $T_{\mathrm{s}}=330-375{ }^{\circ} \mathrm{C}$ if $P_{t o t}$ raises from 0.2 to 1 mbar and remains rather unaffected (i.e., $\sim 0.012 \mathrm{~nm} /$ cycle) for $P_{\text {tot }}$ in the range of 1-5 mbar. Further increase of the $P_{\text {tot }}$ up to $10 \mathrm{mbar}$ at $T_{\mathrm{s}}=330^{\circ} \mathrm{C}$ results in a similar GPC value of $\sim 0.011 \mathrm{~nm} /$ cycle. At $250{ }^{\circ} \mathrm{C}$, the GPC gradually increases with pressure for all $P_{\text {tot }}$ values (see Figure 7-5). However, deposition below the onset of thermal decomposition of TEB $\left(250{ }^{\circ} \mathrm{C}\right)$ is impractical due to the very low GPC values (0.006 nm/cycle at $5 \mathrm{mbar})$.

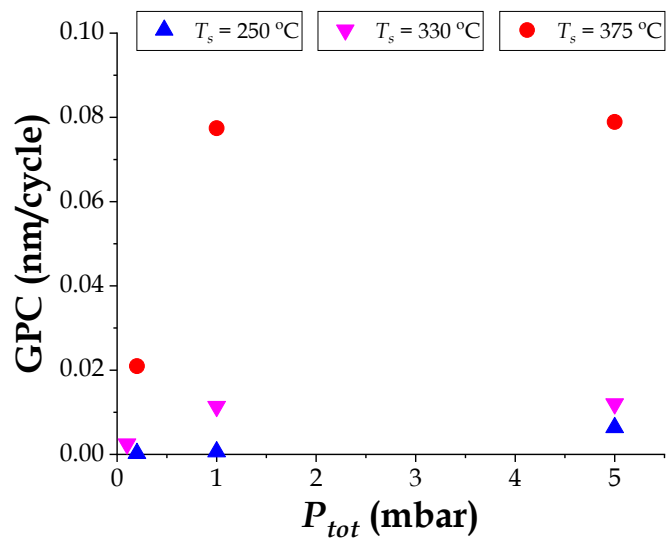

Figure 7-5. Variation of GPC as a function of $P_{\text {tot }}$ and $T_{s}$ (see label). Depositions were performed at various substrate temperatures as shown in the label. Other conditions: $0.5 \mathrm{~s}$ of TEB pulse, $5 \mathrm{~s}$ of Ar for post-TEB pulse, $5 \mathrm{~s}$ of $\mathrm{NH}_{3}$ pulse and $40 \mathrm{~s}$ of Ar for post- $\mathrm{NH}_{3}$ purge. To note, any data reported in the graph do not correspond to GPC of zero. 
Taking into account the observed temperature-pressure effects w.r.t. the deposition kinetics, we further characterize film composition and their optical properties by XPS and SE.

\subsection{Deposition of BCN films}

Purely thermal depositions were carried out at 330, 375 and $400{ }^{\circ} \mathrm{C}$, see Table 7-1 for the conditions. The effect of adding a hot-wire (HW) was researched for $T_{S}=375{ }^{\circ} \mathrm{C}$. Since increasing $t_{N H 3}$ may affect the efficiency of surface nitridation 6,21, the $\mathrm{NH}_{3}$ pulse time was changed accordingly.

Table 7-1: Deposition conditions for BCN films.

\begin{tabular}{|c|c|c|c|c|}
\hline $\begin{array}{c}\text { Pressure } \\
\text { (mbar) }\end{array}$ & $\begin{array}{c}\text { Substrate } \\
\text { temperature ( } \mathbf{(} \mathbf{C})\end{array}$ & $\begin{array}{c}\text { TEB pulse / } \\
\text { purge time (s) }\end{array}$ & $\begin{array}{c}\mathbf{N H}_{3} \text { pulse } \\
\text { time (s) }\end{array}$ & $\begin{array}{c}\mathbf{N H}_{3} \text { purge } \\
\text { time (s) }\end{array}$ \\
\hline 10 & 330 & $0.5 / 5$ & 5 & 60 \\
\hline 10 & 375 & $0.5 / 5$ & 5 & 60 \\
\hline 10 & 400 & $0.5 / 5$ & 5 & 60 \\
\hline 10 & $375-\mathrm{HW}(1850 \mathrm{~K})$ & $0.5 / 5$ & 5 & 60 \\
\hline 10 & 375 & $0.5 / 5$ & 30 & 60 \\
\hline 10 & 375 & $0.5 / 5$ & 60 & 60 \\
\hline
\end{tabular}

\subsubsection{Growth aspects from SE}

Figure 7-6 shows that the GPC increases with temperature, indicating the ongoing thermal decomposition of TEB. The GPC is rather unaffected by the $t_{\mathrm{NH} 3}$, similar to the findings of ref. 6,22 , indicating that a $t_{\mathrm{NH} 3}$ of $5 \mathrm{~s}$ is enough to complete reactions between the available surface sites and $\mathrm{NH}_{3}$.

Since the presence of $\mathrm{H}_{2}$ is reported to change the growth mechanism 11,17, adding atomic hydrogen (at-H) and $\mathrm{NH}_{2}$ radicals generated by $\mathrm{HW} 23,24$ may facilitate alternative chemical routes, as discussed earlier in Section 7.2.3 and Chapter 4 and 6. The HW-assisted deposition (Figure 7-6) revealed only a slight 
increase of the GPC. The effect of HW on the material properties will be discussed below and in Section 7.4.2.

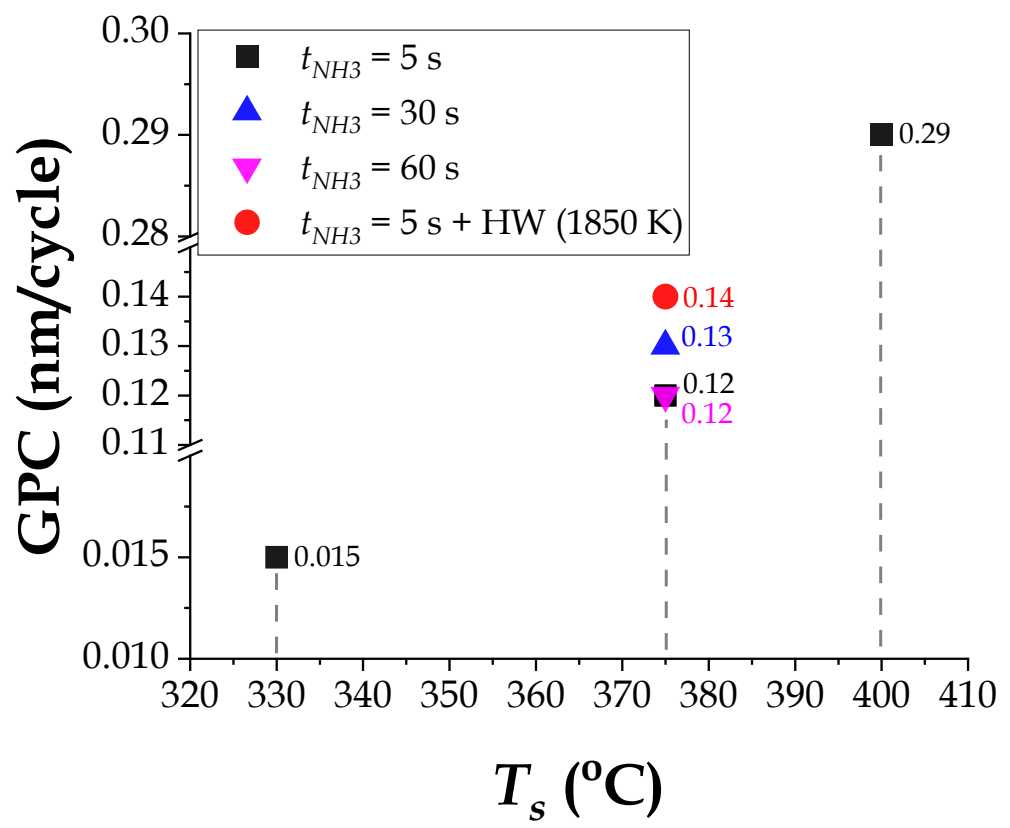

Figure 7-6. GPC of samples deposited at various substrate temperatures and ammonia pulse durations, as measured by in-situ SE. For a comparison, HW-assisted deposition was performed at $375^{\circ} \mathrm{C}$. Other process conditions can be found in Table 7-1.

Figure 7-7 compares the shapes of individual pulses recorded by SE at various conditions. To bear in mind, the small signal variations within a cycle are interpreted by the SE optical model as thickness changes. Apart from actual thickness changes, altering optical properties as a result of surface reactions may also cause this effect. Upward steps may indicate the successful chemisorption of TEB. At higher $T_{s}$, the steps become larger, suggesting enhanced chemisorption. Turning on the HW and varying the $t_{N H 3}$ has no clear effect. 


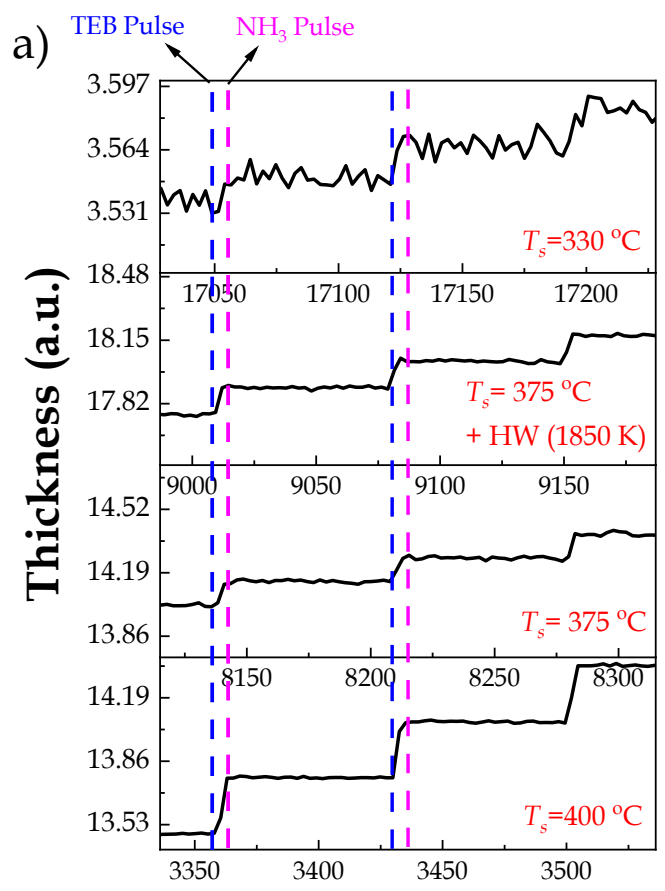

Time (s)

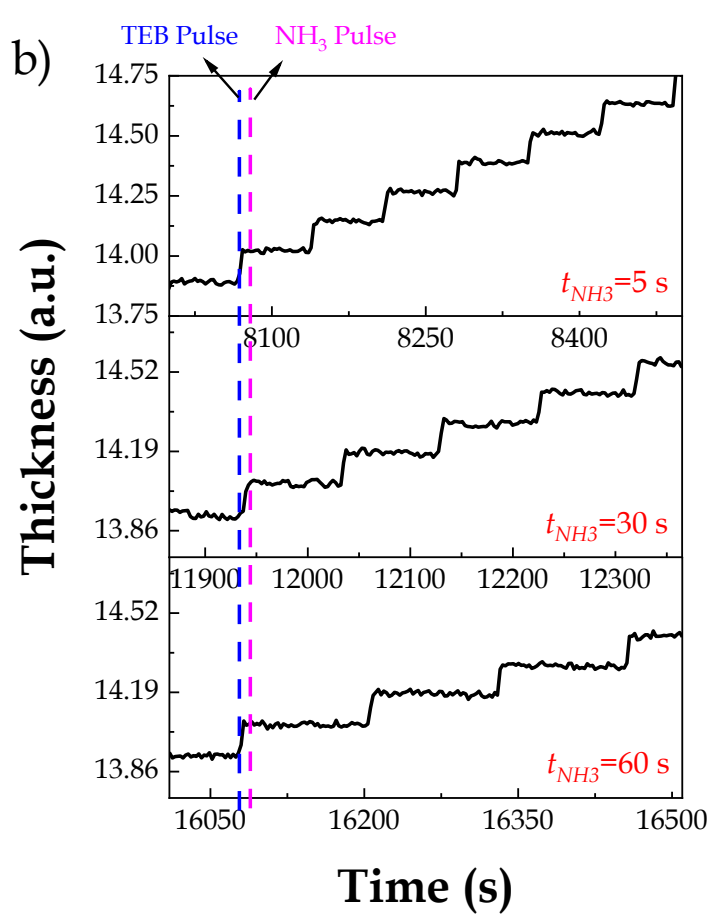

Figure 7-7. Step shapes (by in-situ SE) obtained from the samples deposited at (a) various substrate temperatures and (b) various $t_{\mathrm{NH}}$ durations. The HW-assisted deposition shows no effect on the shapes. Other process conditions can be found in Table 7-1.

The film-thickness uniformity was mapped by ex-situ SE (see Appendix 7.2). The large non-uniformity and its increase at higher $T_{s}$ confirms once more (i) the absence of self-limiting surface reactions (and thus an ALD mode) and (ii) thermal decomposition of TEB, dominating the film growth. A slight decrease of the non-uniformity with increasing the $t_{N H 3}$ may indicate some effects but needs further investigation.

The refractive index $(n)$ of the $\mathrm{BCN}$ films is given in Figure 7-8. There is no significant effect of $T_{s}$ on the $n$, suggesting similar elemental composition (see Section 7.4.2.1). A slight increase of $n$ in case of the $\mathrm{HW}$-assistance is possibly due to the 5 at.\% higher share of $\mathrm{C}$ incorporated into the films. Changing the ammonia pulse duration has a bigger effect: the $n$ decreases for a longer $t_{N H 3}$ (Figure 7-8.b). Importantly, the XPS sputter-depth profiles (refer to Figure 7-9) exhibit slightly higher $\mathrm{N}$ content for the longer times. It should be noted that relatively small compositional changes may still cause an impact on the optical properties. For example, Lei et.al. ${ }^{25}$ observed a decrease of the refractive index of their $\mathrm{BCN}$ films 
by $\sim 6 \%$ if going from $\mathrm{B}_{10} \mathrm{C}_{55} \mathrm{~N}_{35}$ to $\mathrm{B}_{13} \mathrm{C}_{54} \mathrm{~N}_{33}$ and further to $\mathrm{B}_{14} \mathrm{C}_{51} \mathrm{~N}_{35}$ stoichiometry. They attributed the effect to the increased $\mathrm{sp}^{3}$-binding share of $\mathrm{B}-\mathrm{N}$ and $\mathrm{C}-\mathrm{N}$ in the compound. Kimura et.al. ${ }^{26}$ and Sota et.al. ${ }^{27}$ reported a decreased optical bandgap for samples containing 13 at.\% of C. The authors attributed this change to the incorporation of $\mathrm{C}$ atoms into the amorphous region of $\mathrm{BCN}$ films and suggested that formation of certain bonds, namely $\mathrm{sp}^{2} \mathrm{C}=\mathrm{C}$ and $\mathrm{C}=\mathrm{N}$, may decrease the optical bandgap. Prakash et.al. ${ }^{28}$ reported 15\% larger bandgap for their samples exhibiting similar compositions and attributed that to changes in the chemical bonding network. Angus and Hayman ${ }^{29}$, Dischler et.al. ${ }^{30}$ and Robertson et.al. ${ }^{31}$ reported a smaller bandgap if H-content in their amorphous C:H films decreased. Similar effects of changing the composition may play a role in our case as well. This will be further discussed in the next section.

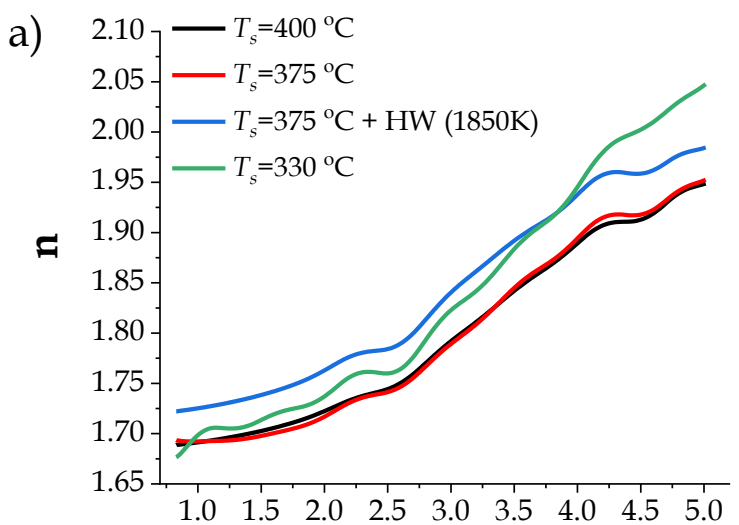

Photon energy (eV)

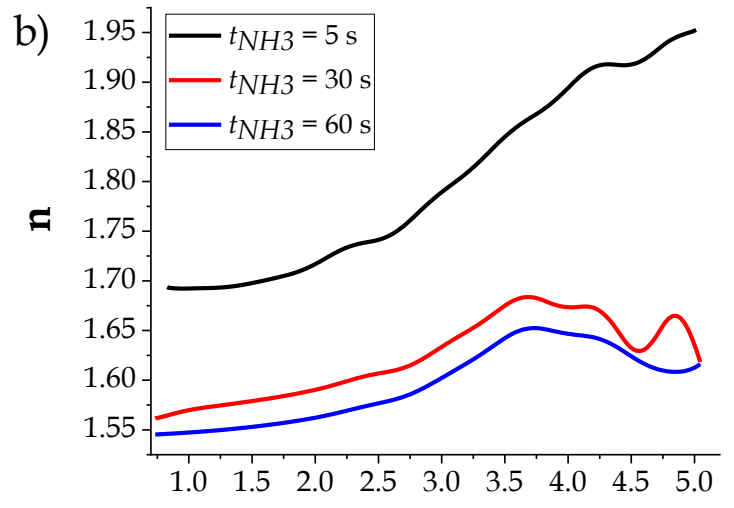

Photon energy (eV)

Figure 7-8. Refractive index of films deposited at various $T_{s}(\boldsymbol{a})$ and $t_{N H 3}(\boldsymbol{b})$. Other process conditions can be found in Table 7-1.

\subsubsection{Compositional analysis from XPS}

\subsubsection{Sputter depth profiles}

Sputter-depth profiling of a representative BCN sample is shown in Figure 7-9. In Table 7-2, the elemental shares in at.\% obtained from different samples are given. The layers consisted of B, C and N. Small amounts of $\mathrm{O}(<3$ at. \%) and Si $(<2$ at.\%) were also detected, not shown in the table. Varying $T_{s}$ (Table 7-2) only influenced the GPC, hardly affecting the composition. The introduction of HW leads to a lower $\mathrm{N}$ - but higher $\mathrm{C}$-share, contrary to the expected enhancement of 
the removal of carbon by at-H. In this light, Chubarov et.al ${ }^{32}$ proposed an altered surface chemistry to explain similar observations. Since at-H can promote decomposition of hydrocarbons, this can enhance deposition of carbon. Further, the attempt to increase the $\mathrm{N}$ incorporation by elongating the $t_{\mathrm{NH} 3}$ pulse hardly influenced the composition (Table 7-2). This confirmed that the time was not the limiting factor at $375^{\circ} \mathrm{C}$.

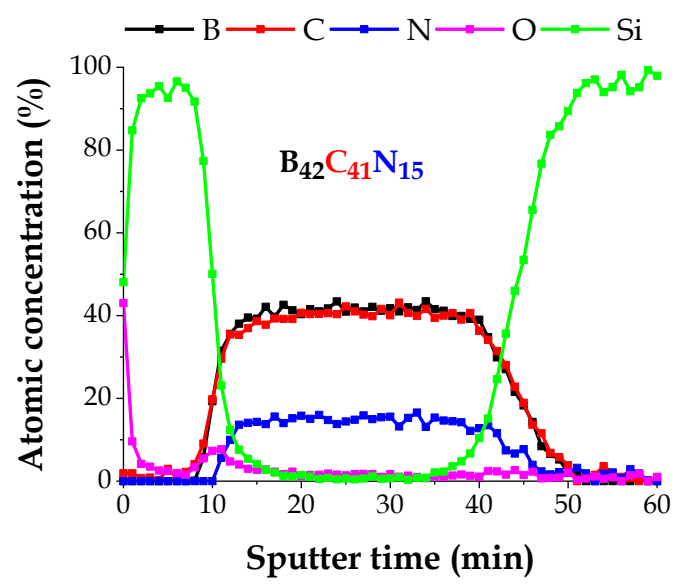

Figure 7-9. XPS sputter-depth profile of a representative $B_{0.42} C_{0.41} N_{0.15}$ sample capped with an a-Si layer. The given stoichiometry does not necessarily imply a single-phase material. Conditions: $T_{\mathrm{s}}=330^{\circ} \mathrm{C}, t_{\mathrm{NH} 3}=5 \mathrm{~s}$. Other process conditions can be found in Table 7-1.

Table 7-2. Shares of various elements (in at.\%) for samples deposited at different conditions. Other conditions can be found in Table 7-1.

\begin{tabular}{|c|c|c|c|c|}
\hline \multicolumn{2}{|c|}{ Variable parameter } & B & $\mathrm{C}$ & $\mathbf{N}$ \\
\hline \multirow{3}{*}{$T_{s}$} & $330{ }^{\circ} \mathrm{C}$ & 42 & 41 & 15 \\
\cline { 2 - 5 } & $375^{\circ} \mathrm{C}$ & 43 & 40 & 12 \\
\cline { 2 - 5 } & $400{ }^{\circ} \mathrm{C}$ & 43 & 42 & 12 \\
\hline \multirow{4}{*}{$\mathbf{H W}$} & $\mathrm{HW}-1850 \mathrm{~K}$ & 45 & 47 & 6 \\
\hline \multirow{3}{*}{$\boldsymbol{t}_{\text {NH3 }}$} & $5 \mathrm{~s}$ & 43 & 40 & 12 \\
\cline { 2 - 5 } & $30 \mathrm{~s}$ & 43 & 40 & 15 \\
\cline { 2 - 5 } & $60 \mathrm{~s}$ & 42 & 40 & 16 \\
\hline
\end{tabular}

\subsubsection{Chemical bonding environments}

The chemical nature of the BCN films was investigated by XPS. Figure 7-10 shows the representative peak fitting analysis for B 1s, C 1s and $\mathrm{N} 1 \mathrm{~s}$ peaks. 
Gaussian fitting is performed after fixing peak positions at the corresponding values in accordance with Table 7-3. For the samples of Table 7-2, there is no apparent shift detected for the $B 1$ s and $C 1$ s peaks neither with varying $T_{\mathrm{s}}$ and $t_{\mathrm{NH}}$ nor $\mathrm{HW}$-assistance. The B 1s peak is observed at approximately $189.6 \mathrm{eV}$ and the fits suggest three possible binding states of boron (by neglecting the O-subpeak) centered at 187.6, 189.4 and 190.6 eV (Figure 7-10.a). Three subpeaks are needed to adequately describe the $C 1$ s spectra (Figure 7-10.b). The N 1s spectrum is found to have a tail towards higher binding energies, when a longer $t_{N H 3}(30-60 \mathrm{~s})$ is used, indicating a different bonding environment. Namely, the peak located at $399.3 \mathrm{eV}$ is attributed to $\mathrm{sp}$ or $\mathrm{sp}^{3}$ hybridized carbon-nitrogen bonds whereas the peak located at $400.3 \mathrm{eV}$ is assigned to $\mathrm{sp}^{2}$ hybridized carbon-nitrogen bonds (for references please refer to Table 7-3). The earlier mentioned differences in the refractive index (Figure 7-8.b) can be attributed to the changes in the bonding environments. The literature-based assignment of the subpeaks is listed in Table 7-3. 


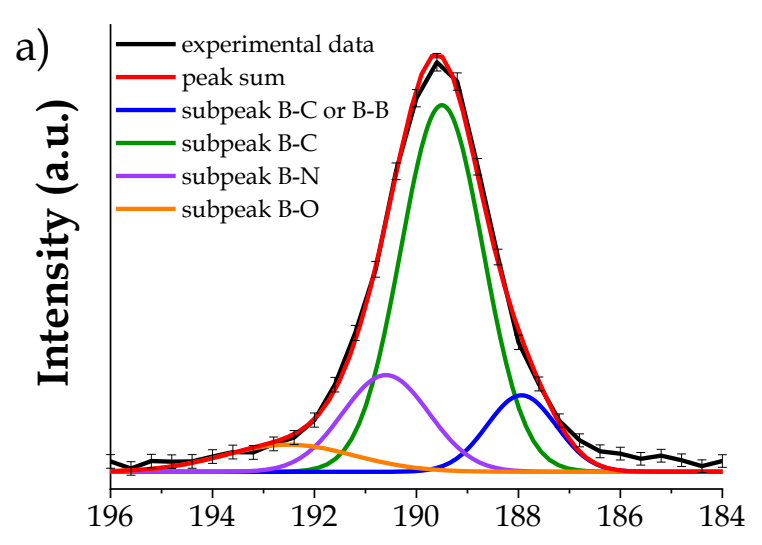

Binding energy - B 1s (eV)

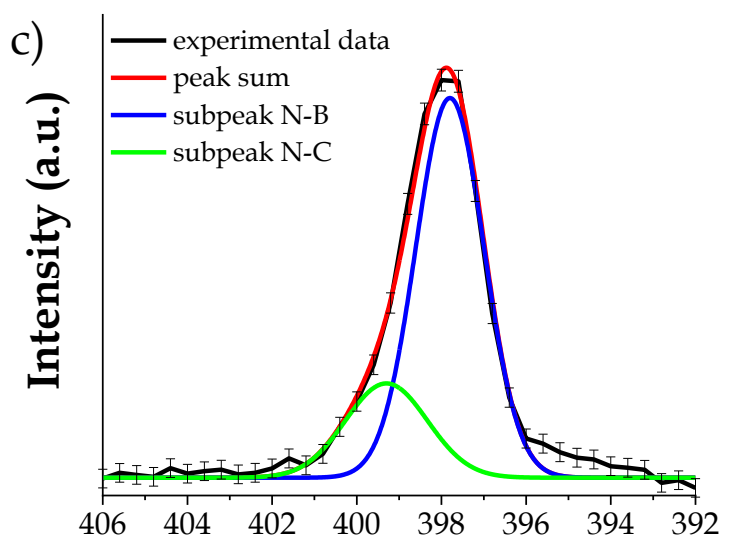

Binding energy - N 1s (eV)

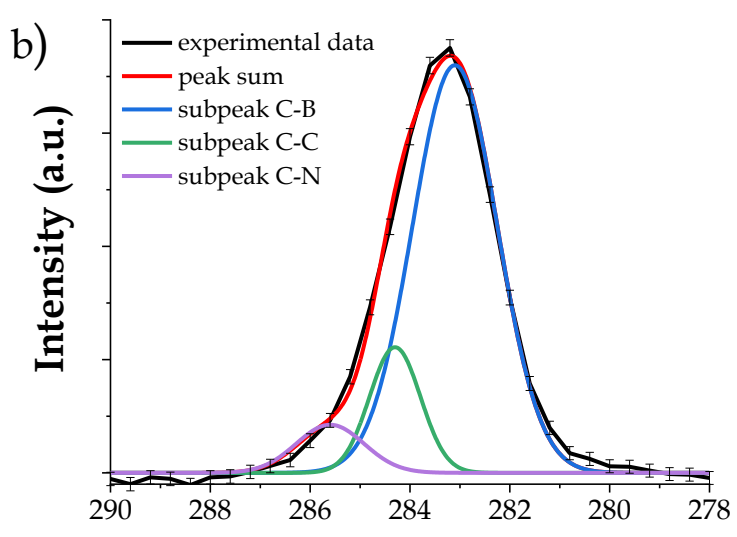

Binding energy - C 1s (eV)

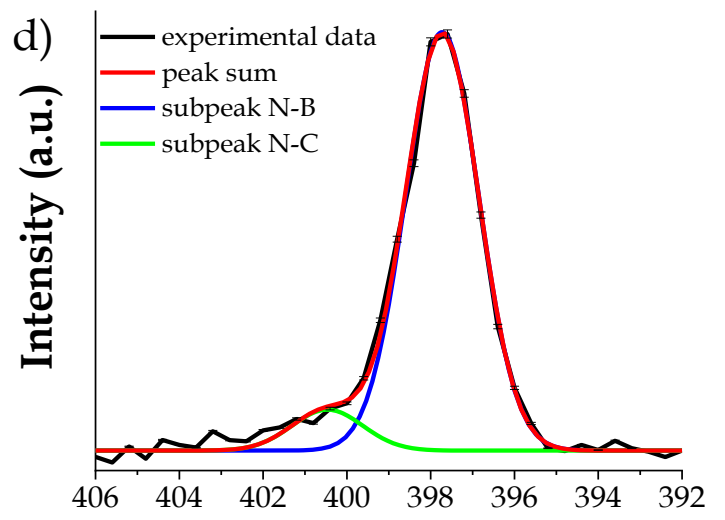

Binding energy - N 1s (eV)

Figure 7-10. Deconvolution of representative XPS peaks of a BCN film: B 1s (a), C 1s (b), N 1 s with (c) and without (d) HW-assistance. For the films deposited at longer $t_{N H 3}$ of 30-60 s, a shift towards higher binding energies was observed in the N 1s spectra, see (d).

Solely based of the subpeaks, it is difficult to conclude on a phase separation and claim the occurrence of either a composite or single-phase " $\mathrm{BCN}$ " material. At least two bonding environments can be suggested for $\mathrm{N}$, three for $\mathrm{C}$ and $\mathrm{B}$ (the latter neglects the O-subpeak). From this, one may for example speculate the appearance of $\mathrm{B}_{\mathrm{x}} \mathrm{C}, \mathrm{C}_{\mathrm{y}} \mathrm{N}$, pure $\mathrm{C}$ and stoichiometric $\mathrm{BN}$ phases. It does however not exclude a contribution of a single $\mathrm{B}_{\mathrm{x}} \mathrm{C}_{\mathrm{y}} \mathrm{N}_{\mathrm{z}}$ phase as well. A detailed investigation is required in order to identify the available phases. 
Table 7-3. XPS binding energies of B 1 s, $C 1$ s and $N$ 1s peaks observed for the samples listed in Table 7-2 and peak assignment from the literature.

\begin{tabular}{|c|c|c|c|}
\hline element & $\begin{array}{c}\text { binding energy } \\
(\mathrm{eV})\end{array}$ & possible bonds and compounds & references \\
\hline \multirow{7}{*}{ B 1s } & \multirow{3}{*}{187.5} & $\mathrm{~B}-\mathrm{C}$ in $\mathrm{B}_{4} \mathrm{C}$ & $33-36$ \\
\hline & & $\mathrm{B}-\mathrm{B}$ in $\mathrm{B}_{4} \mathrm{C}$ & 36 \\
\hline & & $B-B$ in pure-B & 37 \\
\hline & \multirow{2}{*}{189.4} & $\mathrm{~B}-\mathrm{C}$ in $\mathrm{BC}_{3.4}$ & $38-40$ \\
\hline & & $\mathrm{B}-\mathrm{C}$ in $\mathrm{B}_{\mathrm{x}} \mathrm{C}_{\mathrm{y}} \mathrm{N}_{\mathrm{z}}$ & 41 \\
\hline & 190.6 & $\mathrm{~B}-\mathrm{N}$ in $\mathrm{BN}$ & $39,42-44$ \\
\hline & 192.7 & $\mathrm{~B}-\mathrm{O}$ in $\mathrm{B}_{2} \mathrm{O}_{3}$ & 45 \\
\hline \multirow{4}{*}{ C 1s } & 283.2 & $\mathrm{C}-\mathrm{B}$ in $\mathrm{B}_{4} \mathrm{C}$ & $36,38,40,46-48$ \\
\hline & \multirow{2}{*}{284.3} & $\mathrm{C}-\mathrm{C}$ in $\mathrm{a}-\mathrm{C}$ & $26,28,39,43,49$ \\
\hline & & $\mathrm{C}-\mathrm{C}$ in $\mathrm{BC}_{2} \mathrm{~N}$ & 50 \\
\hline & 285.6 & C-N in carbonitrides & 51 \\
\hline \multirow{3}{*}{$\mathrm{N} 1 \mathrm{~s}$} & 397.8 & $\mathrm{~N}-\mathrm{B}$ in $\mathrm{BN}$ & $38,44,49$ \\
\hline & 399.3 & $\begin{array}{l}\text { carbon-nitrogen bond in } \mathrm{sp} \text { or } \mathrm{sp}^{3} \\
\text { hybridization }\end{array}$ & $38,41,43,49,52,53$ \\
\hline & 400.4 & $\begin{array}{l}\text { carbon-nitrogen bond in } \mathrm{sp}^{2} \\
\text { hybridizations }\end{array}$ & $49,52,53$ \\
\hline
\end{tabular}

\subsection{AlBCN films obtained by super-cycles}

The films were deposited at $T_{s}$ of $375^{\circ} \mathrm{C}$ and a $P_{\text {tot }}$ of 0.2 or $10 \mathrm{mbar}$, to investigate the total pressure effect. Each TEB/ $\mathrm{Ar} / \mathrm{NH}_{3} / \mathrm{Ar}$ cycle was followed by a TMA/Ar/ $\mathrm{NH}_{3} /$ Ar cycle. The chosen pulse durations of the first sub-cycle were: $0.5 \mathrm{~s}$ of TEB $\left(t_{T E B}\right), 5 \mathrm{~s}$ of post-TEB purge, $30 \mathrm{~s}$ of $\mathrm{NH}_{3}\left(t_{N H 3}\right)$ and $60 \mathrm{~s}$ of post-NH $\mathrm{NH}_{3}$ purge. For the second sub-cycle, the durations were: $0.5 \mathrm{~s}$ of TMA $\left(t_{T M A}\right), 5 \mathrm{~s}$ of post-TMA purge, $10 \mathrm{~s}$ of $\mathrm{NH}_{3}\left(t_{\mathrm{NH}}\right)$ and $5 \mathrm{~s}$ of post- $\mathrm{NH}_{3}$ purge. The latter was copied from the earlier works performed in the group.

As shown in Section 7.3.2, BCN deposition at 0.2 mbar is very slow. However, AlN deposition readily occurs at this pressure 54 and may be expected to enhance the process similar to the effect mentioned in ref. ${ }^{55}$. On the other hand, 
at 10 mbar, both $\mathrm{AlN}$ and $\mathrm{BCN}$ can deposit. Composition of AlBCN films is therefore expected to depend on $P_{t o t}$.

\subsubsection{Growth aspects from SE}

Figure 7-11 shows the dependence of GPC on $P_{\text {tot. }}$ At 0.2 mbar, a GPC of 0.1 $\mathrm{nm} /$ cycle was obtained. Considering that GPC of BCN is $0.02 \mathrm{~nm} /$ cycle at this pressure (refer to Figure 7-5), GPC of $0.1 \mathrm{~nm} /$ cycle might indicate dominant AlN deposition. On the other hand, the kinetics of depositions at $10 \mathrm{mbar}$ was found to be thickness dependent. Namely, a GPC of $0.11 \mathrm{~nm} /$ cycle was obtained for the thicknesses up to $\sim 10 \mathrm{~nm}$; above $10 \mathrm{~nm}$, the GPC increased to $0.14 \mathrm{~nm} /$ cycle. Speculatively, it could be explained by the film closure above a critical thickness (i.e., $10 \mathrm{~nm}$ in this case). Alternative explanations might include (i) structural changes during deposition (as observed for $\mathrm{TiO}_{2} 56,57$ and $\mathrm{F}_{16} \mathrm{CuPc} 58$ thin films), (ii) increased effective surface area due to surface roughening ${ }^{56}$, (iii) establishing a preferred orientation due to film doping (see e.g. F doped $\mathrm{ZnO}^{59}$ ), or (iv) increased density of reactive species on the growth surface 56 (i.e., establishing proper reaction sites). To clarify the thickness dependent GPC behavior, a detailed experimental investigation is required, which is out of the scope of this work.
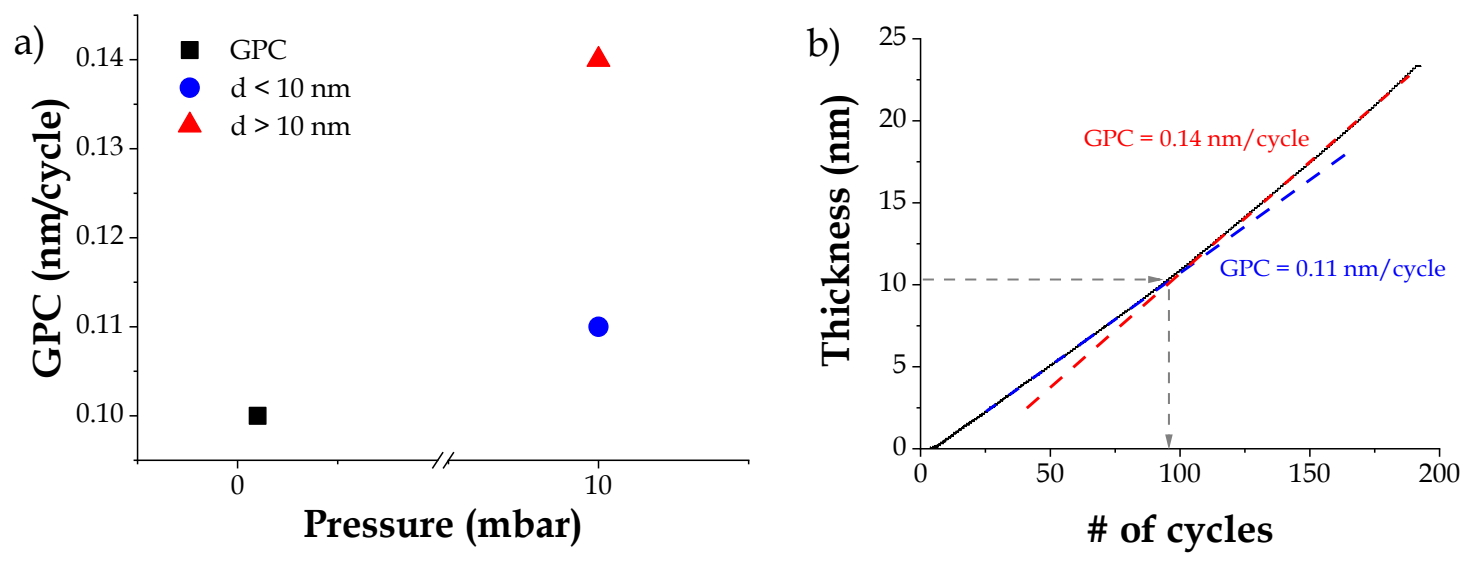

Figure 7-11. (a) GPC of AlBCN films vs total pressure. At 10 mbar, two thickness dependent GPC values were measured, as indicated. For step-shape analysis refer to Figure 7-12. (b) Thickness vs number of cycles for AlBCN sample deposited at 10 mbar showing thickness dependent GPC.

The SE step-shape analysis is shown in Figure 7-12. At 0.2 mbar (Figure 712.a), a "thickness" change was observed following the introduction of both TMA 
and TEB. The latter contributed much less compared to the former, suggesting the dominant growth of AlN once again. At 10 mbar (Figures 7-12.b and 7-12.c), introduction of TMA had no visible effect below $10 \mathrm{~nm}$ thickness. Above $10 \mathrm{~nm}$, a small contribution due to each TMA pulse can be seen (Figure 7-12.c).
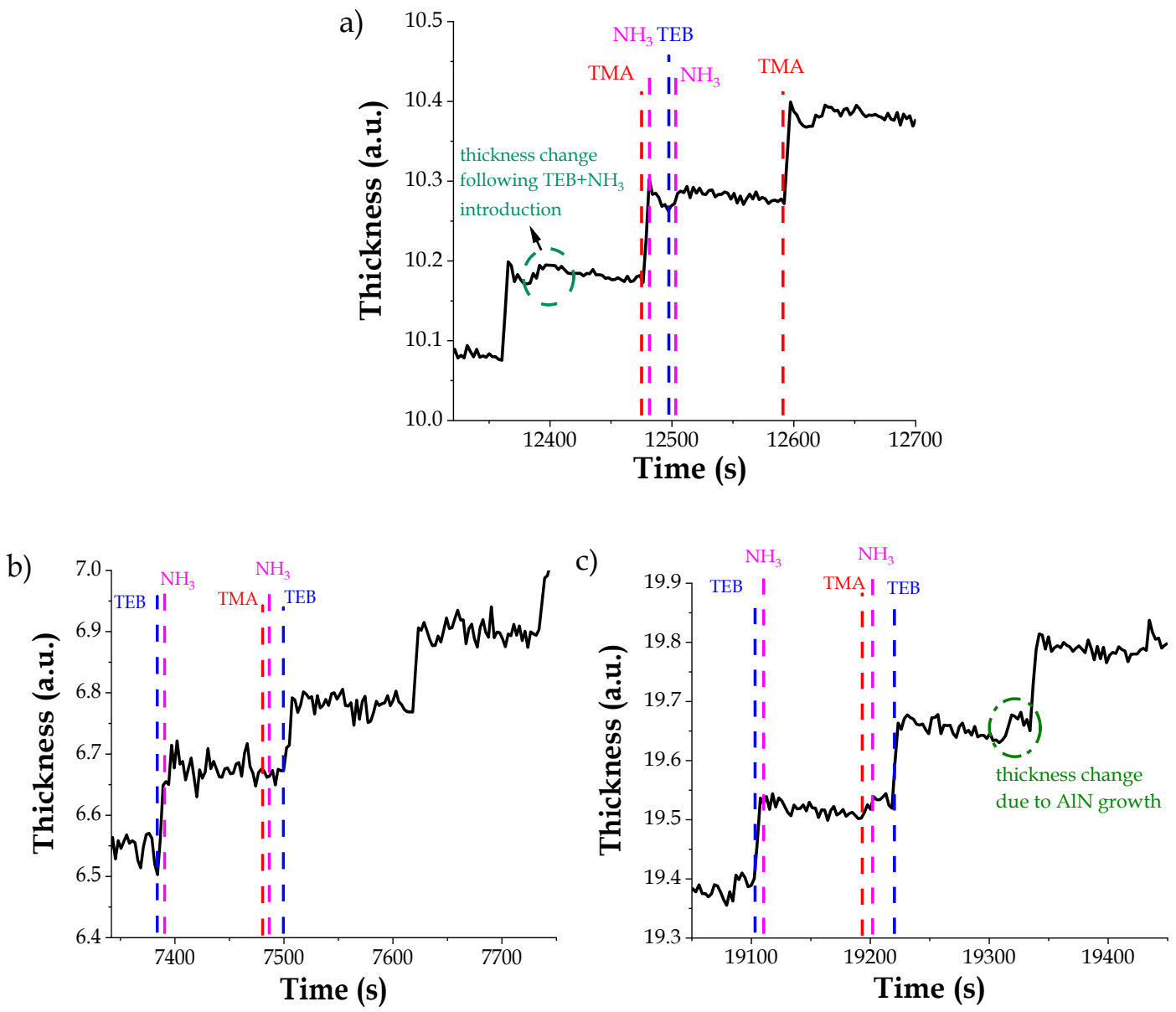

Figure 7-12. Step-shape comparison for deposition at $0.2 \mathrm{mbar}(\boldsymbol{a})$ and $10 \mathrm{mbar}$ ( $\boldsymbol{b}$ and

c). Figure (b) corresponds to thickness $<10 \mathrm{~nm}$ and (c) to thickness $>10 \mathrm{~nm}$.

The corresponding refractive index graphs are given in Figure 7-13. There is a difference in $n$ of less than $\sim 20 \%$. The $n$ obtained at 0.2 mbar deviates from that of AlN ${ }^{54}$ by $\sim 10 \%$, which can be attributed to small amounts of boron and carbon atoms present in the film (please refer to Figure 7-14). At 10 mbar, a lower $n$ is obtained, which can be ascribed to a larger share of the $\mathrm{BCN}$ compound; the latter is better formed at high pressures. 


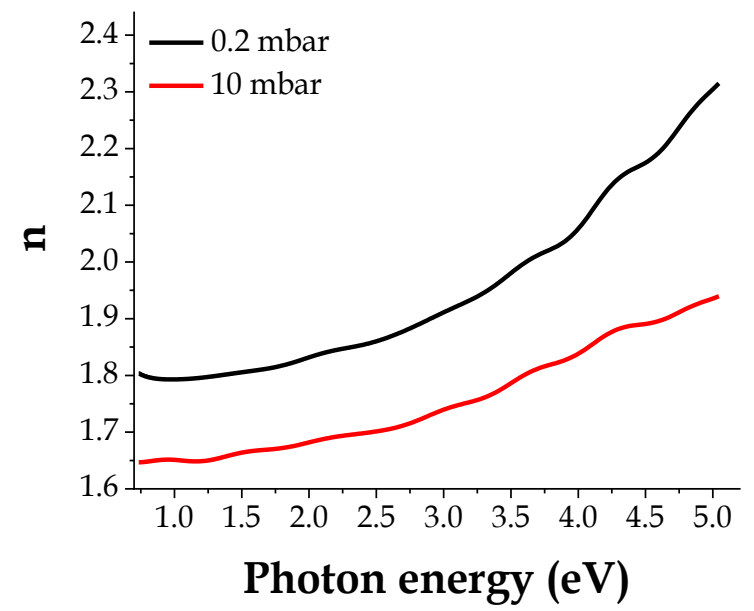

Figure 7-13. Refractive index (from in-situ SE) of films deposited at $P_{\text {tot }}$ of 0.2 (black) and 10 (red) mbar. Other conditions: 0.5-5-30-60 s durations for a TEB-Ar-NH3-Ar sequence and 0.5-5-10-5 s durations for a TMA-Ar-NH$-\mathrm{NH}_{3}-\mathrm{Ar}$ sequence.

The thickness was mapped by ex-situ SE (see Appendix 7.3). It shows a high non-uniformity with a thickness variation of up to $60 \%$, which once more (recall Appendix 7.2) confirms thermal decomposition of TEB. Deposition at $0.2 \mathrm{mbar}$ results in an improved thickness uniformity compared to that at 10 mbar, presumably due to a dominant AlN growth.

\subsubsection{Compositional analysis from XPS}

\subsubsection{Sputter depth profiles}

Sputter-depth profiling is given in Figure 7-14. Apart from Al, B, C and N, low amounts of oxygen (less than 5 at.\%) can be seen. For the deposition at a $P_{t o t}$ of 10 mbar (Figure 7-14.a), the layer mainly consists of B, C and N, with approx. 2 at.\% of $\mathrm{Al}$. We conclude that, at high total pressures, $\mathrm{BCN}$ deposition takes over AlN deposition, somehow preventing the involvement of TMA molecules. Presumably, boron and/or carbon can occupy active surface sites, preventing the chemisorption of TMA. At low pressures, 34 at. $\%$ of $\mathrm{Al}$ is incorporated into the film (see Figure 7-14.b). This can be explained by the inhibited growth of $\mathrm{BCN}$, as earlier demonstrated in Figure 7-5. 
a)

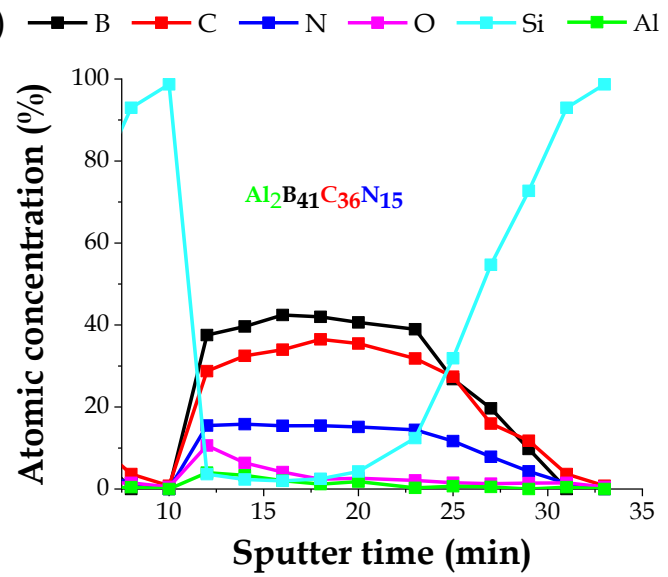

b) $\rightarrow-\mathrm{B} \rightarrow-\mathrm{C} \rightarrow-\mathrm{N} \rightarrow-\mathrm{O} \rightarrow-\mathrm{Si} \rightarrow \mathrm{Al}$

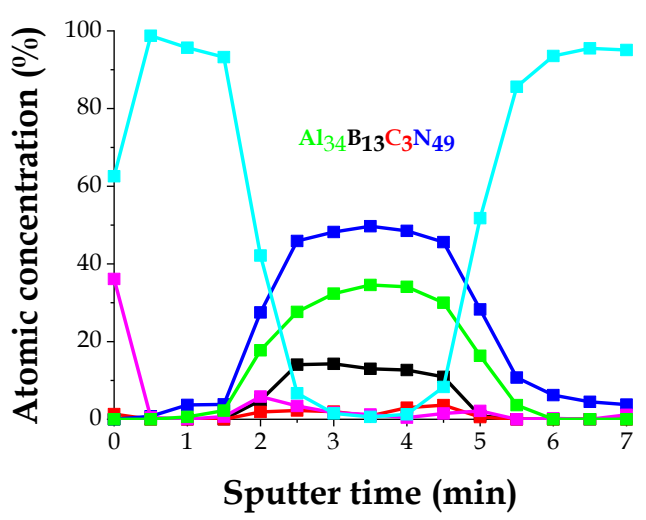

Figure 7-14. XPS depth profiles of AlBCN samples (capped with a-Si layer) deposited at $P_{\text {tot }}$ of (a) 10 mbar and (b) 0.2 mbar. The indicated stoichiometric coefficients are calculated from the peak-intensity ratios and do not necessarily imply the occurrence of a single-phase.

\subsubsection{Chemical bonding environments}

Figure 7-15 shows Gaussian fitting of Al 2p, B 1s and N 1s peaks of a sample deposited at a $P_{\text {tot }}$ of 0.2 mbar. Positions of the subpeaks were fixed according to Table 7-4. The C 1s peak (intensity within error margin - no deconvolution performed) position shifted towards lower energies, namely to $282.0 \mathrm{eV}$, possibly due to the presence of Al. the $\mathrm{Al} 2 \mathrm{p}$ peak was successfully fitted by two subpeaks. Nitrogen showed two different bonding states attributed to N-Al and N-B bonds as in AlN and BN, respectively. Weak subpeaks of a N-C bond were observed at 399.0 and $400.0 \mathrm{eV}$, due to the shift in $\mathrm{N}$ 1s peak positions during sputtering (see Appendix 7.4), to be assigned to $\mathrm{sp}$ or $\mathrm{sp}^{3}$ and $\mathrm{sp}^{2}$ hybridizations, respectively. 

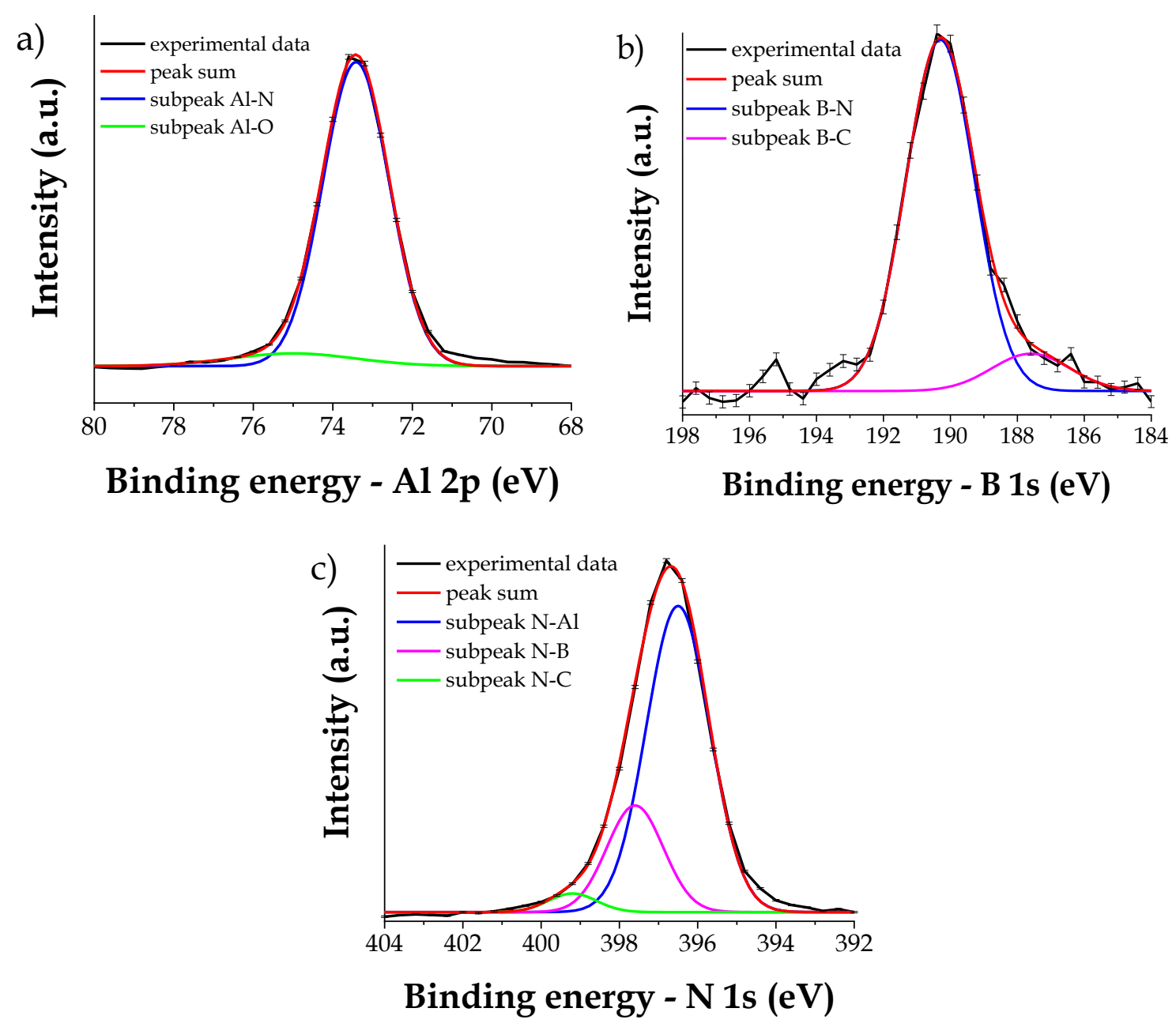

Figure 7-15. Deconvolution of representative Al $2 p$ (a), B 1s (b) and N 1s (c) XPS peaks of the $\mathrm{Al}_{34} \mathrm{~B}_{13} \mathrm{C}_{3} \mathrm{~N}_{49}$ sample of Figure 7-14.b deposited at $P_{\text {tot }}=0.2$ mbar. 2 different peak positions were determined for $N$ 1s clearly indicating the formation of AlN and BN compounds.

From the measured composition and the peak-deconvolution analysis, it might be speculated that the $\mathrm{Al}_{34} \mathrm{~B}_{13} \mathrm{C}_{3} \mathrm{~N}_{49}$ sample contained stoichiometric $\mathrm{AlN}$ and $\mathrm{BN}$ phases with some small incorporations of carbon. 
Table 7-4. XPS binding energies of $A l 2 p, B$ ss and $N$ 1s peaks of the $A l_{34} B_{13} C_{3} N_{49}$ sample deposited at $P_{\text {tot }}=0.2 \mathrm{mbar}$, and peak assignment from the literature.

\begin{tabular}{|c|c|c|c|}
\hline element & $\begin{array}{c}\text { binding energy } \\
(\mathbf{e V})\end{array}$ & possible bonds and compounds & references \\
\hline \multirow{3}{*}{$\mathrm{Al} 2 \mathrm{p}$} & 73.4 & $\mathrm{Al}-\mathrm{N}$ in $\mathrm{AlN}$ & 60 \\
\cline { 2 - 4 } & 75.2 & $\mathrm{Al}-\mathrm{O}$ in $\mathrm{Al}_{2} \mathrm{O}_{3}$ & 61 \\
\hline \multirow{3}{*}{$\mathrm{B} 1 \mathrm{~s}$} & 187.5 & $\mathrm{~B}-\mathrm{C}$ in $\mathrm{B}_{4} \mathrm{C}$ & $33-36$ \\
\cline { 2 - 4 } & 190.3 & $\mathrm{~B}-\mathrm{B}$ in pure-B & 37 \\
\hline \multirow{4}{*}{$\mathrm{N} 1 \mathrm{~s}$} & 396.7 & $\mathrm{~B}-\mathrm{N}$ in BN & $42-44$ \\
\cline { 2 - 4 } & 397.5 & $\mathrm{~N}-\mathrm{Al}$ in AlN & 60 \\
\cline { 2 - 4 } & 399.0 & N-B in BN & $38,44,49$ \\
\cline { 2 - 4 } & 400.0 & $\begin{array}{c}\text { carbon-nitrogen bond in } \mathrm{sp} \text { or } \mathrm{sp}^{3} \\
\text { hybridizations }\end{array}$ & $38,41,43,49,52,53$ \\
\cline { 2 - 4 } & & $\begin{array}{c}\text { carbon-nitrogen bond in } \mathrm{sp}^{2} \\
\text { hybridization }\end{array}$ & $49,52,53$ \\
\hline
\end{tabular}

Figure 7-16 shows the peak deconvolution of the $\mathrm{Al}_{2} \mathrm{~B}_{41} \mathrm{C}_{36} \mathrm{~N}_{15}$ sample (recall Figure 7-14.a) deposited at a $P_{\text {tot }}$ of 10 mbar. The B 1s and C 1s spectra exhibited bonding states located at binding energies similar to those earlier measured for the BCN films discussed in Section 7.4.2.2. Further, the Al $2 p$ peak was successfully fitted by two subpeaks (Figure 7-16.b) attributed to $\mathrm{AlN}$ and $\mathrm{Al}_{2} \mathrm{O}_{3}$, similar to the 0.2 mbar case (recall Figure 7-15.a). The N 1s peak showed two different bonding states attributed to N-Al and N-B bonds as in AlN and BN, respectively (Figure 716.d). In addition, from deconvolution of the $\mathrm{N} 1 \mathrm{~s}$ peak, a weak subpeak of a N-C bond might be suggested. The peak position ranges between 399.0 and $400.3 \mathrm{eV}$, depending on the vertical position of the volume probed by XPS inside the film. At the film surface, the N-C peak presumably appears at $399.0 \mathrm{eV}$, whereas it shifts to $400.3 \mathrm{eV}$ while approaching the film/ substrate interface (see Appendix 7.4). The shift may point out to a change in the bonding environment of nitrogen, which can be related to the change of GPC observed for the 10-mbar sample (Figure 7-11.b). Since a similar $\mathrm{N}$ 1s peak shift is observed for the 0.2-mbar sample as well, a change in GPC can also be expected there when approaching critical thickness. The latter is however difficult to achieve due to a low GPC at 0.2 mbar. The N 1 s subpeaks at 
399.0 and $400.0 \mathrm{eV}$ can be assigned to $\mathrm{sp}$ or $\mathrm{sp}^{3}$ and $\mathrm{sp}^{2}$ hybridizations, respectively. Please refer to Tables 7-3 and 7-4 for further details.

Summarizing, the $\mathrm{Al}_{2} \mathrm{~B}_{41} \mathrm{C}_{36} \mathrm{~N}_{15}$ sample deposited at 10 mbar resembles, in terms of its composition and chemical bonding environments, the $\mathrm{B}_{0.42} \mathrm{C}_{0.41} \mathrm{~N}_{0.15}$ sample earlier discussed in Section 7.4.2.2. The similar elemental shares of $\mathrm{B}, \mathrm{N}$ and $\mathrm{C}$ can originate from the low share of $\mathrm{Al}$, making these two materials comparable. We can once again speculate the appearance of $B_{x} C, C_{y} N$, pure $C$ and stoichiometric $B N$ phases, perhaps with some additions of a single $B_{x} C_{y} N_{z}$ phase. As for the $\mathrm{Al}_{34} \mathrm{~B}_{13} \mathrm{C}_{3} \mathrm{~N}_{49}$ sample obtained at $0.2 \mathrm{mbar}$, co-existence of stoichiometric AlN and BN phases with some small incorporations of carbon may be speculated.
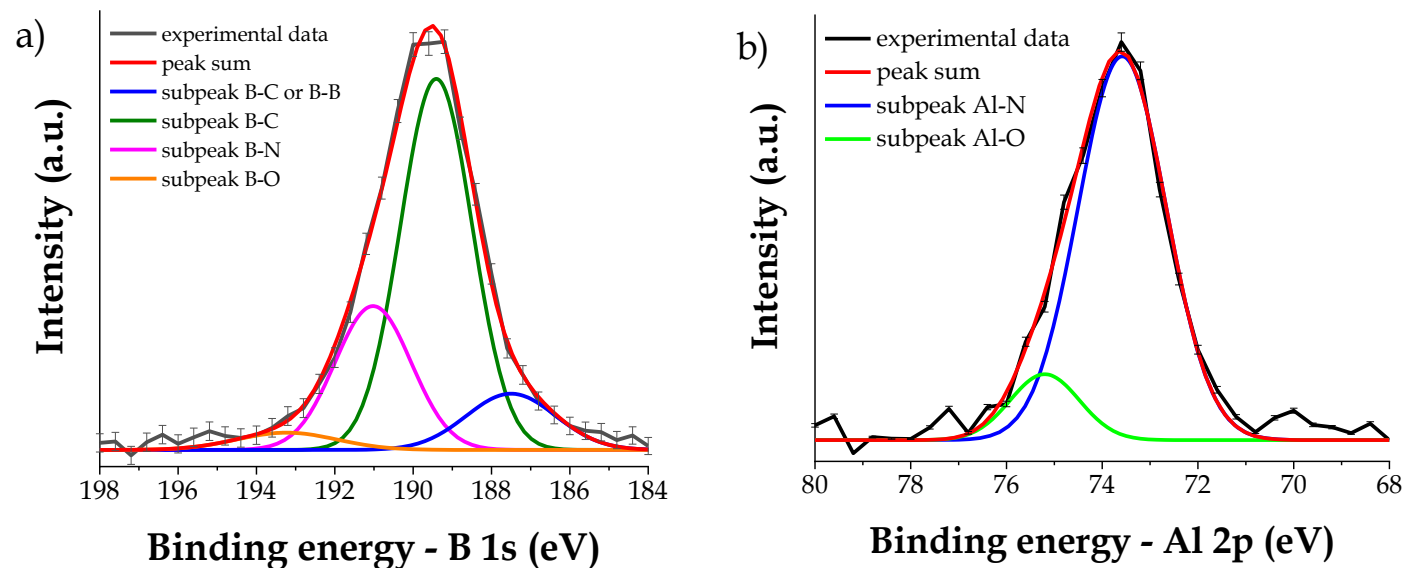

Binding energy - Al 2p (eV)
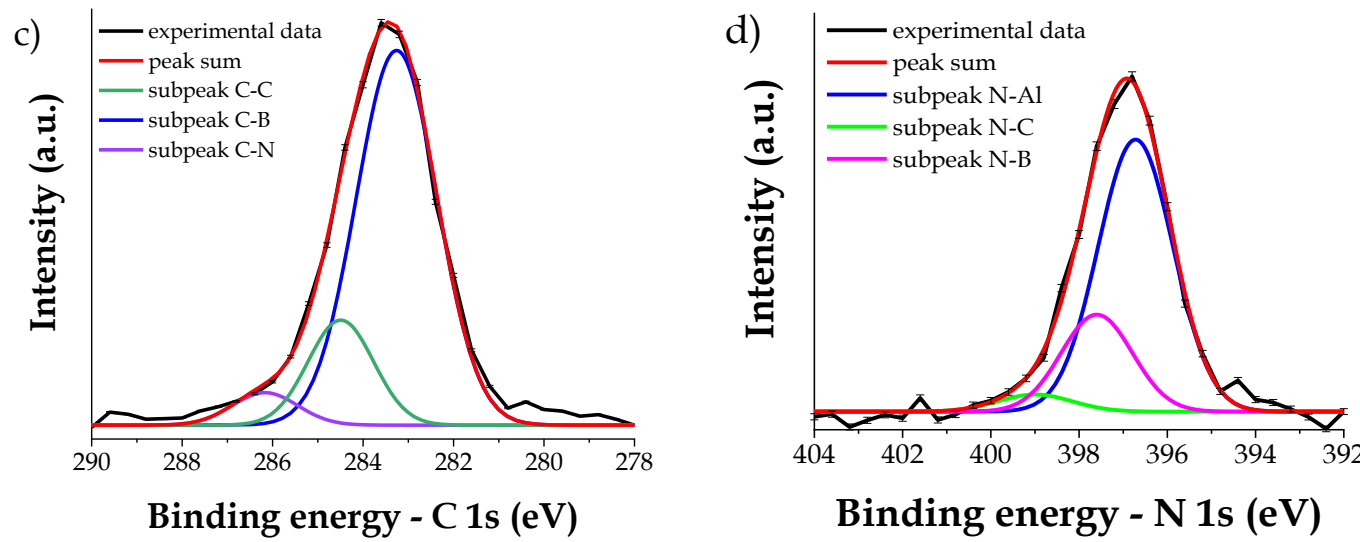

Binding energy - N 1s (eV)

Figure 7-16. Deconvolution of representative B 1s (a), Al 2p (b), C 1s (c) and N 1s (d) XPS peaks of the $A l_{2} B_{41} C_{36} N_{15}$ sample of Figure 7-14.a deposited at $P_{\text {tot }}=10$ mbar. 2 different peak positions were determined for $N 1$ clearly indicating the formation of AlN and BN compounds. 


\subsection{Conclusions}

This work investigated deposition of BCN and AlBCN films in view of the goals mentioned in the introduction. It was shown that, GPC of BCN films increases with $T_{S}$ and $t_{T E B}$, indicating the ongoing thermal decomposition of TEB. The large non-uniformity exhibited by the films confirmed once more the thermal decomposition of TEB, dominating the film growth. The films deposited at different $T_{S}$ comprised similar quantitative elemental compositions (QEC) of $\mathrm{B}_{42} \mathrm{C}_{41} \mathrm{~N}_{15}$ (values vary by \pm 2 ), showing inefficient film nitridation. In order to facilitate nitridation, longer ammonia pulse times were applied, still hardly showing any effect on GPC. However, the $t_{N H 3}$ influenced the $\mathrm{N} 1$ s bonding environment, which was changed from $\mathrm{sp}$ or $\mathrm{sp}^{3}$ hybridized carbon-nitrogen bonding at $t_{\mathrm{NH} 3}=5 \mathrm{~s}$ to $\mathrm{sp}^{2}$ hybridized carbon-nitrogen bonding at $t_{\mathrm{NH} 3}=30-60 \mathrm{~s}$. This change had a significant effect on $n$ which decreased by $\sim 10 \%$.

To investigate alternative chemical routes, HW-assisted deposition was applied, which allowed to provide atomic hydrogen to the system among the other precursors. This lead to a lower $\mathrm{N}$ - and a higher C-share, yielding a QEC of $\mathrm{B}_{45} \mathrm{C}_{47} \mathrm{~N}_{6}$. The effect could be explained by the involvement of different-to-thermal chemical routes, still, however, resulting in inefficient nitridation.

The deposition of AlBCN films were found to be slightly pressure dependent, namely high $P_{\text {tot }}$ resulted in $~ 10 \%$ higher GPC. A thickness dependent GPC was measured by in-situ SE at the high $P_{t o t}$; above a critical thickness $(\mathrm{d}>10$ nm), GPC increased by $\sim 20 \%$. The films exhibited clear compositional differences. Specifically, the very different $Q E C$ of the $\mathrm{Al}_{34} \mathrm{~B}_{13} \mathrm{C}_{3} \mathrm{~N}_{49}$ and $\mathrm{Al}_{2} \mathrm{~B}_{41} \mathrm{C}_{36} \mathrm{~N}_{15}$ film deposited at 0.2 and 10 mbar, respectively, indicated the enhanced BCN deposition at higher $P_{\text {tot }}$ whereas lower $P_{\text {tot }}$ caused mainly $\mathrm{AlN}$ in the films. The $\mathrm{Al}_{2} \mathrm{~B}_{41} \mathrm{C}_{36} \mathrm{~N}_{15}$ sample deposited at 10 mbar resembled, in terms of its composition and chemical bonding environments, to the $\mathrm{B}_{0.42} \mathrm{C}_{0.41} \mathrm{~N}_{0.15}$ sample earlier discussed in Section 7.4.2.2. The similar elemental shares of $B, N$ and $C$ possibly originated from the low share of $\mathrm{Al}$, making these two materials comparable. 
Solely from XPS, appearance of $\mathrm{B}_{\mathrm{x}} \mathrm{C}, \mathrm{C}_{\mathrm{y}} \mathrm{N}$, pure $\mathrm{C}$ and stoichiometric $\mathrm{BN}$ phases, perhaps with some additions of a single $B_{x} C_{y} N_{z}$ phase can be speculated for all samples. As for the $\mathrm{Al}_{34} \mathrm{~B}_{13} \mathrm{C}_{3} \mathrm{~N}_{49}$ sample obtained at 0.2 mbar, co-existence of stoichiometric AlN and BN phases with some small incorporations of carbon may be speculated. However, a detailed investigation is required in order to identify the available phases. 


\section{Appendix 7.1: Stepwise growth of BCN films}

a)

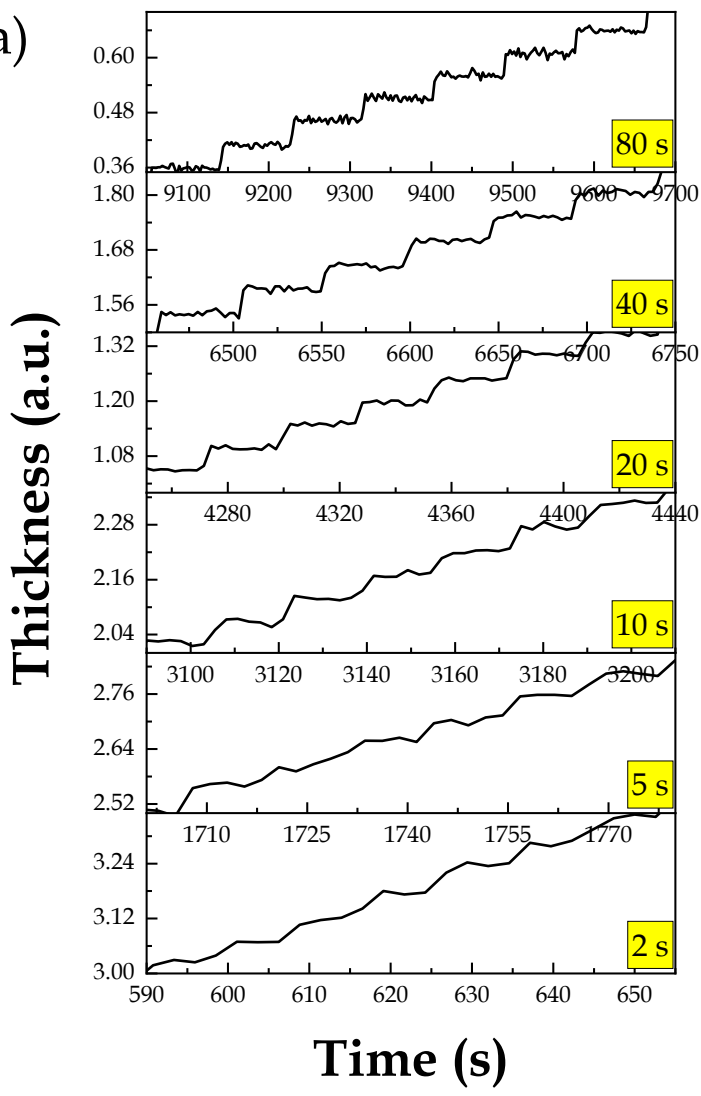

b)

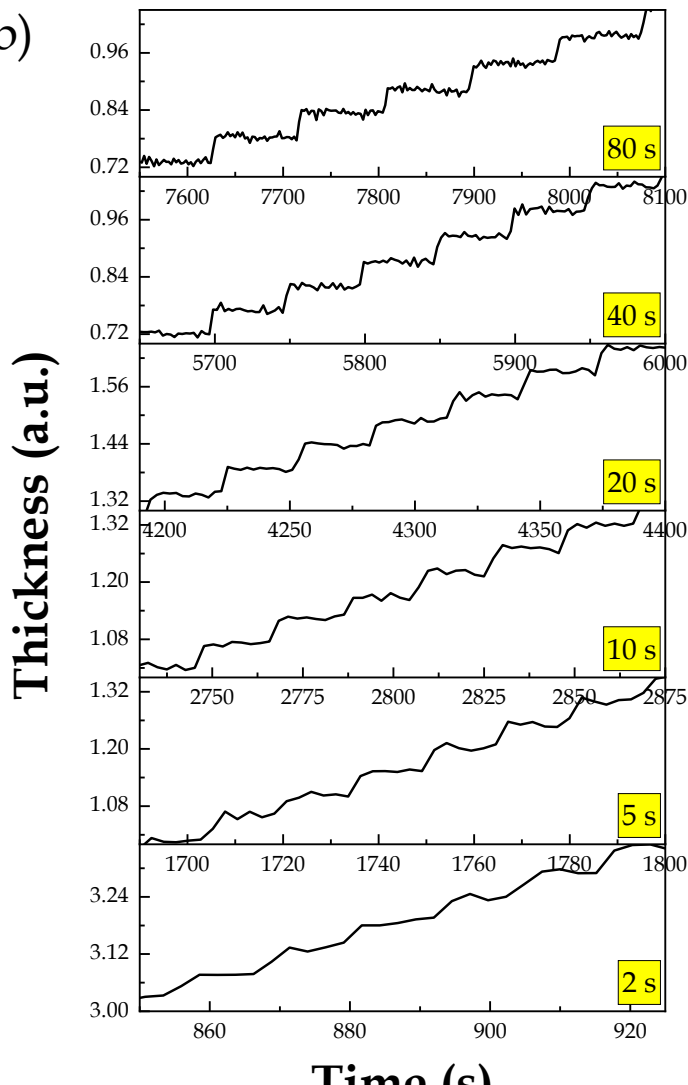

Figure A-7-1. The effect of post-NH3 purge time (given inside the images) on the stepwise growth of BCN films deposited at $P_{\text {tot }}$ of 5 mbar using $t_{N H 3}$ of (a) $2 s$ and (b) $5 s$, as determined by in-situ SE. The graphs show that post-NH3 purge times longer than $20 \mathrm{~s}$ is required to minimize possible gas phase reactions between TEB and $\mathrm{NH}_{3}$. It is important to bear in mind the considerations mentioned in Section 5.5.2 w.r.t. to the small stepvariations interpreted by SE as the thickness changes. 


\section{Appendix 7.2: Thickness variation of BCN films mapped by ex-situ SE}

a)

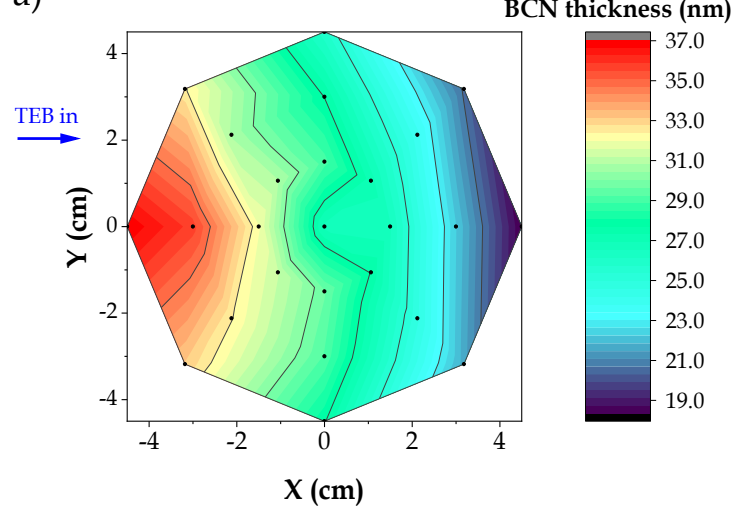

b)

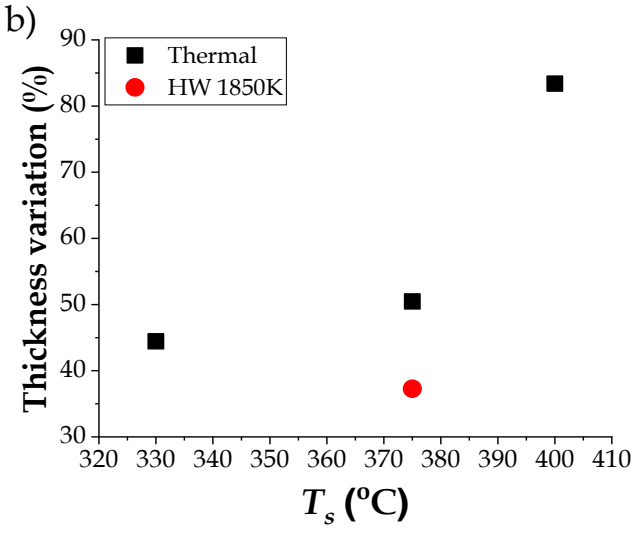

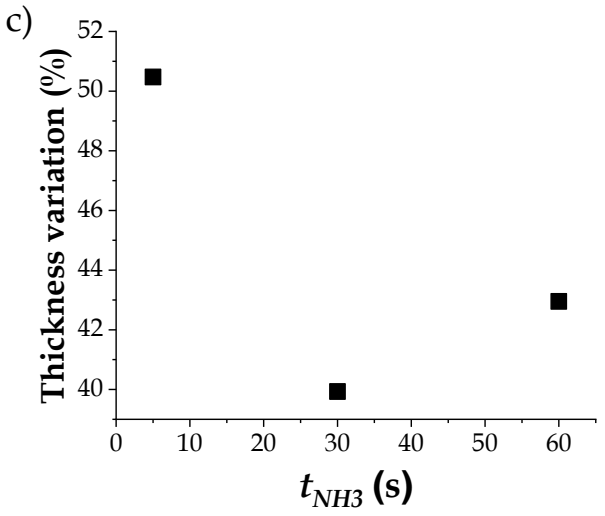

Figure A-7-2. (a) Representative thickness mapping of a BCN layer deposited at $375{ }^{\circ} \mathrm{C}$, 10 mbar and $t_{N H 3}$ of $5 \mathrm{~s}$. To note, TEB is introduced from the left-hand side of the image. The thickness variations in $(\boldsymbol{b})$ and $(\boldsymbol{c})$ are calculated as $[(\max -\min ) / \max ] \times 100$. 


\section{Appendix 7.3: Thickness variation of AlBCN films mapped by ex-situ SE}

a)

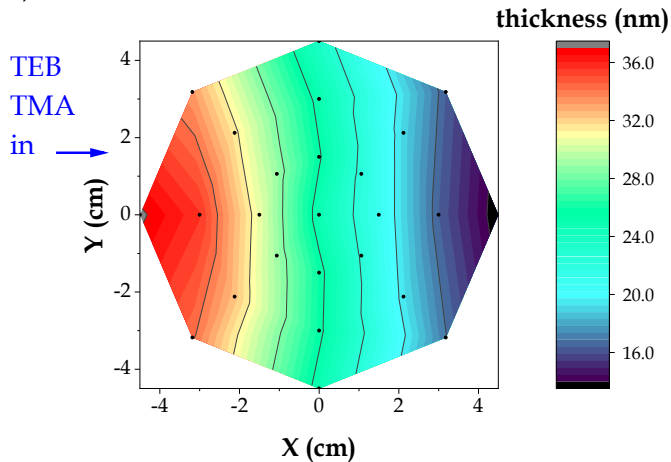

b)

AlBCN thickness (nm)

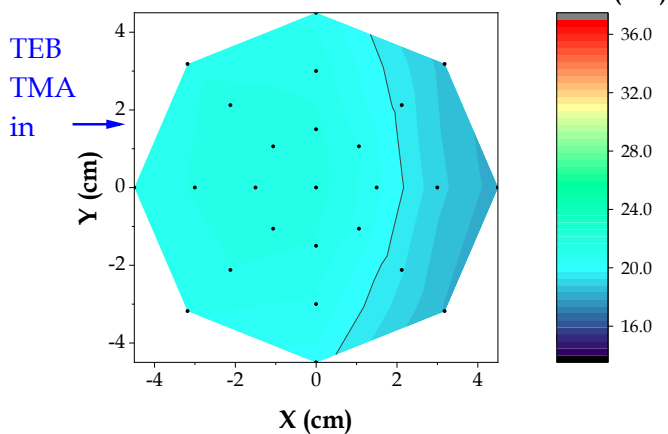

Figure A-7-3. Ex-situ SE thickness maps of AlBCN samples deposited at $P_{\text {tot }}$ of $(a) 10$ mbar and (b) 0.2 mbar. To note: TEB and TMA are introduced from the left-hand side, as indicated. As a result, thicker layers are formed closer to the gas inlet. Deposition at 0.2 mbar results in an improved thickness uniformity, suggesting a dominant AlN growth. 


\section{Appendix 7.4: Sputter depth profile line intensities}

a)

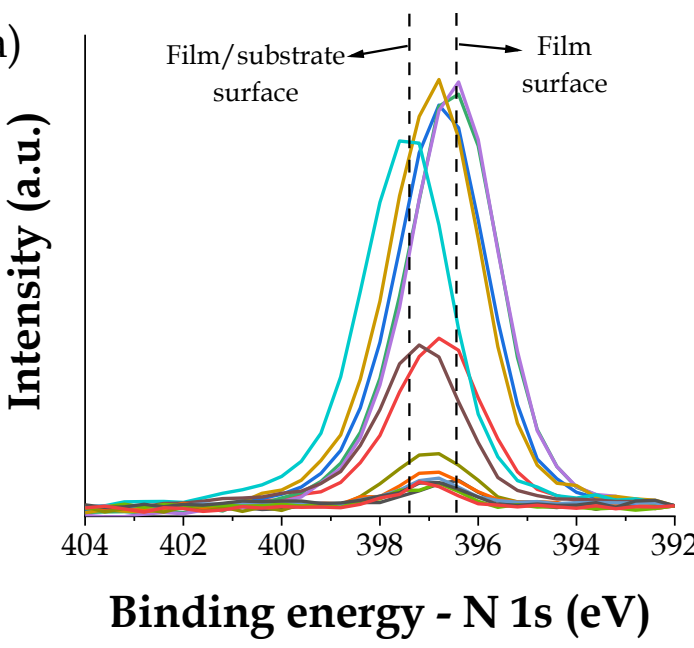

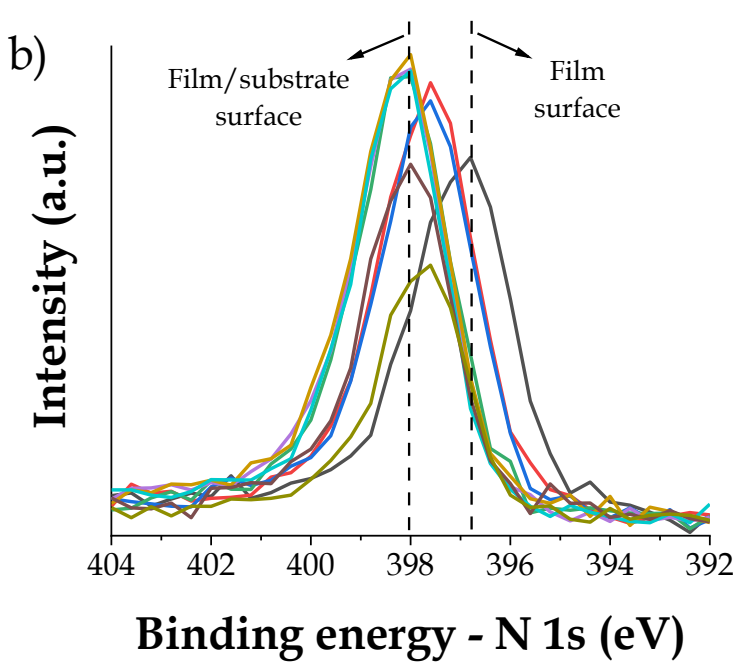

Figure A-7-4: Sputter depth profile line intensities of $N$ 1s peaks for samples deposited at $P_{\text {tot }}$ of (a) 0.2 mbar and (b) 10 mbar. The shift in $N$ 1s peak maxima indicates different bonding environments as discussed earlier in Sections 7.4.2.2 and 7.5.2.2. 


\section{References}

1 S. Banerjee, A.A.I. Aarnink, D.J. Gravesteijn, and A.Y. Kovalgin, J. Phys. Chem. C 123, 23214 (2019).

2 M. Chubarov, Chemical Vapour Deposition of Sp2 Hybridised Boron Nitride, Linköping University, 2014.

3 R.R.Q. Freitas, G.K. Gueorguiev, F. De Brito Mota, C.M.C. De Castilho, S. Stafström, and A. Kakanakova-Georgieva, Chem. Phys. Lett. 583, 119 (2013).

${ }^{4}$ M. Imam, C. Höglund, S. Schmidt, R. Hall-Wilton, J. Birch, and H. Pedersen, J. Chem. Phys. 148, (2018).

${ }^{5}$ A. Haider, C. Ozgit-Akgun, E. Goldenberg, A.K. Okyay, and N. Biyikli, J. Am. Ceram. Soc. 97, 4052 (2014).

${ }^{6}$ M. Snure, Q. Paduano, M. Hamilton, J. Shoaf, and J.M. Mann, Thin Solid Films 571, 51 (2014).

${ }^{7}$ O.J. Kilbury, K.S. Barrett, X. Fu, J. Yin, D.S. Dinair, C.J. Gump, A.W. Weimer, and D.M. King, Powder Technol. 221, 26 (2012).

8 W. Hao, C. Marichy, and C. Journet, 2D Mater. 6, (2019).

${ }^{9}$ S. Joh and G.H. Evans, in Proc. Thirteen. Int. Conf. Chem. Vap. Depos., edited by T.M. Besmann, M.D. Allendorf, M. Robinson, and R.K. Ulrich (The Electrochemical Society, Inc., New Jersey, 1996), pp. 588-593.

10 J.S. Lewis, S. Vaidyaraman, W.J. Lackey, P.K. Agrawal, G.B. Freeman, and E.K. Barefield, Mater. Lett. 27, 327 (1996).

${ }_{11}$ M. Imam, K. Gaul, A. Stegmüller, C. Höglund, J. Jensen, L. Hultman, J. Birch, R. Tonner, and H. Pedersen, J. Mater. Chem. C 3, 10898 (2015).

12 M. Imam, CVD Chemistry of Organoborons for Boron-Carbon Thin Film Depositions, Linköping University, 2017.

${ }^{13}$ H. Jeong, D.Y. Kim, J. Kim, S. Moon, N. Han, S.H. Lee, O.F.N. Okello, K. Song, S.Y. Choi, and J.K. Kim, Sci. Rep. 9, 1 (2019).

14 S.S. Liu and D.A. Stevenson, J. Electrochem. Soc. 125, 1161 (1978).

15 M.E. Bartram, T.A. Michalske, J.W. Rogers, and R.T. Paine, Chem. Mater. 5, 1424 (1993).

16 S. Yamashita, K. Watanuki, H. Ishii, Y. Shiba, M. Kitano, Y. Shirai, S. Sugawa, and T. Ohmi, J. Electrochem. Soc. 158, H93 (2011).

17 H. Pedersen, C. Höglund, J. Birch, J. Jensen, and A. Henry, Chem. Vap. Depos. 18, 221 (2012).

18 C.D. Stinespring and J.C. Wormhoudt, J. Cryst. Growth 87, 481 (1988).

19 A.Y. Kovalgin, M. Yang, S. Banerjee, R.O. Apaydin, A.A.I. Aarnink, S. Kinge, and R.A.M. Wolters, Adv. Mater. Interfaces 4, 1700058 (2017). 
${ }^{20}$ M. Yang, Hot-Wire Assisted Atomic Layer Deposition of Tungsten Films, University of Twente, 2018.

21 X. Yang, S. Nitta, K. Nagamatsu, S.Y. Bae, H.J. Lee, Y. Liu, M. Pristovsek, Y. Honda, and H. Amano, J. Cryst. Growth 482, 1 (2018).

${ }^{22}$ D. Jin-Xiang, Z. Xiao-Kang, Y. Qian, W. Xu-Yang, C. Guang-Hua, and H. DeYan, Chinese Phys. B 18, 4013 (2009).

${ }^{23}$ H. Umemoto, K. Ohara, D. Morita, T. Morimoto, M. Yamawaki, A. Masuda, and H. Matsumura, Jpn. J. Appl. Phys. 42, 5315 (2003).

24 Y.J. Shi, B.D. Eustergerling, and X.M. Li, Thin Solid Films 516, 506 (2008).

${ }^{25}$ M.K. Lei, Q. Li, Z.F. Zhou, I. Bello, C.S. Lee, and S.T. Lee, Thin Solid Films 389, 194 (2001).

${ }^{26}$ C. Kimura, H. Sota, H. Aoki, and T. Sugino, Diam. Relat. Mater. 18, 478 (2009).

27 H. Sota, C. Kimura, H. Aoki, and T. Sugino, Diam. Relat. Mater. 19, 1441 (2010).

28 A. Prakash and K.B. Sundaram, Appl. Surf. Sci. 396, 484 (2017).

${ }^{29}$ J.C. Angus and C.C. Hayman, Science (80-. ). 241, 913 (1988).

30 B. Dischler, A. Bubenzer, and P. Koidl, Appl. Phys. Lett. 42, 636 (1983).

31 J. Robertson and E.P. Oreilly, Phys. Rev. B 35, 2946 (1987).

32 M. Chubarov, H. Pedersen, H. Högberg, J. Jensen, and A. Henry, Cryst. Growth Des. 12, 3215 (2012).

33 W. Cermignani, T.E. Paulson, C. Onneby, and C.G. Pantano, Carbon N. Y. 33, 367 (1995).

34 S. Jacques, A. Guette, X. Bourrat, F. Langlais, C. Guimon, and C. Labrugere, Carbon N. Y. 34, 1135 (1996).

${ }^{35}$ Y. Sun, Q. Meng, M. Qian, B. Liu, K. Gao, Y. Ma, M. Wen, and W. Zheng, Sci. Rep. 6, 1 (2016).

${ }^{36}$ H. Moreno Fernández, D. Rogler, G. Sauthier, M. Thomasset, R. Dietsch, V. Carlino, and E. Pellegrin, Sci. Rep. 8, 1 (2018).

${ }^{37}$ E.A. Il'inchik, V. V. Volkov, and L.N. Mazalov, J. Struct. Chem. 46, 523 (2005).

${ }^{38}$ M.A. Mannan, M. Nagano, K. Shigezumi, T. Kida, N. Hirao, and Y. Baba, Am. J. Appl. Sci. 5, 736 (2008).

${ }^{39}$ M.O. Watanabe, T. Sasaki, S. Itoh, and K. Mizushima, Thin Solid Films 281282, 334 (1996).

${ }^{40}$ H. Künzli, P. Gantenbein, R. Steiner, and P. Oelhafen, Fresenius. J. Anal. Chem. 346, 41 (1993).

41 A. Perrone, A.P. Caricato, A. Luches, M. Dinescu, C. Ghica, V. Sandu, and A. Andrei, Appl. Surf. Sci. 133, 239 (1998). 
42 V.S. Sulyaeva, Y.M. Rumyantsev, V.G. Kesler, and M.L. Kosinova, Thin Solid Films 581, 59 (2015).

43 T. Thamm, D. Wett, W. Bohne, E. Strub, J. Röhrich, R. Szargan, G. Marx, and W.A. Goedel, Microchim. Acta 156, 53 (2006).

44 V.O. Todi and K.B. Sundaram, Electrochem. Solid-State Lett. 14, G49 (2011).

45 A.R. Burke, C.R. Brown, W.C. Bowling, J.E. Glaub, D. Kapsch, C.M. Love, R.B. Whitaker, and W.E. Moddeman, Surf. Interface Anal. 11, 353 (1988).

46 L.G. Jacobsohn, R.K. Schulze, M.E.H. Maia Da Costa, and M. Nastasi, Surf. Sci. 572, 418 (2004).

47 C. Ronning, D. Schwen, S. Eyhusen, U. Vetter, and H. Hofsäss, Surf. Coatings Technol. 158-159, 382 (2002).

${ }^{48}$ L. Liu, Y. Wang, K. Feng, Y. Li, W. Li, C. Zhao, and Y. Zhao, Appl. Surf. Sci. 252, 4185 (2006).

${ }^{49}$ F. Zhou, K. Adachi, and K. Kato, Thin Solid Films 497, 210 (2006).

50 M.O. Watanabe, S. Itoh, K. Mizushima, and T. Sasaki, Appl. Phys. Lett. 68, 2962 (1996).

51 A. Majumdar, J. Schäfer, P. Mishra, D. Ghose, J. Meichsner, and R. Hippler, Surf. Coatings Technol. 201, 6437 (2007).

52 P. Petrov, D.B. Dimitrov, D. Papadimitriou, G. Beshkov, V. Krastev, and C. Georgiev, Appl. Surf. Sci. 151, 233 (1999).

53 E. D’Anna, M.L. De Giorgi, A. Luches, M. Martino, A. Perrone, and A. Zocco, Thin Solid Films 347, 72 (1999).

54 S. Banerjee, From Radical-Enhanced to Pure Thermal ALD of Aluminium and Gallium Nitrides, University of Twente, 2019.

55 S. Banerjee, A.A.I. Aarnink, D.J. Gravesteijn, and A.Y. Kovalgin, in EuroCVD 22-Baltic ALD 16 Conf. (Luxembourg, 2019).

56 S.K. Kim, S. Hoffmann-Eifert, M. Reiners, and R. Waser, J. Electrochem. Soc. 158, 28 (2011).

57 D.R.G. Mitchell, D.J. Attard, and G. Triani, Thin Solid Films 441, 85 (2003).

${ }^{58}$ D.G. De Oteyza, E. Barrena, J.O. Ossó, S. Sellner, and H. Dosch, J. Am. Chem. Soc. 128, 15052 (2006).

${ }^{59}$ K.-M. Kang, Y.-J. Choi, G.Y. Yeom, and H.-H. Park, J. Vac. Sci. Technol. A Vacuum, Surfaces, Film. 34, 01A144 (2016).

60 T. Hagio, A. Takase, and S. Umebayashi, J. Mater. Sci. Lett. 11, 878 (1992).

61 Y.C. Kim, H.H. Park, J.S. Chun, and W.J. Lee, Thin Solid Films 237, 57 (1994). 
8 Conclusions and recommendations 


\subsection{Conclusions}

This thesis addressed deposition of B-, C- and N- containing thin films by thermal and radical-enhanced methods. We explored both pulsed-deposition and ALD approaches, with the aim to comparatively study and understand the growth mechanisms, observe the occurrence of various phases in the compounds, and obtain basic material properties. Several precursor systems have been explored in view of the deposition mechanisms hypothesized and the research goals named. The approach and motivation were outlined in Chapter 1.

Chapter 2 focused on the application of SE for determining thickness, optical functions and composition of the films. The relevant optical SE models were reviewed, finally building the appropriate models used through the entire thesis for analyzing the films and composites under study. The performed literature review outlined the relevant film-growth mechanisms in terms of surface chemical reactions. The mechanisms we further confirmed / disproved to occur in the following up chapters of this thesis, in relation to the particular precursors used.

Chapter 3 experimentally verified the SE approach proposed in Chapter 2 for the films deposited from $\mathrm{B}_{2} \mathrm{H}_{6}$ and $\mathrm{NH}_{3}$ gases. The analysis suggested the multiphase (composite) film nature; the films were further referred to as $\mathrm{B} / \mathrm{BN}$ composites. The composites exhibited refractive indices $(n)$ strongly dependent on the pure-B fraction: a gradual increase of $n$ from 1.7 (stoichiometric $\mathrm{BN}$ ) to 2.9 (pure-B) was achieved by tuning the pure-B share. It was shown that the developed SE model could quantitatively describe the experimental $n$-values as well as the multi-phase nature of the films in terms of the B- and BN-shares. Thin pure-B films revealed a characteristic and not mentioned in the literature absorption peak at 3.3 eV. The XPS measurements confirmed composite nature of the films, indicating the presence of a well-defined stoichiometric BN phase. The crosscorrelation maps provided by EFTEM showed lateral homogeneity of the B- and $\mathrm{N}$-elements, thereby suggesting their vertical inhomogeneity. 
In Chapter 4, the growth mechanism of the B/BN composites deposited from $\mathrm{B}_{2} \mathrm{H}_{6}$ and $\mathrm{NH}_{3}$ gases was investigated. The degree of dissociation of $\mathrm{NH}_{3}$ was gradually changed from zero (purely thermal mode) through low by applying a hot-wire (HW) to high by plasma-assistance. In purely thermal mode, the growth and composition of the layers were strongly dependent on total gas pressure $\left(P_{t o t}\right)$ : increasing the $P_{\text {tot }}$ enhanced the GPC and reduced the pure-B content from $\sim 70$ vol. \% to $\sim 6$ vol. \%. Such a strong pressure dependence allowed to hypothesize the growth mechanism via the surface-adduct reaction pathway, analogous to the earlier suggested mechanisms for AlN and GaN. Introducing additional means to dissociate $\mathrm{NH}_{3}$ significantly affected the growth behavior, film properties and thus the mechanism. The best results were obtained with plasma, which provided near stoichiometric, crystalline and stable in air BN films at approx. $300^{\circ} \mathrm{C}$.

Applicability of the surface-adduct mechanism to ALD of $\mathrm{BN}$ from $\mathrm{BBr}_{3}$ and $\mathrm{NH}_{3}$ was further addressed in Chapter 5 and 6. Chapter 5 showed that the hypothesized role of the $\mathrm{BBr}_{3}: \mathrm{NH}_{3}$ surface adduct in the ALD mechanism could adequately explain the experimental observations. In addition, the kinetics of surface-adduct formation and its conversion to $-\mathrm{NH}_{2}$ - linkages were simulated using a Mathcad code. The results showed a dependence of the adduct surface coverage on ammonia partial pressure, in line with the experimental observations.

Alternative approaches to growing $\mathrm{BN}$ from $\mathrm{BBr}_{3}$ and $\mathrm{NH}_{3}$, such as the radical assistance and the use of a cold-wall reactor instead of a hot-wall reactor, were discussed in Chapter 6. The radical (plasma) assistance led to lower GPC values and the occurrence of a pure-B phase, clearly indicating the involvement of additional-to-thermal chemical routes. A change of the film growth mechanism was suggested. Use of a hot-wire instead of plasma revealed similar results, although less pronounced in view of a lower dissociation degree of ammonia by HW compared to plasma. The cold-wall reactor enabled studying the reaction byproducts, namely $\mathrm{NH}_{4} \mathrm{Br}$, which was suggested for differentiating between ALD and CVD modes and verifying film-growth mechanism. 
Chapter 7 discussed growth of $\mathrm{BCN}$ and AlBCN films from metalorganic precursors. Due to the low temperature required for thermal decomposition of triethylborane (TEB, $\left.\sim 250{ }^{\circ} \mathrm{C}\right)$, ammonia was not able to react with a TEBterminated surface at such low temperatures and thus provide its efficient nitridation. The attempt to enhance this process by activating the surface-adduct pathway was unsuccessful since thermal decomposition of TEB still led the process. Decomposition suppressed the removal of carbon (of TEB) from the layers, which in turn appeared to be beneficial for adding $\mathrm{C}$ impurities to $\mathrm{BN}$ and thus forming BCN. Giving $\mathrm{TEB} / \mathrm{NH}_{3}$ and $\mathrm{TMA} / \mathrm{NH}_{3}$ super-cycles resulted in AlBN or AlBCN compounds, depending on total gas pressure. From XPS, appearance of $\mathrm{B}_{\mathrm{x}} \mathrm{C}, \mathrm{C}_{\mathrm{y}} \mathrm{N}$, pure $\mathrm{C}$ as well as stoichiometric $\mathrm{AlN}$ and $\mathrm{BN}$ phases might be speculated, perhaps with some additions of a $B_{x} C_{y} N_{z}$ phase.

\subsection{Recommendations}

The broad experimental work conducted in this thesis provides many opportunities for additional research. This will be briefly addressed in this section.

The formation of surface adducts of $\mathrm{BH}_{3}: \mathrm{NH}_{3}, \mathrm{BBr}_{3}: \mathrm{NH}_{3}$ and TEB: $\mathrm{NH}_{3}$, and their conversion to $-\mathrm{NH}_{2}$ - linkages is crucial for explaining the film deposition mechanism. The adduct occurrence shall be experimentally confirmed or disproved by using appropriate surface analysis techniques, such as FTIR and XPS.

Additional studies are required to verify the application feasibility of the materials investigated in this thesis. Concerning the $\mathrm{B} / \mathrm{BN}$ composites with tunable refractive index (Chapter 3), it would be interesting to characterize these films in terms of their electronic properties. Can the B/BN lead to bandgap engineering, thus opening new routes towards the applications in electronics?

The plasma assisted depositions from $\mathrm{B}_{2} \mathrm{H}_{6}$ and $\mathrm{NH}_{3}$ resulted in hexagonal boron nitride films with crystal planes stacked perpendicular to the substrate surface (Chapter 4). The high thermal conductivity of BN together with the wide bandgap makes it an attractive material for certain applications. Can $h-B N$ 
outperform the existing gate dielectric materials and be a suitable material for graphenebased devices? The properties of h-BN can additionally suggest using it as a protective layer for EUV pellicles. Further, investigation of substrate effects in relation to area selective growth of h-BN can enable many potential applications, and is therefore an interesting route to explore.

The byproduct characterization suggested in Chapter 6 is practically attractive for the efficient and fast optimization of deposition processes, and scientifically interesting to enable differentiation between ALD and CVD modes as well as verification of film-growth mechanism. Exploring this promising approach has just been started in this work and can be addressed in a future research.

Deposition of BCN and AlBCN films attempted in Chapter 7 is at the beginning stage and will certainly require a continuation. Further experiments are needed to shine light on the (co)-existence of phases as well as on structural, optical and electrical properties of these films. Practically, the ability to manipulate the optical and electronic properties by varying composition and/or chemical bonding environments may lead to specific applications in, for example, (opto)electronics. 


\section{Summary}

This thesis focused on the deposition of B-, C- and N-containing thin films from several precursor systems. We explored both pulsed-deposition and ALD approaches, with the aim to comparatively understand the growth mechanisms and investigate the effects of a variety of activation techniques; namely, thermal-, hot-wire- (HW-) and plasma-assistance. Furthermore, this thesis aims to clarify the occurrence of various phases in the compounds, and obtain the material properties.

The research started with developing recipes for the deposition of BN layers, giving alternating pulses of $\mathrm{B}_{2} \mathrm{H}_{6}$ and $\mathrm{NH}_{3}$. The results suggested the multiphase (composite) film nature, consisting of pure-B and BN. These films exhibited refractive indices $(n)$ strongly dependent on the pure-B fraction. It was found that the growth and composition of these layers were strongly dependent on total gas pressure $\left(P_{t o t}\right)$ : enhanced GPC and reduced pure-B were achieved by increasing the $P_{\text {tot. }}$. This strong pressure dependence allowed to hypothesize the growth mechanism via the surface-adduct reaction pathway analogous to previously reported AlN and GaN. Introducing additional means of activation (i.e. HW and plasma) affected the growth behavior, film properties and therefore the growth mechanism. Plasma-assistance provided near-stoichiometric, crystalline BN film at $\sim 300^{\circ} \mathrm{C}$. These insights established the groundwork towards understanding the growth via the surface-adduct reaction pathway for the ALD of $\mathrm{BN}$ from $\mathrm{BBr}_{3}$ and $\mathrm{NH}_{3}$ precursor system. It was shown that, the experimental results could be adequately explained by the suggested reaction mechanism. Moreover, the results showed the influence of alternative approaches: the occurrence of pure-B phase and lower GPC in the case of plasma-assistance indicated the different-fromthermal growth mechanism. Switching to a cold-wall reactor enabled studying the reaction byproducts, which was suggested for differentiating between ALD and CVD modes. 
The deposition of $\mathrm{BCN}$ and $\mathrm{AlBN}$ layers was subsequently explored from TEB and $\mathrm{NH}_{3}$. The results suggested ineffective nitridation of TEB-terminated surfaces in thermal deposition mode. Utilizing additional means of activation to enable manipulating the composition was unsuccessful due to the low temperature required for thermal decomposition of TEB, which dominated the process. This, however in turn, appeared to be beneficial for the formation of $B C N$. Giving TEB/ $\mathrm{NH}_{3}$ and TMA/ $\mathrm{NH}_{3}$ super-cycles resulted in AlBN or AlBCN compounds, depending on total gas pressure. 


\section{Samenvatting}

Dit proefschrift behandelt de depositie van B-, C- en N-bevattende dunne films met verschillende precursors. We hebben zowel gepulste depositie als ALD technieken onderzocht, met als doel om de groeimechanismen te kunnen vergelijken en begrijpen, en om de effecten van een aantal activatietechnieken in kaart te brengen, namelijk thermische, hot-wire (HW) en plasma activatie. Verder beschrijft dit proefschrift de materiaaleigenschappen en het voorkomen van verschillende fasen in de films.

Het onderzoek begon aanvankelijk met het ontwikkelen van recepten voor BN lagen, gebruik makend van afwisselende pulsen van $\mathrm{B}_{2} \mathrm{H}_{6}$ en $\mathrm{NH}_{3}$. De resultaten duidden de aanwezigheid van meerdere fasen aan, puur B en BN. De brekingsindices $(n)$ van deze films waren sterk afhankelijk van de hoeveelheid puur B in de films. De groei en samenstelling van deze lagen bleek sterk af te hangen van de totale gasdruk $\left(P_{t o t}\right)$ : een verhoogde GPC en een verlaagde hoeveelheid puur B resulteerden door het verhogen van $P_{\text {tot }}$. Deze sterke drukafhankelijkheid heeft geleid tot de hypothese dat in het groeimechanisme reacties van oppervlakte-adducten een rol spelen, analoog aan eerder beschreven groei van AlN en GaN. Het introduceren van toegevoegde activatiemiddelen (HW en plasma) beïnvloedden de groei, de eigenschappen van de films, en dus het groeimechanisme. Plasma-assistentie resulteerde in vrijwel stoichiometrisch, kristallijn $\mathrm{BN}$ bij $\sim 300{ }^{\circ} \mathrm{C}$. Deze inzichten legden de basis voor het begrijpen van ALD van $\mathrm{BN}$, gebruik maken van $\mathrm{BBr}_{3}$ en $\mathrm{NH}_{3}$ precursors, via een oppervlakteadduct mechanisme. De resultaten van de experimenten konden adequaat worden verklaard met dit mechanisme. Ook lieten de resultaten de invloed van alternatieve benaderingen zien: Het voorkomen van een puur-B fase en een lagere GPC in het geval van plasma-assistentie suggereerden een groeimechanisme afwijkend van thermische groei. Overschakelen naar een cold-wall reactor maakte het bestuderen van nevenproducten van de reacties mogelijk, hetgeen voorgesteld was om onderscheid te kunnen maken tussen ALD en CVD modes. 
Vervolgens is de depositie van BCN en ALBN lagen bestudeerd, gebruik makend van TEB en $\mathrm{NH}_{3}$. De resultaten suggereerden onvolledige nitridatie van TEB-getermineerde oppervlakken tijdens thermische depositie. Het gebruiken van toegevoegde activatiemiddelen om de samenstelling te manipuleren was niet succesvol vanwege de lage temperatuur voor thermische decompositie van TEB, waardoor dit laatste het groeiproces domineerde. Dit bleek echter voordelig voor het vormen van $\mathrm{BCN}$. Het gebruiken van TEB/ $\mathrm{NH}_{3}$ en $\mathrm{TMA} / \mathrm{NH}_{3}$ super-cycli resulteerde in $\mathrm{AlBN}$ of $\mathrm{AlBCN}$ verbindingen, afhankelijk van de totale gasdruk. 


\section{List of Publications}

\section{Journals}

Ramazan O. Apaydin, Arnoud J. Onnink, Antonius A.I. Aarnink, Michel P. de Jong, Dirk J. Gravesteijn and Alexey Y. Kovalgin, "Multi-Phase Nature of TunableRefractive-Index B/BN Films Confirmed by Photoelectron Spectroscopy and Quantified by Ellipsometry", submitted to Journal of Vacuum Science and Technology A.

Ramazan O. Apaydin, Arnoud J. Onnink. Xingyu Liu, Antonius A.I. Aarnink, Michel P. de Jong, Dirk J. Gravesteijn and Alexey Y. Kovalgin, "A Comparative Study of Thermal and Radical-Enhanced Methods for Growing Boron Nitride Films from Diborane and Ammonia", submitted to Journal of Vacuum Science and Technology A.

Alexey Y. Kovalgin, Mengdi Yang, Sourish Banerjee, Ramazan O. Apaydin, Antonius A. I. Aarnink, Sachin Kinge, Rob A. M. Wolters, "Hot-Wire Assisted ALD: A Study Powered by In Situ Spectroscopic Ellipsometry", Adv. Mater. Interfaces, 4, 2017, 1700058, Invited.

\section{Conferences}

R.O. Apaydin, A.J. Onnink, X. Liu, A.A.I. Aarnink, M.P. de Jong, D. J. Gravesteijn and A.Y. Kovalgin, "Deposition of boron nitride films from $\mathrm{B}_{2} \mathrm{H}_{6}$ and $\mathrm{NH}_{3}$ ", PRORISC\&SAFE conference, Eindhoven, July 2019, poster presentation.

R.O. Apaydin, A.A.I. Aarnink, M. P. de Jong, D.J. Gravesteijn, A.Y. Kovalgin, “ A comparative study of low-temperature BN ALD in thermal and plasma-enhanced modes", EuroCVD 22 - Baltic ALD 16, Luxembourg, June 2019, oral presentation.

Arnoud J. Onnink, R. Oguzhan Apaydin, Jurriaan Schmitz and Alexey Y. Kovalgin, "In-situ study of ammonium bromide formation for optimizing boron nitride $\mathrm{ALD}$ from $\mathrm{BBr}_{3}$ and $\mathrm{NH}_{3}$ ", EuroCVD 22 - Baltic ALD 16, Luxembourg, June 2019, oral presentation, co-author.

Sourish Banerjee, Ramazan O. Apaydin and Alexey Y. Kovalgin, "A comparative study of low-temperature III- $V$ nitrides ALD in thermal and radical-enhanced modes", ECS 234 meeting (AiMES 2018), Cancun, 2018, oral presentation, co-author.

A.J. Onnink, R.O. Apaydin, J. Schmitz and A.Y. Kovalgin, "Monitoring of hotwireassisted layer deposition and etching", MESA+ Day, September 2018, Enschede, shared first authorship. 
A.J. Onnink, R.O. Apaydin, J. Schmitz, M.P. de Jong, A.Y. Kovalgin, “Strategies to Mitigate the Ammonium Halide Contamination of an ALD/CVD Reactor", SAFE conference, Enshcede, June 2018, poster and oral presentation, shared first authorship.

X. Liu, R.O. Apaydin, S. Banerjee, A.A.I. Aarnink, A. Y. Kovalgin, L.K. Nanver, "Electrical measurement of the conduction along the interface of negatively-charged CVD/ALD depositions on silicon", EuroCVD 21 - Baltic ALD 15, Linkoping, June 2017, poster presentation, co-author.

Sourish Banerjee, Ramazan O. Apaydin, Antonius A. I. Aarnink, Jurriaan Schmitz, Dirk J. Gravesteijn, Michel P. de Jong and Alexey Y. Kovalgin, “Hot wire technique as a radical source for atomic layer deposition of metal and metal nitride films", EuroCVD 21 - Baltic ALD 15, Linkoping, June 2017, oral presentation, co-author. 


\section{Acknowledgements}

The four-year $\mathrm{PhD}$ life was a long, challenging but also a nice journey to me. I have always wanted to do it and here we are. I made my dream come true. Obviously, no single study can be done without the help of valuable contributions of others. Therefore, I would like to take my time here to send my acknowledgements to those who helped me in many different ways through my PhD study. I will do my best on remembering everybody but if I missed someone, please accept my apologies.

First and foremost, I would like to mention the brief story of how ended up with my PhD project. I actually applied for another project for which I was invited for an interview. Following the interviews, I received an e-mail from Jurriaan saying that "We look back on a very good interview round with you. After a team discussion about your application to our group, we wanted to investigate if you would fit the position, we have for a $\mathrm{PhD}$ student on two-dimensional semiconductor growth". After thinking for a few days, I decided to say yes. Herewith, I would like to thank Prof. Dr. Jurriaan Schmitz for offering me the PhD position and giving me this great opportunity to do research with valuable scientists. Jurriaan, thank you for everything you have done for me.

I will always be thankful to my daily supervisors and also my promotors, Dr. Alexey Y. Kovalgin and Dr.ir. Michel P. de Jong for their guidance, patience, motivation and enthusiasm. I remember a lot of times being lost in trivial experiments and data analysis from which you dragged me out and guided me for a better goal in the project. You could stop me wasting time in less meaningful work. When I was frustrated with the results, you could still come up with an idea that allowed us transferring the results into scientific publications. I learned from Alexey and Michel that, sometimes, you just need to take a look at the results from a different perspective. Thank you very much for spending enormous time on guiding me and helping me to improve my scientific skills. In addition, special thanks to Michel for translating the summary of my thesis. 
Besides Alexey and Michel, I would like to acknowledge Prof. Dr. Dirk Gravesteijn. Thank you for your kind support and valuable contribution. Also thank you for being positive all the time.

Apart from my supervisors, I would like to thank to the graduation committee members for taking the time from their busy schedule to evaluate this work.

I would like to thank to my former colleagues at IDS group. First of all, I am very thankful to Remke Assink and Susan Janse-Godschalk (former secretaries of IDS group) for helping with organizing all kinds of paper works till the last moment of their employment in our group.

My special thanks to our dedicated senior engineer Tom. Tom, I cannot think of enough words to thank you for your support and concern in both scientific and personal life. Thank you for creating the perfect atmosphere for us. I will always remember you with your positive, enthusiastic and beer loving personality. I am also thankful to my officemates, colleagues and friends in the second floor. Thank you all for your willingness to help and all the fun we had. Arnoud, thank you for being a really good friend, for your help and more importantly for accepting the tough duty of being my paranymph. Thanks to Kevin (from IDS) for his technical support during my study and thanks to all other IDS members for their kind help.

I also would like thank to Wilfred and Floris for their kind contributions to my work. Besides, I would like to thank to Johnny and all other NE members for their help during our group meetings, for being such good and helpful friends to me.

Let's take a chance to acknowledge some individuals for the fruitful discussions and their contribution. From MESA+: Gerard Kip, Rico Keim, Peter Linders, Marion Nijhuis, Huib van Vossen, Christiaan Bruinink, Robert Wijn, Mike Dikkers and from XUV optics group: Airat Shafikov, Seda Kizir, Marko Sturm, Bart Schurink and Wesley van den Beld. 
Next, I would like to thank to the International Human Resources staff. Special thanks to Maureen S. Melisie and Dagmar J. Keuken for handling all the official works for me and helping me out for communicating with IND.

I would like to take the chance to send my special thanks to the dearest Turkish friends with whom I had great time during the last 4 years. Special thanks to our dedicated group member Muharrem and his family. I am grateful for all your help. Apart from them, I would like to thank to my friends Derya, Güner, Yiğitcan, Cihan, Seda, Pelin, Devrim, Deniz, Derya, Burcu, Akın, Sinem, Armağan, Elif, Özlem, Ozan, Yusuf, Mehmet and Damla. Thank you, guys, for being such good friends. Special thanks to Burcu for designing the cover of my thesis. Next, I owe my deepest gratitude to Yiğitcan for being a really good friend and accepting the responsibility of being my paranymph. Besides, I would like to thank to all other friends in the Turkish community. It was my pleasure meeting you all and I wish you all the best.

I would like to acknowledge my girlfriend for being extremely supportive especially during the last part of my PhD. Thank you for being such an understanding person. Thank you for your support whenever I needed and for helping me out for all sorts of things.

I would like to acknowledge my relatives who supported me during my life in the Netherlands. Among all, I am eternally grateful to my dear father, mother, brother, sister in law and lovely niece Nehir. I am thankful to you with all my heart for your confidence. I would be no match for something like this without your unlimited support. I felt safe and strong with your love and support and I am grateful to have you as my family. You were the ones I missed the most.

I would like to ask your kind understanding here since I would like to write the next paragraph in Turkish and dedicate it to my family.

“Annem, babam, ağabeyim, ablam ve güzel yeğenim Nehir; sizlere nasıl teşekkür edeceğimi bilemiyorum, keza hiçbir kelime bunu gerçekleştirmek için yeterli olmayacaktır. Sizlerin desteği olmadan böyle bir sürecin altından 
kalkamazdım. Zaman zaman belli etmemiş ya da edememiş olsam da, burada bulunduğum süreç boyunca en çok özlediğim sizler oldunuz. Sizlerin hayatının uzağinda kalmak, uzakta olmak ve güzel yeğenimin büyüyüşünü görememek belki de bu kararımın en ağır sonuçlarından birisiydi. Sevginiz ve desteğiniz sayesinde kendimi güvende ve güçlü hissettim. Sizin gibi bir aileye sahip olduğum için kendimi çok şanslı hissediyorum. Sizleri çok seviyorum."

My apologies to whom I might have forgotten to mention here. You will always be in my heart and I will always be grateful for your support.

Sincerely,

R. Oğuzhan APAYDIN 


\section{Author's Biography}

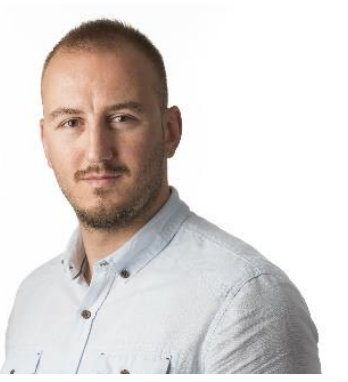

Ramazan Oğuzhan APAYDIN was born in Samsun, Turkey, on April 29th, 1988. He obtained his B.Sc. degree from Department of Metallurgical and Materials Engineering at Istanbul Technical University (ITU), Istanbul, Turkey, in 2011. Following, he obtained his M.Sc. degree from Department of Materials Science and Engineering at Istanbul Technical University (ITU), Istanbul, Turkey, in 2013. He carried out his B.Sc. work on "Design of A System to Manufacture Boron-Fiber Reinforced Aluminum Matrix Composites" under the supervision of Prof. Dr. Ismail DUMAN. He carried out his M.Sc. work on "Production of Copper-Nickel (CuNi) and Copper-NickelIndium (CuNiIn) Alloy Nanoparticles by Ultrasonic Spray Pyrolysis (USP) and Hydrogen Reduction (HR) Method" under the supervision of Prof. Dr. Sebahattin GURMEN. He joined the groups of Integrated Devices and Systems and NanoElectronics at University of Twente in June 2015 as a $\mathrm{PhD}$ candidate and worked on the project named "Ultra-thin Layers and Their Stacks for Nextgeneration Electronics and Energy Storage Devices" under the supervision of Dr. Alexey Y. KOVALGIN and Dr. Ir. Michel P. de JONG. His doctoral research is described in this thesis. 


\section{ERRATA for}

“Thermal and Radical Enhanced Atomic Layer Deposition of Films Containing Boron, Nitrogen and Carbon"

\section{PhD Thesis, Ramazan Oğuzhan Apaydın}

March 30th, 2020

Page 53: typo

The sentence:

Namely, for $P_{\text {tot }}>1$ mbar, the $P_{B 2 H 6}$ was kept in the range of $10^{-3}-10^{-2}$ mbar, whereas the $P_{N H 3}$ was changing between $10^{-2}$ and $10^{-1}$ mbar.

should instead be:

Namely, for $P_{\text {tot }}>1$ mbar, the $P_{B 2 H 6}$ was kept in the range of $10^{-2}-10^{-1}$ mbar, whereas the $P_{N H 3}$ was changing between $10^{-1}$ and 2 mbar. 